Florida International University

FIU Digital Commons

FIU Electronic Theses and Dissertations

University Graduate School

$10-23-2015$

\title{
A Multi-Criteria GIS-Based Route Selection Tool for Hazardous Material Transport: Consideration of Environmental Consequence, Traffic Congestions and Costs
}

Bahareh Inanloo

Florida International University, binan001@fiu.edu

DOI: $10.25148 /$ etd.FIDC000155

Follow this and additional works at: https://digitalcommons.fiu.edu/etd

Part of the Environmental Engineering Commons, Operations Research, Systems Engineering and Industrial Engineering Commons, Risk Analysis Commons, and the Transportation Engineering Commons

\section{Recommended Citation}

Inanloo, Bahareh, "A Multi-Criteria GIS-Based Route Selection Tool for Hazardous Material Transport: Consideration of Environmental Consequence, Traffic Congestions and Costs" (2015). FIU Electronic Theses and Dissertations. 2262.

https://digitalcommons.fiu.edu/etd/2262

This work is brought to you for free and open access by the University Graduate School at FIU Digital Commons. It has been accepted for inclusion in FIU Electronic Theses and Dissertations by an authorized administrator of FIU Digital Commons. For more information, please contact dcc@fiu.edu. 
FLORIDA INTERNATIONAL UNIVERSITY

Miami, Florida

A MULTI-CRITERIA GIS-BASED ROUTE SELECTION TOOL FOR HAZARDOUS MATERIAL TRANSPORT: CONSIDERATION OF ENVIRONMENTAL CONSEQUENCE, TRAFFIC CONGESTIONS AND COSTS

A dissertation submitted in partial fulfillment of the

requirements for the degree of

DOCTOR OF PHILOSOPHY

in

CIVIL ENGINEERING

by

Bahareh Inanloo 
To: $\quad$ Interim Dean Ranu Jung

College of Engineering and Computing

This dissertation, written by Bahareh Inanloo, and entitled A Multi-Criteria GIS-Based Route Selection Tool for Hazardous Material Transport: Consideration of Environmental Consequence, Traffic Congestions and Costs, having been approved in respect to style and intellectual content, is referred to you for judgment.

We have read this dissertation and recommend that it be approved.

$\begin{array}{r}\text { Mehmet Bayraktar } \\ \hline \text { Walter Tang } \\ \hline \text { Xia Jin } \\ \hline \text { Berrin Tansel, Major Professor }\end{array}$

Date of Defense: October 23, 2015

The dissertation of Bahareh Inanloo is approved.

Interim Dean Ranu Jung
College of Engineering and Computing

Florida International University, 2015 
(C) Copyright 2015 by Bahareh Inanloo

All rights reserved. 


\section{DEDICATION}

I dedicate this dissertation to my parents, sister, and beautiful niece. Without their support and love the completion of this work would have not been possible. 


\section{ACKNOWLEDGMENTS}

This dissertation would not have been completed without the support of numerous people. I would like to thank the members of my committee, Dr. Xia Jin, Dr. Mohammad Hadi, Dr. Mehmet Bayraktar, Dr. Walter Tang and Dr. Berrin Tansel, as well as Dr. Fuentes, the Associate Chair of the Department, and Dr. Atorod Azizinamini, the Chair of the Department, for

their support, patience, and insight. Dr. Berrin Tansel, as my academic advisor, was helpful and encouraging in guiding me thought my $\mathrm{PhD}$ study. I would also like to thank Dr. Tansel for having confidence in my abilities, and encouraging me to reach my full potentials.

I wish to thank the Southeastern Transportation Research, Innovation, Development and Education Center (STRIDE) at the University of Florida for providing funding for this research. I also would like to acknowledge and thank Florida International University for financial support provided by the FIU Graduate School Dissertation Year Fellowship (DYF) and providing me the opportunity to focus exclusively on my research.

I thankfully acknowledge the contribution of many individuals; Dr. Albert Gan, Dr. Priyanka Alluri, Dr. Yan Xiao, Mr. Andrew Carter, Mr. Kollol Shams, Ms. Somayeh Fakhairan and Ms. Samaneh Khazraeian.

Last but not least, I would like to thank my family and friends for their support and encouragement throughout the past years. 


\section{ABSTRACT OF THE DISSERTATION \\ A MULTI-CRITERIA GIS-BASED ROUTE SELECTION TOOL FOR HAZARDOUS \\ MATERIAL TRANSPORT: CONSIDERATION OF ENVIRONMENTAL CONSEQUENCE, TRAFFIC CONGESTIONS AND COSTS}

by

Bahareh Inanloo

Florida International University, 2015

Miami, Florida

Professor Berrin Tansel, Major Professor

Hazardous materials are substances that, if not regulated, can pose a threat to human populations and their environmental health, safety or property when transported in commerce. About 1.5 million tons of hazardous material shipments are transported by truck in the US annually, with a steady increase of approximately 5\% per year.

The objective of this study was to develop a routing tool for hazardous material transport in order to facilitate reduced environmental impacts and less transportation difficulties, yet would also find paths that were still compelling for the shipping carriers as a matter of trucking cost. The study started with identification of inhalation hazard impact zones and explosion protective areas around the location of hypothetical hazardous material releases, considering different parameters (i.e., chemicals characteristics, release quantities, atmospheric condition, etc.). Results showed that depending on the quantity of release, chemical, and atmospheric stability (a function of wind speed, meteorology, sky cover, time and location of accidents, etc.) the consequence of these incidents can differ. The study was extended by selection of other evaluation criteria for further investigation because health risk as an evaluation criterion would not be the only concern in selection of routes. Transportation difficulties (i.e., road blockage and congestion) were incorporated as important factor due to their indirect impact/cost on the users of transportation 
networks. Trucking costs were also considered as one of the primary criteria in selection of hazardous material paths; otherwise the suggested routes would have not been convincing for the shipping companies. The last but not least criterion was proximity of public places to the routes.

The approach evolved from a simple framework to a complicated and efficient GIS-based tool able to investigate transportation networks of any given study area, and capable of generating best routing options for cargos. The suggested tool uses a multi-criteria-decision-making method, which considers the priorities of the decision makers in choosing the cargo routes.

Comparison of the routing options based on each criterion and also the overall suitableness of the path in regards to all the criteria (using a multi-criteria-decision-making method) showed that using similar tools as the one proposed by this study can provide decision makers insights in the area of hazardous material transport. This tool shows the probable consequences of considering each path in a very easily understandable way; in the formats of maps and tables, which makes the tradeoffs of costs and risks considerably simpler, as in some cases slightly compromising on trucking cost may drastically decrease the probable health risk and/or traffic difficulties. This will not only be rewarding to the community by making cities safer places to live, but also can be beneficial to shipping companies by allowing them to advertise as environmental friendly conveyors. 


\section{TABLE OF CONTENTS}

\section{CHAPTER}

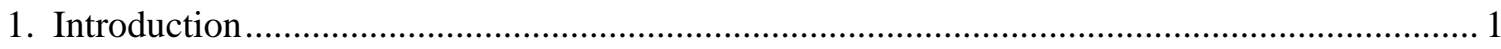

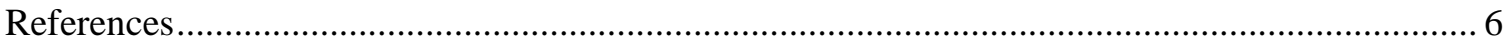

2. Cargo Specific Accidental Release Impact Zones for Hazardous Materials: Risk and Consequence Comparison for Ammonia and Hydrogen Fluoride............................................... 7

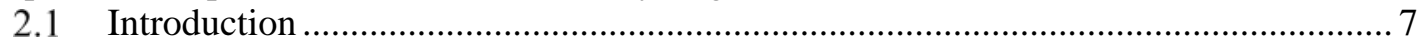

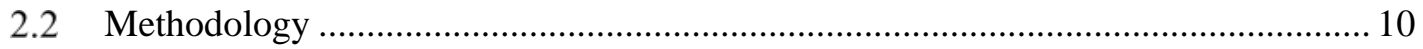

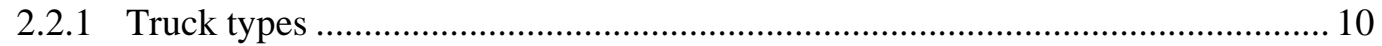

2.2.2 Air Quality Estimations and Exposure Assessment............................................. 11

2.2.3 Areal Locations of Hazardous Atmospheres (ALOHA) ..................................... 12

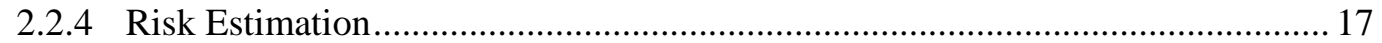

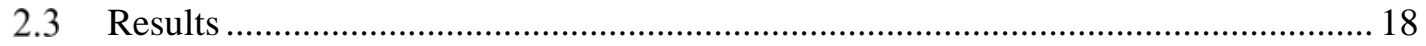

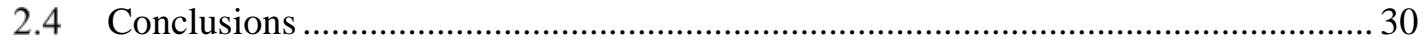

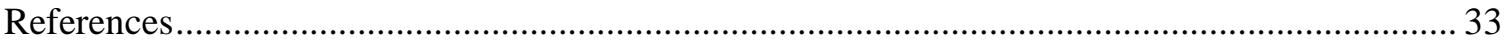

3. Explosion Impacts during Transport of Hazardous Cargo: GIS-Based Characterization of Overpressure Impacts and Delineation of Flammable Zones for Ammonia................................. 36

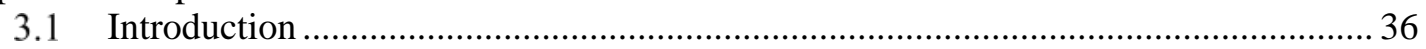

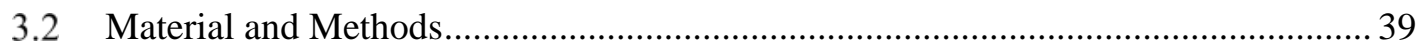

3.2.1 Areal Locations of Hazardous Atmospheres (ALOHA)...................................... 39

3.2.2 Case study for explosion during ammonia transport ......................................... 42

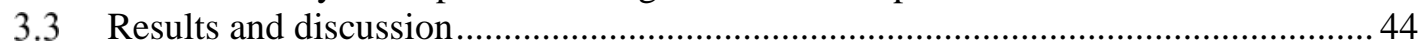

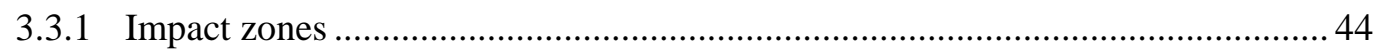

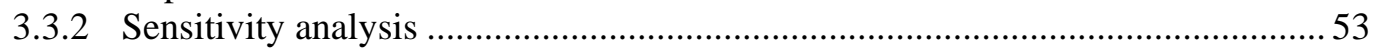

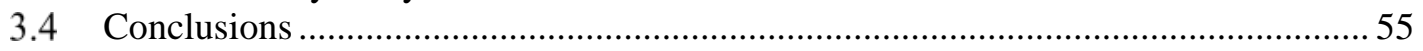

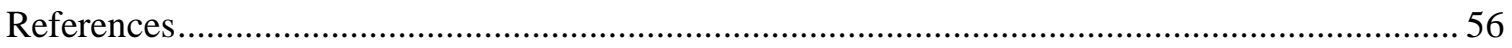

4. A GIS-Based Framework for Hazardous Tanker Truck Routing: Consideration of Health

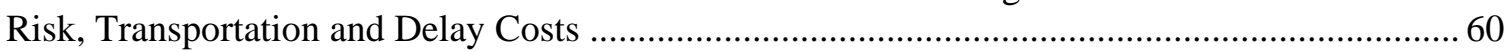

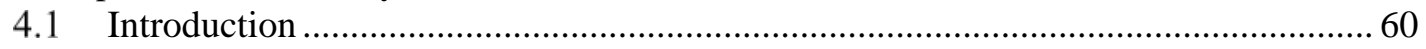

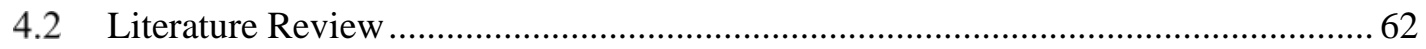

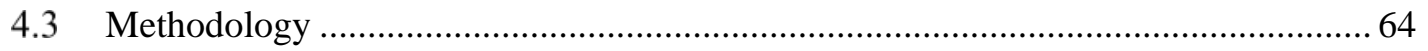

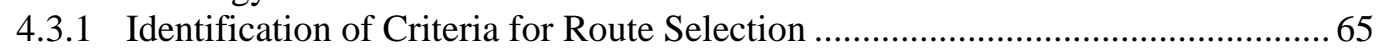

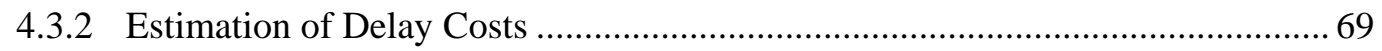

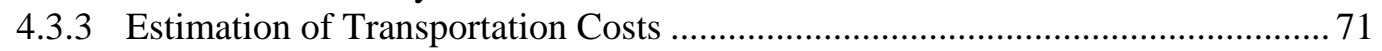

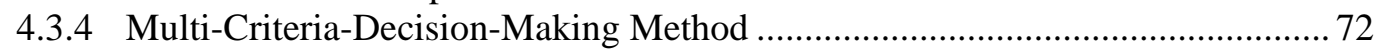

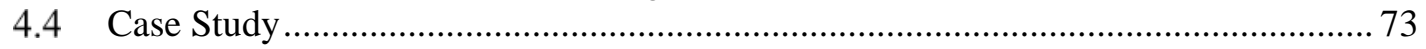

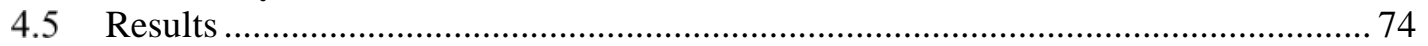

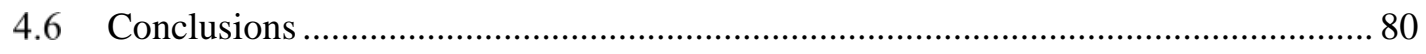

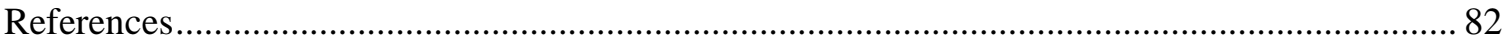

5. A Transportation Network Assessment Tool for Hazardous Material Cargo Routing: Weighing Exposure Health Risks, Proximity to Vulnerable Areas, Delay Costs and Trucking

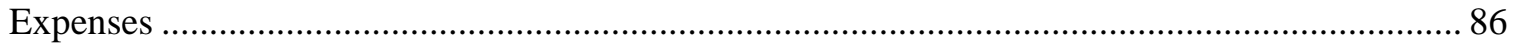

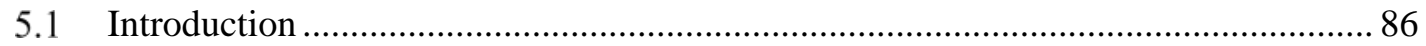




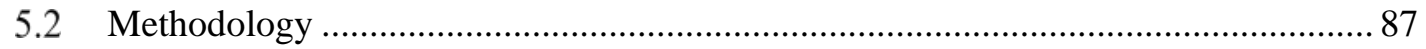

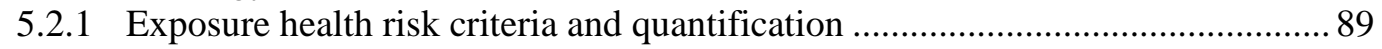

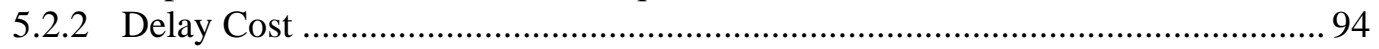

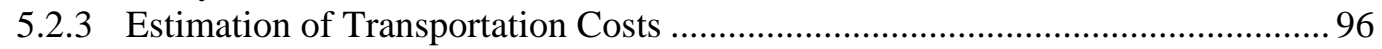

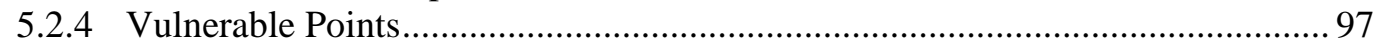

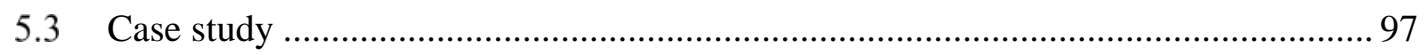

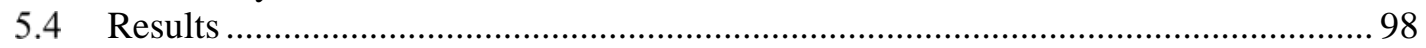

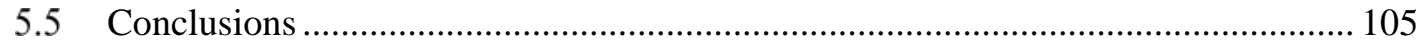

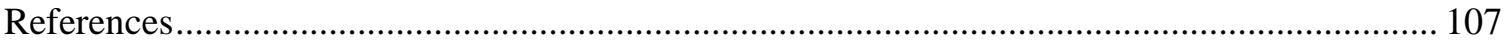

6. Reduction of Exposure Risks to Accidental Releases by Cargo Specific Buffer Zones

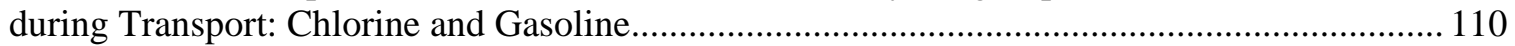

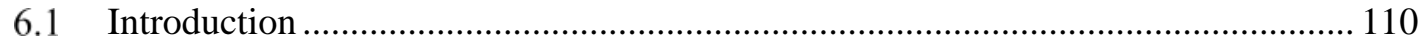

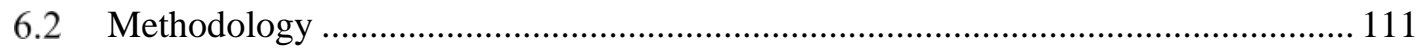

6.2.1 Exposure health risk criteria and quantification ............................................... 113

6.2.2 Estimation of Transportation Costs ................................................................... 118

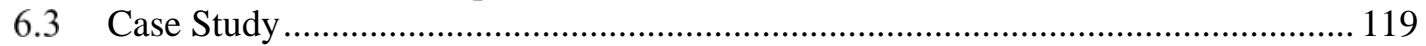

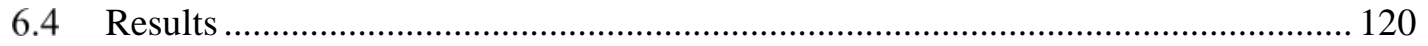

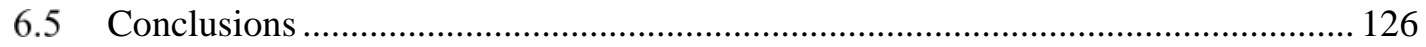

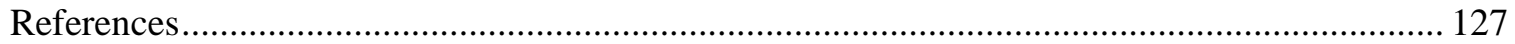

7. A Multi-Criteria Routing Tool for Hazardous Material Shipments: Health Risk, Travel

Cost, Proximity to Vulnerable Places, and Congestion Costs ................................................. 129

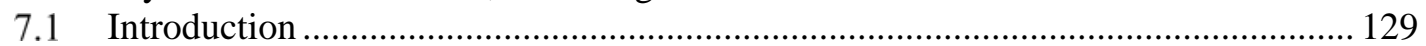

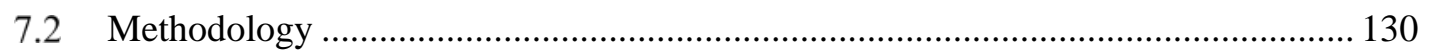

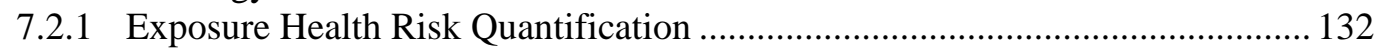

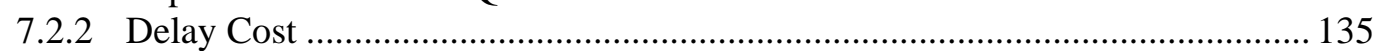

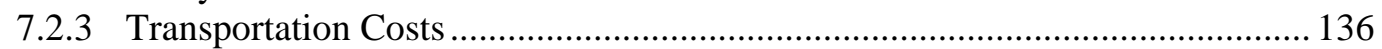

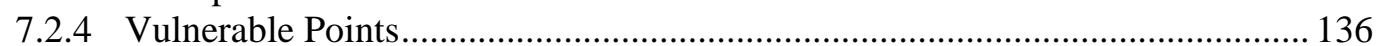

7.2.5 Multi-Criteria-Decision-Making Method .......................................................... 137

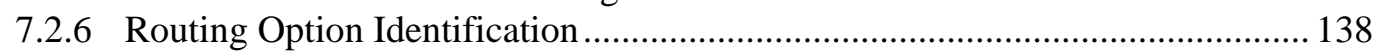

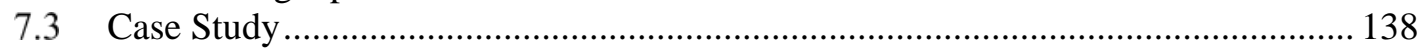

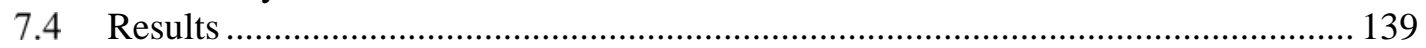

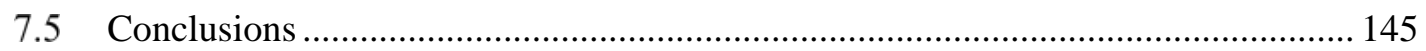

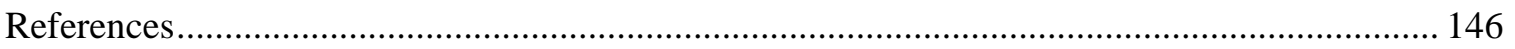

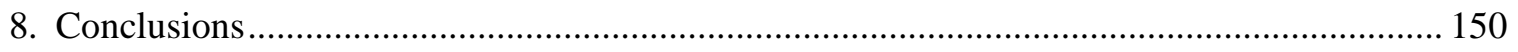

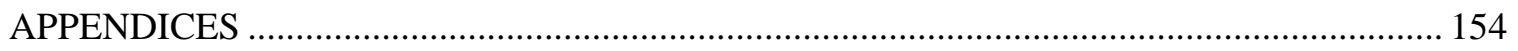

VITA 


\section{LIST OF TABLES}

TABLE

PAGE

Table 2.1 Hazardous material accidents (After NTSB 2013, US EPA 1993, NTSB 1977b).......... 9

Table 2.2 Truck classifications for transporting ammonia and hydrogen fluoride (after Spencer,

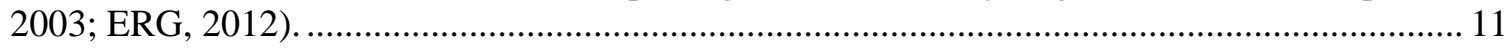

Table 2.3 Atmospheric stability categories (Turner, 1994)................................................... 13

Table 2.4 Characteristics of ammonia and hydrogen fluoride (EPA, 2013)............................... 14

Table 2.5 Characteristics of ammonia and hydrogen fluoride (EPA, 2013)................................ 15

Table 2.6 User specified settings used for dispersion analysis after accidental cargo spills. ........ 16

Table 2.7 Initial Isolation and protective action zones for highway truck or trailer.................... 26

Table 2.8 ARPG-2 and AEGL-2 Impact zone information. .................................................... 28

Table 3.1 Characteristics of ammonia (Barber and Hildebrand, 1980, Cameo chemicals,

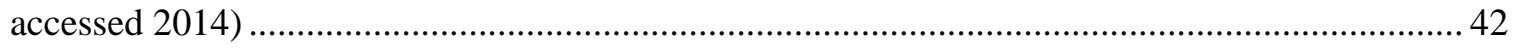

Table 3.2 Parameters used for impact analysis after accidental cargo release............................. 43

Table 3.3 The Pasquill stability classes (Comarova, and Mangul, 2008) ................................... 44

Table 3.4 Levels of damage expected at specific overpressure values (Lee and Frank, 1980). ... 45

Table 3.5 Decrease in the area of impact zone by increase in wind speed. ..................................53

Table 4.1 Common criteria used in hazardous cargo truck route in selected studies ................... 66

Table 4.2 Residual freeway capacity in incident zones (HCM, 2000)........................................ 71

Table 4.3 Route options evaluation (weight set \#1)................................................................. 79

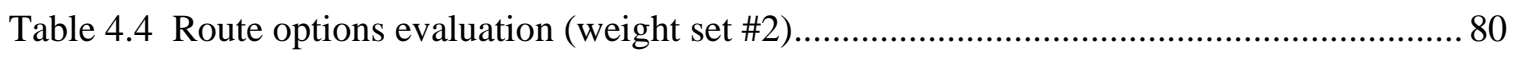

Table 5.1 Equations used for $\sigma \mathrm{x}, \sigma \mathrm{y}$, and $\sigma \mathrm{z}$ calculations (Slade, 1968)................................... 92

Table 5.2 Urban stability categories (Ludwig et al., 1976)........................................................ 93

Table 5.3 Residual freeway capacity in incident zones (HCM, 2000)........................................ 96

Table 6.1 Equations used for $\sigma \mathrm{x}, \sigma \mathrm{y}$, and $\sigma \mathrm{z}$ calculations (slade, 1968).................................116 
Table 6.2 Urban stability categories (ludwing and dabberdt, 1976).

Table 6.3 Length comparison of route options ... 


\section{LIST OF FIGURES}

FIGURE

PAGE

Figure 2.1 Comparison of ALOHA's threat zone plots for the case scenario of an accidental release of ammonia and hydrogen fluoride based on their Acute Exposure Guideline Levels (AEGLs). Calculations performed using input data given in Table 2.6 for a class $\mathrm{C}$ atmospheric stability.

Figure 2.2 Geographical areas impacted by the dispersion of toxic release of ammonia under different atmospheric stability classes: (a) A, (b) B, (c) C, (d) D, (e) E, (f) F.

Figure 2.3 Geographical areas impacted by the dispersion of a toxic release of hydrogen fluoride under different atmospheric stability classes: (a) A, (b) B, (c) C, (d) D, (e) E, (f) F. ...... 23

Figure 2.4 Comparison of the magnitude of the areas impacted (square miles) at specific exposure levels under different atmospheric stability conditions: (a) ammonia, and (b) hydrogen fluoride.

Figure 2.5 Initial isolation and protective action zones.

Figure 2.6 Health risks based on impacted area and population for ammonia and hydrogen

fluoride.

Figure 3.1 Definition of impact zones of ammonia, a: Flammable zone, b: Overpressure wave zone.

Figure 3.2 Site specific map overlaying in ArcGIS (*layers used in this study). 47

Figure 3.3 Flammable impact zones for different quantities of ammonia release. (1) 2 ton release: (a) stability class A, (b) stability class B, (c) stability class C, (d) stability class E, (e) stability class F; and (2) 20 ton release: (f) stability class A, (g) stability class B, (h) stability class $\mathrm{C}$, (i) stability class $\mathrm{E}$, (j) stability class F.

Figure 3.4 Overpressure wave impact zones for different quantities of ammonia release. (1) 2 ton release: (a) stability class A, (b) stability class B, (c) stability class C, (d) stability class E, (e) stability class F; and (2) 20 ton release: (f) stability class A, (g) stability class B, (h) stability class C, (i) stability class E, (j) stability class F.

Figure 3.5 Impact areas for different quantities of ammonia release. (1) 2 ton release: (a) overpressure waves, (b) flammable zone; and (2) 20 ton release: (c) overpressure waves, (d) flammable zone.

Figure 3.6 Estimated population that can be affected by overpressure waves after ammonia releases. (a) 2 ton release, (b) 20 ton release.

Figure 4.1 Pareto optimal solutions 
Figure 4.2 Flow chart for the multi-criteria framework for routing options

Figure 4.3 Health risk, delay cost and travel cost calculations................................................. 76

Figure 4.4 Comparison of alternative route using different criteria.......................................... 77

Figure 5.1 Methodology of the hazardous cargo transportation network assessment tool ........... 88

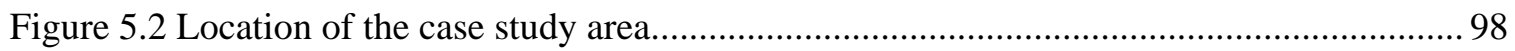

Figure 5.3 Health risk data and output of inhalation hazard buffer zones. .................................. 101

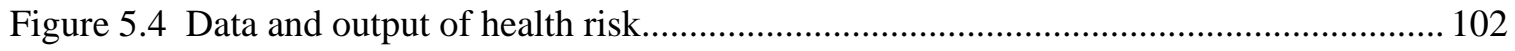

Figure 5.5 Outputs of health risk and vulnerable areas.......................................................... 103

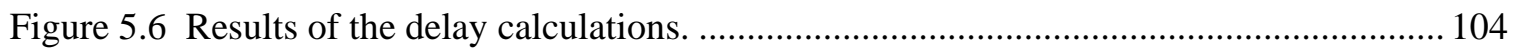

Figure 5.7 Results of the delay and travel costs calculations................................................... 105

Figure 6.1 Methodology of the hazardous cargo transportation network assessment tool. ........112

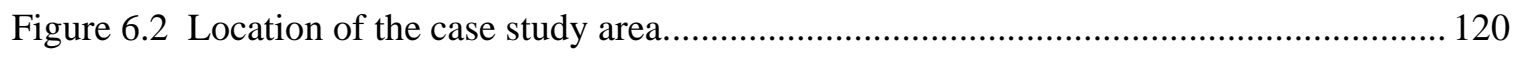

Figure 6.3 Input data maps and stability classes during the day and night. .............................. 122

Figure 6.4 Population density and travel costs network. ...................................................... 123

Figure 6.5 Routing options of each criterion. …................................................................. 125

Figure 7.1 Methodology of the hazardous cargo transportation network assessment tool. ........132

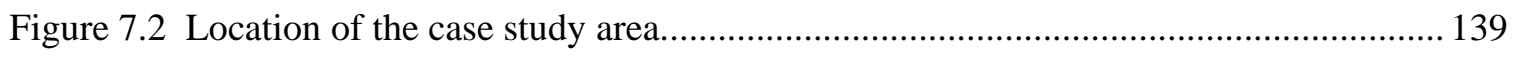

Figure 7.3 Health risk evaluated networks during weekdays and weekends............................ 141

Figure 7.4 Vulnerable point networks during weekdays and weekends.................................. 142

Figure 7.5 Delay and travel costs networks during weekdays and weekends............................ 143

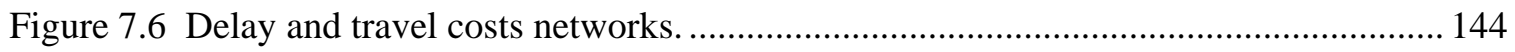




\section{Introduction}

Steadily growing demand for hazardous materials has led to an increase in the number of hazardous shipments on U.S. highways. Increased transportation of these materials has raised public concern regarding potential hazards due to en route accidents involving tanker trucks carrying the cargos (Shaver, 1998). Hazardous material shipments carried by trucks in the US add up to approximately 1.5 million tons annually, representing about $59.4 \%$ of the total commodity shipments in 2012. The historical shipment records show an increase by $27.3 \%$ from 2007 to 2012, and the trend is steadily increasing by 5\% annually in hazardous materials volume (U.S. Census Bureau, 2012). However, the reported and estimated cost and the risk associated with accidents in transportation of hazardous material cargos are lower than actual values (Craft, 2004), due to the facts that, most incidents are small (Verter and Kara, 2008); only specific incidents are reported which satisfy certain criteria, and there are limitations to long-term impact estimation, as the data is collected at the scene and the time of the accident solely. Designation of routes for hazardous materials transport can be an effective way to reduce the potential hazards and damages.

The main purpose of this study was to propose a tool for routing and scheduling hazardous materials cargos in an attempt to reduce the adverse environmental impacts of possible hazards due to en route accidents, as well as reduce the delay time and accordingly costs associated with such accidents, while also considering trucking cost in order to make the alternatives routes convincing to the shipping carriers. This dissertation will focus on various steps towards proposing the routing tool. In the very preliminary stage, the behavior of chemicals regarding to their inhalation hazard zones due to their releases in the air was investigated using different chemicals and quantities, and various atmospheric conditions. Chapter 2, entitled "Cargo Specific Accidental Release Impact Zones for Hazardous Materials: Risk and Consequence 
Comparison for Ammonia and Hydrogen Fluoride” aims to characterize the dispersion characteristics of two hazardous materials (ammonia and hydrogen fluoride) in relation to meteorological parameters, land use, and cargo characteristics, and evaluate the health risks associated with the exposure after accidental releases. The magnitudes of the impact zones were compared in relation to atmospheric stability and exposure levels. Impact zones were estimated by Areal Locations of Hazardous Atmospheres (ALOHA) software and imported into ArcGIS. For ammonia, the areas impacted by exposure levels over 1100 ppm (Acute Exposure Guideline Level 3 (AEGL-3)) were limited to less than 0.3 miles downwind from the incident location under unstable atmospheric conditions, which favor high vertical mixing and rapid dilution, and extended further downwind to distances between 0.5 and 0.7 miles under stable atmospheric conditions. For hydrogen fluoride, the AEGL-3 impact zone (exposure levels over $44 \mathrm{ppm}$ ) extended between 0.6 and 0.9 miles directly downwind from the incident location under unstable conditions, and reached approximately 2.0 miles directly downwind from the incident location under stable atmospheric conditions. The results were compared with the Emergency Response Guideline (ERG 2012) and showed agreement.

Chapter 3, titled “Explosion Impacts During Transport of Hazardous Cargo: GIS-Based Characterization of Overpressure Impacts and Delineation of Flammable Zones for Ammonia,” is dedicated to the investigation of accidental releases of ammonia followed by en route accidents in an attempt to further predict the consequences of hazardous cargo accidents. The air dispersion model ALOHA was employed to estimate the probable outcomes of a hazardous material release of a tanker truck under different explosion scenarios. The significance of identification of the flammable zones was taken into consideration in case the flammable vapor causes an explosion. The impacted areas and the severity of the probable destructions were evaluated for an explosion by considering the overpressure waves. ALOHA in conjunction with ArcMap was used to delineate the flammable and overpressure impact zones for different scenarios. The expansions of 
the impact areas under the overpressure value which can lead to property damage for 2 and 20 tons releases, under very stable and unstable atmospheric conditions were estimated to be around 1708, 1206, 3742, and 3527 feet respectively toward the wind direction. A sensitivity analysis was done to assess the significance of wind speed on the impact zones.

Upon investigation of the effects of chemical characteristics, cargo size, and atmospheric conditions and by gaining insights on the expected impact zones around release locations, the next step of this dissertation is to suggest a framework for evaluation of routing alternatives. In the framework health risk, delay cost and trucking costs were taken into consideration as will be discussed in Chapter 4: “A GIS-Based Framework for Hazardous Tanker Truck Routing: Consideration of Health Risk, Transportation and Delay Costs”. Chapter 4 proposes a multicriteria framework for comparison of characteristics of different routes in view of accidental release risks and consequences for transporting hazardous cargo. The criteria which were incorporated into the framework were again delay and travel costs, and health risks, which can be caused by a possible truck tanker accident. The health risks were computed using the health impact zones determined by integrated analysis of ALOHA software which was coupled with ArcGIS. The Queuing method was used to estimate the delay time and total cost of delay. Travel costs were estimated from the operational cost of trucking based on the distance traveled. The results showed different routes became favorable depending on the decision criteria used and also the decision maker's priorities in regards to the evaluation criteria.

Unlike Chapter 4, in which the evaluations were done for pre-identified alternative routes; Chapter 5, entitled “A Transportation Network Assessment Tool for Hazardous Material Cargo Routing: Weighing Exposure Health Risks, Proximity to Vulnerable Areas, Delay Costs and Trucking Expenses," focuses on the entire transportation network of the study area to propose a tool for evaluation and comparison of the transportation networks which can be used to assess the routing options between origins and destinations of the cargos by investigating their 
suitability for transporting hazardous material cargos by tanker trucks, and finally to identify routes which cause lower accidental release risks, lower public exposure risks, and offer economic benefits. Each route segment of transportation networks were evaluated using specific criteria which included health risk and cost of delay in case of an accidental release of materials, trucking cost and proximity to vulnerable areas. Since the health impacts of hazardous materials differ depending on the characteristics of the material being transported, as well as release quantities and atmospheric conditions, Chapter 5 aims in providing a tool that can be used to estimate the impact radius (for health risks) after accidental release of hazardous materials by taking into account different atmospheric conditions based on the meteorological data and solar elevation angle. The Gaussian air dispersion model paired with ArcMap using the Python programming language were employed to estimate the health risk impact zones by considering the meteorological data and accordingly to analyze road segments for cost impacts (delay and trucking costs), and the proximity to vulnerable areas. The route assessment tool was demonstrated with a case study.

Having investigated the transportation networks, the next step was to find routing options for hazardous materials. Chapter 6, "Reduction of Exposure Risks to Accidental Releases by Cargo Specific Buffer Zones during Transport: Chlorine and Gasoline,” intends to investigate transportation networks in regards to their suitability for hazardous material shipments as a matter of inhalation risk and further evaluates routing options based on transport time and cargo characteristics. To evaluate the routing options, an integrated and multi-objective route assessment tool was developed. Information and data were interfaced and visualized (as maps and graphical outputs) using the Python programming language and ArcMap, and incorporating Gaussian dispersion model (for air dispersion)for hazard assessments. Two hazardous materials (chlorine and gasoline) were selected for evaluation of the tool, by considering the time of transport (day or night). The health risks due to inhalation of the chemicals after accidental 
releases, as well as the trucking costs, were estimated for the entire transportation network by segmentation. Routing options were identified based on the health risks and trucking costs. Comparison of the alternative paths connecting the origin and destination showed that using an integrated method to quantify the exposure risks due to accidental releases and travel cost amongst the possible routing options for transporting hazardous material cargos can be an effective decision-making tool for visualizing the potential consequences. The methodology eases tradeoffs between the possible routes based on travel costs and exposure risks.

Finally Chapter 7, entitled “A Multi-Criteria Routing Tool for Hazardous Material Shipments: Health Risk, Travel Cost, Proximity to Vulnerable Places, and Congestion Costs,” is dedicated to investigating the transportation networks to identify the most suitable routes for transport of hazardous material cargos, as well as quantifying and comparing the feasibility of different paths using different criteria. The criteria used to evaluate each link of the transportation network included measures such as health risk and cost of delay caused by accidental releases of hazardous materials, proximity of the routes to vulnerable areas, and travel cost. The Gaussian air dispersion model was used to estimate the exposure health risk and the possible affected population. Queuing analysis was utilized to estimate the delay time and the associated costs. Critical location around the road segments were identified and assigned to the road segments. Trucking cost was calculated based on the length of the links. Having the networks evaluated, the tool then identified the best route depending on the criteria using a multi-criteria decision making method.

Two side studies focusing on scheduling of hazardous materials cargos, and delineation of odor nuisance around landfills are found in the Appendix. 


\section{References}

Craft, R. (2004). Crashes involving trucks carrying hazardous materials. federal motor carrier safety administration. Washington, DC: US Dept.of Transportation.Publication\#: FMCSARI-04-024.

Verter, V., Kara, B. Y. (2008). A path-based approach for hazmat transport network design. Management Science, 54(1), 29-40.

Shaver, D. K., Kaiser, M. (1998). Criteria for highway routing of hazardous materialsTransportation Research Board.

U.S. Census Bureau, (2015). 2012 Commodity Flow Survey. Technical Report. U.S. Department of Transportation and U.S. Department of Commerce.

http://www.census.gov/econ/cfs/2012/ec12tcf-us-hm.pdf. Accessed May 25, 2015. 


\section{Cargo Specific Accidental Release Impact Zones for Hazardous Materials: Risk and Consequence Comparison for Ammonia and Hydrogen Fluoride}

\subsection{Introduction}

The accidental releases of hazardous materials occur not only during transport, but also at fixed locations during loading and unloading activities (US DOT, 2010). Each year over 15,000 hazardous material incidents are reported to the Pipeline and Hazardous Materials Safety Administration. The most common spills involve releases of hydrocarbons (i.e., diesel oil, road tar, gasoline, fuel oil, asphalt, LPG, jet fuel, hydraulic oil, and creosote). In the event of an accident, if volatile hazardous materials are released, they are dispersed in air and transported by wind, impacting the air quality in the surrounding areas. In the US, over 1 million shipments of hazardous materials in trucks take place on a daily basis (PHMSA, 2010). Due to the risks associated with accidents during hazardous material transport, consequences can be significant due to toxic nature of the chemicals (PHMSA, 2010). According to US DOT, the number of large trucks carrying hazmat that were involved in fatal traffic crashes averaged 225 per year from 1980 through 1990. Less than 5 percent of the trucks involved in the traffic crashes were carrying hazardous materials. During the period from 1991 through 2000, there were 636 hazardous materials cargo releases in fatal truck crashes, which correspond to an average of 64 release incidents per year (Craft, 2004). Although the number of hazmat spills in fatal truck crashes is relatively small, the probability of a spill occurring at the time of accident is 50 percent higher than that for non-hazmat cargo. Based on the historical records from 1991 to 2000, about 31 percent of hazmat cargos were spilled from the cargo compartment in an average year, as opposed to 21 percent of the non-hazmat cargos (Craft, 2004).

Hazardous material shipments carried by trucks in the US add up to approximately 1.5 million tons annually, representing about $59.4 \%$ of the total commodity shipments in 2012 (U.S. 
Census Bureau, 2012). The historical shipment records show an increase by $27.3 \%$ from 2007 to 2012, and the trend is steadily increasing by 5\% annually in hazardous material volume (Transportation Research Board, 2005, and U.S. Census Bureau, 2012).

There have been several major incidents with hazardous cargo releases near urban areas which have received national attention. For example, in 1976, in Houston, Texas, a tanker carrying about 7,500 gallons of ammonia crashed causing six deaths and many people with severe injuries (NTSB, 1977a). Another incident occurred in 2001, in Ramona, Oklahoma where a flammable gas was discharged due to truck overturn and causing death, evacuation of neighboring areas and highway blockage for 12 hours (NTSB, 2001). During another incident in Memphis, Tennessee, (in 1997), hydrogen fluoride was released resulting in evacuations in the surrounding area (NTSB, 1977b).

Chlorine and anhydrous ammonia are two chemicals transported in large quantities and classified as Toxic Inhalation Hazards (TIH). Other chemicals transported in large quantities include sulfur dioxide, ethylene oxide, and hydrogen fluoride, and a variety of other substances used by various industries. However, since the air dispersion model used by this study was a Gaussian based approach; ammonia and hydrogen fluoride were selected for analyses as they are lighter than air and the dispersion model would be more appropriate for predicting their behavior (Branscomb at al., 2010).

Table 2.1 presents examples of incidents where ammonia and hydrogen fluoride releases to the atmosphere have been reported. 
Table 2.1 Hazardous material accidents (After NTSB 2013, US EPA 1993, NTSB 1977b).

\begin{tabular}{lllc}
\hline Date & Location & Chemical & Amount \\
& & & released \\
\hline May 1976 & Houston Texas & Ammonia & 7500 \\
January 1986 & Gore, Oklahoma & Hydrogen fluoride & 400 \\
October 1987 & Texas city, Texas & Hydrogen fluoride & 3500 to 6300 \\
June 1989 & El Dorado, Arkansas & Hydrogen fluoride & 160 \\
April 1997 & Memphis, Tennessee & Hydrogen fluoride & --- \\
August 2003 & Middletown, Ohio & Ammonia & 10600 \\
April 2003 & Calamus, Iowa & Ammonia & 1300 \\
\hline
\end{tabular}

Air pollution increases risks of cancer, respiratory and allergy diseases, and aggravates the conditions for people suffering from such diseases (Jensen et.al, 2001). Over the last three decades, many nations have been involved with research for developing operational strategies to improve transport and disposal of hazardous materials and reduce accidental release risks (Rakas et.al, 2004).

In the literature, there are several studies focused on risk assessment of hazardous material transport accidents, including but not limited to a study by Saccomanno and Shortreed (1993), where they estimated the dangerous areas around accidental releases of chorine using an air dispersion model called EPI (Emergency Prediction Information). In another study by Margai (2001), ALOHA (Areal Locations of Hazardous Atmospheres) was utilized to identify the threat zone around accidents for chlorine. Zhang et al., 2000 estimated the risk associated with hazardous material accidents by using Gaussian plume model and ArcGIS. Other similar studies such as Fabiano et al., 2002, Wu et al., 2004, Jiang et al., 2006, Liu et al., 2012 also focused on risk quantifications of accidental hazardous material spills.

The goal of this research is to estimate the size of the areas impacted after accidental releases of hazardous materials by coupling air dispersion modeling with ArcGIS. The impact 
zones for two hazardous chemicals (ammonia and hydrogen fluoride) were compared in relation to atmospheric stability conditions and exposure levels (i.e., concentration), to quantify and compare the consequences after the accidental releases. Impact zones were estimated using the ALOHA software and the output was exported into ArcGIS for aerial mapping and risk calculations. The exposure levels were defined according to the level of concern (LOC) concentrations for each chemical. The impacts zones of the two chemicals were compared with the initial and the protective action zones provided by Emergency Response Guideline (PHMSA, 2012). The health risks associated with accidental releases of the materials were compared in terms of the size of impacted area and population at risk.

\subsection{Methodology}

\subsubsection{Truck types}

In highway transport, cargo tanks with special safety features are used to transport hazardous materials (i.e., liquids, flammable and non-flammable liquids, and corrosive materials or compressed gases). The common classification of trucks suitable for transport hazardous materials is mandated by US Code of Regulations for transporting hazardous materials (49 CFR). In this classification, tankers are categorized in five types as non-pressure tanks, low-pressure tanks, corrosive cargo tanks, high-pressure tanks and cryogenic liquid tanks. The appropriate truck classifications for transporting ammonia and hydrogen fluoride are provided in Table 2.2 (Spencer, 2003). 


\subsubsection{Air Quality Estimations and Exposure Assessment}

Different types of air dispersion models have been developed to estimate contaminant concentrations over time or affected area (Griffin, 2006). Gaussian-type algorithms are the most commonly used to predict the dispersion of pollutants emitted from point sources. These models assume that dispersion of the pollutant in the atmosphere follows a normal probability distribution pattern. Gaussian models generally consider an average wind speed and constant wind direction and estimate the ground-level pollutant levels in the wind direction. In this study, the dispersion analyses were conducted using ALOHA software which was developed for accidental chemical spills by the Hazardous Materials Response and Assessment Division of National Oceanic and Atmospheric Administration) (NOAA). The Gaussian algorithm of the model was used for the comparative analyses.

\subsubsection{Areal Locations of Hazardous Atmospheres (ALOHA)}

The air dispersion model used is suitable for predicting the characteristics of atmospheric dispersion associated with the hazardous chemical releases. In the literature, ALOHA software has been used for the modeling of different release scenarios. For example, Dandrieux et al. (2002) used ALOHA to estimate chlorine concentration in a small scale release scenario; authors also compared the results from the model with the traditional Gaussian dispersion approach. Gharabagh et al. (2009) utilized the model as part of a comprehensive risk assessment study for the petrochemical feed and product pipeline network. Verma (2011) applied the model for risk management of hazardous material transported by railroad to evaluate the impacts of incidents during transport. There are also studies which use the model to analyze the historical incidents. For example, Leelossy et al. (2011) used the model as an assessment tool for prediction of the short and long term air quality impacts of the Fukushima Nuclear power plant accident. 
Table 2.2 Truck classifications for transporting ammonia and hydrogen fluoride (after Spencer, 2003; ERG, 2012).

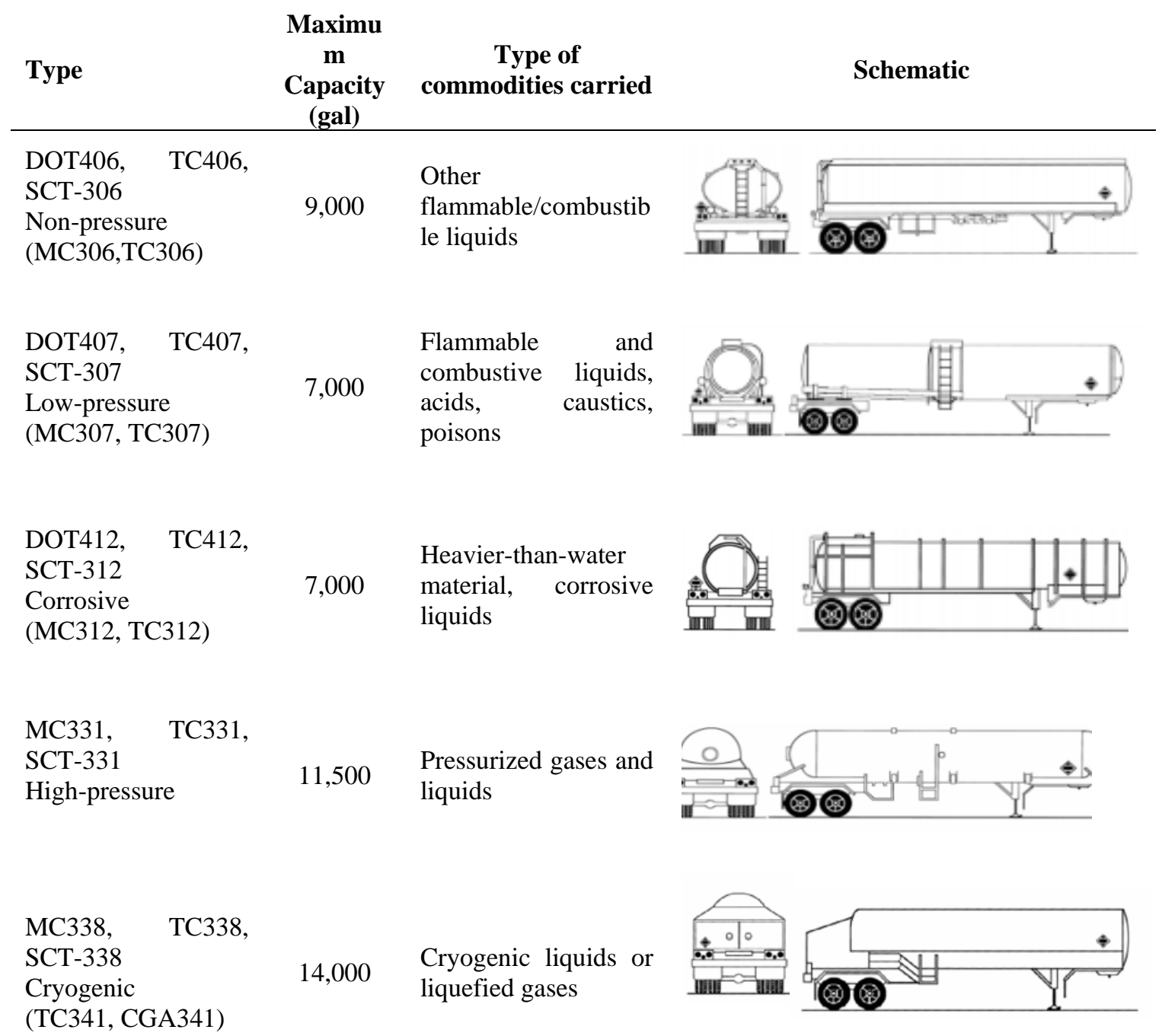


Table 2.3 Atmospheric stability categories (Turner, 1994).

\begin{tabular}{|c|c|c|c|c|c|}
\hline \multirow{3}{*}{$\begin{array}{l}\text { Surface wind } \\
\text { speed }^{a} \text { (at 10m) } \\
(\mathrm{m} / \mathrm{s})\end{array}$} & \multicolumn{3}{|c|}{ Day $^{b}$} & \multicolumn{2}{|c|}{ Night } \\
\hline & \multicolumn{3}{|c|}{ Incoming solar radiation } & \multirow{2}{*}{ Cloudy } & \multirow{2}{*}{ Clear } \\
\hline & Strong $^{c}$ & Moderate $^{d}$ & Slight $^{e}$ & & \\
\hline$<5$ & $\mathrm{~A}$ & A-B & B & $E$ & $\bar{F}$ \\
\hline $5-7$ & $A-B$ & B & $\mathrm{C}$ & E & $\mathrm{F}$ \\
\hline $7-11$ & $\mathrm{~B}$ & $\mathrm{~B}-\mathrm{C}$ & $\mathrm{C}$ & $\mathrm{D}$ & E \\
\hline $11-13$ & $\mathrm{C}$ & C-D & $\mathrm{D}$ & $\mathrm{D}$ & $\mathrm{D}$ \\
\hline$>13$ & $\mathrm{C}$ & $\mathrm{D}$ & $\mathrm{D}$ & $\mathrm{D}$ & $\mathrm{D}$ \\
\hline
\end{tabular}

${ }^{\mathrm{a}}$ Surface wind speed measure at $10 \mathrm{~m}$ above ground.

${ }^{\mathrm{b}}$ A: Very unstable D: Neutral

${ }^{\mathrm{c}}$ Clear summer day with sun higher than $60^{\circ}$ above the horizon.

${ }^{d}$ Summer day with a few broken clouds, or a clear day with sun $35-60^{\circ}$ above the horizon.

${ }^{\mathrm{e}}$ Fall afternoon, or a cloudy summer day, or clear summer day with sun $15-35^{\circ}$. 
Table 2.4 Characteristics of ammonia and hydrogen fluoride (EPA, 2013).

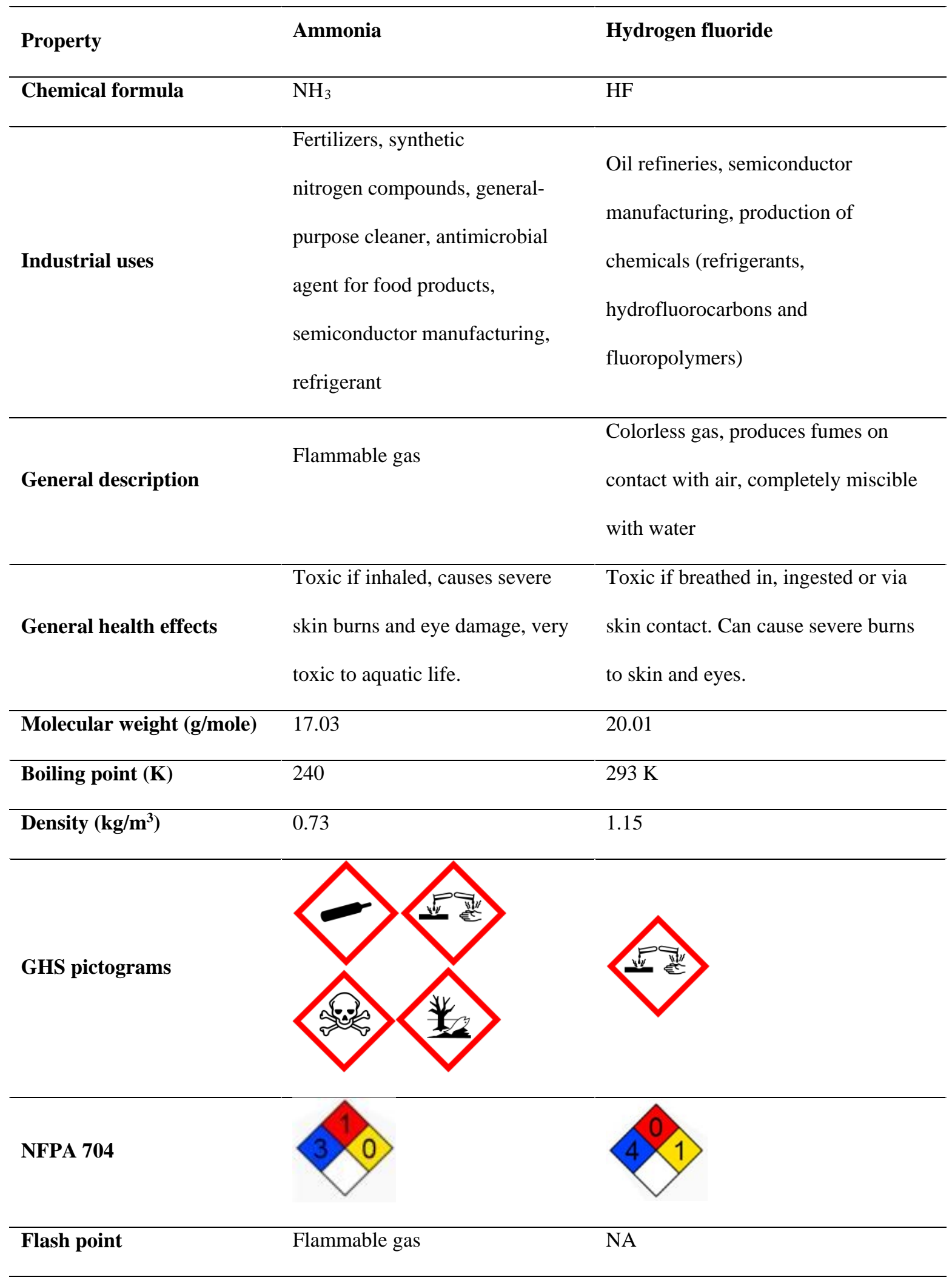




\begin{tabular}{lcc}
\hline Explosive limits & \multicolumn{2}{l}{ NA } \\
\hline Table 2.5 Characteristics of ammonia and hydrogen fluoride (EPA, 2013). \\
\hline Property & Ammonia & Hydrogen fluoride \\
\hline Permissible exposure & $50 \mathrm{ppm}(25 \mathrm{ppm}$ ACGIH-TLV; & $3 \mathrm{ppm}$ \\
limit (PEL) & $35 \mathrm{ppm}$ STEL) & \\
\hline LD50 & $0.015 \mathrm{~mL} / \mathrm{kg}$ (human, oral) & $1 \mathrm{ppm}$ \\
\hline LC50 & $30 \mathrm{ppm}$ & $24 \mathrm{ppm}$ \\
\hline AEGL-1 & $160 \mathrm{ppm}$ & $44 \mathrm{ppm}$ \\
AEGL-2 & $1100 \mathrm{ppm}$ & $2 \mathrm{ppm}$ \\
AEGL-3 & $25 \mathrm{ppm}$ & $20 \mathrm{ppm}$ \\
\hline ERPG-1 & $150 \mathrm{ppm}$ & $50 \mathrm{ppm}$ \\
ERPG-2 & $750 \mathrm{ppm}$ & \\
ERPG-3 & & (rat, 1 hour, inhalation) \\
\hline
\end{tabular}

The inputs to the model include properties and amount of the released chemical as well as the meteorological data (i.e., air temperature and humidity, wind direction and speed, and the atmospheric stability class). The stability class has a significant effect on the prediction of the size of the toxic threat zone under different atmospheric dispersion conditions. Atmospheric stability is related to the tendency of a parcel of air to move upward or downward after it has been displaced vertically by a small amount (Woodward, 1998). ALOHA uses the Pasquill-GiffordTurner classification system consisting of six classes based on five surface wind speed categories, three types of daytime solar insolation, and two types of nighttime cloud cover (Turner, 1994). This scale, presented in Table 2.3, ranges from stability class A (indicating unstable atmospheres which tend to develop vertical updrafts with high turbulence intensities), to stability class F 
(indicating stable atmospheres which tend to suppress vertical updrafts and reduce turbulence intensity) (Woodward, 1998, Hanna, 1982).

Two chemicals, anhydrous ammonia and hydrogen fluoride, were selected to compare the dispersion characteristics and size of the impact zones after an accidental release incident. Table 2.4 and Table 2.5 present the properties of these two chemicals which are highly volatile and classified as toxic compounds. Both chemicals are used in numerous industrial applications; therefore, they are transported frequently on the highways. Table 2.6 presents the accidental release scenarios considered in this study. For a specific location in Miami-Dade County, Florida, these scenarios were compared for the dispersion of either anhydrous ammonia or hydrogen fluoride as a function of varying only the Pasquill-Gifford stability classes. This was performed by applying the Gaussian algorithm of the model to predict the dispersion of the hazardous chemicals under specific conditions of air temperature, humidity, and wind speed and direction.

Based on the information presented in Table 2.3, a wind speed of $5 \mathrm{mph}$ is amenable to the selected criteria for comparison since five of the six stability classes are possible at this wind speed, either during the day or night (however, the sixth class was also considered). The remaining inputs for weather conditions were selected to be representative of the winter conditions in the selected location (Miami, Florida).

Table 2.6 User specified settings used for dispersion analysis after accidental cargo spills.

\begin{tabular}{lc} 
Parameters & Settings \\
\hline Hazardous materials & Ammonia, Hydrogen Fluoride \\
Amount released (tons) & 2 \\
Atmospheric stability class & A, B, C, D, E, F \\
Wind speed (mph) & 5 \\
Wind direction & SW \\
Temperature $\left({ }^{\circ} \mathrm{F}\right)$ & 55 \\
Air humidity $(\%)$ & 80 \\
Time (min) & 60 \\
\hline
\end{tabular}




\subsubsection{Risk Estimation}

Risk can be quantified from the number of similar events occurring per year and the corresponding consequences. The consequence can be expressed from different perspectives (i.e., impacted population, fatalities, size of the impacted areas, cost of traffic congestion due to delay, environmental impacts) and the frequency of events can be estimated from the number of similar events occurring per year. In this study, the health risk due to exposure to a hazardous chemical released to the atmosphere was estimated by the following equation (US DOT, 2015):

Risk $=$ Likelihood $\times$ Consequences

In order to estimate the consequences in Equation 1, the health impact zones estimated by ALOHA were utilized based on the air quality and by incorporating the possible health impacts due to exposure to hazardous materials which are released to the atmosphere. The likelihood of an accident occurrence is broken into two related quantities: the rate that an accident takes place (threat), and the likelihood that the accident leads to a chemical release (vulnerability). In order to calculate the accident rate, as defined in the Highway Safety Manual (HSM, 2010), the normalized value of the crash frequency with exposure (the degree to which a road user is exposed to traffic risks) was calculated. Exposure in 100 million vehicle miles traveled was calculated by Equation 2. Crash rate was acquired by the Equation 3 (HCM, 2000).

EXPO $=\frac{\text { AADT } \times 365 \times \text { number of years } \times \text { total segment length }}{100,000,000}$ 
Crash rate $=\frac{\text { Total crash count }}{\text { EXPO }}$

where, EXPO is exposure and AADT is annual average daily traffic. The truck AADT was considered in the equation to represent the frequency of truck accidents, as the main focus of this research and the primary cause of chemical releases. The total crash count was calculated by identifying accidents involving trucks within a search radius around the target segment of the road which the accident assumed to happen. In order to take into account the probability of releases caused by accidents involving trucks, as they may not lead to spills always, statistics of hazardous material accidents were considered as the percentage of the accidents which led to releases to the number of total hazardous material accidents according to PHMSA, which was equal to 27.3\% (Battelle, 2001). In the accident rate calculation, eight years of crash data in the area were taken into account. The accidents involving trucks were selected and then enumerated; further, the crash rate was computed using AADT data of trucks using Equation 3. All the calculations related to estimation of the impacted areas, population at risk, truck crashes identification, crash rate calculation, as well as visualization of the impact zones were executed employing ArcGIS.

\subsection{Results}

One of the display outputs of the model is the toxic threat zone plots which provide visualization and mapping of concentration contours (or threshold concentrations for specific effects due to exposure). The size of the impact zones estimated by the model depends on the level of concern (LOC) defined by the user. A toxic LOC refers to exposure limits at which exposure for a defined length of time poses a specified health risk. For this study, the LOC was set to be equal to the Acute Exposure Guideline Levels (AEGLs). AEGLs concentrations, 
expressed in ppm, are available for individual chemicals and are categorized in three levels according to the type of risk that a given exposure duration may cause to the general public, including sensitive individuals. The first level, AEGL-1, refers to the threshold concentration for mild effects (i.e., discomfort, irritation, or any other temporary and reversible symptoms) on the exposed individuals. The second level, AEGL-2, refers to the irreversible or long-lasting adverse health effects which may impair the individual's ability to escape the zone of exposure. The third level, AEGL-3, refers to life-threatening health effects or death. All three levels are established for five exposure periods: 10 minutes, 30 minutes, 60 minutes, 4 hours, and 8 hours. Only the 60min AEGLs are provided in the model which is the maximum time limit for the model prediction. However, other types of possible consequences could have been taken into account, such as flammable zones and overpressure areas identification around accidents (Inanloo and Tansel, 2015), which were beyond the scope of this study.

Figure 2.1 presents the threat zone output plots for the dispersion of ammonia and hydrogen fluoride under atmospheric stability C for the conditions specified in Table 2.6. The model generates the puff isopleth plots; the isoconcentration contours corresponding to each of the three AEGLs. These contour lines represent the longitudinal and lateral boundaries of the area where the ground-level concentration is predicted to reach or exceed the specific LOC (i.e., AEGL) during the advection of the puff. The confidence lines enclosing the area where the gas cloud is expected to be found with $95 \%$ of confidence if probable changes in the wind direction occur. Confidence lines are depicted around the longest travel distance. 


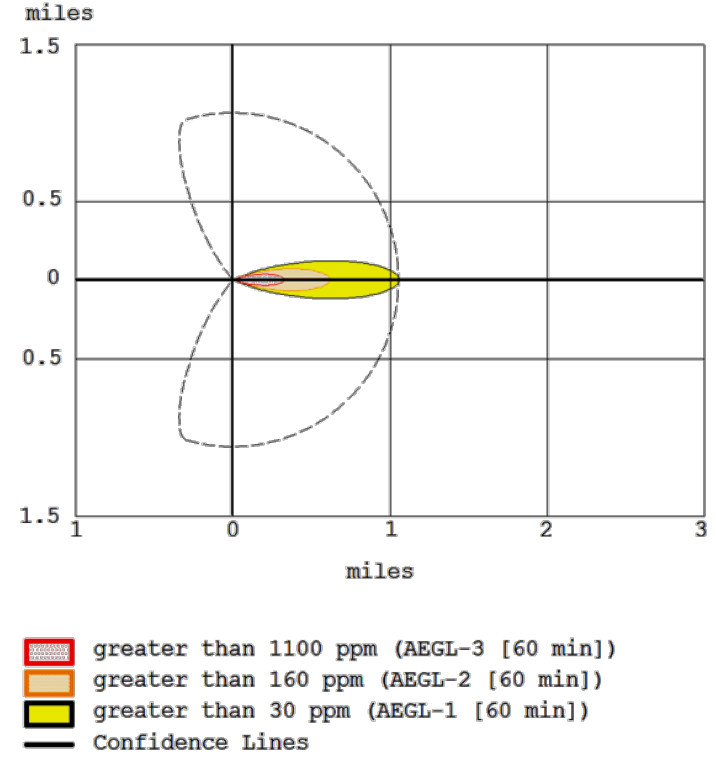

(a) Ammonia

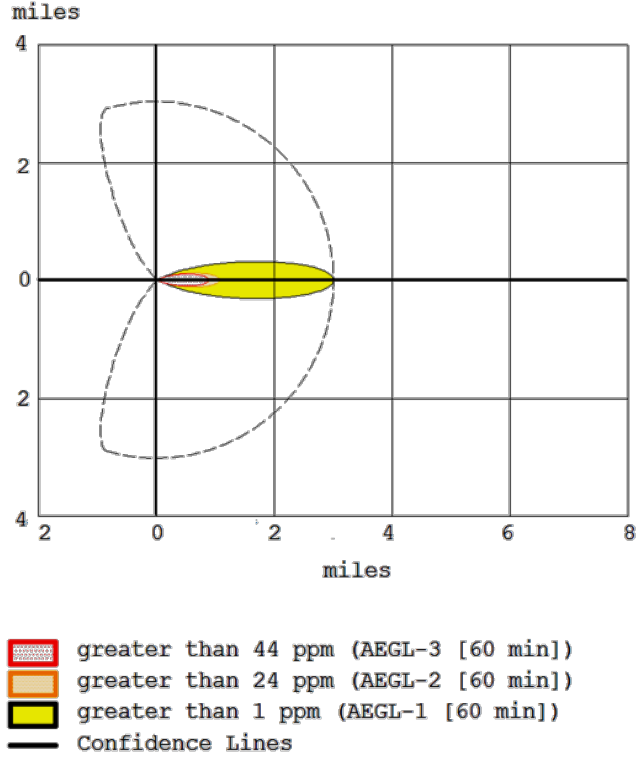

(b) Hydrogen fluoride

Figure 2.1 Comparison of ALOHA's threat zone plots for the case scenario of an accidental release of ammonia and hydrogen fluoride based on their Acute Exposure Guideline Levels (AEGLs). Calculations performed using input data given in Table 2.6 for a class $\mathrm{C}$ atmospheric stability.

The model determines the final shape of the confidence line via the implicit standard deviation of wind direction, a parameter termed sigma-theta (Turner, 1994). The value of this parameter in the algorithm reflects the amount of variation in wind direction. Since the probable amount of variation is different for each stability condition, the shape and size of the confidence outline changes according to the stability class. Figure 2.1 shows the differences in the mobility of the two chemicals for an identical release scenario (i.e., amount released, wind conditions). In the case of ammonia, the threat zone outer limit extends for 1.1 miles while that of the hydrogen fluoride extends for 3.0 miles. This difference can be explained based on the time it takes for the puff to be diluted and reach the specific concentration (i.e., AEGL selected). For example, the AEGL-1 concentration for hydrogen fluoride is $1 \mathrm{ppm}$; 30 times lower than that of ammonia at 30 ppm. 
The atmospheric dispersion resulting from the accidental release of hydrogen fluoride and ammonia was studied using several different sets of atmospheric inputs for summer and winter conditions and the model predictions were found to be very similar. Furthermore, wind speeds in the range from 5 to $11 \mathrm{mph}$ were tested and only minor differences in the final downwind transport distance was found between the puff scenarios of the two chemicals. In these cases, the main difference was that the confidence lines area became wider as the wind speed became lower. This is a result of the greater uncertainty (standard deviation) in the wind direction at lower wind speeds.

The results from the winter scenario modeling runs conducted at a wind speed of $5 \mathrm{mph}$ (other inputs reported in Table 2.6) for the possible atmospheric stability conditions. Figure 2.2 presents the predicted toxic threat zone plots for ammonia for the six atmospheric stability classes superimposed to the GIS maps. This representation provides an easy visualization tool for the geographical areas that would be impacted by the toxic release. Results show that the downwind distance traveled by the puff is predicted to be progressively larger with atmospheric stabilities, from 0.7 miles for class A (turbulent) to 2.7 miles for class F (very stable). Considering the same wind speed, the higher turbulence of a vertically unstable atmosphere will facilitate rapid dilution of the initial cloud of buoyant gas (both gases are less dense than air) via upward movement and consequently, the threat zone (as defined by AEGL) will extend to a shorter downwind distance. 

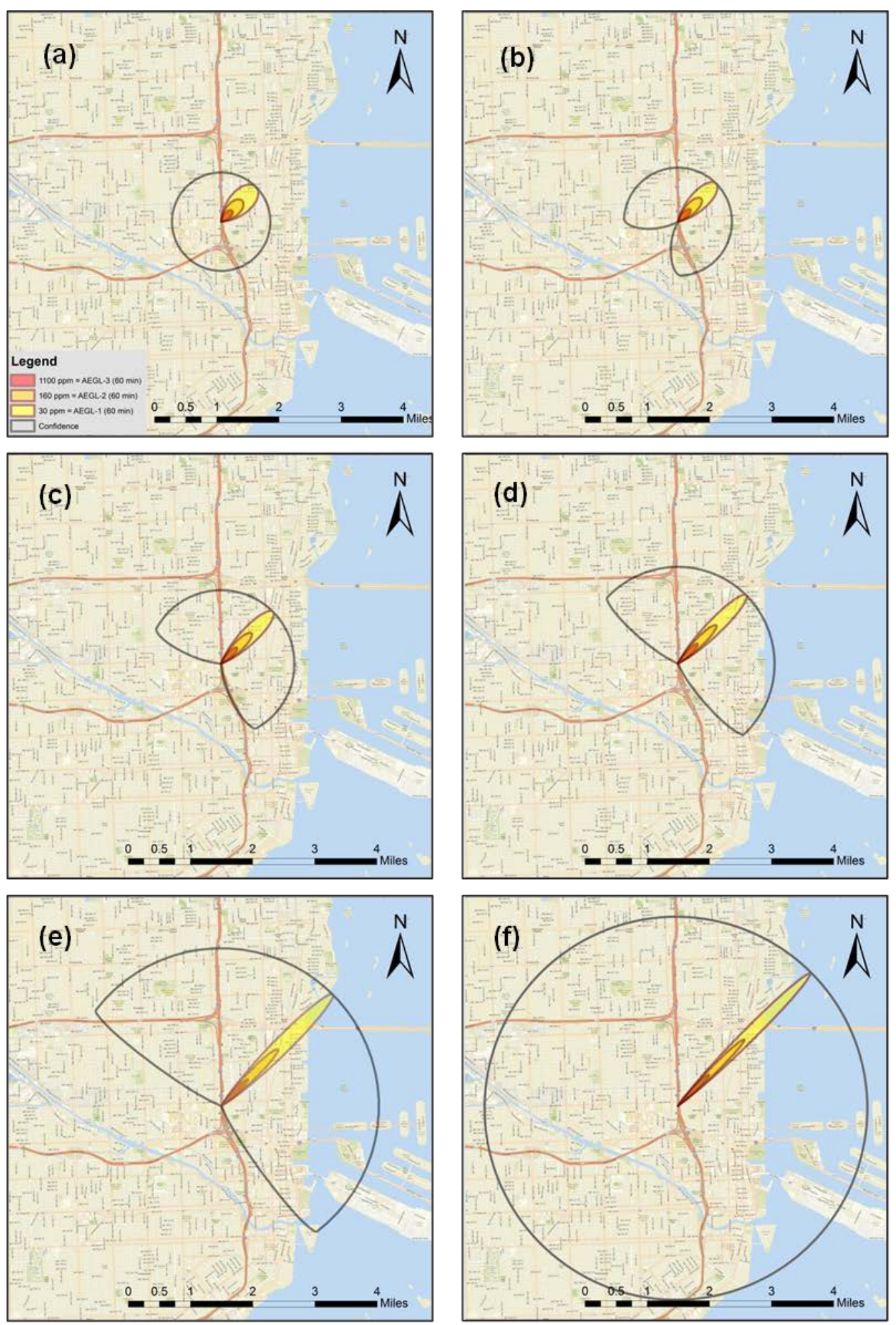

Figure 2.2 Geographical areas impacted by the dispersion of toxic release of ammonia under different atmospheric stability classes: (a) A, (b) B, (c) C, (d) D, (e) E, (f) F. 

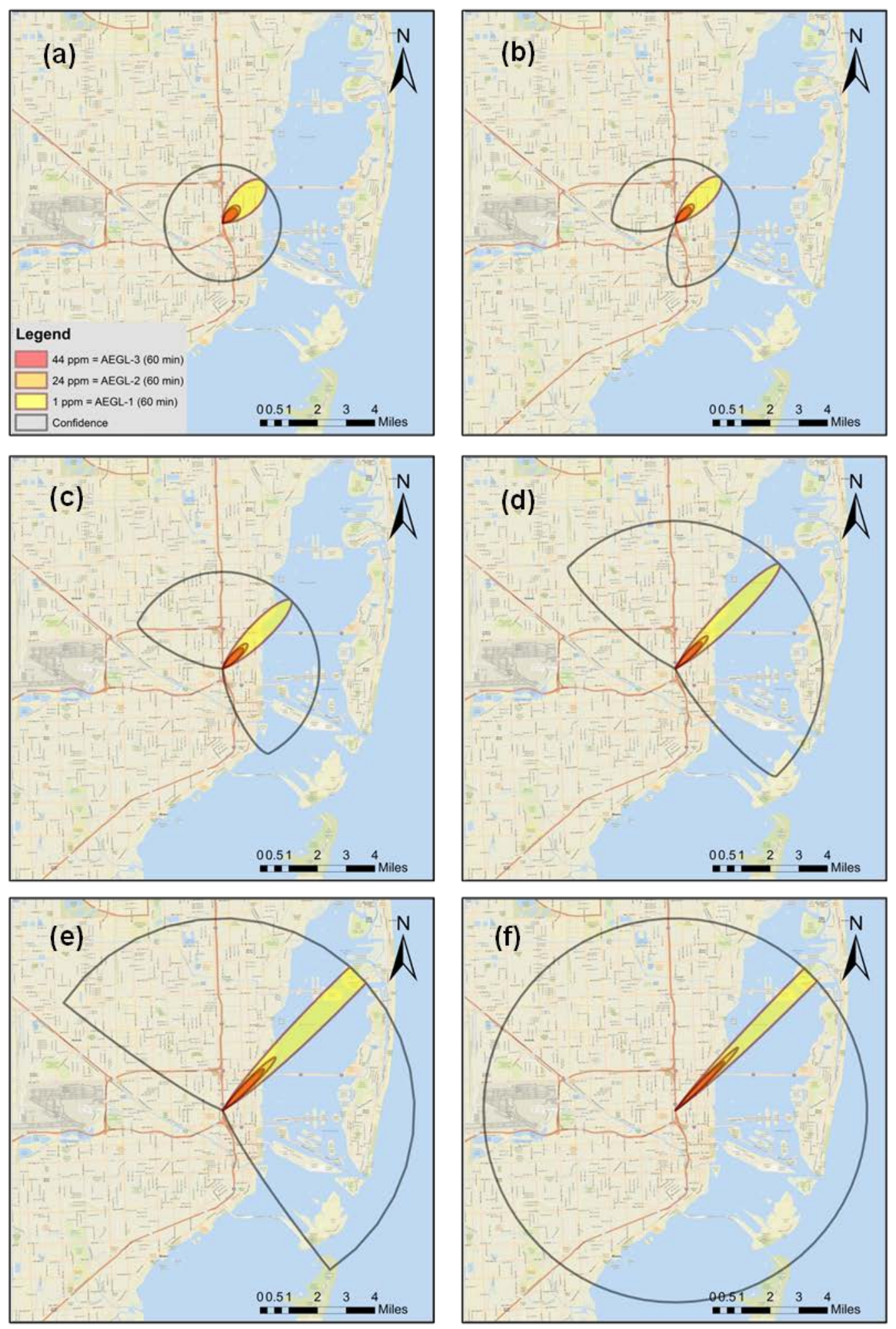

Figure 2.3 Geographical areas impacted by the dispersion of a toxic release of hydrogen fluoride under different atmospheric stability classes: (a) A, (b) B, (c) C, (d) D, (e) E, (f) F. 
The model also allows displaying the output for the downwind concentration as a function of time at a specific point or location (user-defined) by entering a downwind and crosswind distance relative to the release point. This concentration profile plot follows a symmetrical bell-shaped curve. For example, for the scenario depicted in Figure 2.2; for the atmospheric stability class $\mathrm{C}$, plots of the concentration profiles show that the cloud of ammonia would arrive at the 0.3 miles threshold for the AEGL-3 in about 7 minutes, at the 0.6 miles threshold for the AEGL-2 in about 17 minutes, and at the 1.1 miles threshold for the AEGL-1 in about 20 minutes. Figure 2.2 presents the dispersion predictions for ammonia to reach the 60 -min time limitation at atmospheric stability E (Figure 2.2(e)).

The toxic threat zone plots for hydrogen fluoride are shown in Figure 2.3. Similar to ammonia, the downwind distance traveled by the puff also becomes progressively larger from atmospheric stability class A to F. However, the distances are much larger than those for ammonia, ranging from 1.8 miles for class A (turbulent) to 4.6 miles for class D (neutral). The model could not provide useful concentration information for stability classes $\mathrm{E}$ and $\mathrm{F}$, as the threat zone is greater than 6 miles. The plots of the concentration profiles for the advection of the hydrogen fluoride puff scenario under atmospheric stability C, corresponding to the threat zone shown in Figure 2.3(b), indicate that the cloud of hydrogen fluoride would arrive at the 0.9 mile threshold for the AEGL-3 in about 18 minutes, at the 1.1 mile threshold for the AEGL-2 in about 22 minutes, and at the 3 mile threshold for the AEGL-1 in about 60 minutes. Hence, the dispersion predictions for hydrogen fluoride only provide useful information for stability classes A, B and C (Figure 2.3).

Figure 2.4 compares the magnitude of the impact zones in relation to exposure levels for ammonia and hydrogen fluoride under different stability conditions. For a similar release quantity, the impact zone for hydrogen fluoride covers a significantly larger area in comparison to that for ammonia. 


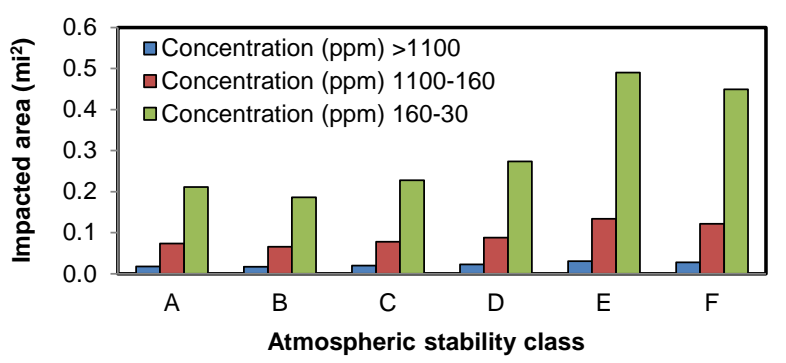

(a) Ammonia

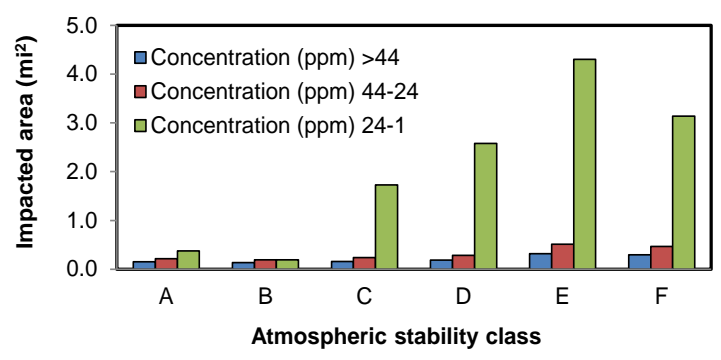

(b) Hydrogen Fluoride

Figure 2.4 Comparison of the magnitude of the areas impacted (square miles) at specific exposure levels under different atmospheric stability conditions: (a) ammonia, and (b) hydrogen fluoride.

In order to validate the results from the models, ERG 2012 manual was used and the predicted impact zones by the two approaches were compared. Pipeline and Hazardous Materials Safety Administration's (PHMSA) ERG describes the procedures for the first emergency responders (i.e., police, firefighters or other emergency service providers) who deal with hazardous material accidents during the first 30 minutes after the incident. The initial isolation zone distances is defined as the area surrounding an accident, within people may be exposed to hazardous (upwind) and life threatening (downwind) concentration of chemical, and protective action zone is the area downwind from the incident in which people may suffer irreversible health impacts (Figure 2.5). These zones are derived from the historic data on similar incidents and by the statistical models. The initial isolation and protective action distances vary according to the chemical, time of release (day or night), and amount of release (small or large). According to ERG, the protective action zone considers AEGL-2 or ERPG-2 (Emergency Response Planning Guideline 2) values for exposure concentration limits. 


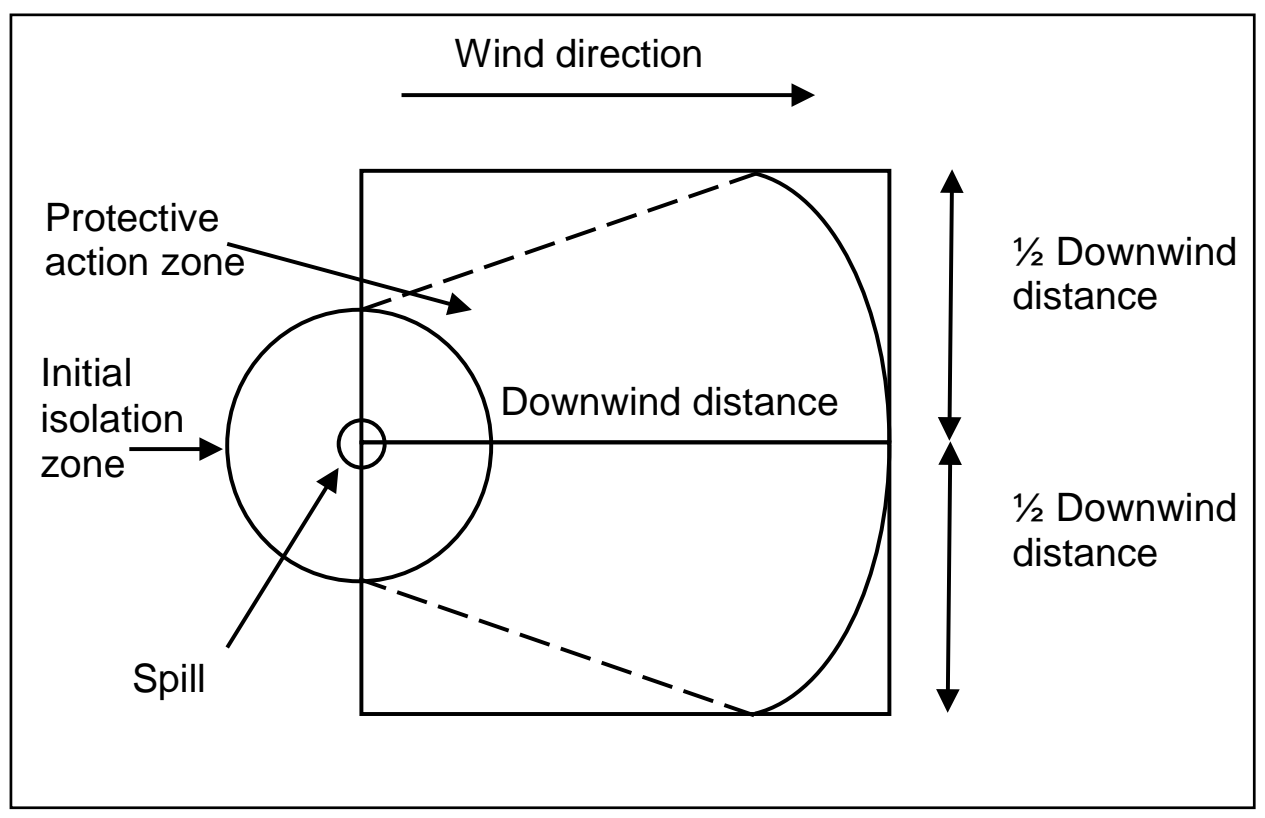

Figure 2.5 Initial isolation and protective action zones.

ERG defines the isolation and the protective zones in accordance with the released chemical, time of release (day or night), and amount of release (small or large). According to the ERG 2012 table, for highway truck or trailer carrying ammonia and hydrogen fluoride, extension of initial isolation and protective action distances are shown in Table 2.7.

Table 2.7 Initial Isolation and protective action zones for highway truck or trailer.

\begin{tabular}{|c|c|c|c|c|c|c|c|}
\hline \multirow{5}{*}{ Chemical } & \multirow{5}{*}{$\begin{array}{c}\text { Isolation } \\
\text { Zone } \\
\text { (feet) }\end{array}$} & \multicolumn{6}{|c|}{ Protective action zone (miles) } \\
\hline & & \multicolumn{3}{|c|}{ Day } & \multicolumn{3}{|c|}{ Night } \\
\hline & & Low Wind & Moderate & High & Low & Moderate & High \\
\hline & & \multirow[t]{2}{*}{$<6 \mathrm{mph}$} & Wind & Wind & Wind & Wind & Wind \\
\hline & & & 6-12 mph & $>12 \mathrm{mph}$ & $<6 \mathrm{mph}$ & 6-12 mph & $>12$ \\
\hline Ammonia & 400 & 0.6 & 0.3 & 0.2 & 1.6 & 0.5 & 0.3 \\
\hline Hydrogen & 700 & 1.2 & 0.6 & 0.5 & 2.4 & 1.0 & 0.6 \\
\hline Fluoride & & & & & & & \\
\hline
\end{tabular}


Since ERG uses AEGL-2 thresholds for predicting the protective action zone, in this study the areas predicted by ALOHA under AEGL-2 and EPRG-2 levels were considered for the comparison with the protective zones defined by ERG 2012. The comparisons were conducted between two stability classes of $\mathrm{C}$ and $\mathrm{F}$ for both chemicals. The reason for selection of these two stability classes (Table 2.3) is because the most expanded impact zone during day (considering wind speed of $5 \mathrm{mph}$ ) happens under atmospheric class of C. Therefore, this scenario was selected for comparison with the protective zone defined by ERG during day time and under low wind category of protective action zone. In addition, class of $\mathrm{F}$ was used to compare the most extended impact zone with the protective zone defined by ERG during night (also under low wind category of protective action zone).

According to the model, the vapor cloud of ammonia would arrive at the 0.6 miles threshold for the AEGL-2 in about 17 minutes under stability class $C$ (the most unstable conditions) during day time) with the assumed wind speed (5 mph). For hydrogen fluoride under the same conditions, the expansion of toxic cloud would be around 1.1 miles in 22 minutes. While, according to ERG 2012, the protective zone of ammonia and hydrogen fluoride during day expand to 0.6 and 1.2 miles downwind respectively. Comparison between results of ALOHA and ERG 2012 manual shows that the result of this study is very close to those provided by ERG but more accurate in terms of retention time (Table 2.8). On the other hand, for the chemicals under stable atmospheric class of $\mathrm{F}$ (at night), ammonia would travel 1.4 miles in 38 minutes. However, ALOHA does not report the expansion of AEGL-2 for hydrogen fluoride, since its retention time exceeds 1 hour, which is the limitation of ALOHA. Under the stability class of E hydrogen fluoride would arrives at 2.35 miles from the release point in 55 minutes. The results of ALOHA in comparison to that of ERG are comparable as presented in Table 2.7 and Table 2.8. The similar comparison was performed, comparing Emergency Response Planning Guidelines 2 (ERPG -2) threshold and the results of both approaches were close (Table 2.8). 
Table 2.8 ARPG-2 and AEGL-2 Impact zone information.

\begin{tabular}{lcccccc}
\hline \multirow{2}{*}{ Level of } & & \multicolumn{2}{c}{ Ammonia } & & \multicolumn{2}{c}{ Hydrogen Fluoride } \\
\cline { 3 - 4 } \cline { 6 - 7 } concern $^{\mathbf{a}}$ & Stability class & Distance & Time & & Distance & Time \\
& & (mile) & (minute) & & (mile) & (minute) \\
\hline \multirow{2}{*}{ ERPG-2 } & $\mathrm{C}$ & 0.63 & 15 & & 1.15 & 23 \\
& $\mathrm{E}$ & 1.20 & 28 & & 2.55 & 57 \\
& $\mathrm{~F}$ & 1.40 & 38 & & - & - \\
\hline \multirow{2}{*}{ AEGL-2 } & $\mathrm{C}$ & 0.60 & 17 & & 1.10 & 22 \\
& $\mathrm{E}$ & 1.15 & 28 & & 2.35 & 55 \\
& $\mathrm{~F}$ & 1.40 & 38 & & - & - \\
\hline
\end{tabular}

a ERG 2012 Manual: ERPG is Emergency Response Planning Guideline Level, and AEGL is Acute Exposure Guideline Level

For the size of the impacted zones estimated by ALOHA and ERG, though, the areas assigned by ERG are significantly larger than the areas by ALOHA under different stability of atmosphere. However, ALOHA does not consider any impact area upwind, while ERG defines a circular area (initial isolation) surrounding the incident in all directions to be evacuated. Since ALOHA is based on Gaussian dispersion in which the concentration only disperses downwind, the model does not provide any chemical concentration upwind, and assumes the chemical to be carried by wind in downwind only.

The health risks were calculated for the two chemicals and under different atmosphere stability scenarios. Two approaches were taken into account in order to estimate the risk, which are based on the size of the impact area and the population under risk. The size of the area impacted after a chemical release depends on the characteristics of the chemical along with the meteorological and atmospheric conditions. However, the magnitude of the population exposed depends on the population density in the surrounding area. In this regard, a similar an accidental release in two different locations would affect similar square miles but different number of people 
depending of the populations density (i.e., rural, urban). In this study, health risks were calculated according to the three concentration levels of the chemicals as defined by AEGLs which correspond to life threatening, significant or short term health impacts.

Figure 2.6 compares the risks based on the impacted area and exposed population for each chemical at different AEGLs. In comparison of impacted areas under different stability classes from stability class of B to E, the risk increased by increase in instability of atmosphere for both chemicals. However, comparing population at risk for the two substances reveals different patterns of change. As for ammonia, similar to the pattern of impacted area, the population increased from stability B to E, although, for hydrogen fluoride the trend was different so that the population decreased from stability class of B to D. This is due to the fact that in considering the population affected by the chemical, the impacted zones of hydrogen fluoride became narrower and extended further along and above the water bodies close to the accident location by moving from unstable atmospheres to stable ones (Figure 2.3). Therefore, the number of people who live or work in the surrounding area decreases because most parts of the impacted areas are located above the water bodies covering the regions with no population density (Figure 2.3). The results presented in Figure 2.6(c) indicate that stability condition D had the smallest risk based on the population exposed, however, stability condition B had the smallest risk based on the size of the impacted area (Figure 2.6(d)). The analyses show that the impacts of the release and the consequences would be different if the release location was near densely populated areas. 


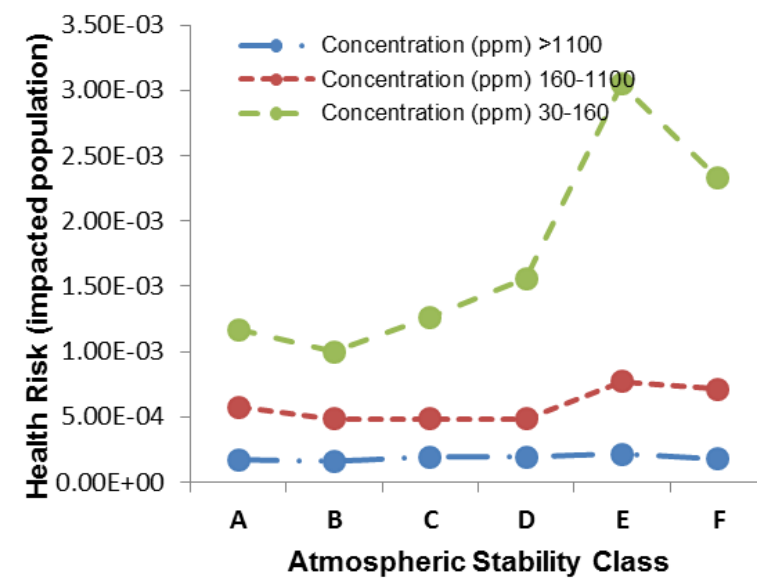

(a) Health risk based on impacted population (ammonia)

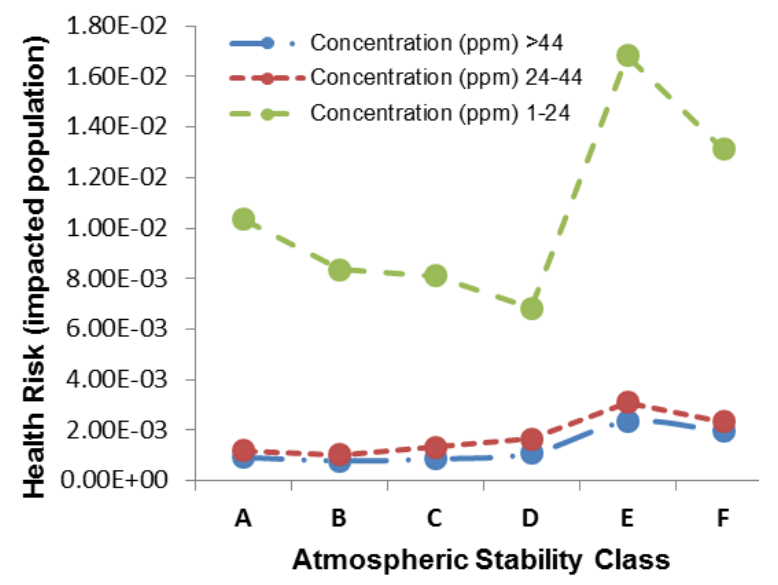

(c) Health risk based on impacted population (hydrogen

fluoride)

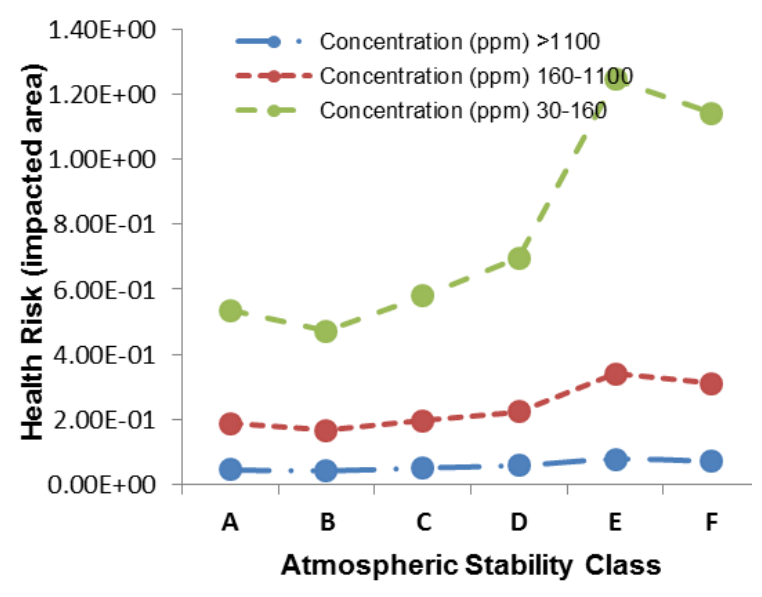

(b) Health risk based on impacted area (ammonia)

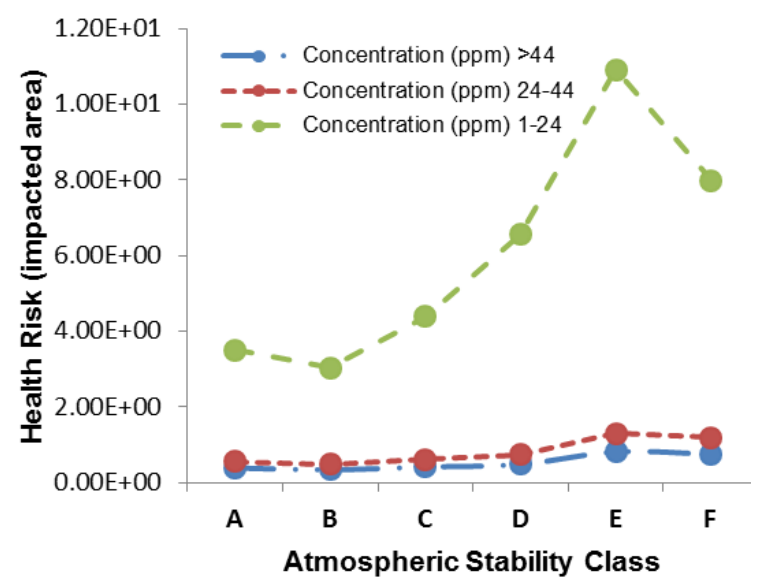

(d) Health risk based on impacted area (hydrogen fluoride)

Figure 2.6 Health risks based on impacted area and population for ammonia and hydrogen fluoride.

\subsection{Conclusions}

Impact zones after a hazardous material release of either ammonia or hydrogen fluoride were compared for 2 tons of the chemicals subject to atmospheric dispersion at wind speed of 5 mph for different Pasquill-Gifford atmospheric stability classes. The study area was in Miami, 
FL, USA, considering the crash data, traffic volume, and meteorological data in the region. The results of the simulations showed that for ammonia releases that occur at atmospheric conditions conducive to vertical mixing (therefore rapid dilution), at stability classes A (turbulent) to C (unstable), the downwind concentrations that are deemed to be immediate danger (over AEGL-3 threshold of $1100 \mathrm{ppm}$ ) extends up to 0.3 miles from the release location. Under less favorable vertical mixing conditions (e.g., typical of the nighttime), at stability classes $\mathrm{E}$ (stable) and $\mathrm{F}$ (very stable), the downwind distance over the threshold levels extends up to 0.5 to 0.7 miles. Zones with concentrations over the exposure threshold levels for mild/reversible symptoms (AEGL-1 threshold of $30 \mathrm{ppm}$ ) extend approximately 0.7 to 1.1 miles downwind under unstable atmospheric classes (A, B, and C) and 2 to 3 miles under stable conditions classes (E and F).

The impact zones estimated for hydrogen fluoride release scenario were significantly larger than those estimated for ammonia. Dilution of the chemical to the AEGL-3 threshold of 44 ppm extended approximately 0.6 to 0.9 miles downwind under unstable atmospheric conditions (classes A, B, C), and approximately 2 miles downwind under stable atmospheric conditions (classes $\mathrm{E}$ and F). Concentration within the exposure threshold for mild/reversible symptoms (AEGL-1 threshold of $1 \mathrm{ppm}$ ) extended approximately 1.8 to 3.0 miles downwind under unstable atmospheric conditions, and are predicted to be larger than 4.6 miles under neutral atmospheric conditions (class D); at which point the 60-minute cutoff of the model was reached.

The analyses showed that the impact zones can be significantly different for different types of hazardous cargo. The aerial magnitudes of the impact zones are highly dependent on the atmospheric stability. Releases during the day time would have relative smaller impact areas in comparison to those that occur at night. The overlay of the toxic threat zone plots over the GIS map of the accident location provided an effective tool to visualize the geographical domain affected by the release (number of people exposed, age distribution of the exposed population, potential secondary exposure routes such as water and soil). Comparison between the results of 
ALOHA with ERG manual for the impacted areas showed acceptable accuracy for the estimates by ALOHA. The health risks estimated based on the area and population at risk showed the significance of the consequences of the accidental releases. The analyses showed that the risk which is quantified for a specific consequence can be different from the risk quantified based upon another type of consequence (e.g., impacted area vs. population). For example, for the case of hydrogen fluoride release scenario, the lowest quantity of health risk corresponded to the stability condition D when the magnitude of impacted area was taken into account for consequence calculation. However, when the size of the exposed population was considered, stability class B was the favorable scenario (with less number of exposed people). Therefore, a great consideration should be focused on the selecting of the consequences of accidents. The results vary depending on the released chemical, atmospheric condition, location, traffic volume, and crash rate data. However, the US emergency response guideline and any other similar guidelines provide reactive approach for responding to accidents, as in recommendation of evacuation or protective distances after the accident happen. Nonetheless, this research provides a proactive action strategy, based on quantitative risk assessment and prediction of the threat zones. Considering uncertainties and lack of data, risk assessments similar to the proposed approach can help to decrease the accidental release risks of hazardous chemicals during transport by avoiding densely populated areas or segments with high crash rates, as well as selecting specific paths or road segments based on their level of accident risks. The multilevel analysis of impacts after hazardous material releases during transport (i.e., type of material, geographical data, dispersion profile, meteorological information, population density, and traffic data) can be used for planning and implementing appropriate response and mitigation measures for hazardous cargo releases to atmosphere. The insights provided by this research can aid decision makers for routing and scheduling of hazardous material cargos and developing strategies which avoid high risk and vulnerable regions for transporting hazardous materials. 


\section{Acknowledgements}

Partial funding for this research has been provided by Southeastern Transportation

Research, Innovation, Development and Education Center (STRIDE), University of Florida as well as the Florida International University Graduate School Dissertation Year Fellowship.

\section{References}

Battelle, (2001). Comparative risks of hazardous materials and non-hazardous materials truck shipment accidents/incidents: final report. Federal Motor Carrier Safety Administration.

Branscomb, L., Fagan, M., Auerswald, P. E., Ellis, R. N., Barcham, R. (2010). Rail transportation of toxic inhalation hazards: Policy responses to the safety and security externality. Available at SSRN 2397482.

Craft, R. (2004). Crashes involving trucks carrying hazardous materials. federal motor carrier safety administration. Washington, DC: US Dept.of Transportation.Publication\#: FMCSA-RI-04-024.

Dandrieux, A., Dusserre, G., Ollivier, J. (2002). Small scale field experiments of chlorine dispersion. Journal of Loss Prevention in the Process Industries, 15(1), 5-10.

Fabiano, B., Curro, F., Palazzi, E., Pastorino, R. (2002). A framework for risk assessment and decision-making strategies in dangerous good transportation. Journal of hazardous materials, 93(1), 1-15.

Gharabagh, M. J., Asilian, H., Mortasavi, S., Mogaddam, A. Z., Hajizadeh, E., Khavanin, A. (2009). Comprehensive risk assessment and management of petrochemical feed and product transportation pipelines. Journal of Loss Prevention in the Process Industries, 22(4), 533-539.

Griffin, R. D. (2006). Principles of air quality managementCRC Press.

Hanna, S. R., Briggs, G. A., Hosker Jr, R. P. (1982). Handbook on atmospheric diffusion.

Manual, H. C. (2000). Highway capacity manual. Washington, DC.

Manual, H. S. (2000). Highway safety manual. Washington, DC.

Inanloo, B., Tansel, B. (2015). Explosion impacts during transport of hazardous cargo: GIS-based characterization of overpressure impacts and delineation of flammable zones for ammonia. Journal of environmental management, 156, 1-9.

Jensen, S. S., Berkowicz, R., Hansen, H. S., Hertel, O. (2001). A danish decision-support GIS tool for management of urban air quality and human exposures. Transportation Research Part D: Transport and Environment, 6(4), 229-241.

Jiang, X., Xu, Z., Deng, Y. (2006). Development in risk study on hazardous chemical materials road transportation. Journal of Catastrophology, 21, 94-98. 
Leelőssy, Á., Mészáros, R., Lagzi, I. (2011). Short and long term dispersion patterns of radionuclides in the atmosphere around the fukushima nuclear power plant. Journal of environmental radioactivity, 102(12), 1117-1121.

Liu, L., Sun, L., Li, J., Li, C., Hu, X. (2012). An approach to the real-time risk analysis for hazardous material transportation. Intelligent decision technologies (pp. 361-366) Springer.

Margai, F. L. (2001). Health risks and environmental inequity: A geographical analysis of accidental releases of hazardous materials. The Professional Geographer, 53(3), 422-434.

NTSB, (1977a). Highway Accident Report, Transport Company of Texas Tractor-Semitrailer (Tank) Collision with Bridge Column and Sudden Dispersal of Anhydrous Ammonia Cargo I-610 at Southwest Freeway. http://www.ntsb.gov/investigations/summary/HAR7701.htm. (May 15, 2013a).

NTSB, (1977b). Hazardous Materials Accident Brief, Tank Car Failure and Release of Corrosive and Poisonous Liquid. http://www.ntsb.gov/investigations/fulltext/HZB9804.htm. Accessed May 15, 2013.

NTSB, (2001). Highway Accident Report, Release and Ignition of Hydrogen Following Collision of a Tractor-Semitrailer with Horizontally Mounted Cylinders and a Pickup Truck near Ramona, Oklahoma. http://www.ntsb.gov/investigations/summary/HZM0202.html. (May 15, 2013).

NTSB, (2013). Hazardous Materials Accident Reports. http://www.ntsb.gov/investigations/reports_hazmat.html, Accessed on October 10, 2013.

PHMSA, (2010). Pipeline and Hazardous Materials Safety Administration, U.S. Department of Transportation, Office of Pipeline Safety, Building Safe Communities: Pipeline Risk and its Application to Local Development Decisions. http:/primis.phmsa.dot.gov/comm/publications/PIPA/PIPA-PipelineRiskReport-Final20101021.pdf. Accessed May15, 2013.

PHMSA, (2012). Pipeline and Hazardous Materials Safety Administration, U.S. Department of Transportation, Emergency Response Guidebook.

Rakas, J., Teodorović, D., Kim, T. (2004). Multi-objective modeling for determining location of undesirable facilities. Transportation Research Part D: Transport and Environment, 9(2), $125-138$.

Spencer, A. B., Colonna, G. R. (2003). NFPA pocket guide to hazardous materials and Jones Bartlett Learning.

Saccomanno, F. F., Shortreed, J. (1993). Hazmat transport risks: Societal and individual perspectives. Journal of Transportation Engineering, 119(2), 177-188.

Turner, D. B. (1994). Workbook of atmospheric dispersion estimates: An introduction to dispersion modeling. CRC press.

U.S. Census Bureau, (2015). 2012 Commodity Flow Survey. Technical Report. U.S. Department of Transportation and U.S. Department of Commerce. http://www.census.gov/econ/cfs/2012/ec12tcf-us-hm.pdf. Accessed May 25, 2015.

US DOE, (2004). United States. Department of Energy, Office of Environment, Safety and Health, ALOHA Computer Code Application Guidance for Documented Safety Analysis. 
http://www.hss.doe.gov/nuclearsafety/qa/sqa/central_registry/ALOHA/Final_ALOHA_G uidance_Reportv52404.pdf. Accessed May 15, 2013.

US DOT, (2015). Risk Assessment. Federal Highway Administration, Office of International Programs. http://international.fhwa.dot.gov/riskassess/risk_hcm06_03.cfm. Accessed June 3, 2015.

US EPA, (1993). United States Environmental Protection Agency, Hydrogen Fluoride Study: Report to Congress, Section 112(n)(6) Clean Air Act as Amended; Final Report.

US EPA, (2013). United States Environmental Protection Agency, http:/www.epa.gov. Accessed October 1, 2013.

Verma, M. (2011). Railroad transportation of dangerous goods: A conditional exposure approach to minimize transport risk. Transportation research part C: emerging technologies, 19(5), 790-802.

Woodward, J. L. (2010). Estimating the flammable mass of a vapor cloudJohn Wiley \& Sons.

Wu, Z., Duo, Y., Liu, M. (2004). A study on the method of risk assessment of hazardous materials during road transportation. Journal of Basic Science and Engineering, 12, 3644.

Zhang, J., Hodgson, J., Erkut, E. (2000). Using GIS to assess the risks of hazardous materials transport in networks. European Journal of Operational Research, 121(2), 316-329. 


\section{Explosion Impacts during Transport of Hazardous Cargo: GIS-Based \\ Characterization of Overpressure Impacts and Delineation of Flammable Zones for}

\section{Ammonia}

\subsection{Introduction}

Over 1 million hazardous material shipments are carried mostly by trucks, containing toxic and flammable liquids or gases on a daily basis in the United States (PHMSA, 2012). Based on a report by the Federal Motor Carrier Safety Administration (FMCSA) in 2004, each year about 200 hazardous material trucks are involved in fatal and 5,000 in non-lethal incidents (Craft, 2004). Despite the small number of crashes compared to the totals of truck accidents (the chance

of a person in the U.S. to be killed by lightning is three times as the chance by hazardous material accidents in transportation (PHMSA, 2012).), the danger that hazardous material crashes pose on human health and properties is significant (Craft, 2004). According to a Battelle report to FMCSA in 2001, hazardous material highway crashes have a societal cost impact of more than $\$ 1$ billion a year (Craft, 2004). According to Oggero et al., (2006), a study of 1932 accidents during hazardous material transport through roads and rails from early 20th century to 2004 showed that more than half of the incidents took place on roads. The outcome of the incidents was reported as $78 \%$ release, $6 \%$ caused vapor cloud, $28 \%$ followed by fire, $14 \%$ ended in explosions (Oggero et al., 2006).

According to the US Department of Transportation, a hazardous material is defined as a substance or material capable of causing harm to human health, property, and the environment when is transported in commerce. The risk of hazardous material transport through urban transportation networks and highways depends on the characteristics of the hazardous materials being transported in their specified routes. The population living/working around and along the 
routes used for hazardous materials shipments may suffer from the undesirable consequences of an accident (Verter and Kara, 2008). In spite of the risk associated with the transport of hazardous materials; such chemicals have been shipped and have been experienced an increasing trend all around the world, especially in industrialized countries till years. Dependence on hazardous materials is a fact of daily life in industrialized societies. Hazardous materials are fundamental to the United States economy and industry. The U.S. economy in a large extends relies on utilization of hazardous materials, including manufacturing, mining, agriculture, construction, and medical and sanitary services (Verter and Kara, 2008). Therefore, consumption of hazardous materials and consequently transportation of such chemicals seem inevitable nowadays, as a result, hazardous material cargo incidents and releases are still probable to take place. According to DOT (1998), around 2 billion tons of hazardous materials are produced in the United States annually, and approximately 3 million tons of hazardous materials are shipped crisscrossing the US (DOT, 2012). However, the reported and estimated cost and the risk associated with accidents in transportation of hazardous material cargos is lower than actual values (Craft, 2004) due to the facts that: most incidents are small (Verter and Kara 2008), only specific incidents are reported which satisfy certain criteria, and there are limitations to long-term impact estimation, as the data is collected at the scene and the time of the accident solely.

About $90 \%$ of hazardous material transportation incidents take place on highways, intersections and junctions of rural/urban roads (approximately one out of five trucks on U.S. highways is a Hazardous Material truck (Erkut and Verter 1998)). The spillages due to transportation incidents involving road tankers carrying hazardous chemicals through highways, pose not only flammability hazards due to pool fire, flash fire, but also create substantial toxic hazards (Chakrabarti and Parikh, 2013a).

The accidental explosions causing unexpected destructions, injuries and deaths have occurred and continue to happen as a result of the production, storage or transportation of 
explosives, chemical and petrochemical plant operations, the failure of high pressure vessels, etc. The public concern regarding accidental explosions increased in the recent years with the increase in chemical use dictated by economic changes (Baker et al., 1983).

Historically, there have been numerous accidents which led to explosions, health threats and property damages. For example, an explosion of vapor cloud occurred in Naples, Italy, 1985 in a fuel storage containing gasoline, diesel fuel and fuel oil. The accident originated form a spill during a filling operation and the outcome fire lasted for over a week destroying all the buildings and facilities in surrounding areas (Maremonti et al., 1999). In Bangkok, Thailand, 1990 a truck carrying LPG crashed and overturned and led to the discharge of 5 tons LPG, a vapor cloud was created and a flash fire explosion caused 68 death and over 100 injuries beside considerable property damages. Another incident happened in East St. Louis, Illinois, in 1973; an accident in Saint Herblain, France, 1991; a fire and explosion in Crescent City, Illinois, in 2008, and many other examples of such incidents (Beroggi, 1994).

In the literature, several studies focused on hazardous material transport employing/introducing methodologies and techniques. For instance, Das et al. (2012) created a framework for risk assessment of transportation of hazardous wastes in respect to the population involved. Ronza et al., (2007) proposed an event tree in an attempt to predict the probability of ignition of hydrocarbon spills based on statistical data. In addition, Van Aerde et al. (1988) utilized a model to predict the impact of a spill followed by transportation accident according to the atmospheric condition and time of accident and thermodynamic properties of the material shipped. Having categorized the available studies in the area of hazardous material cargo incidents, significant portion of studies focused on risk analysis and best route selection. Researches regarding the risk associated with hazardous material transport are quite extensive (Leonelli et al., 2000; Glickman et al., 2007; Zografos and Androutsopoulos, 2008; Reniers et al., 2010; Toumazis and Kwon, 2013; Kang et al., 2014; Saat et al., 2014; Chakrabarti and Parick, 
2013b; Van Raemdonck et al., 2013). Several studies focused on routing of the hazardous material cargos, the key approach was taking into account scheduling, location, and perhaps high risk routes and nods (Beroggi, 1994; Guo and Verma, 2010; Karkazis and Boffey, 1995; Erkut, 1995; Frank et al., 2000; Leonelli et al., 2000; Gunasekera and Edwards, 2003; Bubbico et al., 2004; Carotenuto et al., 2007; Singh et al., 2011; Mahmoudabadi and Seyedhosseini, 2013).

The aim of this study was to investigate hazardous material cargo incidents in a location along a main highway in an attempt to predict the outcome of such accidents. In an event of incident during transport of hazardous materials, a portion or the entire shipment may spill in the scene. The accidental release of hazardous materials may cause vapor cloud at first, but as for domino effects, the cloud could lead to an explosion or fire. Therefore, in order to reduce the adverse consequences and take the proper emergency response strategies in facing the hazardous material incidents, decision makers need to have access to a perspective of the disaster such as; the probable out comes (whether toxic vapor, fire or explosion), the extent that the impacts of the accident will proceed, the right people to be taken care of or to be evacuated. The air dispersion model ALOHA was utilized to predict the outcome of a hazardous material release of tanker carrying ammonia which is categorized as hazardous material. Using ALOHA, probable impacts of hazardous flammable cloud and overpressure waves were predicted. In the following section the methodology of the research is introduced, then assumed scenarios are introduced and the results are shown. Finally, the paper concludes with discussions, suggestions and conclusion.

\subsection{Material and Methods}

\subsubsection{Areal Locations of Hazardous Atmospheres (ALOHA)}

Dispersion models deal with fluid flow systems including air, such models are classified as heavy gases which are heavier than air, and volatile chemical vapor cloud. These models are 
available in a range of simple to sophisticated, those which are solved using simple algebraic equations to those that by solving complex equations with a variety of inputs attempt to find the most accurate results. The type of model appropriate for a particular case is dependent to the properties of the problem such as the scale of the problem, demanded accuracy, available input data, and desired outputs.

ALOHA (Areal Locations of Hazardous Atmospheres) is a dispersion modeling program capable of estimating threat zones associated with hazardous chemical releases, including toxic vapor clouds, flash fires, and explosions. The model is able to predict the outcome of an instantaneous release of a chemical in the air and visualization of the impacted area on maps in order to have a better understanding of the situation and the extent of the impacted area. The model can keep the track of a chemical from release to vapor cloud in the air, through flammable cloud and finally fire and explosion (DOE, 2004).

Beside the health impacts of toxic could, the flammable vapor cloud is potentially dangerous, as once it reaches an ignition source the cloud can catch on fire. ALOHA predicts the flammable zones for different chemicals as the area where a flash fire could occur following a release of chemicals. ALOHA models explosions which may happen as a result of accidents involving hazardous chemicals. Intentional explosions can be modeled by ALOHA as well which result in greater hazard damage to be considered as the worst case scenario. A major danger of any explosion is overpressure or blast wave, which refers to the abrupt extension of a pressure wave followed by an explosion. Although, the wave seems less dangerous than fire, it can be precisely as damaging. The overpressure wave which is nearly instantaneous and travels at the speed of sound can cause serious damages to surrounding obstacles and population. Clearly, the closer to the source of the explosion the greater the destructing effects of the overpressure and the impacts lessen as move farther from the source. ALOHA investigates the surroundings at the potential explosion site to predict an explosion's effects (DOE, 2004). 
The model takes into account a number of parameters such as the chemical characteristics (the more volatile a chemical, the faster it evaporates through the atmosphere and the quicker forms a flammable vapor cloud.); the cloud size at the time of explosion; ignition type; ignition time; and congestion level. The ignition type which has a significant influence on the severity of the explosion practically is the source of ignition. Two types of ignition are defined in ALOHA; deflagration and detonation explosions. The former explosions are most often triggered by common ignition like sparks, flames, heat, and electricity or even if a chemical is above its autoignition temperature it will spontaneously catch on fire without an external ignition source. The later ignition type covers those ignitions which are initiated by detonation (usually by a highpower explosive device). Generally, this type of explosion is more destructive than deflagration (DOE, 2004).

Based on the characteristics of the substance, in case of existence of a flammable vapor, the probability of contacting the toxic gas with an ignition source should be taken into account. Occurrence of an explosion, not only threaten people's life and properties, but also, since the explosion happens in a very few glance of time, makes the control and the prevention of expansion of the fire significantly difficult. The ignition destructive power is a function of the amount of released chemical, chemical type and presence of ignition sources in the surrounding area. The higher the amount of release, the larger the area covered by flammable cloud and the higher the probability of the vapor reaching an ignition source and causing an explosion. The type of substance is also crucial; some hazardous chemicals are not flammable and some are extremely volatile and flammable (Fire, 2006). 


\subsubsection{Case study for explosion during ammonia transport}

A case study was developed for hazardous material release from a tanker truck during transport at a location along the I-95 highway in Miami, Florida, United State. As a result, a cloud containing a hazardous chemical (ammonia, Table 3.1) was released from the source point. In this study two cargo quantities (2 and 20 tons) were used to evaluate the impacts after release from the accident location causing a cloud of ammonia affecting the surrounding area. In this study, first the flammable cloud was identified, afterward, the overpressure waves followed by an explosion were modeled. The impact zones were visualized using ArcGIS.

Table 3.1 Characteristics of ammonia (Barber and Hildebrand, 1980, Cameo chemicals, accessed 2014)

\begin{tabular}{|c|c|c|c|c|c|}
\hline Chemical & $\begin{array}{l}\text { Chemical } \\
\text { formula }\end{array}$ & General description & $\begin{array}{l}\text { Density } \\
\text { (relative } \\
\text { to air) }\end{array}$ & $\begin{array}{c}\text { Boiling } \\
\text { point } \\
\left({ }^{\circ} \mathrm{K}\right)\end{array}$ & NFPA 704 \\
\hline Ammonia & $\mathrm{NH}_{3}$ & $\begin{array}{l}\text { Alkaline, colorless chemical. } \\
\text { Is not flammable but burns } \\
\text { within specific concentration } \\
\text { limits with ignition source }\end{array}$ & 0.6 & -33.34 & \\
\hline
\end{tabular}

To evaluate the probable impact zone of such an incidental release, two different scenarios of spill as a matter of quantity of the chemical were considered ( 2 and 20 tons).The amounts of releases were selected based on an actual accident in Swansea, Sought Carolina, 2009; the cargo carried around 20 tons of ammonia and due to an accident a part of its cargo was 
released (NTSBA, 2009). Thus, 2 and 20 tons of ammonia releases were considered as partial and entire releases of the cargo to be investigated. In estimation of the impact of the over pressure waves, the worst-case scenario by the ignition by detonation was used. Different atmospheric conditions were defined to predict the outcome of the incident for visualizing the probable outcomes and impact zones (Table 3.2).

Table 3.2 Parameters used for impact analysis after accidental cargo release.

\begin{tabular}{lc}
\hline Parameters & Settings \\
\hline Hazardous material & Ammonia \\
Release amount (Ton) & 2 and 20 \\
Stability class & A, B, C, E, F \\
Wind speed (m/s) & 2.23 \\
Wind direction & SW \\
Temperature $\left({ }^{\circ} \mathrm{C}\right)$ & 12.8 \\
\hline
\end{tabular}

According to Hanna et al. (1982), stability class is defined as the tendency of a particle of air to swing upward and downward after release through the atmosphere. Unstable class A tends to create vertical upward movements which increases the turbulence intensity, as a result dispersion of chemicals in the air happens rapidly. On the other hand, stable class F tends to conquer turbulence and updraft movements which results in impeded dispersion of chemicals comparing to unstable atmospheres (Table 3.3). Since the measurement of stability is difficult, Pasquill (1961) proposed a scheme in order to estimate the stability classes taking into consideration the solar radiation (during day), cloudiness (at night) and wind speed (Woodward, 2010). Since in this study wind speed was considered to be constant from the moment that the accident occurs through complete dilution of the chemical, the only parameter which could alter 
the stability class was solar radiation or cloudiness. Taking into account different stability classes under predefined wind speed, five out of six classes were possible to occur (at night or day) (Table 3.2). The characteristics of the scenarios used illustrate how the conditions of the accident can be integrated to reflect the site-specific information for analysis of possible impacts.

Table 3.3 The Pasquill stability classes (Comarova, and Mangul, 2008).

\begin{tabular}{lc}
\hline Stability class & Settings \\
\hline A & Highly unstable \\
B & Moderately unstable \\
C & Slightly unstable \\
D & Neutral \\
E & Slightly stable \\
F & Moderately stable \\
\hline
\end{tabular}

\subsection{Results and discussion}

\subsubsection{Impact zones}

The flammable area is located in between two threshold values defined by the lover explosive limit (LEL) and the upper explosive limit (UEL). This range (LEL-UPL) represents the concentration of chemical vapor in the air (as percentage) for flammability. Flammable chemical vapor may contact with an ignition source and start to burn only if the concentration of the substance in the air is between the two limits. Beyond these limits the ignition will not happen; since below the LEL the concentration of the chemical is too small to start and maintain burning and above the upper limit the amount of oxygen needed to assist the ignition is not enough to begin fire. ALOHA uses $60 \%$ and $10 \%$ of LEL as the limits of flammable area identification. Once, the chemical vapor cloud reaches an ignition source, part of the cloud which has a mix of 
air-chemical between the LEL and UEL could burn. In some cases the chemical will burn fast enough to cause an explosive force (overpressure wave). The severity of the explosion is a function of chemical, cloud size, type of ignition, and congestion level inside the vapor cloud.

The destructive explosion force of the vapor cloud in parts depends on the speed of explosion spread. The explosion creates a pressure wave which is destructive to people and properties in its way dispersing over surrounding areas. The more quick spread the more intense the pressure wave and destructive force and damage to obstacles along the wave path. Table 3.4 presents the levels of damage which can be expected at specific overpressure values are shown.

Table 3.4 Levels of damage expected at specific overpressure values (Lee and Frank, 1980).

\begin{tabular}{ll}
\hline Overpressure (psi) & Expected Damage \\
\hline 0.04 & Loud noise; sonic boom glass failure. \\
0.15 & Typical pressure for glass failure. \\
0.40 & Limited minor structural damage. \\
$0.50-1.0$ & Windows usually shattered; some window frame damage. \\
0.70 & Minor damage to house structures. \\
1.0 & Partial demolition of houses; made uninhabitable. \\
$1.0-8.0$ & Range for slight to serious laceration injuries from flying glass and \\
2.0 & Partial collapse of walls and roofs of houses. \\
$2.0-3.0$ & Non-reinforced concrete or cinder block walls shattered. \\
$2.4-12.2$ & Range for 1-90\% eardrum rupture among exposed populations. \\
2.5 & 50\% destruction of brickwork of houses. \\
3.0 & Steel frame buildings distorted and pulled away from foundation. \\
$5.0-7.0$ & Nearly complete destruction of houses. \\
10.0 & Probable total destruction of buildings. \\
$14.5-29.0$ & Range for 1-99\% fatalities among exposed populations due to direct \\
\hline
\end{tabular}


There are no specific standards or guidelines to appraise the overpressure danger.

Therefore, in this study default overpressure values (in pounds per square inch, psi) provided in the model (ALOHA) were used based on a review of widely accepted sources on overpressure and explosions. The overpressure wave zones were defined as follows: 8.0 psi (destruction of buildings), 3.5 psi (serious injury likely), and 1.0 psi (shattered glass).

In case of chemical explosions, the output of ALOHA can be obtained as text summary as well as in graphical forms for the flammable zone and the blast waves as presented in Figure 3.1 The flammable impact zone of ammonia presented in Figure 3.1(a) delineates the areas which are located in between the two threshold values (90000 ppm and 15000 ppm), therefore have the potential to experience an explosion if the chemical reaches an ignition source. The Figure 3.1(b) presents the blast wave zone (overpressure wave) based upon the location where the residents can experience shattered windows, injuries or destruction of buildings.

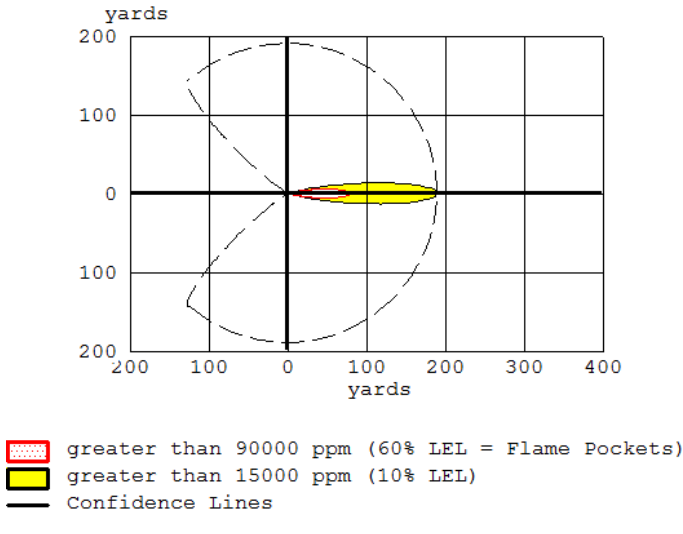

(a) Flammable Zone

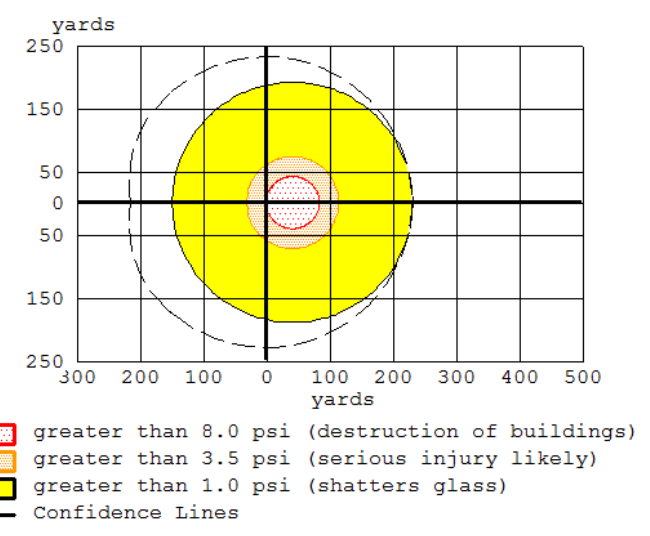

(b) Overpressure Wave Zone

Figure 3.1 Definition of impact zones of ammonia, a: Flammable zone, b: Overpressure wave zone. 
This study employed ArcGIS both to visualize the impacted areas and for further analysis of the threat zones where the hazardous cargo accidents may pose on people living/working around the incident location. The size and the characteristics of the impact areas as well as the number of people who would be impacted by the accident were estimated by overlaying maps using ArcGIS as presented in Figure 3.2.

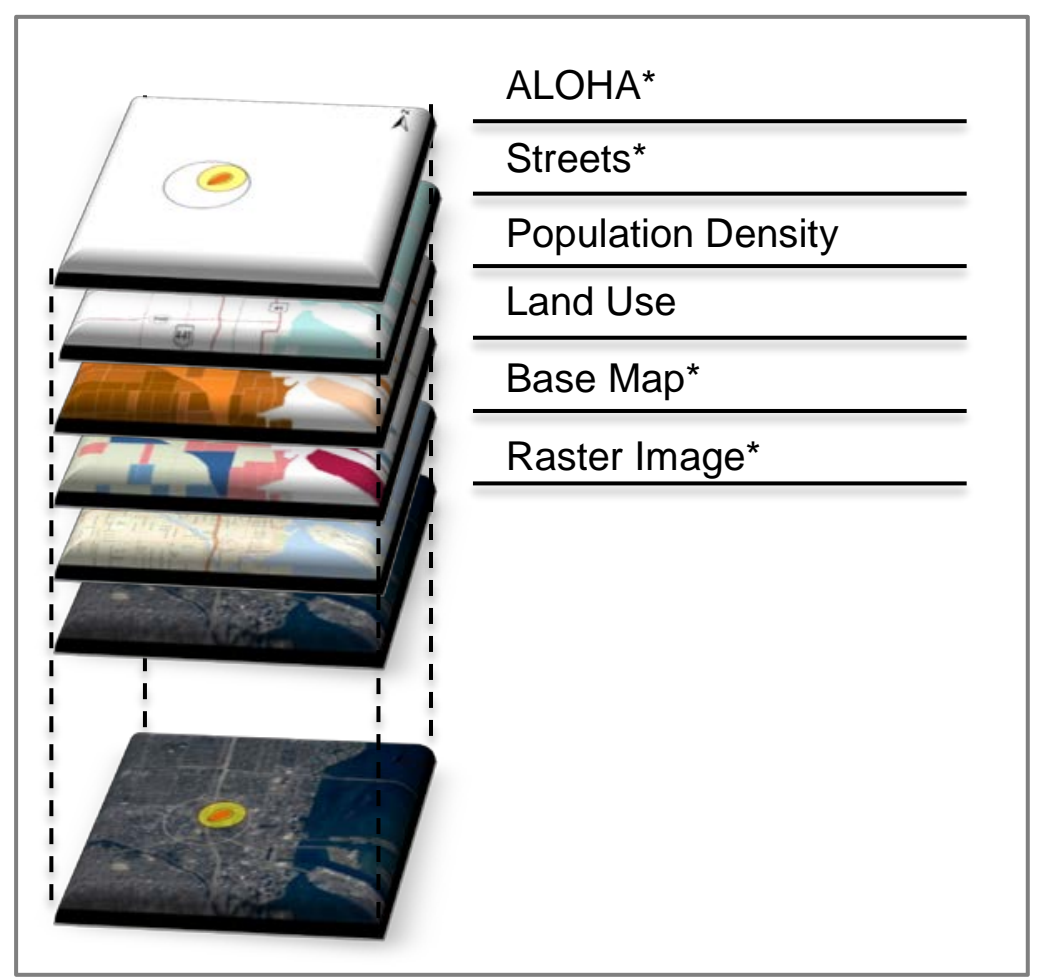

Figure 3.2 Site specific map overlaying in ArcGIS (*layers used in this study).

Figure 3.3 presents the flammable impact zones for two different sizes of hazardous cargo accidents under different stability conditions (A refers to the most unstable and $\mathrm{F}$ to the most stable class of atmosphere). In Figure 3.3, from (a) to (e) the flammable zones of 2-ton release are shown, and (f) to (j) depicts the impact zones from a 20-ton release condition. The 
review of atmospheric stabilities of A, B, and C which occur during daytime (according to Pasquill's table) and the other two scenarios which occur at night (E and F) showed significant differences for both release quantities (2 and 20 tons). For the conditions under the atmospheric stabilities of A to C the contaminant diluted faster due to the level of atmospheric turbulence, hence, the impacted zones did not expand much in the surrounding areas. However, during the night which corresponds to the atmospheric classes of $\mathrm{E}$ and $\mathrm{F}$, the flammable zones expanded faster and more from the incident location. The review of the impact zones in relation to the atmospheric stability shows that, as the conditions change from unstable to the stable atmospheric conditions the impacted zones become narrower and more extended in the wind direction.
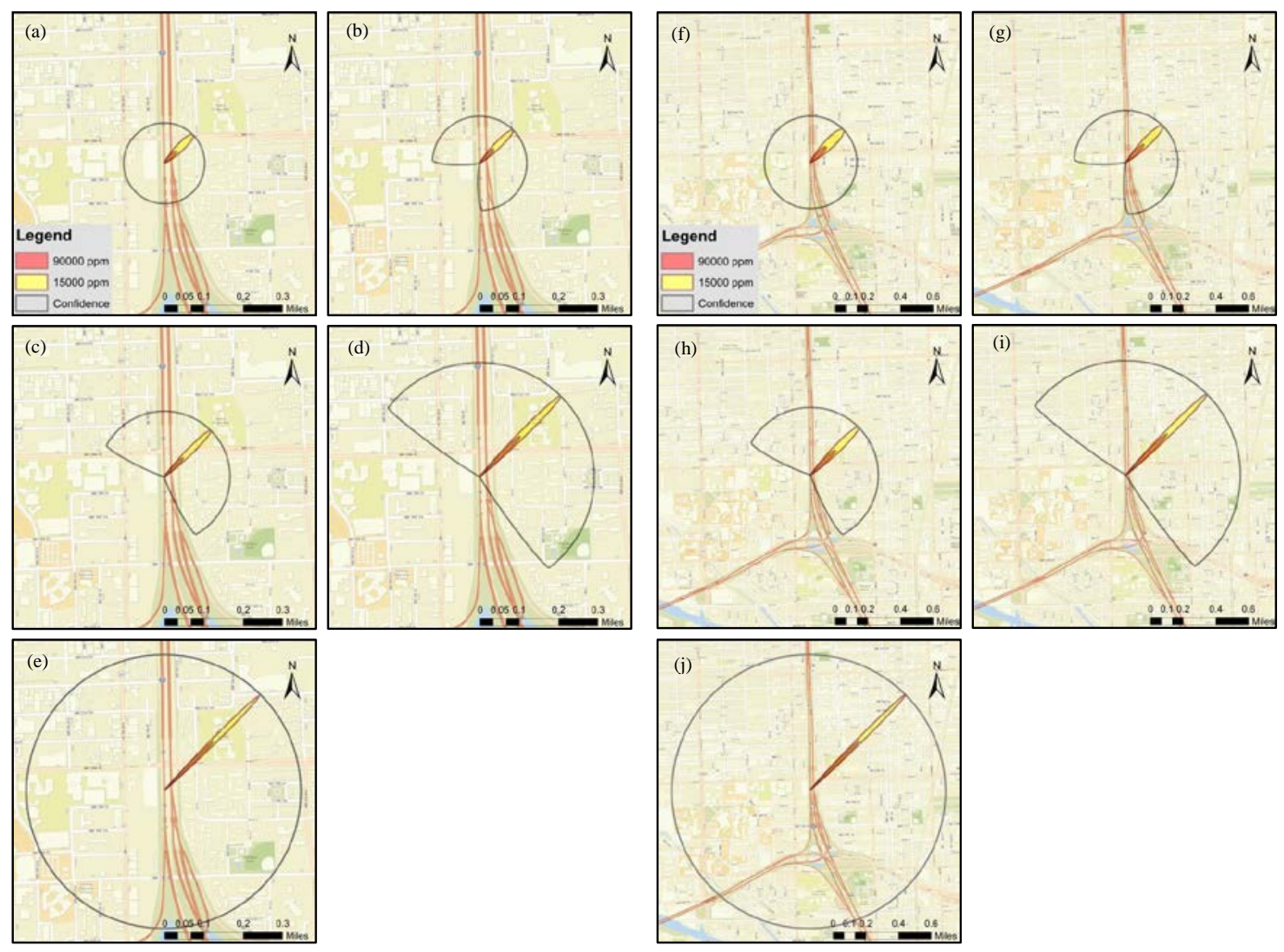

Figure 3.3 Flammable impact zones for different quantities of ammonia release. (1) 2 ton release: (a) stability class $A$, (b) stability class $B$, (c) stability class $C$, (d) stability class $E$, (e) stability class F; and (2) 20 ton release: (f) stability class A, (g) stability class B, (h) stability class $C$, (i) stability class $E$, (j) stability class $F$. 
Figure 3.4 presents the estimated impact zones for overpressure waves at different stability conditions from A (very unstable) to F (stable). The analysis of the impact zones showed that the waves expand in semicircular shapes which is the nature of the explosion; taking into account, assuming that the surrounding areas did not have tall building which may block the explosion wave and accordingly change the shape of the overpressure waves significantly. Therefore, the areas of the impacted zones were significantly larger in comparison to those for the flammable impact zones. On the other hand, although the amount of release increased significantly from 2 to 20 tons, the expansion of the impacted areas by overpressure waves did not increase by the same factor. The comparison of the overpressure waves under stability conditions A to C with those under classes $\mathrm{E}$ and $\mathrm{F}$ showed the inability of the atmosphere in dilution of the chemical, which resulted in more existence of the chemical in the air (larger impact zones) and accordingly movement of the substance particles with the power of wind along the wind direction. Under stability of $\mathrm{E}$ and $\mathrm{F}$ and somehow $\mathrm{C}$ the impacted areas of blast waves were in oval shape due to the movement of air and the chemical by wind. 

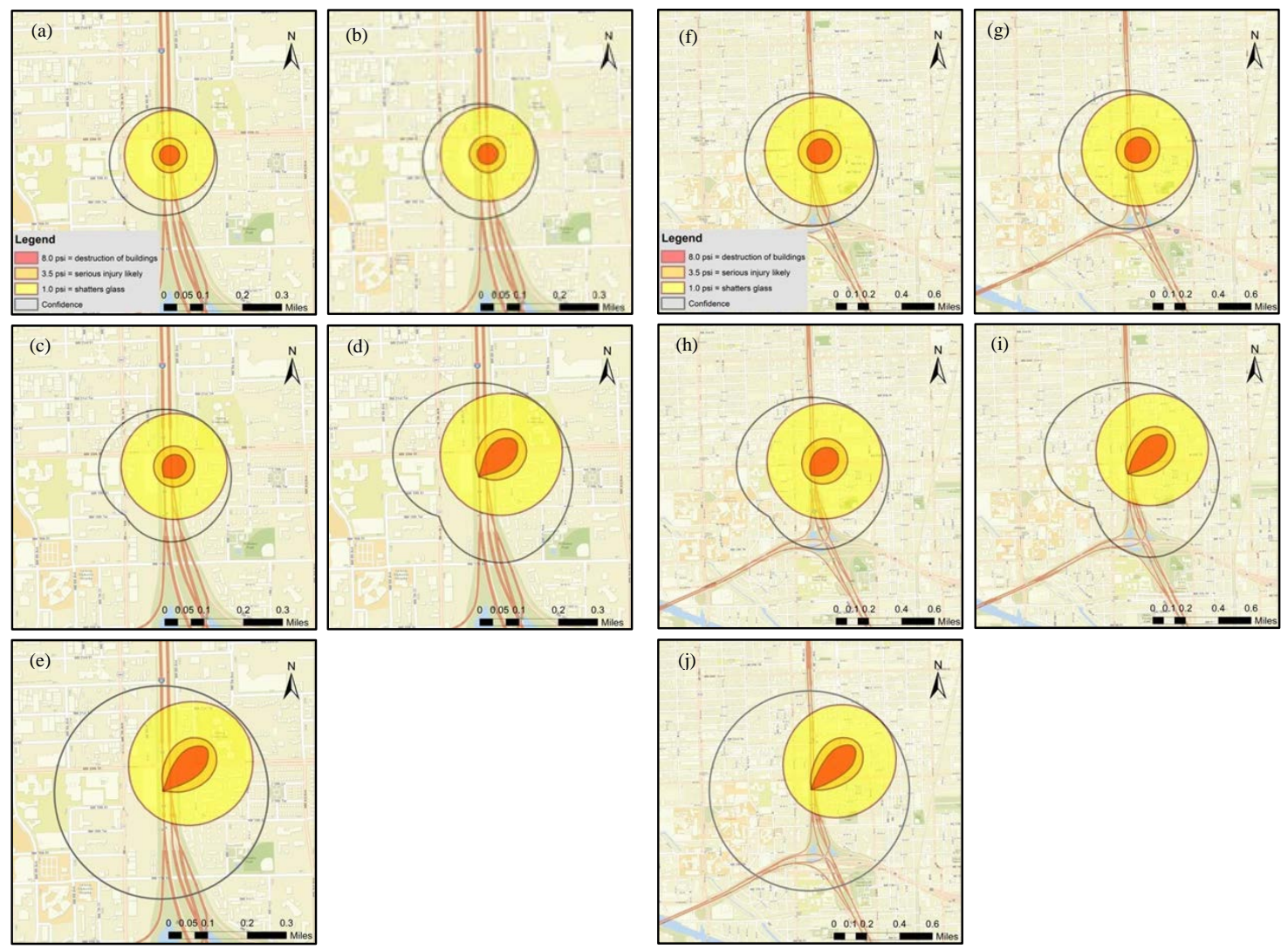

Figure 3.4 Overpressure wave impact zones for different quantities of ammonia release. (1) 2 ton release: (a) stability class $A$, (b) stability class $B$, (c) stability class $C$, (d) stability class E, (e) stability class F; and (2) 20 ton release: (f) stability class A, (g) stability class B, (h) stability class $C$, (i) stability class $E$, (j) stability class F.

The life threatening impact areas (blast waves over 8.0 psi) expansion along the wind direction under two extreme atmospheric conditions of A and F for the case of 2 tons release showed around 270 and 820 feet respectively, and for 20 tons release values change to 820 and 1925 feet long for the atmospheric conditions of A and F respectively. This fact shows the enlarging of the impact areas by changing the cargo size, however not in a linear relationship with the amount of chemical. Figure 3.5 presents the impact areas of overpressure waves and flammable cloud under each scenario. The flammable impact areas of both quantities of ammonia (2 and 20 tons) showed increase in the affected zones from stability class of B to E. However, 
atmospheric stabilities of A and F seem to follow another trend; the impacted area of class A is larger than of class B, also the impact area of $\mathrm{F}$ is less than of $\mathrm{E}$ for both quantities of release. These differences are because of the limitations of ALOHA in modeling the very stable atmosphere and also a fact in extremely unstable classes of the atmosphere. Similar to any other model, ALOHA has limitations, the program under very stable atmospheric conditions (typically at night or very early in the morning) is not very reliable. Very stable atmosphere is not able to dilute the released material by declination of chemical concentration, therefore the material slowly moves with the wind and this may take much longer than the limitation of ALOHA in time (60 min). Therefore, part of the concentration of material was not modeled and taken into consideration, which led to under prediction of the cloud and concentration, which can be seen in the afore mentioned case (stability F). Furthermore, under atmospheric stabilities of $\mathrm{E}$ and $\mathrm{F}$ for the case of 20 tons release of Ammonia, the model showed inability in modeling the blast waves which led in estimation of less area of danger under flammable cloud. On the other hand, under very unstable atmosphere (class A), chemical concentration remains higher at closer distance to the origin of the release with shorter axis along the wind direction, however moving from stable atmosphere to more unstable one (B) the shape of concentration contour of the chemical extended more and became narrower in compare. Therefore, although the chemical under stability of B travels more from the accident location, its impact area was less due to its narrower shape in compare to the stability of A's impacted area which was shorter along the wind direction but wider area. 


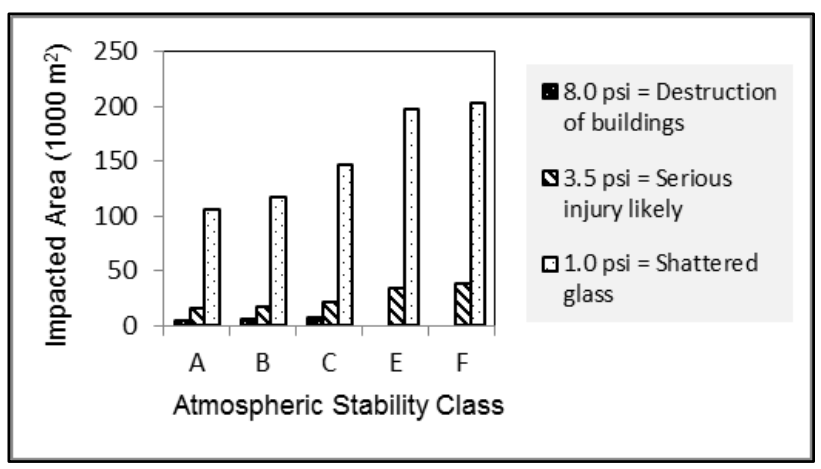

(a) Overpressure Waves Impact Zone (2 tons ammonia)

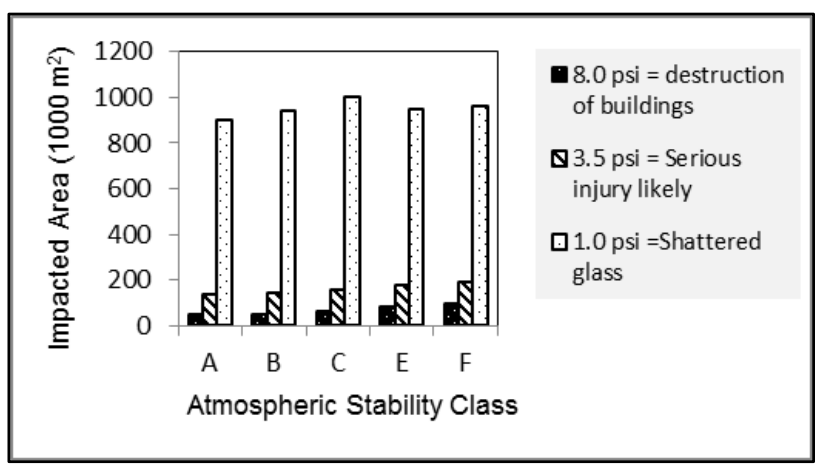

(c) Overpressure Waves Impact Zone (20 tons ammonia)

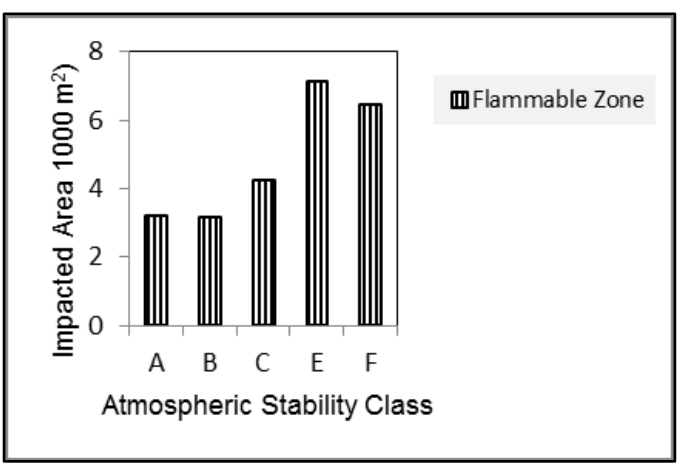

(b): Flammable Impact Zone (2 tons ammonia)

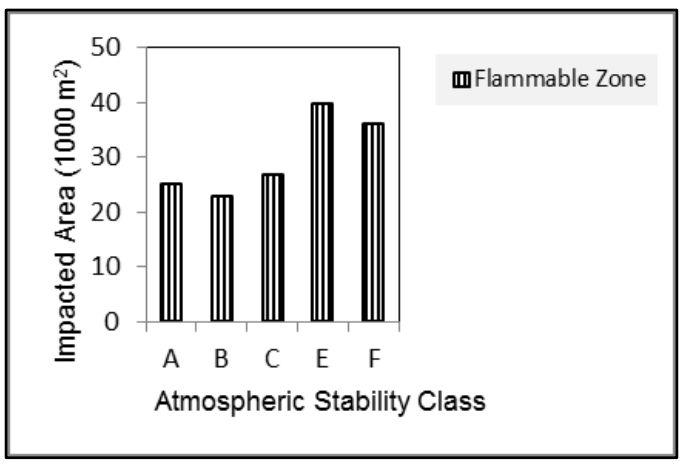

(d): Flammable Impact Zone (20 tons ammonia)

Figure 3.5 Impact areas for different quantities of ammonia release. (1) 2 ton release: (a) overpressure waves, (b) flammable zone; and (2) 20 ton release: (c) overpressure waves, (d) flammable zone.

Comparison of the overpressure waves impact areas of 2 tons ammonia presented in

Figure 3.5 shows that the blast waves also obeyed the increase trend from stability A to F, however, still some differences was noticeable on stability F, which became extreme in the case of 20 tons accidental release for overpressure value of less than 1.0 psi. According to Figure 3.5, under stability of $\mathrm{E}$ and $\mathrm{F}$ for the larger release, unlike to the theoretical expectations, the impacted area from stability of C to E and F decreased while assumed to be increased. Therefore, the model showed inability in modeling stable atmospheres which let to under estimation of the impact zones. Having discussed the fact, the results of ALOHA was more reliable for stability classes from A to $\mathrm{C}$ than the other two conditions ( $\mathrm{E}$ and $\mathrm{F}$ ). 


\subsubsection{Sensitivity analysis}

In this study the main focus was on the prediction of the outcome of hazardous material incidents under different atmospheric conditions. In this section in an attempt to perform a sensitivity analysis on the impact zones by changing wind speed, three new scenarios were defined considering different wind speeds. Based on the results, the increase in the wind speed leads to the higher rate of dispersion of the chemical since the wind carries the substance faster, hence, the material dilutes quicker in the air. In this regard three different wind speeds were selected based on 50, 150 and 200\% increase of the default wind speed selected by this research $(2.23 \mathrm{~m} / \mathrm{s})$ which are equal to 3.35, 5.59 and $6.70 \mathrm{~m} / \mathrm{s}$ respectively. Under the new selected scenarios of wind speed four stability classes were possible for the wind speed of $3.35 \mathrm{~m} / \mathrm{s}$ (B, C, $\mathrm{D}$ and $\mathrm{E}$ ), and two stabilities for wind speed equal and more than $5 \mathrm{~m} / \mathrm{s}$ (C and D). Therefore, the sensitivity analysis was done assuming the mutual stability class of $C$ under three new wind speed scenarios (3.35, 5.59 and $6.70 \mathrm{~m} / \mathrm{s})$. The results showed that by changing wind speed from 2.23 to $3.35 \mathrm{~m} / \mathrm{s}$, the impacted area by blast waves under threat of glass shatter decreases by $32.7 \%$ and with increasing more of the wind speed to $5.59 \mathrm{~m} / \mathrm{s}$ and $6.7 \mathrm{~m} / \mathrm{s}$ the areas declines by 59.6 and 66.4\%, respectively, for 2 tons release. However, for 20 ton release the decreases were 11.6, 40.5 and 50.4\%, respectively for the new three wind speeds. The extended results are shown in Table 3.5 .

Table 3.5 Decrease in the area of impact zone by increase in wind speed.

\begin{tabular}{|c|c|c|c|c|c|c|}
\hline \multirow{4}{*}{$\begin{array}{l}\text { Overpressure waves } \\
\text { (psi) }\end{array}$} & \multicolumn{6}{|c|}{ Decrease in impact zone area (\%) } \\
\hline & \multicolumn{3}{|c|}{ Amount released: 2 Tons } & \multicolumn{3}{|c|}{ Amount released: 20 Tons } \\
\hline & \multicolumn{3}{|c|}{ Wind speed (m/s) } & \multicolumn{3}{|c|}{ Wind speed $(\mathrm{m} / \mathrm{s})$} \\
\hline & 3.35 & 5.59 & 6.70 & 3.35 & 5.59 & 6.70 \\
\hline 8.0 & 24.7 & 58.7 & 64.8 & 20.0 & 49.2 & 57.5 \\
\hline 3.5 & 33.1 & 59.9 & 66.6 & 14.2 & 43.7 & 53.1 \\
\hline 1.0 & 32.7 & 59.6 & 66.4 & 11.6 & 40.5 & 50.4 \\
\hline
\end{tabular}


Using ArcGIS by this study made the calculation of the threaten population possible; based on the impacted zones under each scenarios and the existing population density provided by maps, ArcGIS could capably calculate the number of people in danger. According to the results which are shown in Figure 3.6, following the increase in wind speed, the impacted areas under the new scenarios experienced a decrease trend in population. For instance, for the case of the explosion of 2 tons of ammonia, the population involved by at least 1.0 psi overpressure waves is more than 500 with the wind speed of $2.23 \mathrm{~m} / \mathrm{s}$ and the population decreases to less than 200 having wind speed of $6.70 \mathrm{~m} / \mathrm{s}$.

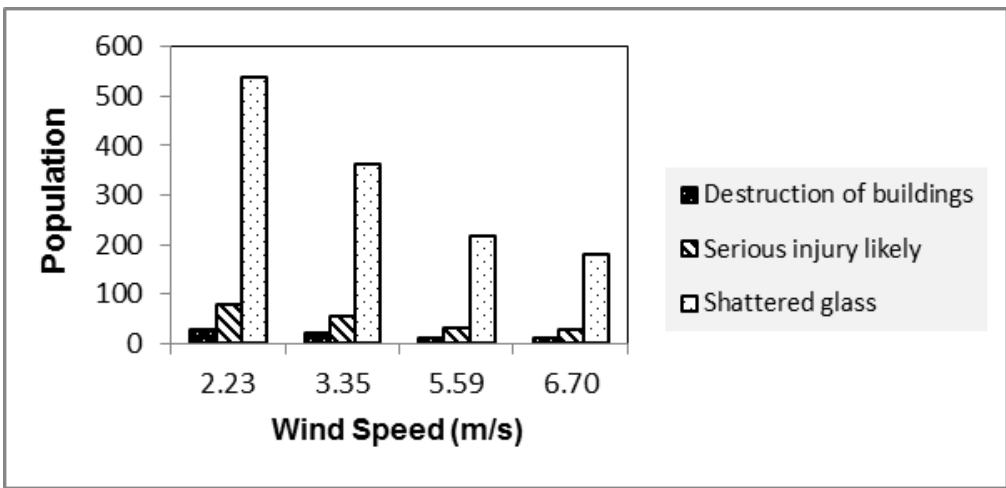

(a) Impacted population by overpressure waves (2 tons)

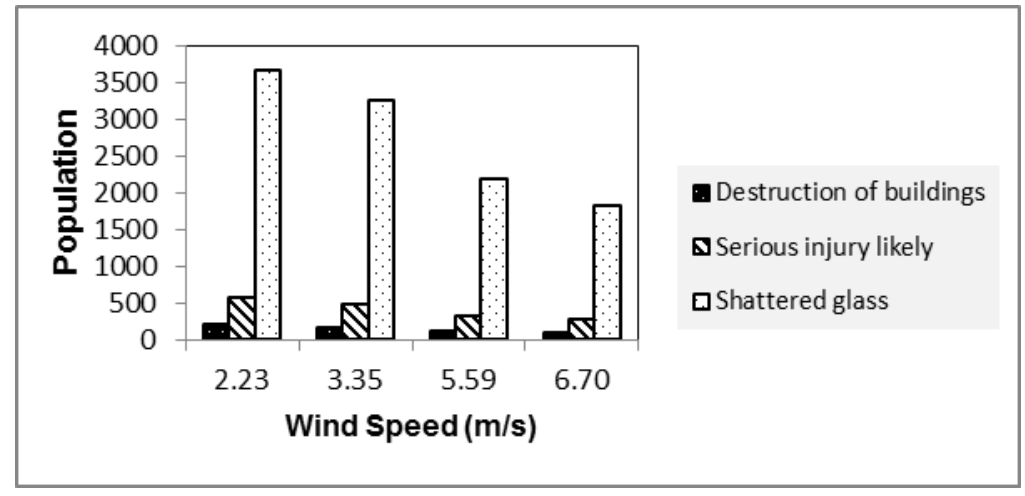

(b) Impacted population by overpressure waves (20 tons)

Figure 3.6 Estimated population that can be affected by overpressure waves after ammonia releases. (a) 2 ton release, (b) 20 ton release. 


\subsection{Conclusions}

The aim of this study was to investigate the impacts of hazardous material accidents in regard to blast waves and protective flammable vapor cloud in an attempt to create a perspective of the emergency conditions and further select the best route considering probable environmental impacts. This paper selected two release quantities (2 and 20 tons) of ammonia which is one of the most common hazardous materials transported in the US. ALOHA was employed to model the explosion of ammonia in order to provide an estimate of the impact area of overpressure waves and also flammable vapor to be protected from ignition. According to the results, the impact zones were significantly dependent on the atmospheric condition; dispersion of chemicals in the air during day happened to be faster than during night since the ability of the air in dispersion of the chemicals decreases at night in compare to day due to the lower turbulence of the air molecules. Moreover, the wind speed had a considerable influence on the dispersion of the chemical and the extension of the impact zones. Accordingly, the change in impact zone areas resulted in changes of the population involved in accidents. The number of affected people during night was more than during day; also existence of higher wind speeds resulted in less people involved in the adverse impacts. Based on the results, although the assumed quantities of releases are different by the order of ten, the impacted areas and accordingly the number of affected people did not differ by the same order, this means the adverse impact of such incidents are not in a linear relationship to the size of the cargo. The outcome of this study can be used for scheduling, routing and also to select the proper amount of the shipment. Shipments which are carried at night with high percentage of cloudiness have a higher potential of harm people than during a sunny day with clear sky. In addition, the hazardous material shipments under a windy air has less risk of facing explosion (the flammable vapor disperse rapidly) than in a situation of low wind. However, the habit and the rate of people traveling during day significantly differ than 
during night. Therefore, this fact adds criteria in selecting the best route in carrying hazardous cargos. Furthermore, estimating the potential impact areas by considering the risk factors associated with cargo size, wind speed, time of day can provide additional criteria for improving transport risks for hazardous materials and impacts on the communities located near the transport routes.

\section{Acknowledgments}

Partial funding for this research has been provided by Southeastern Transportation Research, Innovation, Development and Education Center (STRIDE), University of Florida.

\section{References}

Baker, W., Cox, P., Westine, P., Kulesz, J., Strehlow, R. Explosion hazards and evaluation, 1983. Elsiever, Amsterdam.

Barber, E. J., Hildebrand, L. (1980). Guidelines for applying criteria to designate routes for transporting hazardous materials.

Battelle (2001). Comparative risks of hazardous materials and non-hazardous materials truck shipment accident/incident, prepared for Federal Motor Carrier Safety Administration.

Beroggi, G. E. (1994). A real-time routing model for hazardous materials. European Journal of Operational Research, 75(3), 508-520.

Bubbico, R., Di Cave, S., Mazzarotta, B. (2004). Risk analysis for road and rail transport of hazardous materials: A simplified approach. Journal of Loss Prevention in the Process Industries, 17(6), 477-482.

Cameo Chemicals (2014). http://cameochemicals.noaa.gov/chemical/4860, accessed 02/04/2014.

Carotenuto, P., Giordani, S., Ricciardelli, S. (2007). Finding minimum and equitable risk routes for hazmat shipments. Computers \& Operations Research, 34(5), 1304-1327.

Chakrabarti, U. K., Parikh, J. K. (2013a). A societal risk study for transportation of class-3 hazmats-A case of indian state highways. Process Safety and Environmental Protection, 91(4), 275-284. 
Chakrabarti, U., Parikh, J. (2013b). Risk-based route evaluation against country-specific criteria of risk tolerability for hazmat transportation through indian state highways. Journal of Loss Prevention in the Process Industries, 26(4), 723-736.

Comarova, Z., Mangul, S. (2008). Simulation of emission dispersion as the method of air quality management. Simulation and assessment of chemical processes in a multiphase environment (pp. 403-408) Springer.

Craft, R. (2004). Crashes involving trucks carrying hazardous materials. federal motor carrier safety administration. Washington, DC: US Dept.of Transportation.Publication\#: FMCSARI-04-024.

Das, A., Gupta, A., Mazumder, T. (2012). A comprehensive risk assessment framework for offsite transportation of inflammable hazardous waste. Journal of hazardous materials, 227, 88-96.

Erkut, E. (1995). On the credibility of the conditional risk model for routing hazardous materials. Operations Research Letters, 18(1), 49-52.

Erkut, E., Verter, V. (1998). Modeling of transport risk for hazardous materials. Operations research, 46(5), 625-642.

Fire, F. L. (2006). Common sense dictionary for first responders. Fire Engineering Books.

Frank, W. C., Thill, J., Batta, R. (2000). Spatial decision support system for hazardous material truck routing. Transportation Research Part C: Emerging Technologies, 8(1), 337-359.

Glickman, T. S., Erkut, E., Zschocke, M. S. (2007). The cost and risk impacts of rerouting railroad shipments of hazardous materials. Accident Analysis \& Prevention, 39(5), 10151025.

Gunasekera, M., Edwards, D. (2003). Estimating the environmental impact of catastrophic chemical releases to the atmosphere: An index method for ranking alternative chemical process routes. Process Safety and Environmental Protection, 81(6), 463-474.

Guo, X., Verma, M. (2010). Choosing vehicle capacity to minimize risk for transporting flammable materials. Journal of Loss Prevention in the Process Industries, 23(2), 220-225.

Hanna, S. R., Briggs, G. A., Hosker Jr, R. P. (1982). Handbook on atmospheric diffusion.

Kang, Y., Batta, R., Kwon, C. (2014). Generalized route planning model for hazardous material transportation with var and equity considerations. Computers \& Operations Research, 43, 237-247.

Karkazis, J., Boffey, T. (1995). Optimal location of routes for vehicles transporting hazardous materials. European Journal of Operational Research, 86(2), 201-215.

Lees, F. P. (1980). Loss prevention in the process industries: Hazard identification, assessment and controlButterworths.

Leonelli, P., Bonvicini, S., Spadoni, G. (2000). Hazardous materials transportation: A riskanalysis-based routing methodology. Journal of hazardous materials, 71(1), 283-300. 
Mahmoudabadi, A., Seyedhosseini, S. M. (2013). Developing a chaotic pattern of dynamic hazmat routing problem. IATSS Research.

Maremonti, M., Russo, G., Salzano, E., Tufano, V. (1999). Post-accident analysis of vapour cloud explosions in fuel storage areas. Process Safety and Environmental Protection, 77(6), 360365.

NTSBA (2009). Cargo hose rupture and release of anhydrous ammonia during offloading of a Werner Transportation Services cargo tank motor vehicle at the Tanner Industries Plant, Swansea, South Carolina.

Oggero, A., Darbra, R., Munoz, M., Planas, E., Casal, J. (2006). A survey of accidents occurring during the transport of hazardous substances by road and rail. Journal of hazardous materials, 133(1), 1-7.

Pasquill, F. (1961). The estimation of the dispersion of windborne material. Meteorol.Mag, 90(1063), 33-49.

PHMSA (2012), http://www.phmsa.dot.gov/staticfiles/PHMSA/DownloadableFiles/Files/phmsa_infopack.pdf, accessed 02/04/2014.

Reniers, G. L., Jongh, K. D., Gorrens, B., Lauwers, D., Leest, M. V., Witlox, F. (2010). Transportation risk ANalysis tool for hazardous substances (TRANS)-A user-friendly, semiquantitative multi-mode hazmat transport route safety risk estimation methodology for flanders. Transportation Research Part D: Transport and Environment, 15(8), 489-496.

Ronza, A., Vílchez, J., Casal, J. (2007). Using transportation accident databases to investigate ignition and explosion probabilities of flammable spills. Journal of hazardous materials, 146(1), 106-123.

Saat, M. R., Werth, C. J., Schaeffer, D., Yoon, H., Barkan, C. P. (2014). Environmental risk analysis of hazardous material rail transportation. Journal of hazardous materials, 264, 560569.

Singh, K., Ihlenfeld, C., Oates, C., Plant, J., Voulvoulis, N. (2011). Developing a screening method for the evaluation of environmental and human health risks of synthetic chemicals in the mining industry. International Journal of Mineral Processing, 101(1), 1-20.

Toumazis, I., Kwon, C. (2013). Routing hazardous materials on time-dependent networks using conditional value-at-risk. Transportation Research Part C: Emerging Technologies, 37, 73-92.

U.S. DOE, Office of Environment, Safety and Health (2004). ALOHA computer code application guidance for documented safety analysis; DOE-EH-4.2.1.3-final ALOHA code guidance, final report.

U.S. DOT, Office of Hazardous Materials Safety Research and Special Programs Administration (1998). Hazardous materials shipments.

Van Aerde, M., Stewart, A., Saccomanno, F. (1988). Estimating the impacts of LPG spills during transportation accidents. Journal of hazardous materials, 20, 375-392. 
Van Raemdonck, K., Macharis, C., Mairesse, O. (2013). Risk analysis system for the transport of hazardous materials. Journal of Safety Research, 45, 55-63.

Verter, V., Kara, B. Y. (2008). A path-based approach for hazmat transport network design. Management Science, 54(1), 29-40.

Woodward, J. L. (2010). Estimating the flammable mass of a vapor cloud. John Wiley \& Sons.

Zografos, K. G., Androutsopoulos, K. N. (2008). A decision support system for integrated hazardous materials routing and emergency response decisions. Transportation Research Part C: Emerging Technologies, 16(6), 684-703. 


\section{A GIS-Based Framework for Hazardous Tanker Truck Routing: Consideration of Health Risk, Transportation and Delay Costs}

\subsection{Introduction}

Industrial regions depend on transportation of raw materials and products which often include hazardous materials. The U.S. economy relies on the utilization of chemicals for use in industrial applications such as manufacturing, mining, agriculture, construction, medical and sanitary services (Verter and Kara, 2008). As a result, there are risks associated with the accidental releases of hazardous materials and the consequences associated with their release to

the environment. According to the US Department of Transportation (US DOT), around 2 billion tons of hazardous materials are produced in the United States annually. At the same time, approximately 3 million tons of hazardous materials are shipped across the US daily (PHMSA, 2010). It is estimated that every day, over 1 million hazardous material shipments are carried in US mostly by trucks, containing toxic and flammable liquids or gases (PHMSA, 2010). However, the reported and estimated costs and the risk associated with the accidents during transportation of hazardous materials are lower than the actual values (Craft, 2004). This is partly because majority of the incidents are relatively small (Verter and Kara, 2008), hence not reported; and there are limitations for determining the long-term impacts after the accidental releases because the data are collected primarily at the time of the accident (List et al., 1991).

The amounts of chemicals being transported and the number of trucks carrying the hazardous materials have been increasing steadily in the past years. The risks associated with transportation and accidents involving hazardous materials have drawn considerable public attention during the recent years due to accidents and accidental releases during transport. Public awareness of the potential impacts has increased the interest on risk based analyses. Risks 
associated with the transport of hazardous materials depend on both the characteristics of the hazardous chemicals (e.g., volatility, toxicity, solubility, quantity of the cargo) and the characteristics of the environment (e.g., atmospheric conditions, population density, presence of endangered species).

Over the last decade, there have been significant improvements in the techniques for routing and scheduling of hazardous shipments (i.e., development of new models and strategies for transporting the chemicals). The problem of route selection for hazardous materials can be defined as the identification of the path amongst the routing options between the origin and destination of the shipments. The simplest routing approach for route selection is to choose the shortest route with the minimum travel distance between the origin and the destination. However, this method does not take into account the tradeoffs between the characteristics and different challenges associate with each route (i.e., land use and population of the neighboring areas, accident risks and the associated costs of hazardous material accidents).

Single-objective methodologies have the major shortcoming of inability to address the conflict between transportation risks and the cost or other conflicting objectives which are also important for routing of trucks carrying hazardous materials. Thus, routing problems involve multi-objective considerations. The multi-objective problems can be analyzed by developing the Pareto-optimal solution set to select the best option amongst the alternatives. Selection of the best possible solution can be accomplished either by assigning weights to combine the objectives or analysis of tradeoffs between the Pareto-optimal solutions.

The objective of this study was to develop a multi-criteria framework for comparison of different routes in view of the accidental release risks and possible consequences for transporting hazardous cargos. The proposed framework takes into account criteria other than just travel cost which is the most commonly used criterion in route selection of cargos. The criteria used in this study included the health risks and delay and travel costs. A multi-criteria framework was 
developed by considering the characteristics of different routes, accidental release risks, and possible consequences after the release of the hazardous materials (depending on the characteristics of the cargo). The health risks were estimated using an air quality dispersion model. The methodology was illustrated by a case study and numerical analyses to compare the ratings of different routes from different perspectives. Novelty of this research is consideration of three criteria which take into account environmental and financial aspects of hazardous material transport, as well as possible transportation difficulties (due to traffic congestion). In the literature, studies considered delay costs originated by accidents; however, the costs were related to delivery delays that subject the shipping carriers. This study considers the time wasted due to hazardous material accidents which affect general population who use the same route; as such accidents are high consequence events that usually cause closure of the road with the average duration of cleanups of 5 hours (Craft, 2004). The importance of the priorities for the decision makers is emphasized in view of the tradeoffs in selection of the routes.

\subsection{Literature Review}

Multi-objective optimization (or Pareto optimization) is used in cases involving more than one objective function to be optimized simultaneously. Hence, the Pareto optimal or nondominated solutions are not dominated by any of the other alternatives in the set. For example for a two-dimensional multi-criteria problem which is shown in Figure 4.1, with the goal of minimizing the two criteria $\mathrm{C}_{1}$ and $\mathrm{C}_{2}$, solutions $\mathrm{A}$ and $\mathrm{B}$ are non-dominated solutions, meaning neither of the solutions is preferred to the other. Since, point A has a smaller value of $\mathrm{C}_{2}$ which is in favor of the problem (minimizing the two criteria) but shows a larger value for $\mathrm{C}_{1}$. Similarly, point $B$ has a smaller value of $C_{1}$ than point $A$, however, larger value of $C_{2}$ in comparison to point A. 


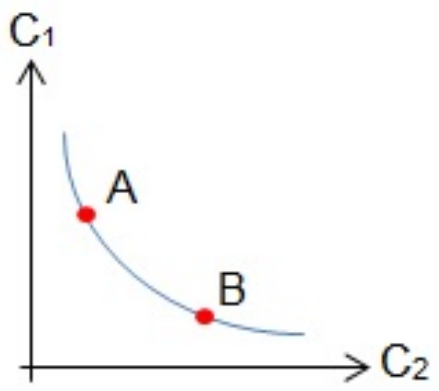

Figure 4.1 Pareto optimal solutions

There are a number of studies in the literature focusing on hazardous material transport using different methodologies. A significant number of the studies have focused on risk analysis and best route selection for transporting hazardous materials. Estimation and modeling of risk is an important task for transporting hazardous materials due to uncertainty of the consequences. The risks associated with an accidental release during transport can have significant and long lasting impacts to the environment and human health depending on the vulnerability of the areas near the transportation routes and the characteristics of the hazardous materials being transported. There is significant amount of research on identification of the risks associated with hazardous material accidents (Das et al., 2012; Leonelli et al., 2000; Glickman et al., 2007; Zografos and Androutsopoulos, 2008; Reniers et al., 2010; Toumazis and Kwon, 2010; Kang et al., 2014; Saat et al., 2014; Chakrabarti and Parikh, 2013; and Van Raemdonck et al., 2013). In the studies which focused on routing the hazardous freights, the common criterion was the risks associated with the transport of hazardous goods (Zografos and Davis, 1989; Lepofsky et al., 1993, Beroggi, 1994; Jacobs and Warmerdam, 1994; Erkut, 1995; Giannikos, 1998; Frank et al., 2000; Leonelli et al., 2000; Gunasekera and Edwards, 2003; Bubbico et al., 2004; Fabiano et al, 2005; Akgün et al, 2007; Carotenuto et al., 2007; Sadjadi, 2007; Bonvicini and Spadoni, 2008; Dadkar et al., 2008; Zografos and Androutsopoulos, 2008; Bianco et al., 2009; Guo and Verma, 2010; Pradhananga et al., 2010; Singh et al., 2011; Das et al., 2012; Mahmoudabadi and Seyedhosseini, 2013; and 
Cappanera and Nonato, 2014). However, other criteria have been utilized to either identify or select the best possible route for hazardous materials such as costs associated with property damage (Zografos and Davis, 1989, and Lepofsky et al., 1993); travel distance (Leonelli et al., 2000; Das et al., 2012; and Cappanera and Nonato, 2014); and travel time (Zografos and Davis, 1989; Lepofsky et al., 1993; Jacobs and Warmerdam, 1994; Frank et al., 2000; Sadjadi, 2007; Dadkar et al., 2008; Zografos and Androutsopoulos, 2008; Pradhananga et al., 2010; Mahmoudabadi and Seyedhosseini, 2013; and Cappanera and Nonato, 2014). There are also studies which considered risk equity (Zografos and Davis, 1989, and Bianco et al., 2009).

There is a gap in the literature in evaluating the risks associated with the type of cargo and the routes due to accidental release risks, and possible consequences (e.g., number of people exposed and levels of exposure) after the release of the hazardous materials depending on the characteristics of the chemical released to the environment. Incorporation to population affected (in terms of number of people and levels of exposure) due to accidental releases is an important factor in estimating long term liability due to health effects.

\subsection{Methodology}

The risk associated with accidental release of hazardous substances during transport is a function of the characteristics of the chemicals, quantity of materials released, population density and wildlife around the spill location, atmospheric conditions and other parameters which can affect the exposure and persistence of the materials released to the environment. In order to avoid the regions with higher accidental release ratings and higher impacts, routing of the hazardous cargos through paths which have relatively smaller risks can be an option. However, the costs associated with rerouting could be challenging depending on the willingness of the distribution companies to change the routes because the new routes which are less risky could be more expensive in terms of transportation costs. In order to evaluate the tradeoffs between different 
routing options for transporting hazardous materials, a framework was developed to evaluate the advantages and disadvantages of different routes using a multi-objective-decision-making framework presented in Figure 4.2.

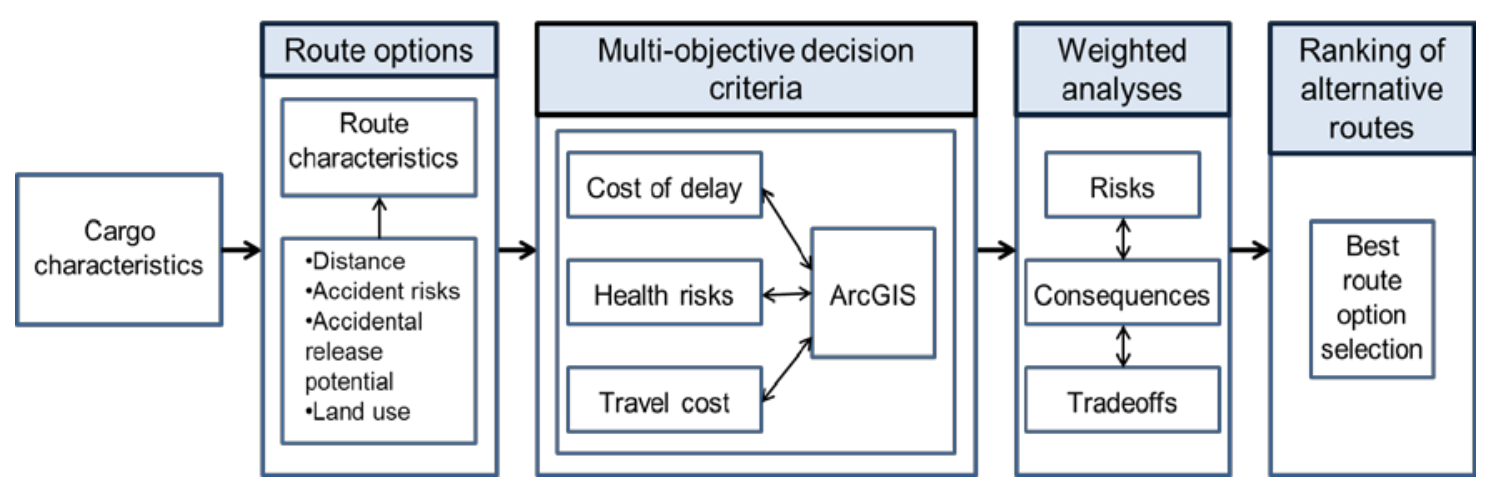

Figure 4.2 Flow chart for the multi-criteria framework for routing options.

\subsubsection{Identification of Criteria for Route Selection}

To compare the alternative routes for transporting hazardous materials, it is important to identify appropriate criteria. A comprehensive literature review was conducted on similar studies to identify different criteria used as presented in Table 4.1.

Based on the literature review and discussions with transportation experts, the three criteria were identified as health risks, costs of delay, and travel costs. Health risks and travel costs are not new criteria to be considered for route selection problems. However, the model utilized in this research incorporated an interactive air quality model (Areal Locations Hazardous Atmospheres, referred as ALOHA) to estimate the health risks due to exposure. 
Table 4.1 Common criteria used in hazardous cargo truck route in selected studies

\begin{tabular}{|c|c|c|c|c|c|c|c|c|c|}
\hline Author & Year & Risk & Damage & $\begin{array}{l}\text { Travel } \\
\text { time } \\
\text { (cost) }\end{array}$ & $\begin{array}{l}\text { Distance } \\
\text { (cost) }\end{array}$ & $\begin{array}{c}\text { Number } \\
\text { of } \\
\text { vehicle }\end{array}$ & $\begin{array}{l}\text { Risk } \\
\text { (cost) }\end{array}$ & $\begin{array}{c}\text { Risk } \\
\text { (special } \\
\text { people) }\end{array}$ & $\begin{array}{r}\text { Risk } \\
\text { equity }\end{array}$ \\
\hline $\begin{array}{l}\text { Zografos and } \\
\text { Davis }\end{array}$ & 1989 & $\checkmark$ & $\checkmark$ & $\checkmark$ & & & & $\checkmark$ & \\
\hline Lepofsky et al. & 1993 & $\checkmark$ & & $\checkmark$ & & & & & \\
\hline $\begin{array}{l}\text { Jacobs and } \\
\text { Warmerdam }\end{array}$ & 1995 & $\checkmark$ & & $\checkmark$ & & & & & \\
\hline Giannikos & 1998 & $\checkmark$ & & & & & & & $\checkmark$ \\
\hline Frank et al. & 2000 & $\checkmark$ & & $\checkmark$ & & & & & \\
\hline Leonelli et al. & 2000 & $\checkmark$ & & & $\checkmark$ & & $\checkmark$ & & \\
\hline Fabiano et al. & 2005 & $\checkmark$ & & & & & & & \\
\hline Akgün et al. & 2007 & $\checkmark$ & & & & & & & \\
\hline Sadjadi & 2007 & $\checkmark$ & & $\checkmark$ & & & & & \\
\hline $\begin{array}{l}\text { Bonvicini and } \\
\text { Spadoni }\end{array}$ & 2008 & $\checkmark$ & & & & & & & \\
\hline $\begin{array}{l}\text { Zografos and } \\
\text { Androutsopoulo } \\
\text { s }\end{array}$ & 2008 & $\checkmark$ & & $\checkmark$ & & & & & \\
\hline Dadkar et al. & 2008 & $\checkmark$ & & $\checkmark$ & & & & & \\
\hline Bianco et al. & 2009 & $\checkmark$ & & & & & & & $\checkmark$ \\
\hline $\begin{array}{l}\text { Pradhananga et } \\
\text { al. }\end{array}$ & 2010 & $\checkmark$ & & $\checkmark$ & & $\checkmark$ & & & \\
\hline Guo and Verma & 2010 & $\checkmark$ & & & & & & & \\
\hline Das et al. & 2012 & $\checkmark$ & & & $\checkmark$ & & & & \\
\hline $\begin{array}{l}\text { Mahmoudabadi } \\
\text { and Seyed }\end{array}$ & 2013 & $\checkmark$ & & $\checkmark$ & & & & & \\
\hline $\begin{array}{l}\text { Chakrabarti and } \\
\text { Parikh }\end{array}$ & 2013 & $\checkmark$ & & & & & & & \\
\hline $\begin{array}{l}\text { Cappanera and } \\
\text { Nonato }\end{array}$ & 2014 & $\checkmark$ & & $\checkmark$ & $\checkmark$ & & & & \\
\hline
\end{tabular}

In the literature there are studies which utilized ALOHA in identification of health threat/risk of hazardous material accidents, in Margai’s study (2001), ALOHA was utilized to identify the threat zone around accidents for chlorine. Dandrieux et al. (2002) used ALOHA to estimate chlorine concentration in a small scale release scenario; authors also compared the results from the model with the traditional Gaussian dispersion approach. Gharabagh et al. (2009) utilized the model as part of a comprehensive risk assessment study for the petrochemical feed and product pipeline network. Verma (2011) applied the model for risk management of 
hazardous material transported by railroad to evaluate the impacts of incidents during transport. There are also studies which use the model to analyze the historical incidents. For example, Leelossy et al. (2011) used the model as an assessment tool for prediction of the short and long term air quality impacts of the Fukushima Nuclear power plant accident.

Delay costs, caused by truck accidents to transportation networks users, used as a criterion which is a new and important consideration that based on the knowledge of this study has not been used in other hazardous material transport routing studies.

After the identification of the possible routes between the origin and destination, ArcGIS software was used to incorporate health risk and transportation data so that the magnitude of the health risk as well as cost of delay and operation cost could be estimated. The multi-criteriadecision-making methodology was developed to quantify the tradeoffs between the route options based on the costs and the associated risks as described below.

\subsection{Risk Estimation}

Risk can be quantified from the number of similar events occurring per year and the corresponding consequences. The consequence can be expressed from different perspectives (i.e., impacted population, fatalities, size of the impacted areas, cost of traffic congestion due to delay, environmental impacts) and the frequency of events can be estimated from the number of similar events occurring per year. In this study, the health risk due to exposure to a hazardous chemical released to the atmosphere was estimated by the following equation (Verter and Kara, 2008):

Risk $=$ Likelihood $\times$ Consequences 
In order to estimate the consequences in Equation 1, the health impact zones estimated by ALOHA were utilized based on the air quality and by incorporating the possible health impacts due to exposure to hazardous materials which are released to the atmosphere. The likelihood of an accident occurrence is broken into two related quantities: the rate that an accident takes place (threat), and the likelihood that the accident leads to a chemical release (vulnerability). In order to calculate the accident rate, as defined in the Highway Safety Manual (HSM, 2010), the normalized value of the crash frequency with exposure (the degree to which a road user is exposed to traffic risks) was calculated. Exposure in 100 million vehicle miles traveled was calculated by Equation 2. Crash rate was acquired by the Equation 3.

EXPO $=\frac{\text { AADT } \times 365 \times \text { number of years } \times \text { total segment length }}{100,000,000}$

Crash rate $=\frac{\text { Total crash count }}{\text { EXPO }}$

where, EXPO is exposure and AADT is annual average daily traffic. The AADT data map was considered in the equation to represent the frequency of accidents, as the main focus of this research and the primary cause of chemical releases. The total crash count was calculated by identifying accidents within a search radius around the target route options on which the accident assumed to happen. However, the crash rate is overestimated as the crash data was related to all the crashes and not specific to truck related accidents. In the accident rate calculation, four years of crash data (2007-2010) in the area were taken into account. The accidents were selected and then enumerated; further, the crash rate was computed using AADT data using Equation 3. Only four years of crash data were available for this study, however, having access to more years of data and newer records could lead to more realistic results. Also, being equipped with the truck related crash data along with the truck AADT would make the output more dependable. 
All the calculations related to estimation of the impacted areas, population at risk, truck crashes identification, crash rate calculation, as well as visualization of the impact zones were executed employing ArcGIS.

The air quality dispersion model (ALOHA) was used to estimate the air concentration of the hazardous chemicals which can be carried by wind to the surrounding areas of the accident location. The impact zone associated with each route or segment can be visualized by overlaying the output impact zones estimated by ALOHA along the routes. The impacted zones were mapped using ArcGIS by defining buffer zones based on the impact radius in relation to the levels of concentration (estimated by ALOHA) surrounding each route or segment of the road. The population density map of 2010 was used to estimate the number of people and the size of the area at risk. The impact zone concentrations were categorized into three Acute Exposure Guideline Levels (AEGLs). These levels correspond to the concentrations of a chemical in air, above which general population could experience notable irritation (AEGL-1), long-lasting adverse health effects (AEGL-2) or even life-threatening health effects or death (AEGL-3) (U.S. DOE, 2004, and Inanloo et al., 2014). In this study life-threatening health effects or death hazard zone was taken into account. Accordingly, based on the size of the impact zones, the risk levels and the consequences were estimated.

\subsubsection{Estimation of Delay Costs}

A consideration which has not been well studied in the field of hazardous materials transport is the burden that accidents involving hazardous materials pose on transportation networks due to congestions and traffic delays. In the literature, delays that affect the delivery of the hazardous goods have been investigated; however, the traffic delays within the transportation network and the impact on the users of these routes have not been addressed. 
In the event of an incident, accident cost includes property damage, fatalities and injuries. The delay costs correspond to the expenses that occur as an indirect result of the accident as the other users of the transportation system are affected by the incident due to congestions and delays. According to a report in 2007, congestions caused an additional 4.2 billion hours for travel in the US, resulting in consumption of 2.9 billion gallons additional fuel corresponding to a congestion cost of $\$ 78$ billion (Schrank et al., 2007). Delay cost can be estimated by multiplying the delay time caused by an accident to the dollar value of travel time delay.

Delay cost can be estimated by multiplying the delay time caused by an accident to the dollar value of travel time delay. Queuing analysis was used to estimate the incident delays as the major impacts. Based on the queuing theory, total delay time for one incident, TD, can be estimated by the following equation:

$\mathrm{TD}=\frac{\mathrm{t}_{\mathrm{R}}^{2}\left(\mu-\mu_{\mathrm{R}}\right) \times\left(\lambda-\mu_{\mathrm{R}}\right)}{2 \times(\mu-\lambda)}$

where, $t_{R}$ represents the incident duration, $\lambda$ is the mean arrival rate, $\mu$ is the mean capacity, and, $\mu_{R}$ is the capacity during the incident. The values $\mu$ and, $\mu_{R}$ were acquired from the Highway Capacity Manual (HCM, 2000, and Hadi et al., 2008). The delay costs for each route was estimated based on the values provided in the 2007 Urban Mobility Report (Schrank et al., 2007). According to the 2007 Urban Mobility Report, the value of travel time delay is $\$ 14.60$ per hour of person travel. Delay costs were estimated by multiplying the value of hourly person travel by the average passenger vehicle occupancy rate which is 1.58 occupants in Florida (FDOT, 2011).

In order to do the calculations of each parameter of Equation 5, the proposed framework of this study was to identify other criteria such as: number of lanes, speed limit and function class of the road segments (i.e. freeway, expressway, street, etc.) to calculate the capacity of the road. 
To further calculate the capacity during the incident, Table 4.2 was taken into account, considering number of lanes before and after the accident. In this study, up to three lanes blockage was considered, not shoulder disablements.

In this study the effect of ramps on the capacity of segments was not considered, nor the influence of intersections.

Table 4.2 Residual freeway capacity in incident zones (HCM, 2000).

\begin{tabular}{|c|c|c|c|c|c|}
\hline \multirow{2}{*}{$\begin{array}{l}\text { Number of lanes } \\
\text { before incident } \\
\text { (One direction) }\end{array}$} & \multirow{2}{*}{ Shoulder disablement } & \multirow{2}{*}{ Shoulder accident } & \multicolumn{3}{|c|}{ Number of lanes blocked ${ }^{a}$} \\
\hline & & & 1 & 2 & 3 \\
\hline 2 & 0.95 & 0.81 & 0.35 & 0.00 & N/A \\
\hline 3 & 0.99 & 0.83 & 0.49 & 0.17 & 0.00 \\
\hline 4 & 0.99 & 0.85 & 0.58 & 0.25 & 0.13 \\
\hline 5 & 0.99 & 0.87 & 0.65 & 0.40 & 0.20 \\
\hline 6 & 0.99 & 0.89 & 0.71 & 0.50 & 0.26 \\
\hline 7 & 0.99 & 0.91 & 0.75 & 0.57 & 0.36 \\
\hline 8 & 0.99 & 0.93 & 0.78 & 0.63 & 0.41 \\
\hline
\end{tabular}

${ }^{\mathrm{a}}$ Proportion of original freeway capacity.

\subsubsection{Estimation of Transportation Costs}

Freight transportation cost is a significant element in the economy of nations and cities. Society and transport companies try to minimize the total cost of conveyance not only to help businesses to be competitive but also to make sure goods are moved and delivered efficiently (Forkenbrock, 2001). Operational costs of trucking involve vehicle-based and driver-based costs. Vehicle-based costs consist of fuel, truck lease or purchase payment, maintenance and repair, insurance, tires, permits and licenses, and tolls. Driver-based costs include the driver wages and benefits. According to a study by the American Transport Research Institute (ATRI) in 2011, the average total carrier cost per mile in 2011 was $\$ 1.706$ per mile. This value was used in this study. 
The transportation costs were estimated by multiplying the average total carrier cost with the length of travel for each route (Fender and Pierce, 2012). The cost per unit of length of travel by ATRI was considered equal for any cargo, disregarding of the chemicals/goods being transport or the size of tankers; however, in reality they cost may be different under different circumstances.

\subsubsection{Multi-Criteria-Decision-Making Method}

Nearly all the real world problems involve multi-objective and can be modeled using multi-criteria-decision-making methods (Köksalan et al., 2011). These techniques help decision makers in ranking the alternatives based on their performances for each criterion. This provides a justification for selection of the best option between alternatives (Carver, 1991). The simplest method which can be utilized in solving multi-criteria problems is to assign weights for each of the criterion in order to combine them into one value so that a coherent value can be obtained to compare the alternatives (Linkov and Moberg, 2011). The weighted performances of the alternatives can be estimated by the following equation (Equation 6) if the goal is to minimize the impacts (e.g., cost, risk):

Minimum $V(\vec{a})=\sum_{i=1}^{n} w_{i} V_{i}\left(a_{i}\right)$

where, $w_{i}$ is the weight assigned to a criterion $i$ and $V_{i}\left(a_{i}\right)$ is the performance of alternative $\vec{a}$ on criterion $i$. The weight assigned to each criterion plays a significant role in the selection of the best alternative. The weights are identified based on the interests and priorities of decision makers (possibly through answering a number of pairwise comparison questions). Therefore, the best alternative may change depending on the weights assigned to the criteria. For example, if the operation cost has higher importance than the health risk and delay cost, assigning 
higher weight coefficient to trucking cost can resulted in selection of the route which lead to lower transport cost, and probably higher risk and/or cost of delay.

Since the range of values for all the criteria are not the same as a matter of order of numbers, comparison of the alternative using Equation 6 could be unrealistic. In other words, in simple summation of the values of criteria, the criterion which is in a larger range of numerical order turns to determinant of the formula, this means the alternative which has the largest value under one criterion controls the outcome (Read et al., 2014). Therefore, the concept of weighted sum with standardized values of data was as well used to reduce the influences of criterion with large values so that a realistic comparison could be made between the alternatives, also to perform a comparison between the two approaches.

\subsection{Case Study}

The case study for implementing the proposed framework was developed for selection of the best route option for a tanker truck carrying gasoline from a specific origin to a specific destination in Florida, USA. It was assumed a non-pressure cargo tank MC 306/ DOT 406 was carrying 9000 Gallons of E 10 blend gasoline from Port Everglades, USA, which supplies about one-fifth of Florida's energy and provides petroleum products to gas stations in 12 counties all over South Florida. As the destination, a gas station in Downtown, Miami, USA was selected. It was assumed that the cargo would be released into the air as a result of an accident. Gasoline is a flammable liquid and a dangerous fire hazard, as well as, carcinogen and potential to cause health problems. In this study the health effects of exposure to Toluene (as one of the primary substances in gasoline) was taken into account. The accident was assumed to cause the closure of three lanes of the route for one hour. Based on the origin and destination, three different route options were selected for analyses (Figure 4.3(a)). The health risk and travel and delay costs were calculated for each route to identify the best route for this scenario. 


\subsection{Results}

The impact zone associated with each route or segment mapped based on the output from the air quality model. Using the buffer zones were defined by the impact radius (for each range of concentration) and mapped by ArcGIS for each route or segment of the road by considering all possible wind directions (Figure 4.3). The population density map was used to calculate the area and the number of people at risk. Based on the three levels of concern for the concentration of the chemical, three risk zones can be defined for each route as presented in Figure 4.3.

Figure 4.3(a) presents the alternatives routes for transport of hazardous material cargo. (Figure 4.3(b) presents the impact zones with different levels of concerns as delineated along the routes (buffer zones). Figure 4.3(c) presents the using population density in the study area which was used to calculate the number of people who would be exposed to the chemical released to the atmosphere at each level of concentration. Figure 4.3(d) presents the population density along the routes that will be exposed to the chemical released to the atmosphere. The crashes along each route were mapped as presented in Figure 4.3(f) and the crash rates were estimated by Equation 4. These calculations were performed for each route and the results were plotted in the form of a Pareto-optimal set of solutions as shown in Figure 4.4.

Since the case study which was investigated is a three-dimensional problem (i.e., three criteria were considered), it is difficult to compare the alternatives in a two-dimensional form. Therefore, parametric analyses were performed as presented in Figure 4.4 to compare the relative rankings of the alternatives in view of each criterion. Figure 4.4(a) presents the comparison of delay cost (\$) in relation to health risk based on the area that will be impacted. Route_2 has the highest delay cost but the smallest health risk, while Route_1 offers the smallest delay cost but highest health risk. On the other hand, Route_3 has both delay cost and health risk between the other two options. Figure 4.4(a) compares the magnitude of the area for health risk, however, in 
reality the land use and population density vary along the route. Hence, considering the risk solely based on the area would be unrealistic. The comparisons were performed by considering the population density and the number of people at risk around the routes as presented in Figure 4.4(b) to investigate the sensitivity of the framework to this fact, also to point out the importance of the selected consequence for investigation of risks. However, based on the characteristics of the case study area, the results were similar (i.e., Route_2 has the largest delay cost and Route_1 the largest health risk). Figure 4.4(c) and Figure 4.4(d) present the comparison of travel cost in relation to health risk based on the impact area and the population at risk, respectively. Route_2 presents the highest travel cost and the lowest risk while Route_1 has the highest risk and lowest travel cost based on both area and population at risk. 


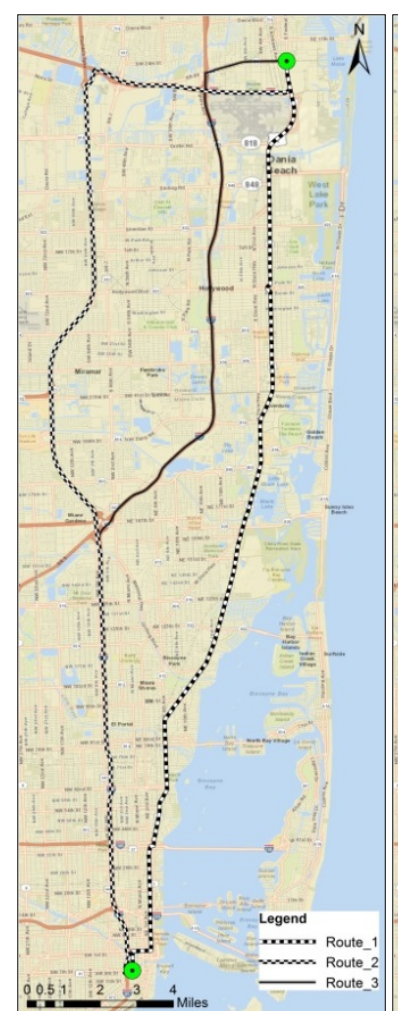

(a) Cargo Routes

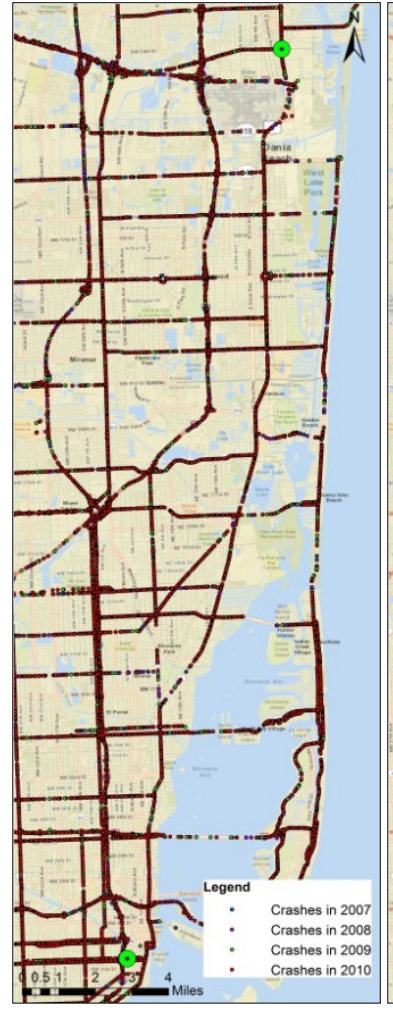

(e) Crashes

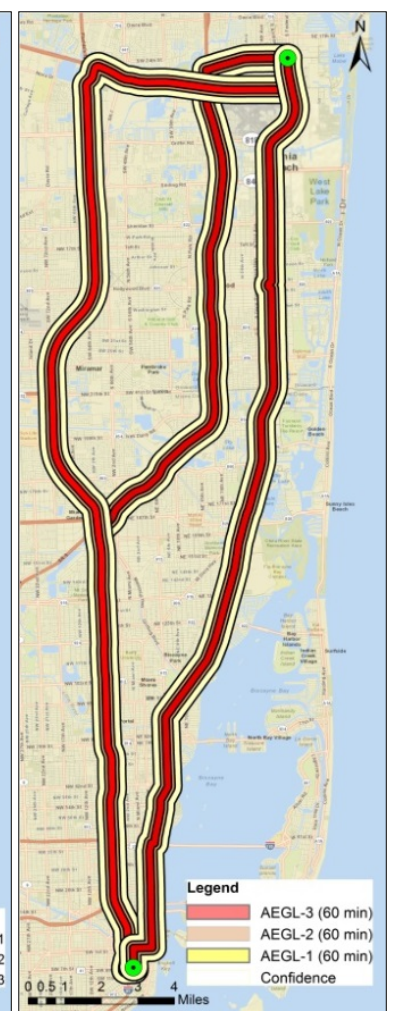

(b) Threat zones

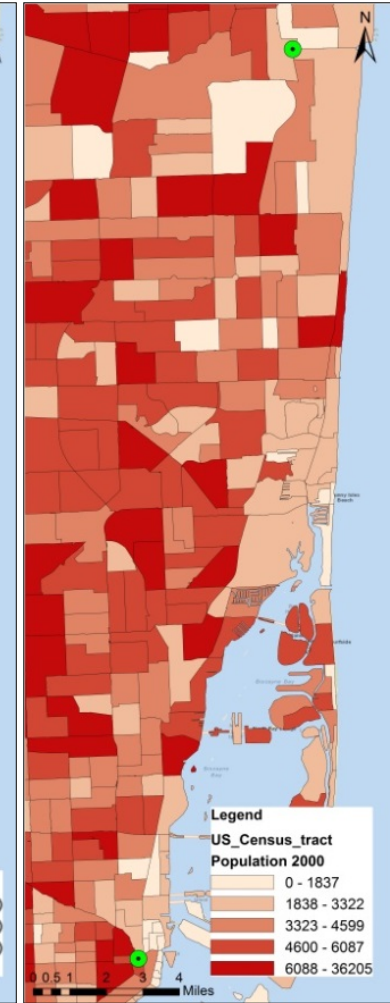

(c) Population density

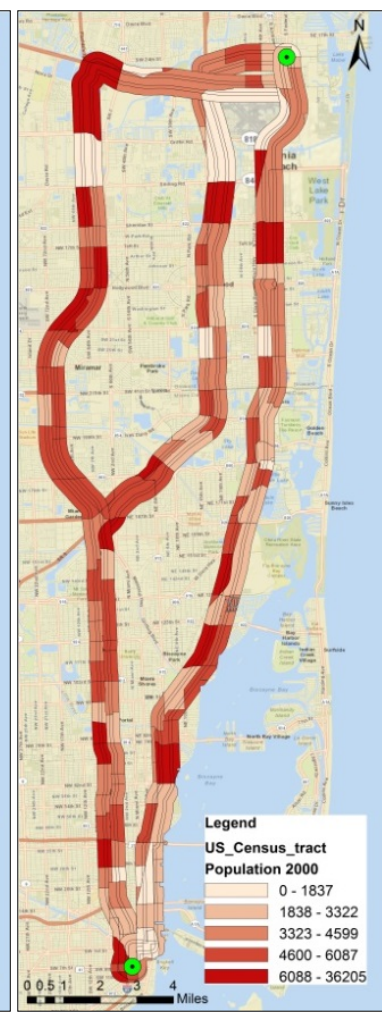

(d) Population at risk

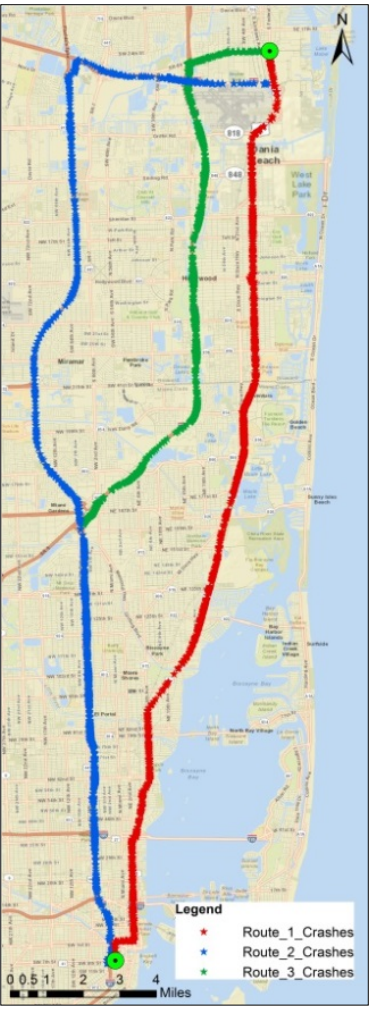

(f) Route crashes

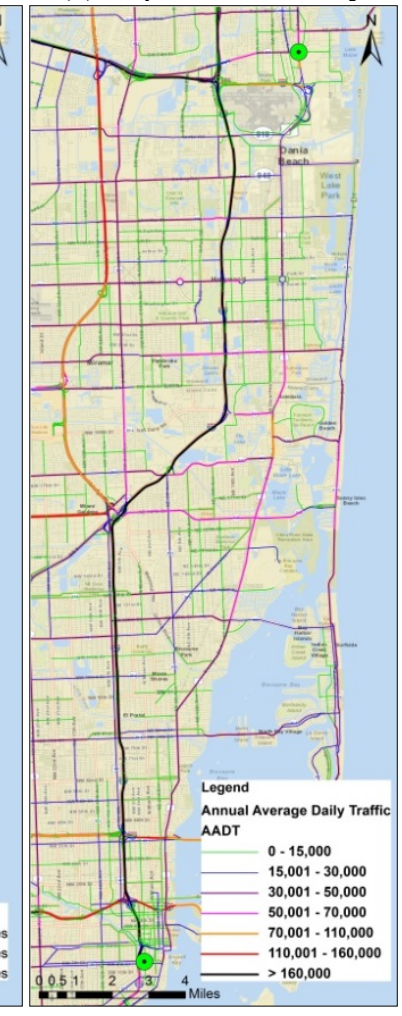

(g) AADT

Figure 4.3 Health risk, delay cost and travel cost calculations. 


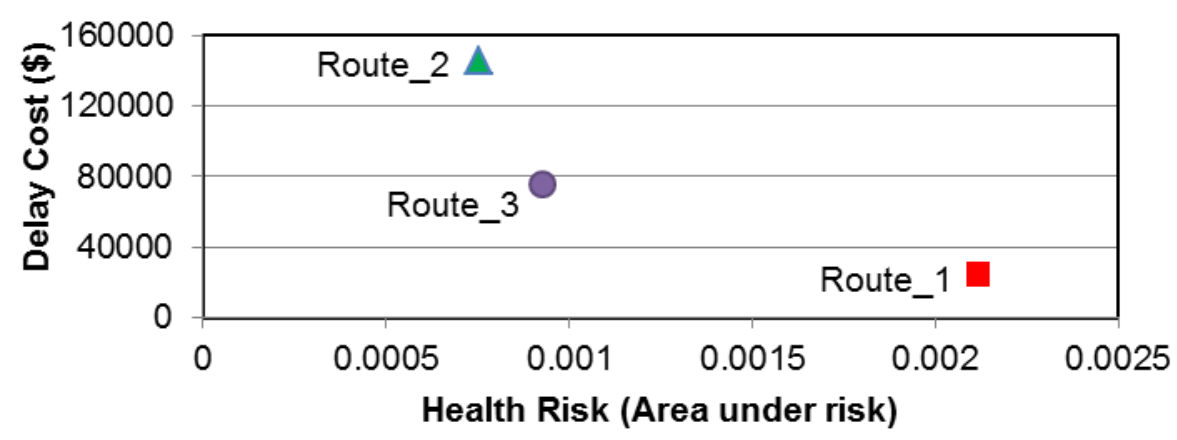

(a) Delay Cost vs. Health Risk (considering area under risk)

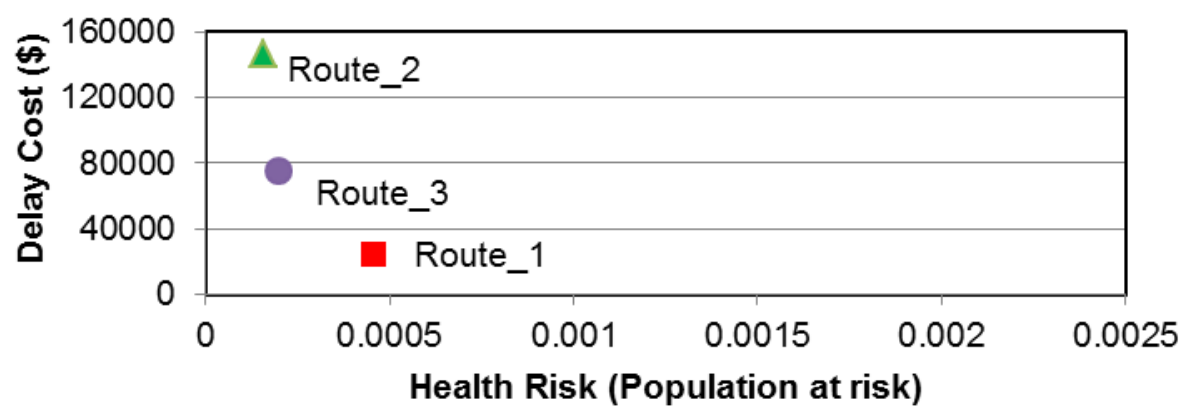

(b) Delay Cost vs. Health Risk (considering population at risk)

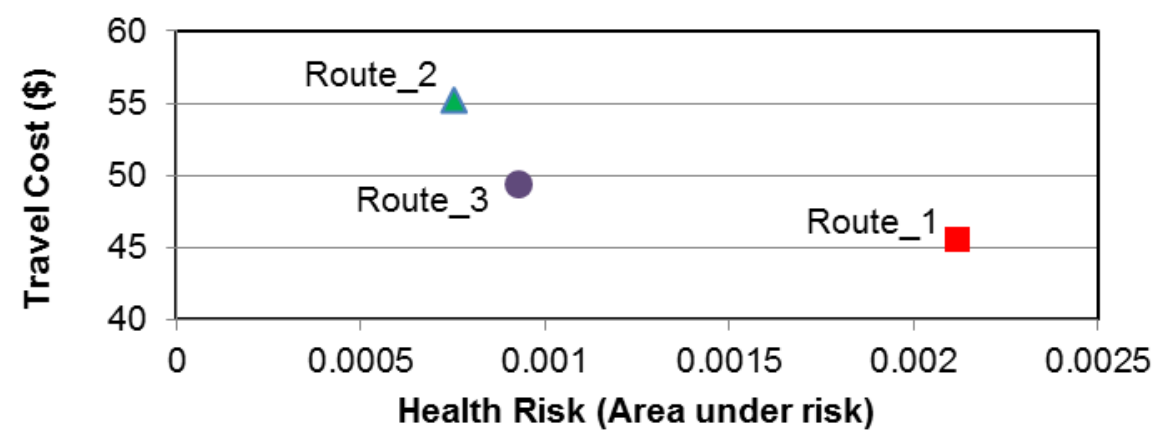

(c) Travel Cost vs. Health Risk (considering area under risk)

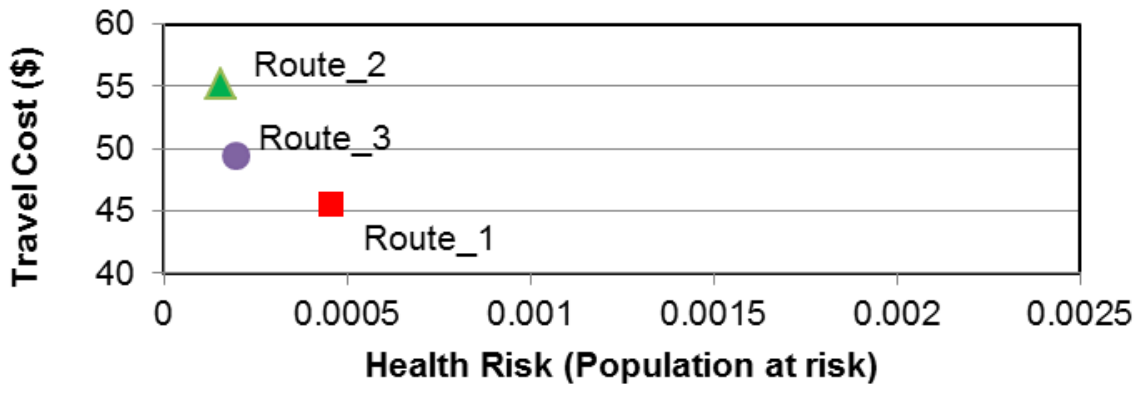

(d) Travel Cost vs. Health Risk (considering population at risk)

Figure 4.4 Comparison of alternative route using different criteria. 
Comparing the result presented in Figure 4.4, it is apparent that each alternative offers a favorable position depending on the criteria. For example Route_1 has the smallest delay and travel costs, however, largest health risk; while, Route_2 has a higher travel costs but lower health risk. Thus, based on the priorities of the decision makers, the best solution may vary. For example, if the decision maker is the freight transportation company, the main priority would be a route with the lowest transportation cost (e.g. Route_1). On the other hand, from the perspective of Department of Transportation, the main priority would be a route with the lowest delay cost. From the perspective of an environmental and health organization, the main priority would be the safest route in view of potential health risks. Therefore, based on the characteristics of the alternatives, there is a need for a method which employs multi-criteria-decision-making method to identify the tradeoffs and the best alternative route.

The weights were assigned for each criterion so that the different criteria can be integrated for an overall comparison. The weights assigned to each criterion play a significant role in the selection of the best option. Table 4.3 and Table 4.4 present the results of two different sets of weight assigned to the criteria. Weight set \#1 presents the prioritization of the health risk and delay cost over travel cost, while weight set \#2 allocate higher we ight to travel expenses than health and congestion cost. Weight sets can be identified according to decision makers' preferences obtained from questionnaire data. The comparisons were performed by considering both the size of the impact area and the number of people at risk. The assigned weight coefficients for the health risk for the area and the people at risk are the same in either of the scenarios (i.e., weight set \#1 and \#2). The "Weighted Sum” rows compare the alternative routes either based on the size of the impacted area or the population. The highlighted cells present the best option among the alternatives. 
Table 4.3 Route options evaluation (weight set \#1)

\begin{tabular}{|c|c|c|c|c|}
\hline Weighted Sum & Weight & Route 1 & Route 2 & Route 3 \\
\hline Health Risk (Based on Area) & 0.5 & 0.00212 & 0.00075 & 0.00093 \\
\hline Health Risk (Based on Population) & 0.5 & 0.00045 & 0.00016 & 0.00020 \\
\hline Delay Cost (\$) & 0.4 & 24620 & 146051 & 75285 \\
\hline Travel Cost (\$) & 0.1 & 45 & 55 & 49 \\
\hline Weighted Sum (Based on Area) & & 9852 & 58426 & 30119 \\
\hline Weighted Sum (Based on Population) & & 9853 & 58426 & 30119 \\
\hline Standardized Weighted Sum & Weight & Route 1 & Route 2 & Route 3 \\
\hline Health Risk (Area) & 0.5 & 1 & 0 & 0.12765 \\
\hline Health Risk (Population) & 0.5 & 1 & 0 & 0.13208 \\
\hline Delay Cost (\$) & 0.4 & 0 & 1 & 0.41723 \\
\hline Travel Cost (\$) & 0.1 & 0 & 1 & 0.40307 \\
\hline Weighted Sum (Based on Area) & & 0.5 & 0.5 & 0.27102 \\
\hline Weighted Sum (Based on Population) & & 0.5 & 0.5 & 0.27324 \\
\hline
\end{tabular}

As shown in Table 4.3, based on regular weighted sum method Route_1 is the best alternative based on the conditions used in weight set \#1. However, after the standardization of the data range, Route_3 became the best alternative.

Based on the assigned weights (weight set \#2) presented in Table 4.4, Route_1 is the favorable alternative based on both the regular and standardized weighted sum method. However, the results of standardized weighted sum could be more realistic since the standardization of the results makes the comparisons more logical. For the case study used in this paper, the results also showed that considering either the population or the size area at risk did not have a significant effect on the identification of the best option. Although, depending on the characteristics of the cargo, population density along the buffer zones, land use, crash data, traffic volume, criteria weights and so on, the result may vary. 
Table 4.4 Route options evaluation (weight set \#2)

\begin{tabular}{|c|c|c|c|c|}
\hline Weighted Sum & Weight & Route 1 & Route 2 & Route 3 \\
\hline Health Risk (Based on Area) & 0.2 & 0.00212 & 0.00075 & 0.00093 \\
\hline Health Risk (Based on Population) & 0.2 & 0.00045 & 0.00016 & 0.00020 \\
\hline Delay Cost (\$) & 0.2 & 24620 & 146051 & 75285 \\
\hline Travel Cost (\$) & 0.6 & 45 & 55 & 49 \\
\hline Weighted Sum (Based on Area) & & 4951 & 29243 & 15087 \\
\hline Weighted Sum (Based on Population) & & 4951 & 29243 & 15087 \\
\hline Standardized Weighted Sum & Weight & Route 1 & Route 2 & Route 3 \\
\hline Health Risk (Based on Area) & 0.2 & 1 & 0 & 0.12765 \\
\hline Health Risk (Based on Population) & 0.2 & 1 & 0 & 0.13208 \\
\hline Delay Cost (\$) & 0.2 & 0 & 1 & 0.41723 \\
\hline Travel Cost (\$) & 0.6 & 0 & 1 & 0.40307 \\
\hline Weighted Sum (Based on Area) & & 0.2 & 0.8 & 0.35082 \\
\hline Weighted Sum (Based on Population) & & 0.2 & 0.8 & 0.35170 \\
\hline
\end{tabular}

Based on the results presented in Table 4.3 and Table 4.4, if the goal is to find the cheapest route for carrying the cargo, Route_1 with the lowest travel cost would be the favorable option. However, if the goal is to minimize the possible health impacts, the favorable option would be Route_3 which offer a lower exposure risks.

\subsection{Conclusions}

The objective of this study was to develop a framework for identification of best routes for transporting hazardous cargo by considering different criteria individually and collectively. Three criteria used in the analyses were delay cost, travel costs, and health risk which would be caused by a possible accident resulting in release of a hazardous chemical to the atmosphere. The method developed is an interactive approach which can be used for decision making depending on the characteristics of the cargo and the transportation routes. The result of the case study showed that the identification of the best route for transporting hazardous chemicals can be 
challenging due to the conflicting interests of the decision makers. Depending on the parameters such as the characteristics and the quantity of the material being transported, atmospheric conditions as well as the characteristics of the routes (i.e., proximate population density, crash data and traffic volume), the overall ratings of the routes can change; hence changing the best route option. Also according to the traffic volume or crash rate of the routes and segments along with the land use and population density of the areas along the routes, the safest route option may be different. One of the main characteristics of the proposed framework is its sensitivity towards data (e.g. population, crash rates, traffic volume, etc.) and its capability in bridging the gap between transportation and environmental aspects of cargo truck transportation.

The results of this study provide the decision makers insights into the suitability of the transportation routes from the three aspects that were considered in the framework (i.e. health risk, delay cost, and travel expenses). The framework proposed by this study is not recommended for long distance routing, as the available data are related to a specific location and also the moment that the program is run. Apparently, by the time, the accuracy of the results would decrease. Some aspects were beyond the scope of this research; however, this paper suggests considering truck crashes and traffic data as well as spillage probability due to accidents, also whether the time of calculations is during weekdays or weekends, so to consider different schedules. The results of this study can be used for routing and scheduling of hazardous cargos, as the next step could be optimization of the routes using multi-criteria-decision-making methods between any origins and destinations (as there are similar studies in the literature); or even through suggesting networks for hazardous material transport for cities. 


\section{Acknowledgements}

Partial funding for this research has been provided by Southeastern Transportation

Research, Innovation, Development and Education Center (STRIDE), University of Florida as well as the Florida International University Graduate School Dissertation Year Fellowship.

\section{References}

Akgün, V., Parekh, A., Batta, R., Rump, C. M. (2007). Routing of a hazmat truck in the presence of weather systems. Computers \& Operations Research, 34(5), 1351-1373.

Beroggi, G. E. (1994). A real-time routing model for hazardous materials. European Journal of Operational Research, 75(3), 508-520.

Bianco, L., Caramia, M., Giordani, S. (2009). A bilevel flow model for hazmat transportation network design. Transportation Research Part C: Emerging Technologies, 17(2), 175-196.

Bonvicini, S., Spadoni, G. (2008). A hazmat multi-commodity routing model satisfying risk criteria: A case study. Journal of Loss Prevention in the Process Industries, 21(4), 345-358.

Bubbico, R., Di Cave, S., Mazzarotta, B. (2004). Risk analysis for road and rail transport of hazardous materials: A simplified approach. Journal of Loss Prevention in the Process Industries, 17(6), 477-482.

Cappanera, P., Nonato, M. (2014). The gateway location problem: A cost oriented analysis of a new risk mitigation strategy in hazmat transportation. Procedia-Social and Behavioral Sciences, 111, 918-926.

Carotenuto, P., Giordani, S., Ricciardelli, S. (2007). Finding minimum and equitable risk routes for hazmat shipments. Computers \& Operations Research, 34(5), 1304-1327.

Carver, S. J. (1991). Integrating multi-criteria evaluation with geographical information systems. International Journal of Geographical Information System, 5(3), 321-339.

Chakrabarti, U., Parikh, J. (2013). Risk-based route evaluation against country-specific criteria of risk tolerability for hazmat transportation through indian state highways. Journal of Loss Prevention in the Process Industries, 26(4), 723-736.

Craft, R. (2004). Crashes involving trucks carrying hazardous materials. federal motor carrier safety administration. Washington, DC: US Dept.of Transportation.Publication\#: FMCSARI-04-024.

Dadkar, Y., Jones, D., Nozick, L. (2008). Identifying geographically diverse routes for the transportation of hazardous materials. Transportation Research Part E: Logistics and Transportation Review, 44(3), 333-349. 
Dandrieux, A., Dusserre, G., Ollivier, J. (2002). Small scale field experiments of chlorine dispersion. Journal of Loss Prevention in the Process Industries, 15(1), 5-10.

Das, A., Gupta, A., Mazumder, T. (2012). A comprehensive risk assessment framework for offsite transportation of inflammable hazardous waste. Journal of hazardous materials, 227, 88-96.

Erkut, E. (1995). On the credibility of the conditional risk model for routing hazardous materials. Operations Research Letters, 18(1), 49-52.

Fabiano, B., Currò, F., Reverberi, A., Pastorino, R. (2005). Dangerous good transportation by road: From risk analysis to emergency planning. Journal of Loss Prevention in the Process Industries, 18(4), 403-413.

Fender, K. J., Pierce, D. A. (2012). An analysis of the operational costs of trucking: 2011 update. Transportation Research Board 91st Annual Meeting, (12-1090).

Florida Department of Transportation (FDOT) (2011). http://www.dot.state.fl.us/planning/trends/tc-report/behavior082611.pdf, Accessed March 10, 2014.

Forkenbrock, D. J. (2001). Comparison of external costs of rail and truck freight transportation. Transportation Research Part A: Policy and Practice, 35(4), 321-337.

Frank, W. C., Thill, J., Batta, R. (2000). Spatial decision support system for hazardous material truck routing. Transportation Research Part C: Emerging Technologies, 8(1), 337-359.

Gharabagh, M. J., Asilian, H., Mortasavi, S., Mogaddam, A. Z., Hajizadeh, E., Khavanin, A. (2009). Comprehensive risk assessment and management of petrochemical feed and product transportation pipelines. Journal of Loss Prevention in the Process Industries, 22(4), 533-539.

Giannikos, I. (1998). A multiobjective programming model for locating treatment sites and routing hazardous wastes. European Journal of Operational Research, 104(2), 333-342.

Glickman, T. S., Erkut, E., Zschocke, M. S. (2007). The cost and risk impacts of rerouting railroad shipments of hazardous materials. Accident Analysis \& Prevention, 39(5), 10151025.

Gunasekera, M., Edwards, D. (2003). Estimating the environmental impact of catastrophic chemical releases to the atmosphere: An index method for ranking alternative chemical process routes. Process Safety and Environmental Protection, 81(6), 463-474.

Guo, X., Verma, M. (2010). Choosing vehicle capacity to minimize risk for transporting flammable materials. Journal of Loss Prevention in the Process Industries, 23(2), 220-225.

Hadi, M., Shen, L., Zhan, C., Xiao, Y., Corbin, S., Chen, D. (2008). Operation data for evaluating benefits and costs of advanced traffic management components. Transportation Research Record: Journal of the Transportation Research Board, 2086(1), 48-55.

Inanloo, B., Tansel, B., Jin, X., Bernardo Bricker, A. (2014). Cargo-specific air dispersion and impact zone analysis after accidental release of hazardous materials. Transportation Research Board 93rd Annual Meeting, (14-0519) 
Jacobs, T. L., Warmerdam, J. M. (1994). Simultaneous routing and siting for hazardous-waste operations. Journal of Urban Planning and Development, 120(3), 115-131.

Kang, Y., Batta, R., Kwon, C. (2014). Generalized route planning model for hazardous material transportation with var and equity considerations. Computers \& Operations Research, 43, 237-247.

Karkazis, J., Boffey, T. (1995). Optimal location of routes for vehicles transporting hazardous materials. European Journal of Operational Research, 86(2), 201-215.

Köksalan, M. M., Wallenius, J., Zionts, S. (2011). Multiple criteria decision making: From early history to the 21st century. World Scientific.

Leelőssy, Á., Mészáros, R., Lagzi, I. (2011). Short and long term dispersion patterns of radionuclides in the atmosphere around the fukushima nuclear power plant. Journal of environmental radioactivity, 102(12), 1117-1121.

Leonelli, P., Bonvicini, S., Spadoni, G. (2000). Hazardous materials transportation: A riskanalysis-based routing methodology. Journal of hazardous materials, 71(1), 283-300.

Lepofsky, M., Abkowitz, M., Cheng, P. (1993). Transportation hazard analysis in integrated GIS environment. Journal of Transportation Engineering, 119(2), 239-254.

Linkov, I., Moberg, E. (2011). Multi-criteria decision analysis: Environmental applications and case studies. CRC Press.

List, G. F., Mirchandani, P. B., Turnquist, M. A., Zografos, K. G. (1991). Modeling and analysis for hazardous materials transportation: Risk analysis, routing/scheduling and facility location. Transportation Science, 25(2), 100-114.

Mahmoudabadi, A., Seyedhosseini, S. M. (2013). Developing a chaotic pattern of dynamic hazmat routing problem. IATSS Research.

Manual, H. C. (2000). Highway capacity manual. Washington, DC.

Manual, H. S. (2000). Highway safety manual. Washington, DC.

Margai, F. L. (2001). Health risks and environmental inequity: A geographical analysis of accidental releases of hazardous materials. The Professional Geographer, 53(3), 422-434.

PHMSA, Office of Pipeline Safety (2010). Building Safe Communities: Pipeline Risk and its Application to Local Development Decisions. http:/ http:/primis.phmsa.dot.gov/comm/publications/PIPA/PIPA-PipelineRiskReport-Final20101021.pdf. Accessed May 15, 2013.

Pradhananga, R., Taniguchi, E., Yamada, T. (2010). Ant colony system based routing and scheduling for hazardous material transportation. Procedia-Social and Behavioral Sciences, 2(3), 6097-6108.

Read, L., Madani, K., Inanloo, B. (2014). Optimality versus stability in water resource allocation. Journal of environmental management, 133, 343-354. 
Reniers, G. L., Jongh, K. D., Gorrens, B., Lauwers, D., Leest, M. V., Witlox, F. (2010).

Transportation risk ANalysis tool for hazardous substances (TRANS)-A user-friendly, semiquantitative multi-mode hazmat transport route safety risk estimation methodology for flanders. Transportation Research Part D: Transport and Environment, 15(8), 489-496.

Saat, M. R., Werth, C. J., Schaeffer, D., Yoon, H., Barkan, C. P. (2014). Environmental risk analysis of hazardous material rail transportation. Journal of hazardous materials, 264, 560569.

Sadjadi, S. J. (2007). An application of efficient frontier in transportation of hazardous materials. Computers \& Industrial Engineering, 53(2), 357-360.

Schrank, D. L., Lomax, T. J. (2007). The 2007 urban mobility reportTexas Transportation Institute, Texas A \& M University.

Singh, K., Ihlenfeld, C., Oates, C., Plant, J., Voulvoulis, N. (2011). Developing a screening method for the evaluation of environmental and human health risks of synthetic chemicals in the mining industry. International Journal of Mineral Processing, 101(1), 1-20.

Toumazis, I., Kwon, C. (2013). Routing hazardous materials on time-dependent networks using conditional value-at-risk. Transportation Research Part C: Emerging Technologies, 37, 73-92.

U.S. DOE, Office of Environment, Safety and Health (2004). ALOHA computer code application guidance for documented safety analysis; DOE-EH-4.2.1.3-final ALOHA code guidance, final report

Van Raemdonck, K., Macharis, C., Mairesse, O. (2013). Risk analysis system for the transport of hazardous materials. Journal of Safety Research, 45, 55-63.

Verma, M. (2011). Railroad transportation of dangerous goods: A conditional exposure approach to minimize transport risk. Transportation research part C: emerging technologies, 19(5), 790-802.

Verter, V., Kara, B. Y. (2008). A path-based approach for hazmat transport network design. Management Science, 54(1), 29-40.

Zografos, K. G., Androutsopoulos, K. N. (2008). A decision support system for integrated hazardous materials routing and emergency response decisions. Transportation Research Part C: Emerging Technologies, 16(6), 684-703.

Zografos, K. G., Davis, C. F. (1989). Multi-objective programming approach for routing hazardous materials. Journal of Transportation Engineering, 115(6), 661-673. 


\section{A Transportation Network Assessment Tool for Hazardous Material Cargo Routing: Weighing Exposure Health Risks, Proximity to Vulnerable Areas, Delay Costs and Trucking Expenses}

\subsection{Introduction}

According to Federal Motor Carrier Safety Administration (FMCSA), hazardous materials are defined as substances that, if not regulated, are capable of threat for the population and the environment health, safety or property, when transported in commerce (FMCSA, 2006). Hazardous material shipments carried by trucks in the US are approximately 1.5 million tons, representing about $59.4 \%$ of the total commodity shipments in 2012 with an increase by $27.3 \%$ from 2007 to 2012, yet the trend in hazardous material volume is steadily increasing by 5\% each year (U.S. Census Bureau, 2012). Accidents involving hazardous materials are relatively low, yet they are considered as high-consequence incidents, as they can involve injuries, death, and costly damages and cleanup efforts (Toumazis and Kwon, 2013).

Substantial research effort has been devoted to routing of hazardous material truck tankers (Zografos and Davis, 1989; Lepofsky et al., 1993; Jacobs and Warmerdam, 1994; Giannikos, 1998; Frank et al., 2000; Leonelli et al., 2000; Fabiano et al., 2005; Akgün et al., 2007; Sadjadi, 2007; Bonvicini and Spadoni, 2008; Zografos and Androutsopoulos, 2008; Dadkar et al., 2008; Bianco et al., 2009; Pradhananga et al., 2010; Guo and Verma 2010). There are substantial research on designing road networks for hazardous materials as well, in which evaluation criteria were defined for assessment, for example: Kara and Verter, 2004; Erkut and Gzara, 2008, Zhang et al., 2000, Frank et al., 2000, Zografos and Androutsopoulos, 2005, Gzara, 2013, Das et al., 2012, Kang et al., 2014. However, most of the studies focused only on travel cost through link length, in some cases risk also was taken into account for network assessment/design. Not to mention, in the field of hazardous material network design, the design 
term refers to selection of suitable segments within an existing network of roads, as designing a new transportation network for hazardous goods and freight is not cost effective at the time being, so it is not considered as an option.

Transport of hazardous materials involves different parties including shippers, carriers, manufactures, residents, governments and emergency responders, each with different priorities as a matter of criteria and objectives to take into account. One the most referred criterion in transportation of hazardous materials is the travel cost, which is important for providing economic advantages and saving to carriers and shippers, as well as, the consumers. However, the lowest cost route may pass through densely populated areas posing high health risks to people in case of an accidental release. On the other hand, another consideration which has not been well studied in the field of hazardous material is the burden that accidents involving hazardous materials pose on transportation networks due to congestions and traffic delays. In the literature, delays that affect the delivery of the hazardous good have been considered; however, the traffic delays in the transportation network and the impact on the users of these routes have not been addressed.

This paper proposes a framework to evaluate transportation networks in regards to their suitability for hazardous material shipments. The tool developed by this study is flexible for conducting comparative assessments of routing options for a given study area.

\subsection{Methodology}

Road segments for each route were evaluated (quantitatively) and the route options were compared based on the suitability of the road segments within the transportation network. 
The following four criteria were considered in development of the network assessment tool:

1. Health risks due to exposure after accidental releases,

2. Delay costs,

3. Trucking expenses, and

4. Proximity to vulnerable areas.

The approach used in this study is an interactive and flexible tool, written in Python programming language, capable of analysis on the transportation network of any given area of interest provided by the user) for assessing the suitability of the routes for transporting hazardous materials. Evaluations, calculations and analyses are done by one time execution of the program and the outputs are obtained in the form of maps and tables. Figure 5.1 presents the overall methodology used in developing the route assessment tool.

\begin{tabular}{|c|c|c|}
\hline & $\begin{array}{c}\begin{array}{c}\text { Transportation } \\
\text { Network }\end{array} \\
\end{array}$ & \\
\hline & Evaluation criteria & \\
\hline Health risk & Cost of delay & Trucking cost \\
\hline \multirow{2}{*}{$\begin{array}{l}\text { - Chemical } \\
\text { - Level of concern concentration } \\
\text { - Truck accidents history } \\
\text { - Release probability } \\
\text { - Truck traffic volume } \\
\text { - Location and time of accident } \\
\text { - Population density } \\
\text { - Cloud cover } \\
\text { - Wind speed }\end{array}$} & \multirow{2}{*}{$\begin{array}{l}\text { - Traffic volume } \\
\text { - Number of lanes } \\
\text { - Speed limit } \\
\text { - Free capacity } \\
\text { - Duration of blockage } \\
\text { - Number of blocked lanes } \\
\text { - Remained capacity } \\
\text { - passenger vehicle occupancy rate } \\
\text { - Cost per hour delay }\end{array}$} & $\begin{array}{l}\text { - Length of segment } \\
\text { - Cost per distance }\end{array}$ \\
\hline & & $\begin{array}{l}\text { - Locations of public places } \\
\text { - Streets network }\end{array}$ \\
\hline & $\downarrow$ & \\
\hline & Tools & \\
\hline & ArcGIS $\longleftrightarrow$ Python & Vulnerability/Suitability maps \\
\hline
\end{tabular}

Figure 5.1 Methodology of the hazardous cargo transportation network assessment tool 


\subsubsection{Exposure health risk criteria and quantification}

The hazards in risk assessments are usually considered as: acute toxicity, flammability, thermal radiation, blast wave, and missile damage (Alp, 1995) (Inanloo and Tansel, 2015). In this paper, risk is a measure of the probability and severity of threat to a receptor due to acute exposure to hazardous material fumes. Acute Exposure Guideline Levels (AEGLs) were developed to the risk to humans' health causing by exposure to once-in-a-lifetime, or rare airborne chemicals. In this research, in order to quantify the health risk of inhalation of spilled chemicals, AEGL-3 which represents "the airborne concentration (expressed as ppm or mg/m3) of a substance above which it is predicted that the general population, including susceptible individuals, could experience life-threatening health effects or death”, was taken into account as the threshold concentration for health impact radius identifications (EPA, 2015). Having the impact radius calculated, number of exposed people within the threat zone was estimated as the consequence of the accident.

The health risks due to the inhalation of hazardous chemicals after an accidental release was calculated by Equation 1.

Risk $=$ Frequency $\times$ Consequences

Accident frequency can be estimated from the number of similar events occurring per year and the consequences can be expressed from different perspectives (i.e., impacted population, fatalities, size of the impacted area, environmental impacts) (Inanloo et al., 2015). Over the rest of this section the procedure of calculations of the components of risk will be described. 


\subsubsection{Accident Frequencies}

In order to calculate the accident frequency, as defined in the Highway Safety Manual (HSM, 2000), the normalized value of the crash frequency with exposure (the degree to which a road user is exposed to traffic risks) was calculated. Exposure in 100 million vehicle miles traveled was calculated by Equation 2. Crash rate was acquired by the Equation 3 (HCM, 2000).

$\mathrm{EXPO}=\frac{\text { AADT } \times 365 \times \text { number of years } \times \text { total segment length }}{100,000,000}$

Crash rate $=\frac{\text { Total crash count }}{\text { EXPO }}$

where, EXPO is the exposure to accidents and AADT is the annual average daily traffic.

In this study, AADT for trucks was considered to represent the frequency of truck accidents. The total crash count was estimated by identifying accidents involving trucks within a search radius around each segment of the transportation network. The probability of chemical releases in accidents involving trucks was based on the statistics of hazardous material accidents, as the percentage of the accidents which led to chemical releases to the number of total hazardous material accidents. According to PHMSA, 27.3\% of the hazardous material accidents result in chemical releases (Battelle, 2001).

\subsubsection{Consequence analysis}

In order to identify and quantify the health impact buffer zones around the road segments, AEGL-3 concentration for one hour exposure of the released chemical was taken into account; through plug the concentration threshold into Equation 4 and find the farthest distance that the 
certain concentration would be perceived. The proposed tool by this study is provided with a dictionary of AEGLs for common carried hazardous materials, with the capability of selection between the substances, as the thresholds differ from a chemical to the other. Therefore, the impact radiuses also vary by the change in the level of concern concentrations (Inanloo et al., 2014).

$$
\begin{aligned}
& C(x, y, z, t) \\
& =\frac{Q}{(2 \times \pi)^{3 / 2} \sigma_{x} \sigma_{y} \sigma_{z}} \exp \left[-1 / 2\left(\frac{x-u t}{\sigma_{x}}\right)^{2}\right] \exp \left[-1 / 2\left(\frac{y}{\sigma_{y}}\right)^{2}\right]\left\{\exp \left[-1 / 2\left(\frac{z+h}{\sigma_{z}}\right)^{2}\right]\right. \\
& \left.+\exp \left[-1 / 2\left(\frac{z-h}{\sigma_{z}}\right)^{2}\right]\right\}
\end{aligned}
$$

where, $\mathrm{x}, \mathrm{y}$ and $\mathrm{z}$ are the distance downwind and crosswind and vertical directions, respectively. $\mathrm{C}(\mathrm{x}, \mathrm{y}, \mathrm{z})$ is the concentration of the substance at $(\mathrm{x}, \mathrm{y}, \mathrm{z})$ location from the spill at time $t$ after the release. $\mathrm{Q}$ is the release quantity and $\sigma_{\mathrm{x}}, \sigma_{\mathrm{y}} \sigma_{\mathrm{z}}$ are the standard deviations of concentrations distributions in different directions $\left(\sigma_{\mathrm{x}}, \sigma_{\mathrm{y}}\right.$ are considered equal). $\mathrm{u}$ is the wind speed and $\mathrm{h}$ is the effective stack height.

The concentrations were calculated for downwind direction without any deviations from the centerline of the wind, and on the ground level. The standard deviations vary depending on the atmospheric condition and the distance downwind. The coefficients in Table 5.1 were used in order to calculate the standard deviations. However, the stability of atmosphere needed to be identified prior this step. 
Table 5.1 Equations used for $\sigma_{\mathrm{x}}, \sigma_{\mathrm{y}}$, and $\sigma_{\mathrm{z}}$ calculations (Slade, 1968).

\begin{tabular}{ccc}
\hline Stability class & $\sigma_{\boldsymbol{y}}(\mathbf{m})$ & $\boldsymbol{\sigma}_{\boldsymbol{z}}(\mathbf{m})$ \\
\hline Open country conditions & & $0.20 \mathrm{x}$ \\
A & $0.22 \mathrm{x}(1+0.0001 \mathrm{x})^{-1 / 2}$ & $0.12 \mathrm{x}$ \\
B & $0.16 \mathrm{x}(1+0.0001 \mathrm{x})^{-1 / 2}$ & $0.08 \mathrm{x}(1+0.0002 \mathrm{x})^{-1 / 2}$ \\
C & $0.11 \mathrm{x}(1+0.0001 \mathrm{x})^{-1 / 2}$ & $0.06 \mathrm{x}(1+0.0015 \mathrm{x})^{-1 / 2}$ \\
$\mathrm{D}$ & $0.08 \mathrm{x}(1+0.0001 \mathrm{x})^{-1 / 2}$ & $0.03 \mathrm{x}(1+0.0003 \mathrm{x})^{-1}$ \\
E & $0.06 \mathrm{x}(1+0.0001 \mathrm{x})^{-1 / 2}$ & $0.016 \mathrm{x}(1+0.0003 \mathrm{x})^{-1}$ \\
F & $0.04 \mathrm{x}(1+0.0001 \mathrm{x})^{-1 / 2}$ & \\
Urban conditions & & $0.24 \mathrm{x}(1+0.001 \mathrm{x})^{1 / 2}$ \\
A-B & $0.32 \mathrm{x}(1+0.0004 \mathrm{x})^{-1 / 2}$ & $0.20 \mathrm{x}$ \\
C & $0.22 \mathrm{x}(1+0.0004 \mathrm{x})^{-1 / 2}$ & $0.14 \mathrm{x}(1+0.0003 \mathrm{x})^{-1 / 2}$ \\
D & $0.16 \mathrm{x}(1+0.0004 \mathrm{x})^{-1 / 2}$ & $0.08 \mathrm{x}(1+0.00015 \mathrm{x})^{-1 / 2}$ \\
E-F & $0.11 \mathrm{x}(1+0.0004 \mathrm{x})^{-1 / 2}$ &
\end{tabular}

Stability of atmosphere corresponds to the ability of the air molecules in creating vertical movements. These motions generate the ability of dilution of chemical particles in the air. The more and faster the movements, the quicker the dilution of the substance in the atmosphere is, and accordingly, less health impacts can be expected, as the chemical would not stay in the atmosphere long enough to cause irritation and health problems. Atmospheric conditions, as are shown in Table 5.2, can be represented by stability classes; as a function of wind speed, solar radiation, and/or cloud cover. These motions generate the ability of dilution of chemical particles in the air. The more and faster the movements, the quicker the dilution of the substance in the atmosphere is, and accordingly, less health impacts can be expected, as the chemical would not stay in the atmosphere long enough to cause irritation and health problems. Atmospheric conditions, as are shown in Table 5.2, can be represented by stability classes; as a function of wind speed, solar radiation, and/or cloud cover. 
Table 5.2 Urban stability categories (Ludwig et al., 1976).

\begin{tabular}{ccccccc}
\hline $\begin{array}{c}\text { Surface wind } \\
\text { velocity } \\
\left(\mathrm{m} \mathrm{s}^{-1}\right)\end{array}$ & $\begin{array}{c}\text { Strong } \\
\text { insolation }\end{array}$ & $\begin{array}{c}\text { Daytime } \\
\text { insolation }\end{array}$ & $\begin{array}{c}\text { Slight } \\
\text { insolation }\end{array}$ & $\begin{array}{c}\text { Opaque cloud } \\
\text { cover } \\
\geq 9 / 10 \text { day or } \\
\text { night or } \\
\text { solar elevation } \\
\text { angle } \leq 15^{\circ}\end{array}$ & $\begin{array}{c}\text { Night time cloud } \\
\text { cover }\end{array}$ \\
\hline$<2$ & A & B & B & D & E & E \\
$2-3$ & A & B & C & D & D & E \\
$3-5$ & B & C & C & D & D & D \\
$5-6$ & C & C & D & D & D & D \\
$>6$ & C & D & D & D & D & D \\
\hline
\end{tabular}

In this study, in order to identify the stability classes of atmosphere, data maps of cloud cover, as well as, wind speed over the case study area were obtained. Wind speed data was used in order to pinpoint the related row in Table 5.2 to further pick out the stability classes based on the solar radiation or/and the cloud cover based on the table. The cloud cover data was needed to identify the sky cover proportion in the scale of 10 (1 corresponds to clear sky and 10 to completely covered by clouds) to further relate the atmospheric stability classes during nighttime or for the cases with solar radiation angles of less than 15 degrees.

The solar radiation (solar elevation angle) was identified based on equations from Astronomical Algorithms book by Meeus, 1991. Based on the formulations, the coordinate of the study area, as well as, the time of day/ night and the date at the time and location of the accident are taken into account to calculate the solar elevation angle (to be used in Table 5.2). Clearly, based upon the location and time of the accident the solar angle would vary (i.e. as in Egypt vs. Canada; or as in early morning vs. noon or evening). The proposed model by this research is capable of identification of the time and date of the study area at the moment of running the tool, which, leads to a location and time based recognition of solar radiations.

The tool, taking into account the time of evaluations, recognizes whether the transport/accident happens during daytime or night time, so that, it can pick out which columns of 
Table 5.2 are applicable to the case. Having calculated and identified the parameters (wind speed, solar elevation angel and cloud cover), the stability class of atmosphere is identified according to the table.

By the stability class determined, the standard deviations are calculated based on Table 5.1. In this study, open county conditions were taken into account for the worst case scenarios for estimating the impact radius, as urban areas may prevent vapor clouds from propagation due to urban obstructions. Based on the stability classes of atmosphere, the tool selects the corresponding equations for the standard deviation calculations.

Wind direction and speed were considered constant during the calculations, disregarding any changes in the parameters over time. However, in reality these parameters change during the day and night.

Based on the assumptions of Gaussian dispersion equation, particles disperse by the power of wind and toward downwind direction, and there are no chemical particles transmitted upwind. Although, the distance calculated by the suggested model of this study is from the release location to downwind direction with no deviations towards other directions (vertical or horizontal), in order to take into account any changes in the direction of the wind, the predicted health impact radius was used as a buffer distance around the spill location toward any directions, disregards of the orientation of wind.

\subsubsection{Delay Cost}

Accident costs are not limited to property damages, fatalities and injuries; they also include the expenses that occur as an indirect result of the accident, as other users of the transportation system are affected by the incident due to congestions and delays (Inanloo et al., 2015). According to a report in 2007, congestions caused an additional 4.2 billion hours for travel 
in the US, resulting in consumption of 2.9 billion gallons additional fuel corresponding to a congestion cost of \$78 billion (Schrank and Lomax, 2007).

Delay cost can be estimated by multiplying the delay time caused by an accident to the dollar value of travel time delay. Queuing analysis was used to estimate the incident delays as the major impacts. Based on the queuing theory, total delay time for one incident, TD, can be estimated by the following equation (Hadi et al., 2008):

$\mathrm{TD}=\frac{\mathrm{t}_{\mathrm{R}}^{2}\left(\mu-\mu_{\mathrm{R}}\right) \times\left(\lambda-\mu_{\mathrm{R}}\right)}{2 \times(\mu-\lambda)}$

where, $t_{R}$ is the incident duration,

$\mu \_R$ is the capacity during the incident. The values $\mu$ and, $\mu \_R$ were acquired from the Highway Capacity Manual (HCM, 2000 and Hadi et al., 2008).

In order to do the calculations of each parameter of Equation 5, the proposed tool by this study was to identify other criteria such as: number of lanes, speed limit and function class of the road segments (i.e. freeway, expressway, street, etc.) to calculate the capacity of the road. To further calculate the capacity during the incident,

Table 5.3 was taken into account, considering number of lanes before and after the accident. In this study, only lane blockage was considered, not shoulder disablements.

The delay cost for each route was estimated based on the values provided in the 2007 Urban Mobility Report (Schrank and Lomax, 2007). According to the report, the value of travel time delay is $\$ 14.60$ per hour of person travel. Delay costs were estimated by multiplying the value of hourly person travel by the average passenger vehicle occupancy rate which was 1.58 occupants in Florida (FDOT, 2011). 
In this study the effect of ramps, as well as, intersections on the capacity of segments were not considered.

Table 5.3 Residual freeway capacity in incident zones (HCM, 2000).

\begin{tabular}{cccccc}
\hline \multirow{2}{*}{$\begin{array}{c}\text { Number of lanes } \\
\text { before incident } \\
\text { (One direction) }\end{array}$} & Shoulder disablement & Shoulder accident & \multicolumn{3}{c}{ Number of lanes blocked ${ }^{\text {a }}$} \\
\cline { 4 - 6 } & & & 1 & 2 & 3 \\
\hline 2 & 0.95 & 0.81 & 0.35 & 0.00 & N/A \\
4 & 0.99 & 0.83 & 0.49 & 0.17 & 0.00 \\
5 & 0.99 & 0.85 & 0.58 & 0.25 & 0.13 \\
6 & 0.99 & 0.87 & 0.65 & 0.40 & 0.20 \\
7 & 0.99 & 0.89 & 0.71 & 0.50 & 0.26 \\
8 & 0.99 & 0.91 & 0.75 & 0.57 & 0.36 \\
& 0.99 & 0.93 & 0.78 & 0.63 & 0.41 \\
\hline
\end{tabular}

a Proportion of original freeway capacity.

\subsubsection{Estimation of Transportation Costs}

Freight transportation cost plays an important role in the economy of countries and cities. Society and transport companies try to minimize the total cost of conveyance not only to help businesses to be competitive but also to make sure goods are moved and delivered efficiently (Forkenbrock, 2001). According to a study by the American Transport Research Institute (ATRI) in 2011, the average total carrier cost in 2011 was $\$ 1.706$ per mile. This value was used in this study. Transportation costs were estimated by multiplying the average total carrier cost with the travel distance for each route (Fender and Pierce, 2012). The trucking cost of each road segment was calculated by multiplication of the cost per unit of length to the length of the target link. 


\subsubsection{Vulnerable Points}

In this study, vulnerable places such as schools, daycares, and hospitals were identified near each road segment in addition to the mentioned three criteria identified for evaluation of transportation networks for hazardous material transport. The tool developed by this study, considering the map of the public locations, searches a certain distance around the road segments for any of previously mentioned public places and keeps the records of such points, as these public places occupies vulnerable people such as children and patients who are more prone to health risks in case of being exposed to chemicals than other groups of population.

\subsection{Case study}

The city of Miami in Florida, USA was selected as the study area of this paper in order to implicate the tool on a real world problem. The required data for the proposed tool were collected in the formats of maps and tables from different sources of data. However, finding data on truck shipments and their schedules were very challenging, as the data were hard to obtain due to the security purposes also the lack of records.

The shipment was assumed as a full tanker truck of gasoline, with the capacity of 9,000 gallons of E-10 blend of gasoline. It was assumed that the entire tanker content is released to the atmosphere, caused by an en-route accident. In reality, spills are usually a part of cargos and not the entire shipment, however, in order to have taken into consideration the worst case scenario, in this study the whole cargo was presumed to be released by the accident.

Gasoline consists of different compounds, with different proportions. In this study, Toluene was taken into account for health risk evaluations. The quantity of Toluene was calculated based on its proportion in gasoline. Therefore, in the calculations, the suggested tool uses the predefined level of concern concentration of this substance for the impact radius 
identifications. Figure 5.2 shows the location of the study area as well as the boundary of the area of interest.

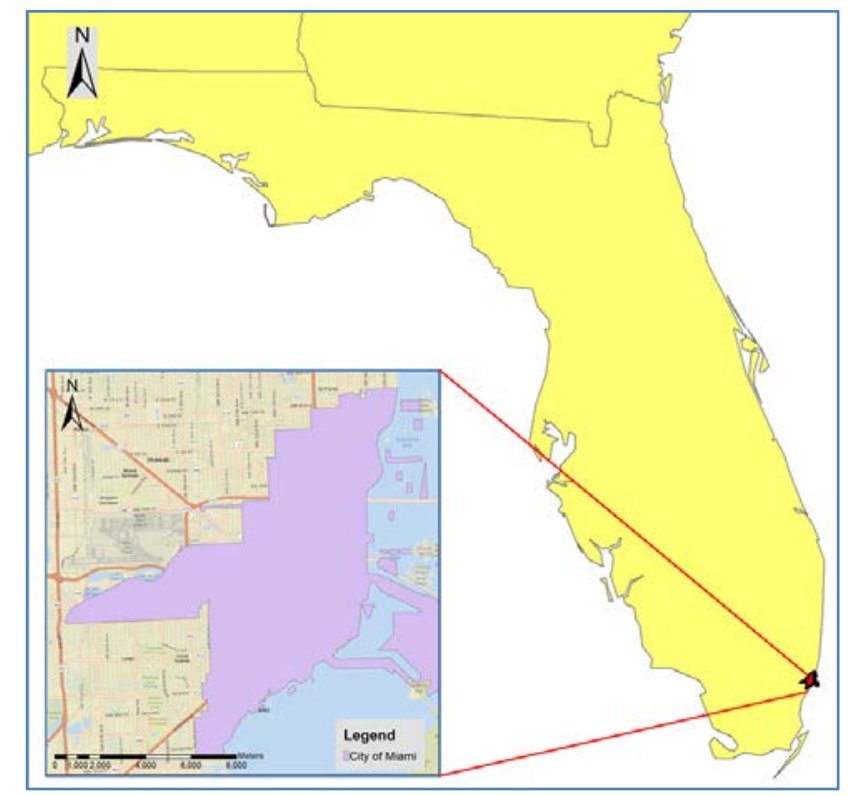

Figure 5.2 Location of the case study area.

\subsection{Results}

The output results include several maps, as well as, tables showing calculated and evaluated properties ready to be interpreted. According to the methodology of this study, having required data, calculations through Python were executed and were visualized using ArcGIS afterwards. Figure 5.3 presents the data maps and the output result of health impact zone. As it is shown in Figure 5.3(a) the sky cover data map was available for the area of study which can be used based on Table 5.2; in case the cloud cover is more than 9/10 ( $>90$, which was not observed during the time of the program execution, as the sky cover range was between 23-30(<3/10)) 
during day; or night (which was not the case either, as the program was run during the daytime); or solar elevation angle of less than $15^{\circ}$, nor this case was applicable, since, based on solar radiation calculations the calculated solar elevation angle was more than the threshold. The solar elevation angle was calculated for the entire area of interest once and considered constant.

The map of wind speed also was available, making the identification of stability classes based on Table 5.2 possible, as it is shown in Figure 5.3(b and c). Having identified the stability classes of atmosphere around road segments, the buffer distances for transportation branches was taken into consideration and delineated around the lines. As it can be seen in Figure 5.3(d), the buffer distances are different according to the stability of atmosphere, as it plays a significant role in the delusion of chemicals in the air. According to Figure 5.3(c) two stability classes were expected in the area of interest (B and C) at the time, date and location of the study. Class of B is more unstable than class of $\mathrm{C}$, since a chemical which enters the more stable atmospheres tends to stay in the air longer than unstable conditions; the health impact radius is also bigger under stable atmosphere, as it can be seen in Figure 5.3(d). The buffer zones which were delineated based on the data (i.e. solar elevation angle, wind speed, cloudiness, etc.) are shown in Figure 5.3(d).

Based on the health risk zones around segments sketched in Figure 5.3(d), population at risk was calculated using population density map in Figure 5.4(a), and is shown in Figure 5.4(b). In this study, the estimations of population were based on the population density of 2010. Having approximated the population at risk for each segment, also equipped with the 8 year crash history in the area (2003-2010) (Figure 5.4(c)), as well as, truck traffic volume (Figure 5.4(d)), and crash rates (Figure 5.5(a)), risks were calculated for road segments as they are shown in Figure 5.5(b). The risk calculated in this study is the multiplication of number of people to truck involved crash rates (crashes per 100 million vehicles), to the probability of the en-route accident which lead to releases (percentage of total truck crashes). 
In this study, the vulnerable places that were prone to health risk were identified based upon their proximity to the health risk buffer zones, as whether they were located within the risky areas of segments. Numbers of vulnerable points which fall into the health risk zones of each segment were assigned to the segment of the transportation network (Figure 5.5(c and d)).

Figure 5.6 was allocated to declaration of the calculations and result of delay cost. Based on the assumptions of this study, closure of three lanes of the segment due to a truck involved accident for one hour is presumed, and calculations were done based on this scenario. Hazardous material accidents are large and serious events, as the accidents which lead to release only, usually cause road closure with the average duration of cleanups of 5 hours (Battelle, 2001). As it is shown in Figure 5.6(a), road capacities were identified based on the number of lanes, function of the road and speed limit. Capacities of segments after accident also were calculated as depicted in Figure 5.6(c). Obtaining the results of road capacity before and after accidents for each segment, as well as, traffic volume (Figure 5.6(b)), delay time was computed for each of the network branch. Unlike to the health risk calculations, traffic volume for delay time computations were considered as vehicle traffic, while for the rash rate assessment truck traffic volume was considered.

Figure 5.7 presents the results for delay and trucking costs. Delay cost is multiplication of the results of Figure 5.6(a) to the cost per hour of delay in the area to the occupancy rate. Figure 5.7(b) presents the travel cost for each segment of the network. 


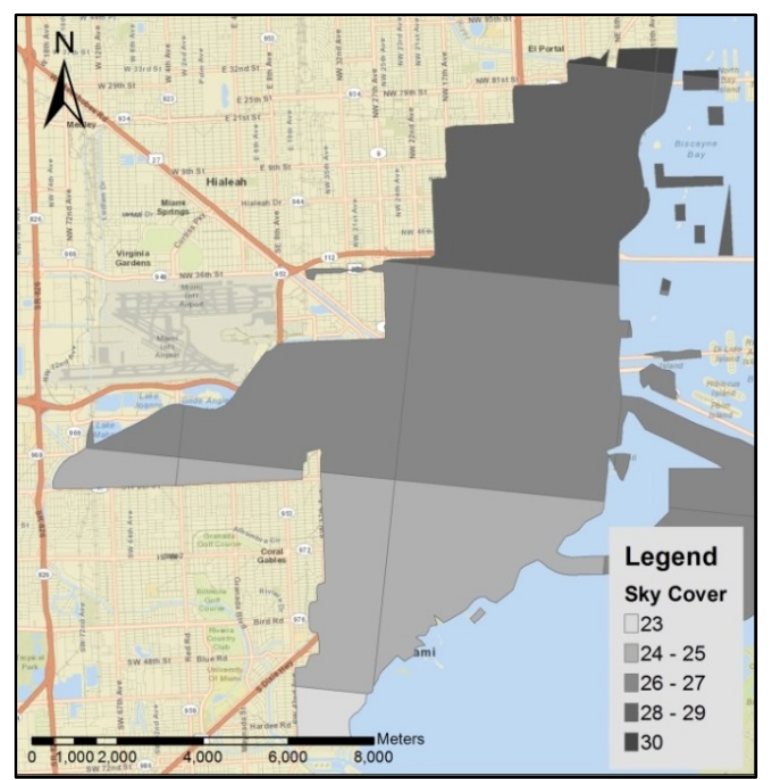

(a) Sky cover

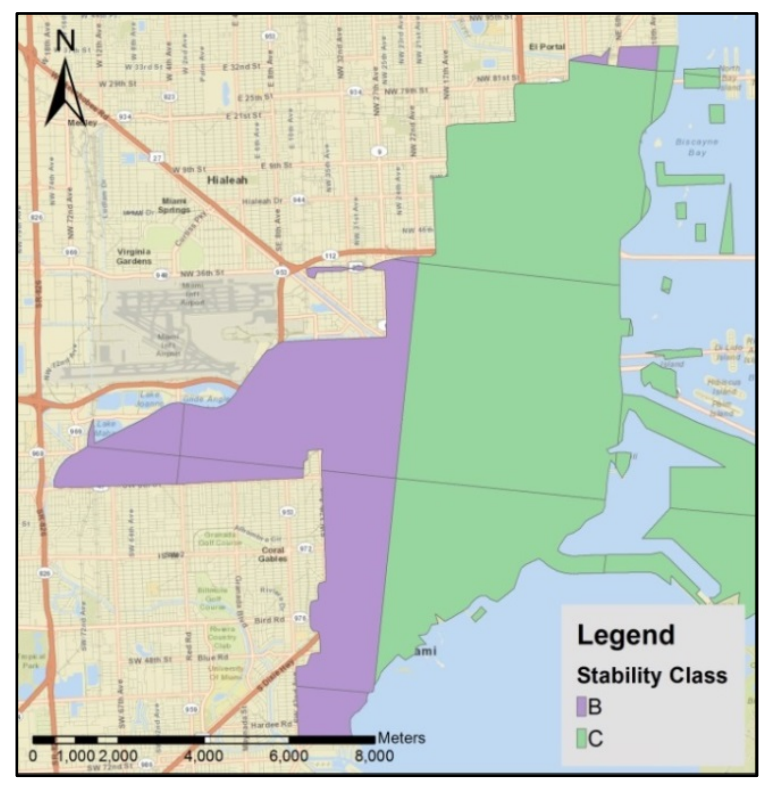

(c) Stability class

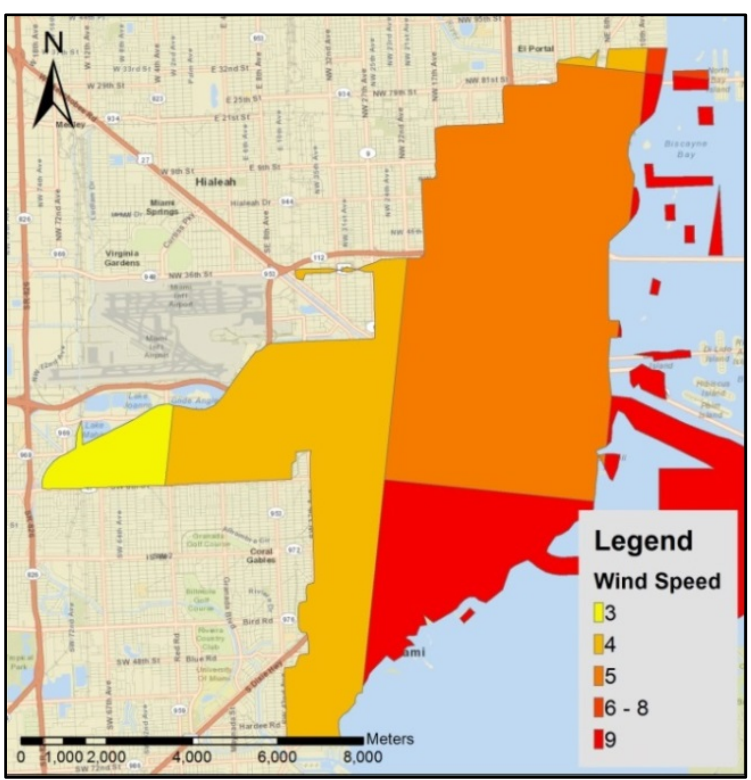

(b) Wind speed

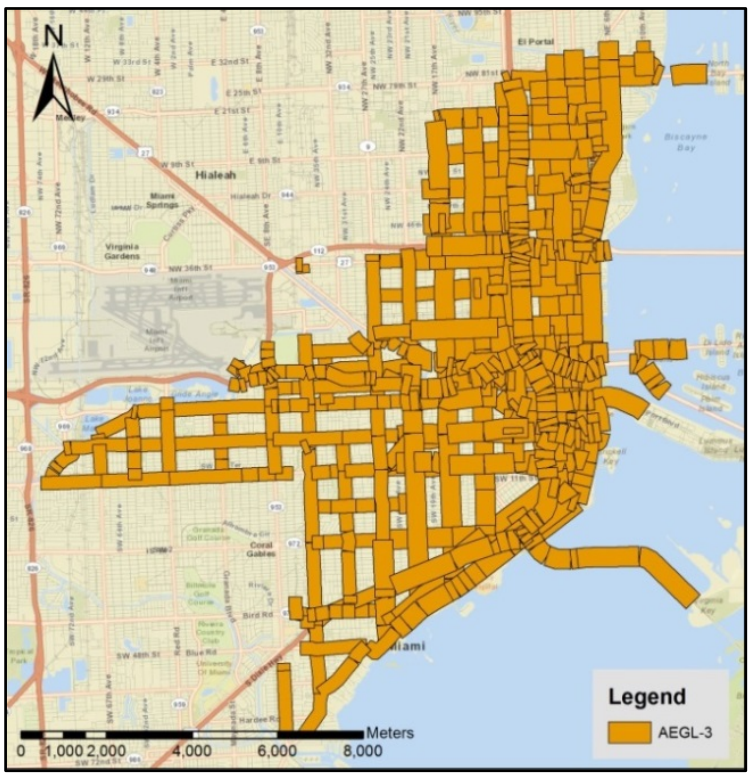

(d) AEGL-3 buffer zones

Figure 5.3 Health risk data and output of inhalation hazard buffer zones. 


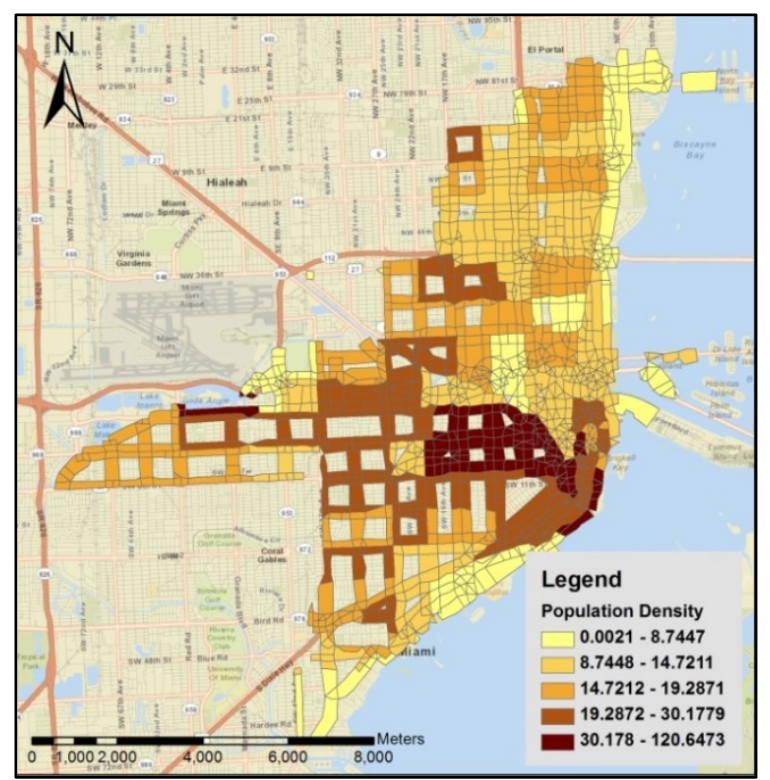

(a) 2010 Population density

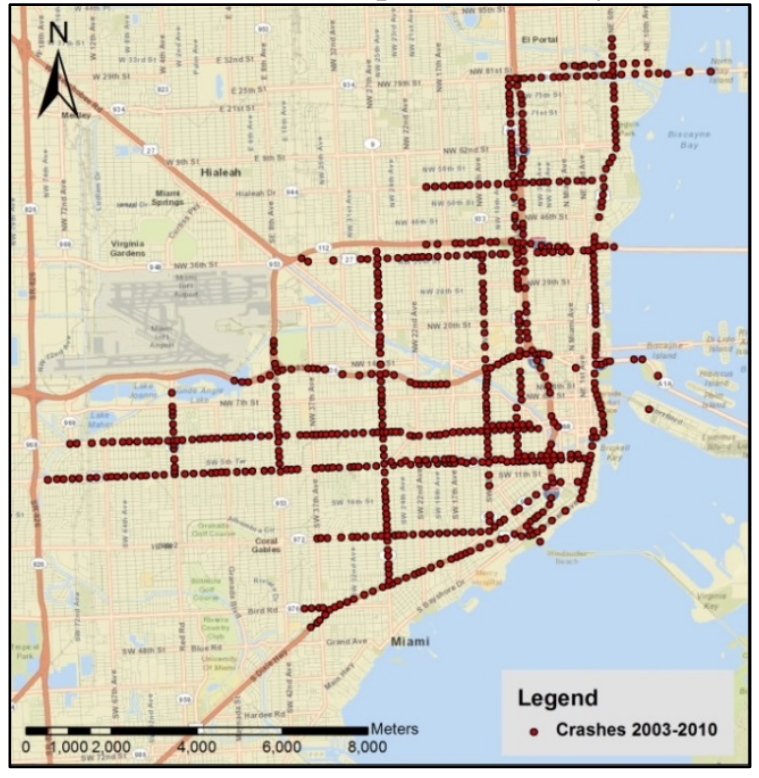

(c) Crashes during 2003-2010

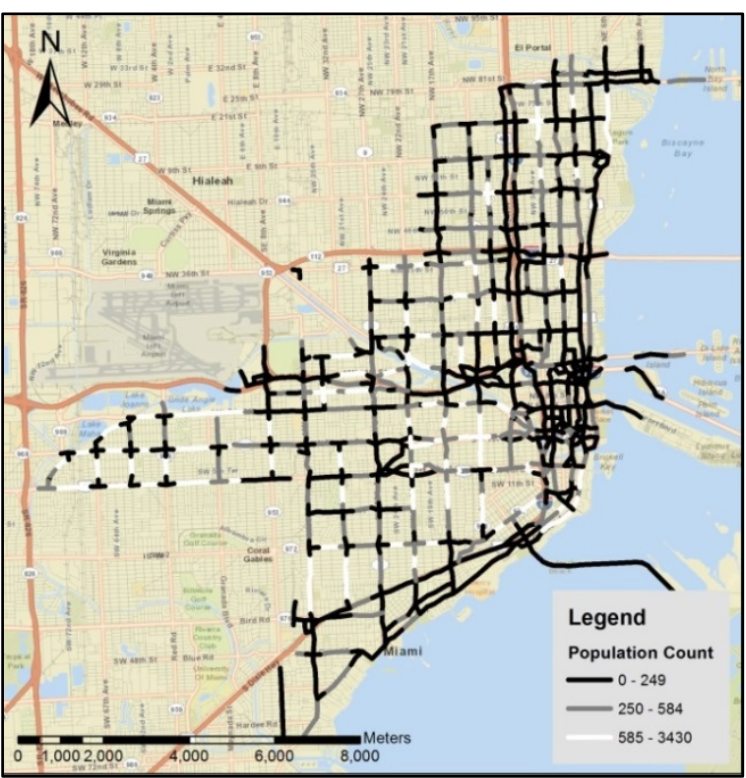

(b) Population at risk

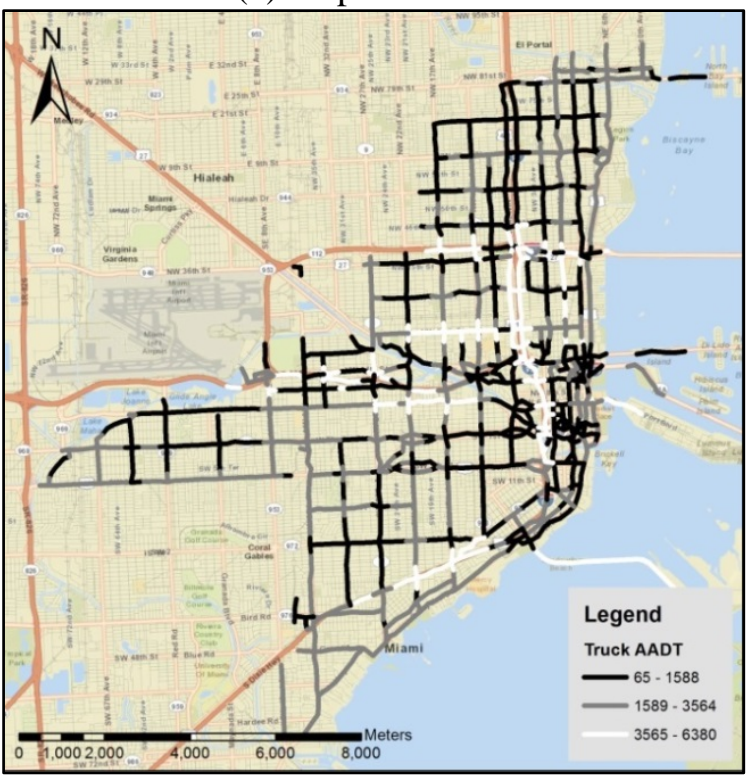

(d) Truck AADT

Figure 5.4 Data and output of health risk. 


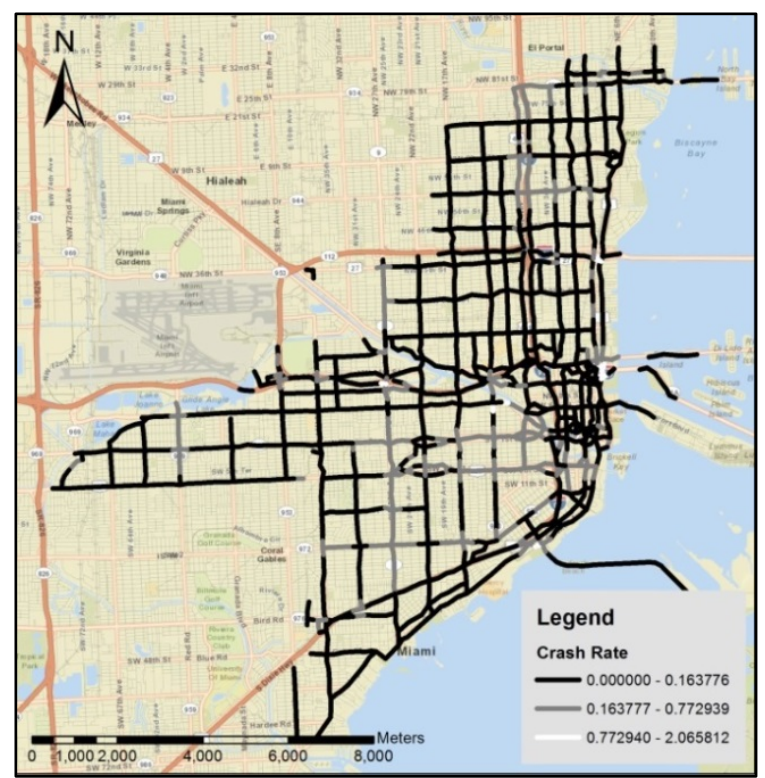

(a) Crash rates of road segments

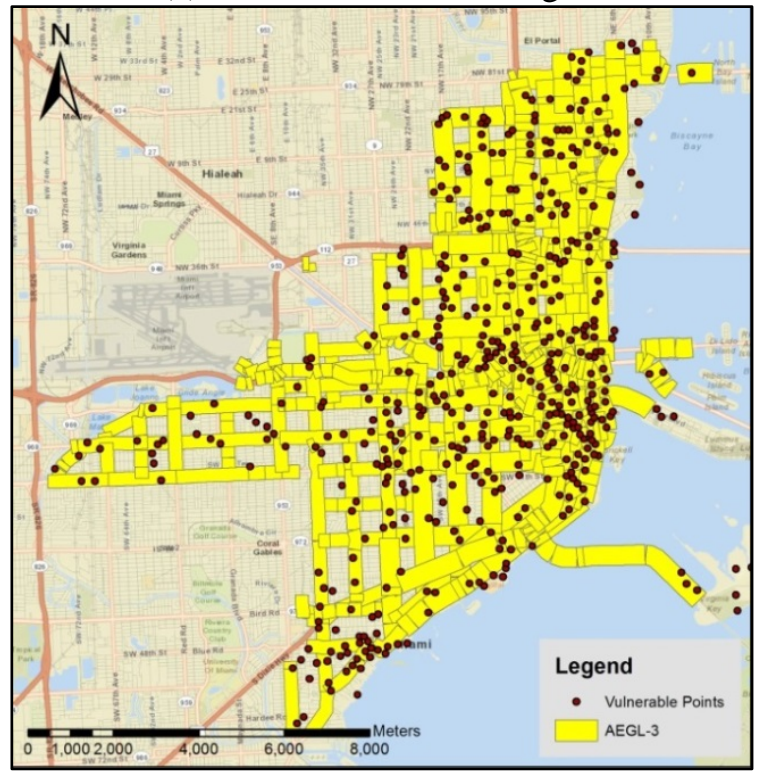

(c) Public places whithin the study area

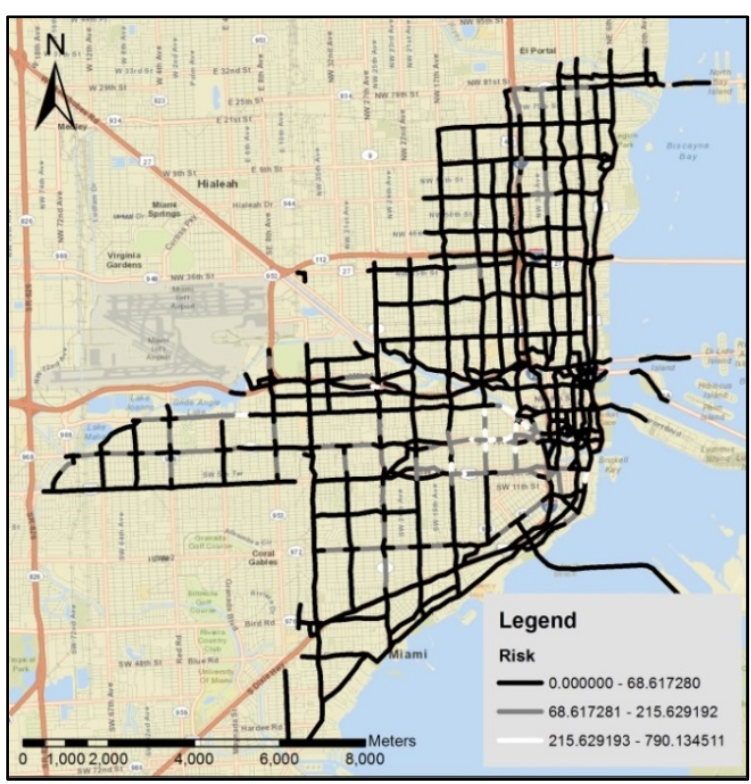

(b) Health risk

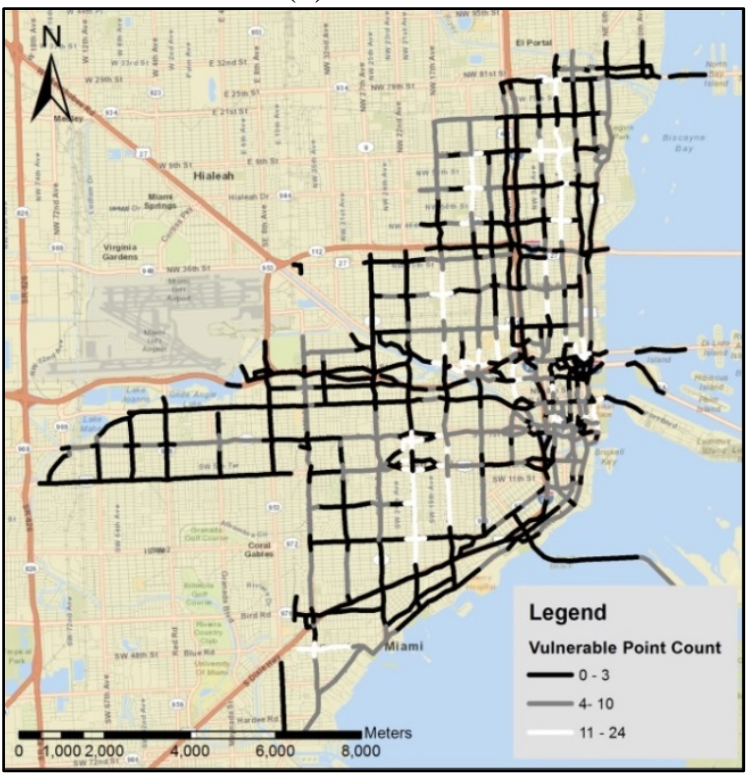

(d) Number of vulnerable points

Figure 5.5 Outputs of health risk and vulnerable areas. 


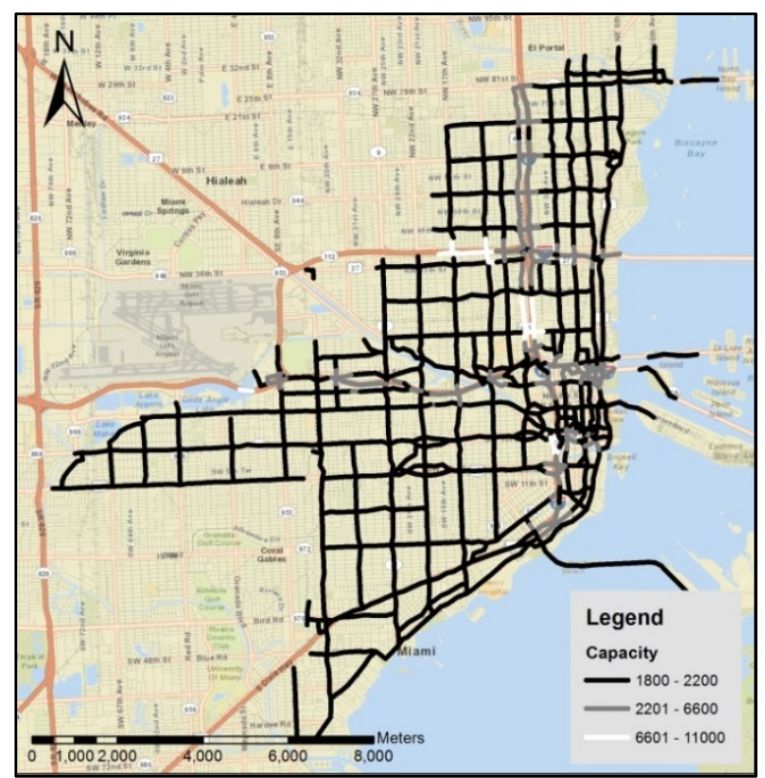

(a) Road capacity

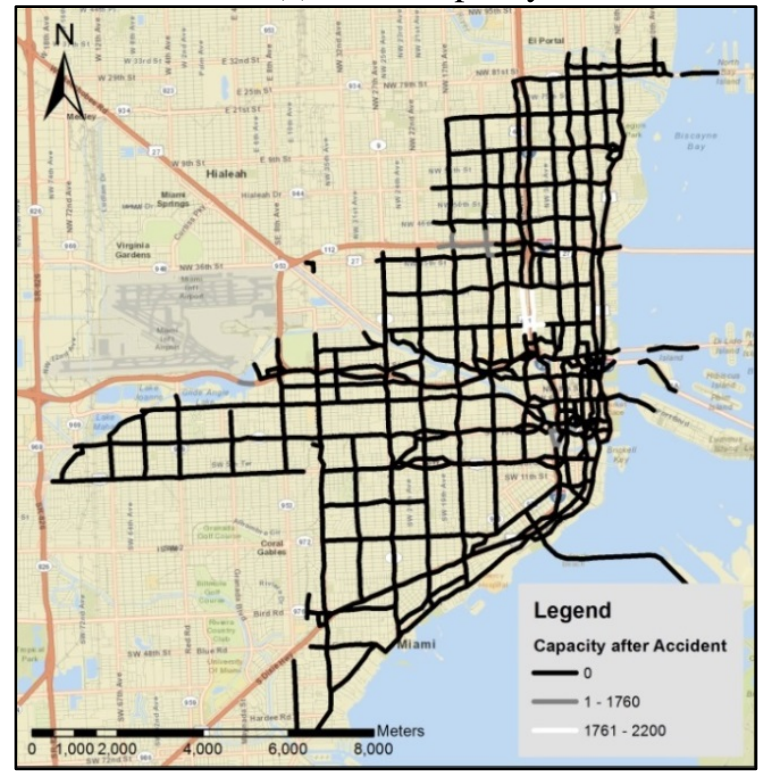

(c) Capacity after accident

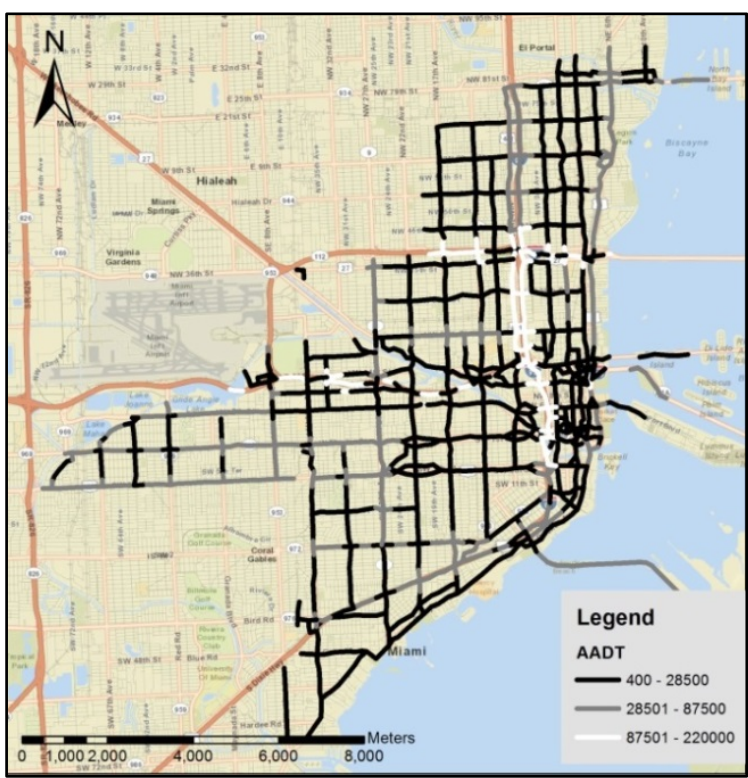

(b) Annual Average Daily Traffic

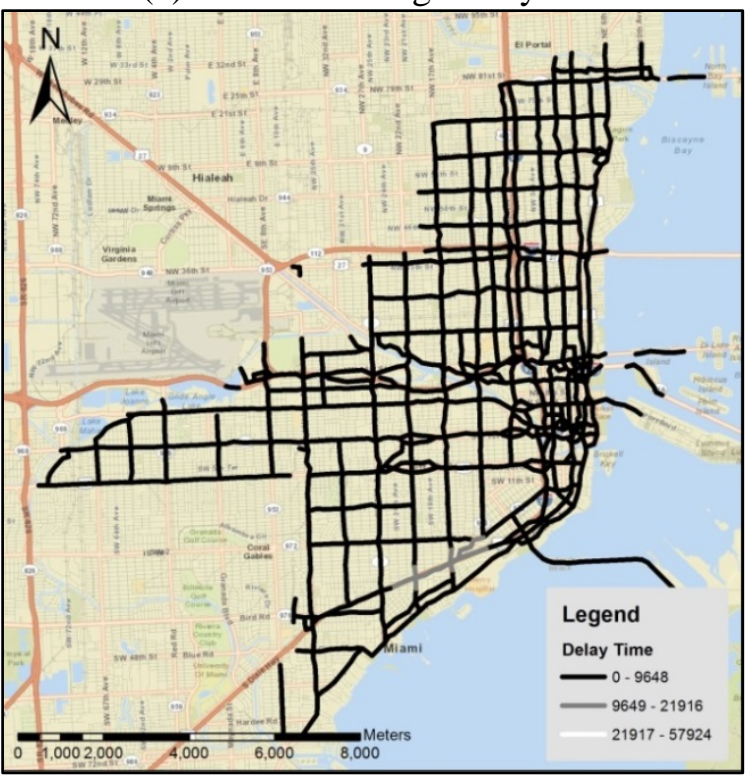

(d) Delay time (hr)

Figure 5.6 Results of the delay calculations. 


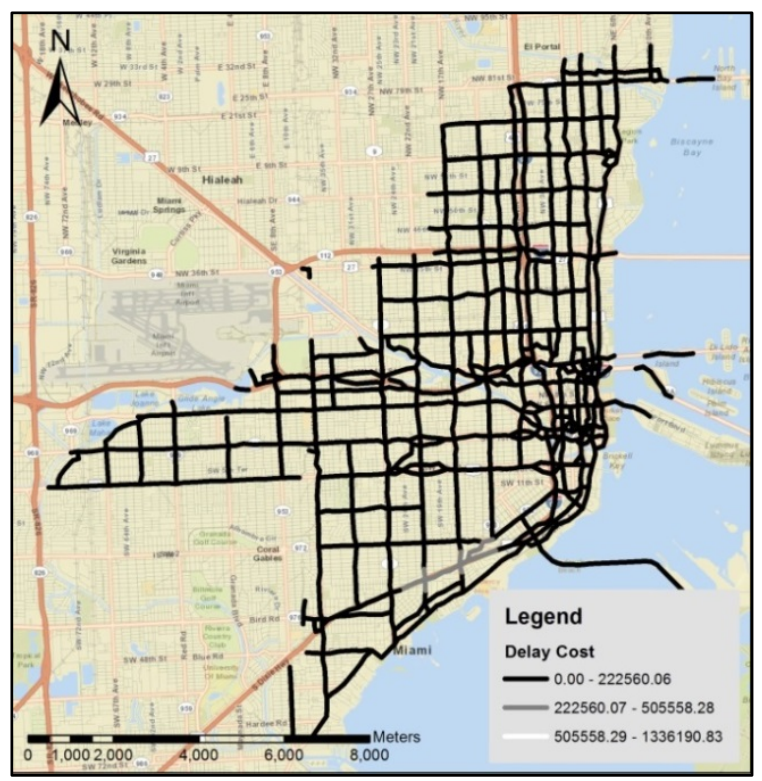

(a) Cost of delay (\$)

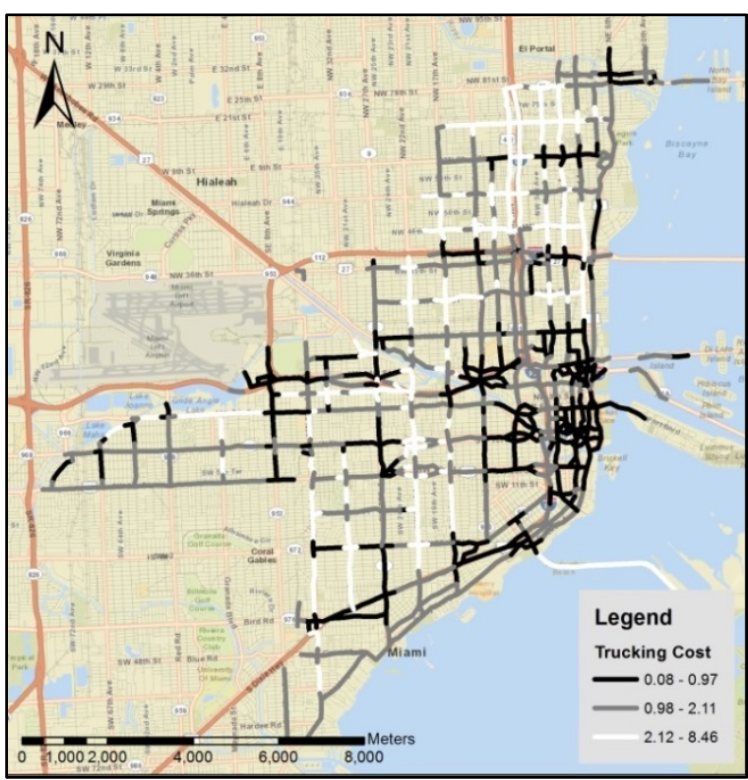

(b) Travel Cost (\$)

Figure 5.7 Results of the delay and travel costs calculations.

The colors representing the values in Figure 5.3 to Figure 5.7 are based on division of the value ranges to three equal intervals. However, a user can chose different thresholds for each criterion to be shown in the maps.

\subsection{Conclusions}

The main purpose of this study was to develop a flexible and user friendly tool, able to fill the gap between environmental health and transportation as well as economy of hazardous material transport. The suggested tool is flexible, as it can model any area of interest, being provided by the required data. User friendly, as the tool is run with entering a few simple parameters by users. The proposed approach of this research considers not only health risks of possible chemical releases, but the delay that the accident may pose on transportation networks as well as people. The economy of hazardous material transport also is considered as the economy and benefits of carriers are a great drive in choosing routes for carrying cargos. Using GIS maps 
provides users a comprehensive view of situations which leads to smarter and faster decision making abilities.

The results of this study provide the decision makers insights into the suitability of the transportation networks from the four aspects that were considered in the tool (i.e. health risk, delay cost, travel expenses, and vulnerable places). The tool proposed by this study is not recommended for long distance routing, as the available data are related to a specific location and also the moment that the program is run. Apparently, by the time, the accuracy of the results would decrease. Some aspects were beyond the scope of this research; however, this paper suggests considering age of the affected population, also whether the time of calculations is during weekdays or weekends, so to consider different schedules. The time of the accidents, as well as, traffic volume in different time of day/night and weekdays/weekends can be taken into account for scheduling the cargos through generating different corresponding network assessments. The results of this study are ready for routing and scheduling of hazardous cargo, as the next step could be optimization of the routes using multi criteria decision making methods between any origins and destinations; or even through suggesting networks for hazardous material transport for cities.

\section{Acknowledgements}

Partial funding for this research has been provided by Southeastern Transportation Research, Innovation, Development and Education Center (STRIDE), University of Florida as well as the Florida International University Graduate School Dissertation Year Fellowship. 


\section{References}

Akgün, V., Parekh, A., Batta, R., Rump, C. M. (2007). Routing of a hazmat truck in the presence of weather systems. Computers \& Operations Research, 34(5), 1351-1373.

Alp, E. (1995). Risk-based transportation planning practice: Overall methodology and a case example. Infor, 33(1), 4.

Battelle (2001). Comparative risks of hazardous materials and non-hazardous materials truck shipment accidents/incidents: final report. Federal Motor Carrier Safety Administration.

Bianco, L., Caramia, M., Giordani, S. (2009). A bilevel flow model for hazmat transportation network design. Transportation Research Part C: Emerging Technologies, 17(2), 175-196.

Bonvicini, S., Spadoni, G. (2008). A hazmat multi-commodity routing model satisfying risk criteria: A case study. Journal of Loss Prevention in the Process Industries, 21(4), 345-358.

Craft, R. (2004). Crashes involving trucks carrying hazardous materials. federal motor carrier safety administration. Washington, DC: US Dept.of Transportation.Publication\#: FMCSARI-04-024.

Dadkar, Y., Jones, D., Nozick, L. (2008). Identifying geographically diverse routes for the transportation of hazardous materials. Transportation Research Part E: Logistics and Transportation Review, 44(3), 333-349.

Das, A., Gupta, A., Mazumder, T. (2012). A comprehensive risk assessment framework for offsite transportation of inflammable hazardous waste. Journal of hazardous materials, 227, 88-96.

EPA, http://www.epa.gov/oppt/aegl/pubs/define.htm, Accessed May 152015.

Fabiano, B., Currò, F., Reverberi, A., Pastorino, R. (2005). Dangerous good transportation by road: From risk analysis to emergency planning. Journal of Loss Prevention in the Process Industries, 18(4), 403-413

FMCSA (Federal Motor Carrier Safety Administration), (2006). Nine Classes of Hazardous Materials.

http://www.fmcsa.dot.gov/facts-research/research-technology/visorcards/yellowcard.pdf

Erkut, E., Gzara, F. (2008). Solving the hazmat transport network design problem. Computers \& Operations Research, 35(7), 2234-2247.

Fender, K. J., Pierce, D. A. (2012). An analysis of the operational costs of trucking: 2011 update. Transportation Research Board 91st Annual Meeting, (12-1090)

Florida Department of Transportation (FDOT), 2011.

http://www.dot.state.fl.us/planning/trends/tc-report/behavior082611.pdf, Accessed March 10, 2014 
Forkenbrock, D. J. (2001). Comparison of external costs of rail and truck freight transportation. Transportation Research Part A: Policy and Practice, 35(4), 321-337.

Frank, W. C., Thill, J., Batta, R. (2000). Spatial decision support system for hazardous material truck routing. Transportation Research Part C: Emerging Technologies, 8(1), 337-359.

Giannikos, I. (1998). A multiobjective programming model for locating treatment sites and routing hazardous wastes. European Journal of Operational Research, 104(2), 333-342.

Guo, X., Verma, M. (2010). Choosing vehicle capacity to minimize risk for transporting flammable materials. Journal of Loss Prevention in the Process Industries, 23(2), 220-225.

Gzara, F. (2013). A cutting plane approach for bilevel hazardous material transport network design. Operations Research Letters, 41(1), 40-46.

Hadi, M., Shen, L., Zhan, C., Xiao, Y., Corbin, S., Chen, D. (2008). Operation data for evaluating benefits and costs of advanced traffic management components. Transportation Research Record: Journal of the Transportation Research Board, 2086(1), 48-55.

Manual, H. C. (2000). Highway capacity manual. Washington, DC.

Manual, H. S. (2000). Highway safety manual. Washington, DC.

Inanloo, B., Tansel, B. (2015). Explosion impacts during transport of hazardous cargo: GIS-based characterization of overpressure impacts and delineation of flammable zones for ammonia. Journal of environmental management, 156, 1-9.

Inanloo, B., Tansel, B., Jin, X. (2015). A framework for hazardous tanker truck routing: Consideration of health risk, transportation, and congestion costs. Transportation Research Board 94th Annual Meeting, (15-0553)

Inanloo, B., Tansel, B., Jin, X., Bernardo Bricker, A. (2014). Cargo-specific air dispersion and impact zone analysis after accidental release of hazardous materials. Transportation Research Board 93rd Annual Meeting, (14-0519)

Jacobs, T. L., Warmerdam, J. M. (1994). Simultaneous routing and siting for hazardous-waste operations. Journal of Urban Planning and Development, 120(3), 115-131.

Kang, Y., Batta, R., Kwon, C. (2014). Generalized route planning model for hazardous material transportation with var and equity considerations. Computers \& Operations Research, 43, 237-247.

Kara, B. Y., Verter, V. (2004). Designing a road network for hazardous materials transportation. Transportation Science, 38(2), 188-196.

Leonelli, P., Bonvicini, S., Spadoni, G. (2000). Hazardous materials transportation: A riskanalysis-based routing methodology. Journal of hazardous materials, 71(1), 283-300.

Lepofsky, M., Abkowitz, M., Cheng, P. (1993). Transportation hazard analysis in integrated GIS environment. Journal of Transportation Engineering, 119(2), 239-254. 
Ludwig, F., Dabberdt, W. F. (1976). Comparison of two practical atmospheric stability classification schemes in an urban application. Journal of Applied Meteorology, 15(11), 1172-1176.

Pradhananga, R., Taniguchi, E., Yamada, T. (2010). Ant colony system based routing and scheduling for hazardous material transportation. Procedia-Social and Behavioral Sciences, 2(3), 6097-6108.

Meeus, J. H. (1991). Astronomical algorithmsWillmann-Bell, Incorporated.

Sadjadi, S. J. (2007). An application of efficient frontier in transportation of hazardous materials. Computers \& Industrial Engineering, 53(2), 357-360.

Schrank, D. L., Lomax, T. J. (2007). The 2007 urban mobility reportTexas Transportation Institute, Texas A \& M University.

Slade, D. H. (1968). METEOROLOGY AND ATOMIC ENERGY, 1968.

Toumazis, I., Kwon, C. (2013). Routing hazardous materials on time-dependent networks using conditional value-at-risk. Transportation Research Part C: Emerging Technologies, 37, 73-92.

U.S. Census Bureau (2015). 2012 Commodity Flow Survey. Technical Report. U.S. Department of Transportation and U.S. Department of Commerce.

http://www.census.gov/econ/cfs/2012/ec12tcf-us-hm.pdf. Accessed May 25, 2015.

Zhang, J., Hodgson, J., Erkut, E. (2000). Using GIS to assess the risks of hazardous materials transport in networks. European Journal of Operational Research, 121(2), 316-329.

Zografos, K. G., Androutsopoulos, K. N. (2008). A decision support system for integrated hazardous materials routing and emergency response decisions. Transportation Research Part C: Emerging Technologies, 16(6), 684-703.

Zografos, K. G., Davis, C. F. (1989). Multi-objective programming approach for routing hazardous materials. Journal of Transportation Engineering, 115(6), 661-673.

Zografos, K., Androutsopoulos, K. N. (2005). A decision support system for hazardous materials transportation and emergency response management. 84th Annual Meeting of the Transportation Research Board, Washington, DC. 


\section{Reduction of Exposure Risks to Accidental Releases by Cargo Specific Buffer Zones during Transport: Chlorine and Gasoline}

\subsection{Introduction}

Accidental releases of hazardous materials occur not only during transport, but also at fixed locations during loading and unloading the chemicals. In the event of an accident, if volatile hazardous materials are released, they are dispersed in air and transported by wind, impacting the air quality of the surrounding areas. In the United States, over 1 million shipments of hazardous materials carried by trucks take place on a daily basis (PHMSA, 2010)). Although the number of hazardous material spills in crashes which involve trucks is relatively small, the probability of a release occurring at the time of accident is $50 \%$ higher than that for non-hazmat cargos (Craft, 2004).

Hazardous material shipments carried by trucks in the US add up to approximately 1.5 million tons annually; representing about 59.4\% of the total commodity shipments in 2012 (U.S. Census Bureau, 2015). Historical shipment records show an increase of $27.3 \%$ from 2007 to 2012, steadily increasing about 5\% annually in hazardous materials volume.

Over the last three decades, many nations have been involved with research for developing operational strategies to improve transport and disposal of hazardous materials and reduce accidental release risks (Rakas et al., 2004). There are several studies focusing on risk assessment of hazardous material accidents during transport; such as a study by Saccomanno and Shortreed (1993), where they estimated the dangerous areas around the accidental releases of chorine using an air dispersion model called EPI (Emergency Prediction Information). Another study by Margai (2001), used ALOHA (Areal Locations of Hazardous Atmospheres) to identify the threat zone around accidents for chlorine. Inanloo et al., (2014) also used ALOHA to track the hazard zones for ammonia and hydrogen fluoride to calculate health risks due to exposure. Zhang 
et al., (2000) estimated the risk associated with hazardous material accidents using Gaussian plume model and ArcGIS. Other similar studies (Wu et al., 2004; Fabiano et al., 2005; Jiang et al., 2006; Liu et al., 2012) also focused on risk quantification due to accidental hazardous material spills.

The goal of this research is to estimate the size of the areas impacted after accidental releases of hazardous materials by coupling the air dispersion model with ArcGIS programming, to find suitable routes for transporting hazardous material. Chlorine as one of the most dangerous, and gasoline as the most commonly carried hazardous material (Branscomb et al., 2010, and Economic Census, 2007) were selected as the two hazardous materials evaluated. The impact zones for two hazardous chemicals (chlorine and gasoline) were compared in relation to atmospheric stability conditions during day and night, to quantify and compare the consequences after the accidental spills as well as corresponding exposure health risks for accidental releases along the routes. This study is more comprehensive in comparison to other studies which focus on risk assessment. In the analyses the entire transportation network was evaluated in regards to exposure health risks from accidental releases, depending on the chemical characteristics and shipment time (day or night); to further suggest route options with lower exposure risks.

\subsection{Methodology}

Figure 6.1 presents the overall methodology used in developing the route assessment tool. The impact zones after accidental releases were estimated using the Gaussian dispersion equation and employing Python programming language. The outputs were visualized using ArcGIS for aerial mapping and risk calculations and ultimately routing. The routing options which were determined based on the health risks of the two hazardous materials (chlorine and gasoline), were compared with the shortest routing option if the selection criterion was only trucking costs. 
The road segments for each route were evaluated (quantitatively) and the route options were compared based on the suitability of the road segments within the transportation network. The two criteria considered in development of the network assessments and routing tool were (PHMSA, 2010) health risks due to exposure after accidental releases, and (Craft, 2004) trucking expenses.

The approach used in this study is an interactive and flexible tool, written in Python programming language, capable of analysis on the transportation network of any given area of interest, defined by the user for assessing the suitability of the routes for transporting hazardous materials. Evaluations, calculations and analyses are conducted by one time execution of the program and the outputs are obtained in the form of maps and tables.

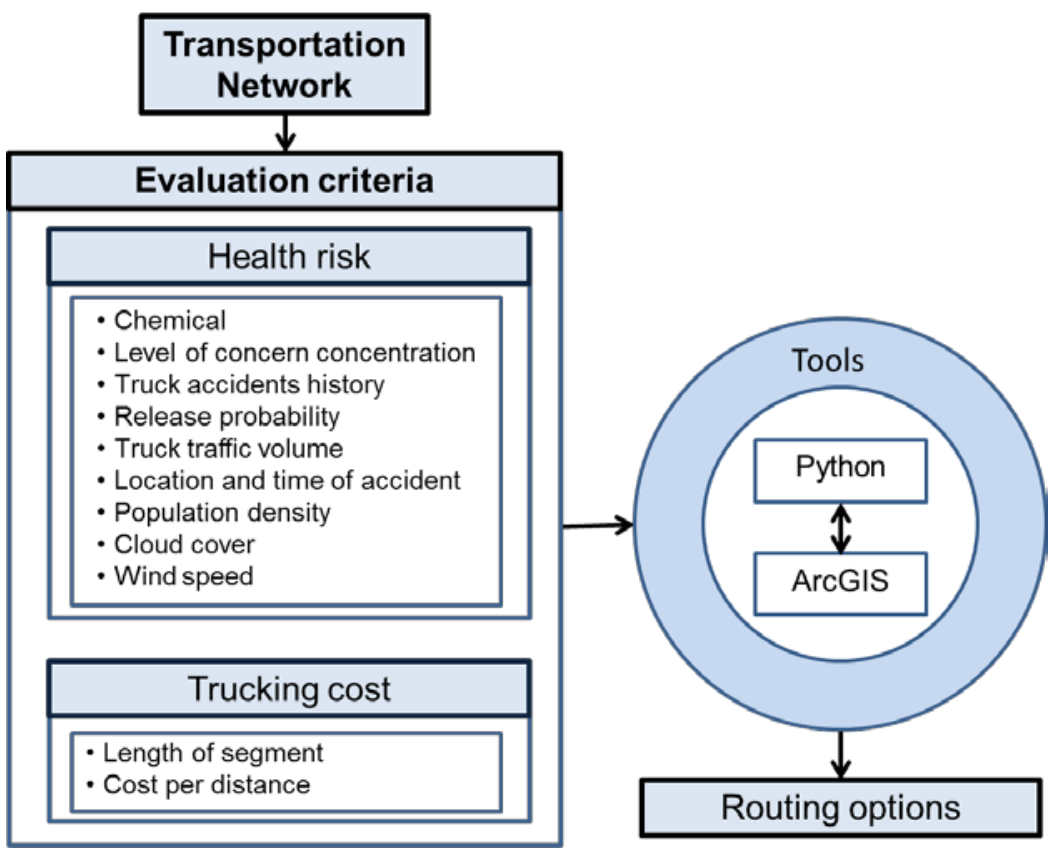

Figure 6.1 Methodology of the hazardous cargo transportation network assessment tool. 


\subsubsection{Exposure health risk criteria and quantification}

The health threats in risk assessment are usually considered in terms of acute toxicity, flammability, thermal radiation, blast wave, and missile damage (Alp, 1995, and Inanloo and Tansel, 2015). In this study, risk was defined as a measure of the probability and severity of threats to a receptor due to acute exposure to hazardous material in air (fumes). Acute Exposure Guideline Levels (AEGLs) were developed for the human health risks caused by one time exposure. In order to quantify the health risks by inhalation of spilled chemicals, AEGL-3, representing “the airborne concentration (expressed as $\mathrm{ppm}$ or $\mathrm{mg} / \mathrm{m}^{3}$ ) of a substance above which it is predicted that the general population, including susceptible individuals, could experience life-threatening health effects or death," was taken into consideration as the threshold concentration for defining the health impact radius (EPA, 2015).

Using the impact radius calculated for the concentration thresholds of the chemicals, the buffer zones around the road segments were defined to estimate the number of people who will be exposed (within the threat zone) as the consequence of the accident. The health risks due to the inhalation of hazardous chemicals after an accidental release was calculated by Equation 1.

Risk $=$ Frequency $\times$ Consequences

\subsubsection{Accident Frequencies}

Accident frequency can be estimated from the number of similar events occurring per year and the consequences can be expressed from different perspectives (i.e., impacted population, number of fatalities, size of the impacted area, environmental impacts) (Inanloo et al., 2015). Crash rate representing the accident frequency, as defined in the Highway Safety Manual (HSM 2000), is the normalized value of the crash frequency with exposure (the degree to which a 
road user is exposed to traffic risks). Exposure in 100 million vehicle miles traveled is calculated by the Equation 2, and crash rate is acquired by the Equation 3 (HCM, 2000).

EXPO $=\frac{\text { AADT } \times 365 \times \text { number of years } \times \text { total segment length }}{100,000,000}$

Crash rate $=\frac{\text { Total crash count }}{\text { EXPO }}$

where, EXPO is the exposure to accidents and AADT is the annual average daily traffic. The AADT for trucks was considered to represent the frequency of truck accidents. The total crash count was estimated by identifying the accidents involving trucks within a search radius around each segment of the transportation network. The probability of the chemical releases in accidents involving trucks was based on the available historical data for the hazardous materials accidents, as the percentage of the accidents which led to chemical releases to the number of total hazardous material accidents. According to PHMSA, around 27.3\% of the hazardous material accidents result in chemical releases (Battelle, 2001).

\subsubsection{Consequence analysis}

Different types of air dispersion models have been developed to estimate contaminant concentrations over time or affected area (Griffin, 2006). Gaussian-type algorithms are most commonly used to predict the dispersion of pollutants emitted from point sources. These models assume that dispersion of the pollutant in the atmosphere follows a normal probability distribution pattern. Gaussian models generally consider an average wind speed and constant wind direction, and estimate the ground level pollutant levels in the wind direction. 
In order to identify and quantify the health impact buffer zones around the road segments, AEGL-3 concentration for one hour exposure of the released chemical was taken into account. The tool developed by this study is provided with a dictionary of AEGLs for the two hazardous materials, with the capability of selection between the substances, as the thresholds differ for each chemical. Therefore, the impact radii also vary depending on the level of concern concentration for each chemical (Inanloo et al., 2014). Based on the concentration threshold (AEGL-3), the farthest distance that this certain concentration would be perceived was estimated using Equation 4:

$C(x, y, z, t)$

$$
\begin{aligned}
& =\frac{Q}{(2 \times \pi)^{3 / 2} \sigma_{x} \sigma_{y} \sigma_{z}} \exp \left[-1 / 2\left(\frac{x-u t}{\sigma_{x}}\right)^{2}\right] \exp \left[-1 / 2\left(\frac{y}{\sigma_{y}}\right)^{2}\right]\left\{\exp \left[-1 / 2\left(\frac{z+h}{\sigma_{z}}\right)^{2}\right]\right. \\
& \left.+\exp \left[-1 / 2\left(\frac{z-h}{\sigma_{z}}\right)^{2}\right]\right\}
\end{aligned}
$$

where, $\mathrm{x}, \mathrm{y}$ and $\mathrm{z}$ are the distance downwind and crosswind and vertical directions, respectively. $\mathrm{C}(\mathrm{x}, \mathrm{y}, \mathrm{z})$ is the concentration of the substance at location defined by $\mathrm{x}, \mathrm{y}, \mathrm{z}$ coordinates from the spill at time $t$ after the release; $\mathrm{Q}$ is the release quantity; $\sigma_{\mathrm{x}}, \sigma_{\mathrm{y}}$, and $\sigma_{\mathrm{z}}$ are the standard deviations of concentration distributions in $\mathrm{x}, \mathrm{y}, \mathrm{z}$ directions $\left(\sigma_{\mathrm{x}}\right.$ and $\sigma_{\mathrm{y}}$ are considered equal); $\mathrm{u}$ is the wind speed; and $\mathrm{h}$ is the effective stack height. The downwind concentrations were without any deviations from the centerline of the wind, and at the ground level. 
Table 6.1 Equations used for $\sigma_{\mathrm{x}}, \sigma_{\mathrm{y}}$, and $\sigma_{\mathrm{z}}$ calculations (slade, 1968).

\begin{tabular}{ccc}
\hline Stability class & $\begin{array}{c}\sigma_{x} \text { and } \sigma_{y} \\
(\mathbf{m})\end{array}$ & $\begin{array}{c}\boldsymbol{\sigma}_{\mathbf{z}} \\
(\mathbf{m})\end{array}$ \\
\hline Open country conditions & & \\
A & $0.22 \times(1+0.0001 \mathrm{x})^{-1 / 2}$ & $0.20 \mathrm{x}$ \\
B & $0.16 \mathrm{x}(1+0.0001 \mathrm{x})^{-1 / 2}$ & $0.12 \mathrm{x}$ \\
C & $0.11 \mathrm{x}(1+0.0001 \mathrm{x})^{-1 / 2}$ & $0.08 \mathrm{x}(1+0.0002 \mathrm{x})^{-1 / 2}$ \\
D & $0.08 \mathrm{x}(1+0.0001 \mathrm{x})^{-1 / 2}$ & $0.06 \mathrm{x}(1+0.0015 \mathrm{x})^{-1 / 2}$ \\
E & $0.06 \mathrm{x}(1+0.0001 \mathrm{x})^{-1 / 2}$ & $0.03 \mathrm{x}(1+0.0003 \mathrm{x})^{-1}$ \\
F & $0.04 \mathrm{x}(1+0.0001 \mathrm{x})^{-1 / 2}$ & $0.016 \mathrm{x}(1+0.0003 \mathrm{x})^{-1}$ \\
Urban conditions & & $0.24 \mathrm{x}(1+0.001 \mathrm{x})^{1 / 2}$ \\
A-B & $0.32 \mathrm{x}(1+0.0004 \mathrm{x})^{-1 / 2}$ & $0.20 \mathrm{x}$ \\
C & $0.22 \mathrm{x}(1+0.0004 \mathrm{x})^{-1 / 2}$ & $0.14 \mathrm{x}(1+0.0003 \mathrm{x})^{-1 / 2}$ \\
D & $0.16 \mathrm{x}(1+0.0004 \mathrm{x})^{-1 / 2}$ & $0.08 \mathrm{x}(1+0.00015 \mathrm{x})^{-1 / 2}$ \\
E-F & $0.11 \mathrm{x}(1+0.0004 \mathrm{x})^{-1 / 2}$ & \\
\hline
\end{tabular}

The standard deviations vary depending on the atmospheric condition and the distance downwind. Table 6.1 provides the coefficients used to calculate the standard deviations. However, the atmosphere stability conditions need to be identified prior this step.

Stability of atmosphere corresponds to the ability of the air in creating vertical movements. These motions generate the ability of dilution of chemical in the air. The more and faster the air movements, the quicker the dilution of the substance in the atmosphere, and accordingly, the lesser the health impacts (as the chemical would not stay in the atmosphere long enough to cause irritation or health impacts). Table 6.2 presents the atmospheric conditions corresponding to different stability classes in relation to wind speed, solar radiation, and/or cloud cover. 
Table 6.2 Urban stability categories (ludwing and dabberdt, 1976).

\begin{tabular}{|c|c|c|c|c|c|c|}
\hline \multirow{2}{*}{$\begin{array}{l}\text { Surface } \\
\text { wind } \\
\text { velocity } \\
\left(\mathrm{m} \mathrm{s}^{-1}\right)\end{array}$} & \multicolumn{3}{|c|}{$\begin{array}{c}\text { Daytime } \\
\text { Solar elevation angle }>15^{\circ} \\
\end{array}$} & \multirow{2}{*}{$\begin{array}{l}\text { Opaque cloud } \\
\text { cover } \\
\geq 9 / 10 \text { day or } \\
\text { night or } \\
\text { solar elevation } \\
\text { angle } \leq 15^{\circ}\end{array}$} & \multicolumn{2}{|c|}{$\begin{array}{c}\text { Night time cloud } \\
\text { cover }\end{array}$} \\
\hline & $\begin{array}{l}\text { Strong } \\
\text { insolation }\end{array}$ & $\begin{array}{l}\text { Moderate } \\
\text { insolation }\end{array}$ & $\begin{array}{c}\text { Slight } \\
\text { insolation }\end{array}$ & & $\geq 5 / 10$ & $\leq 4 / 10$ \\
\hline$<2$ & A & B & B & $\mathrm{D}$ & $E$ & $E$ \\
\hline $2-3$ & A & B & $\mathrm{C}$ & D & $\mathrm{D}$ & E \\
\hline $3-5$ & B & C & $\mathrm{C}$ & $\mathrm{D}$ & $\mathrm{D}$ & $\mathrm{D}$ \\
\hline $5-6$ & $\mathrm{C}$ & C & $\mathrm{D}$ & D & $\mathrm{D}$ & $\mathrm{D}$ \\
\hline$>6$ & $\mathrm{C}$ & D & $\mathrm{D}$ & D & $\mathrm{D}$ & $\mathrm{D}$ \\
\hline
\end{tabular}

In this study, in order to identify the atmospheric stability classes for the case study area, data maps of cloud cover and wind speed were obtained. Wind speed data were used to define the related row in Table 6.2 to further define the stability classes based on the solar radiation or/and the cloud cover. The cloud cover data was used to identify the sky cover proportion on a scale from 1 to 10 (1 clear skies and 10 complete cloud cover) to define the atmospheric stability classes during nighttime or for the cases with solar radiation angles of less than 15 degrees.

The solar radiation (solar elevation angle) was defined based on the equations from Astronomical Algorithms book by Meeus (1991). Based on the formulations, the coordinate of the study area, as well as, the time of day/night and the date at the time and location of the accident are taken into account to calculate the solar elevation angle (to be used in Table 6.2). Based on the location and time of the accident the solar angle varies (i.e., as in Egypt vs. Canada; or as in early morning vs. noon or evening). The methodology and tool developed by this research is capable of identification of the time and date at the moment of running the tool over the study area, which leads to a location and time based recognition of solar radiation levels.

By taking into account the time of evaluations, the tool recognizes whether the transport/accident happens during daytime or nighttime, so that, it can select which conditions (columns of Table 6.2) are applicable to the case. Having calculated and identified the parameters 
(wind speed, solar elevation angel and cloud cover), the atmospheric stability class is identified; and the standard deviations are calculated based on Table 6.1. In this study, open county conditions were taken into account for the worst case scenarios for estimating the impact radius, as urban areas may prevent vapor clouds from propagation due to urban obstructions. Based on the stability classes of atmosphere, the tool automatically selects the corresponding equations for the standard deviation calculations. The wind direction and speed were considered as constant during the calculations, assuming no changes in the parameters over time. However, in reality these parameters change during the day and night.

Based on the assumptions of Gaussian dispersion equation, particles disperse by wind and toward downwind direction, and there are no chemical transmitted upwind. Although, the distance calculated by the model used in this study is for the release location to downwind direction with no deviations towards other directions (vertical or horizontal), in order to take into account the changes in the wind direction, the predicted health impact radius was used as a buffer distance around the spill location, disregards of the orientation of wind.

\subsubsection{Estimation of Transportation Costs}

The freight transportation costs are important from an economical perspective. Society and transport companies try to minimize the total cost of conveyance not only to help businesses to be competitive but also to make sure that the goods are moved and delivered efficiently (Forkenbrock, 2001). According to a study by the American Transport Research Institute (ATRI) in 2011, the average total carrier cost in 2011 was $\$ 1.706$ per mile. This value was used in this study. The transportation costs were estimated by multiplying the average total carrier cost with the travel distance for each route (Fender and Pierce, 2012). The trucking cost of each road segment was calculated by multiplying the cost per unit length with the length of the target link. 


\subsection{Case Study}

The tool was demonstrated for a case study area. The City of Miami in Florida, USA, was selected to evaluate the routing options for a realistic scenario. The data required were collected and compiled in the formats of maps and tables from different sources. However, finding data on truck shipments and their schedules is very challenging due to the security measures and/or lack of records.

The shipment was assumed as a full tanker truck with a capacity of 9,000 gallons of E-10 blend of gasoline or chlorine. It was assumed that the entire contents of the tanker would be released to the atmosphere after an en-route accident. In reality, the accidental releases typically have partial cargo releases and not the entire shipment. However, in order to have taken into consideration the worst case scenario, in this study it was assumed that the entire cargo would be released after the accident.

Gasoline consists of different petroleum hydrocarbons, with different proportions. In this study, toluene was used as the key compound for gasoline for health risk evaluations. The quantity of toluene was calculated based on its proportion in gasoline. For chlorine, the maximum amount of chlorine that fits the tanker was assumed to be released. Therefore, in the calculations, the predefined levels of concern (concentration) of the two substances were used for identifying the impact radius. Figure 6.2 presents the location of the study area as well as the boundary of the area of interest. 


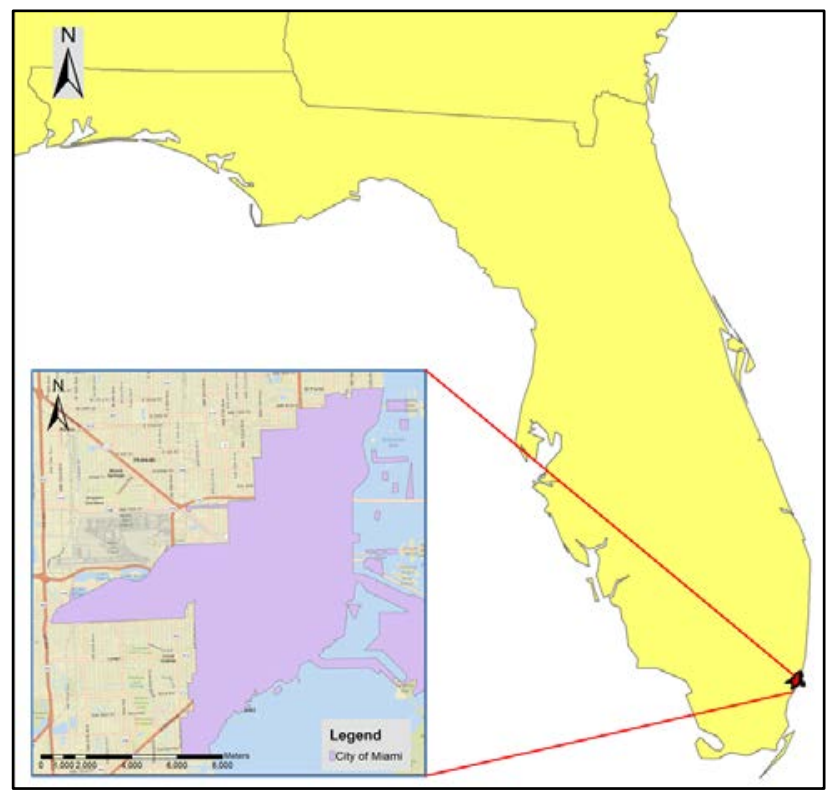

Figure 6.2 Location of the case study area.

\subsection{Results}

The health risks due to inhalation after accidental releases, as well as the trucking costs for hazardous materials were estimated for the entire transportation network by segmentation. The outputs include maps (for visualization) as well as tables of the calculated and evaluated properties. Calculations were performed by Python scripting and visualized using ArcGIS. After defining the atmospheric stability classes around the road segments (for day or night conditions), the buffer distances for transportation branches were delineated around each segment, considering the chemical properties (chlorine or gasoline). The buffer distances are different depending on the atmospheric stability, as it plays a significant role in the dilution of chemicals in the air. A chemical which enters a more stable atmosphere tends to stay in air longer than unstable conditions; therefore, the health impact radius is bigger under stable atmosphere. The buffer radii 
also are function of released chemicals, for the concentration thresholds vary for chemicals, so does the distance that the substance would be a health threat.

The program was run four times; for chlorine and gasoline shipments; during day and night conditions for each chemical. Therefore, the risk networks were different for the runs, as the crash rates were different due to the number of crashes during the two time periods. Also, the networks were different for the two chemicals, as the impact buffer zones varied depending on the substance being transported. On the other hand, the travel cost networks was identical for the runs, as the tool did not differentiate between the costs of travel for any time of the day and night, or any types of chemicals (although the cost may vary in reality). Traffic volumes also were assumed the same for the two days. Therefore, there are four result networks for risk, but, there is one assessed network for travel cost.

Based on the health risk zones around segments, populations at risk were estimated using population density map. In this study, the population was estimated based on the population density of 2010. After estimating the population at risk for each segment, using the 8-year crash history in the area (2003-2010), truck traffic volume, and crash rates; risks were calculated for each road segment. The risk calculated in this study was the multiplication of number of people to truck involved crash rates (crashes per 100 million vehicles), to the probability of the en-route accident which lead to chemical release (percentage of total truck crashes). 


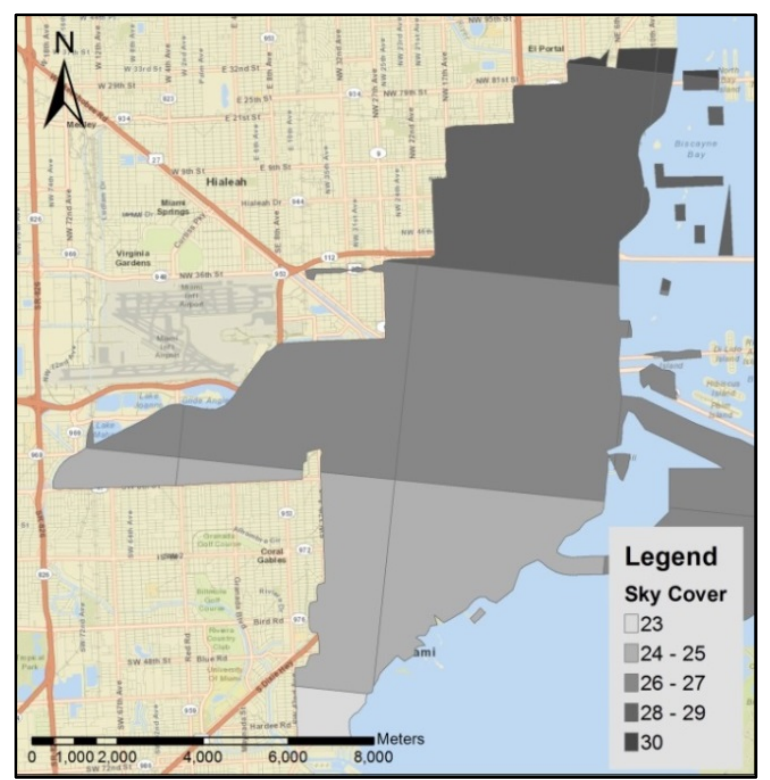

(a) Sky cover

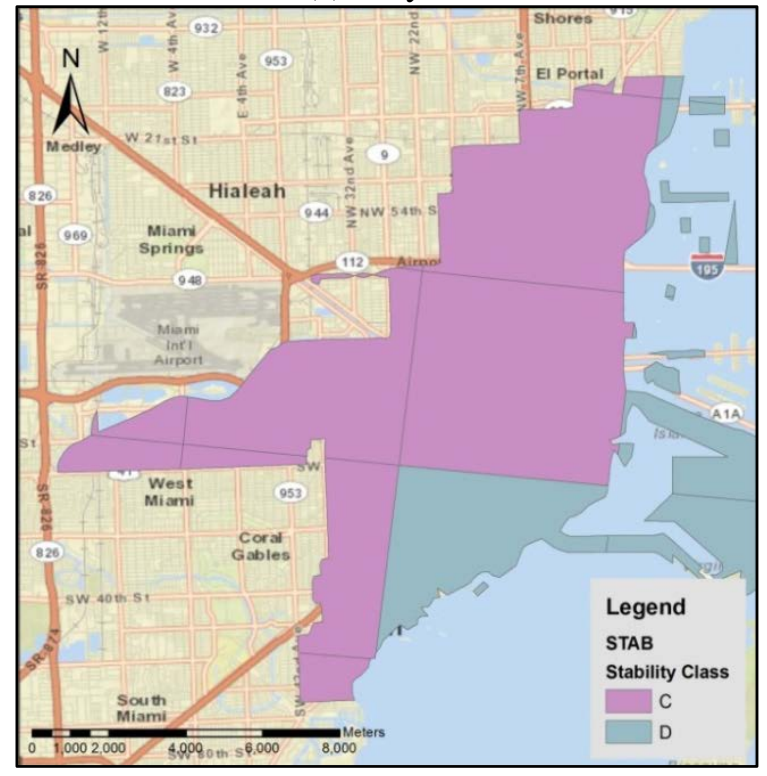

(c) Stability class during day

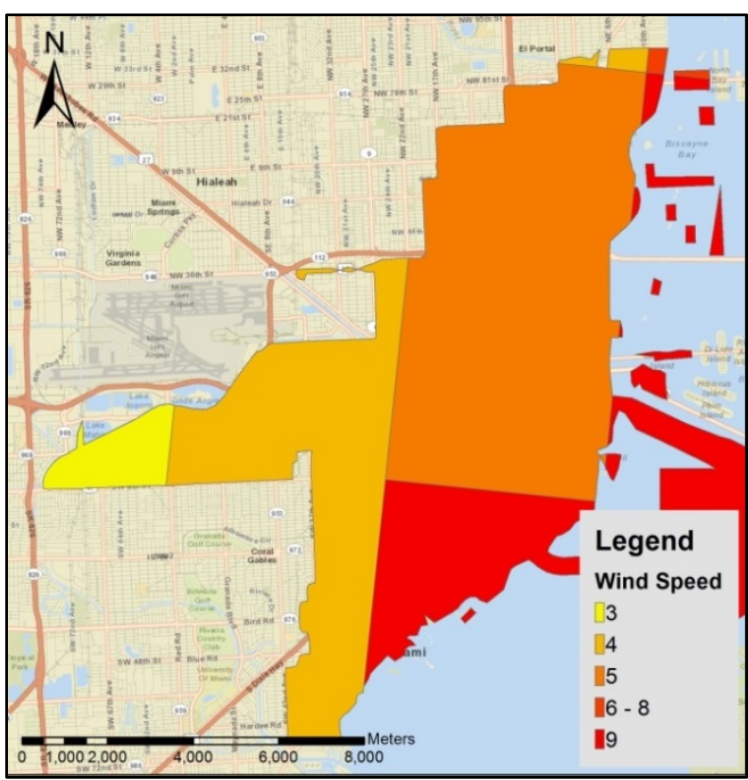

(b) Wind speed

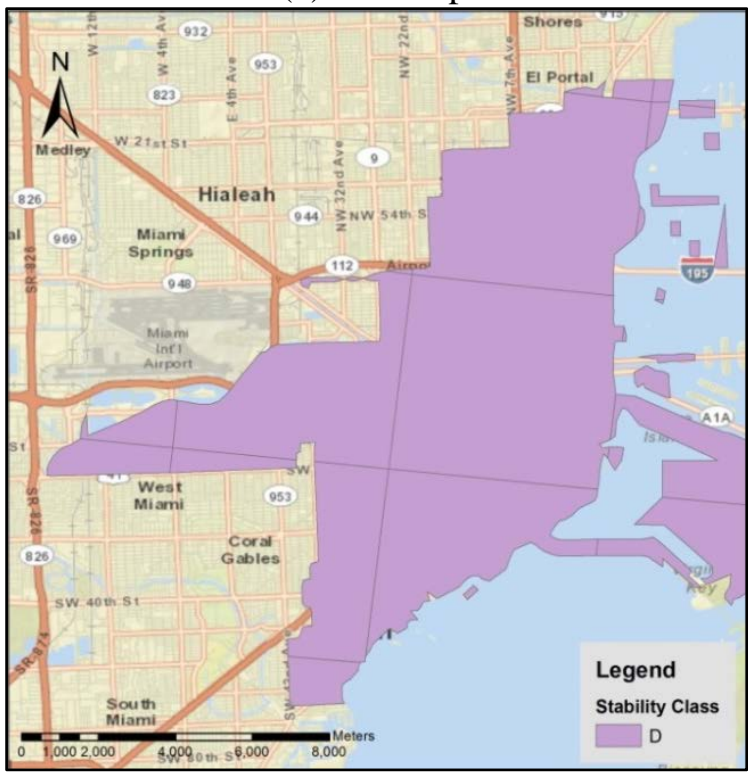

(d) Stability class during night

Figure 6.3 Input data maps and stability classes during the day and night. 
Figure 6.3(a and b) show the data maps of sky cover and wind speed, which were used as inputs. Using the solar radiation angle calculated by the tool, the stability classes of atmosphere during the time of running the program were identified for the day and night conditions (Figure 6.3(c and d)). As presented in Figure 6.3; during the day stability classes of C and D are perceived, while during the night only stability class D is expected. Other atmospheric stability classes could have been observed, if the program was run during the time of the day with higher solar elevation angles; which was not the case in this study. According to the figure, based on theoretical facts of Gaussian dispersion model, under stability condition C, the impact buffer zones are smaller in comparison the atmospheric stability class D, and stability class $\mathrm{C}$ is more unstable than stability class D. Also, for toluene the buffer distances are smaller than that of chlorine under any atmospheric stability condition, since chlorine has lower concentration thresholds than toluene.

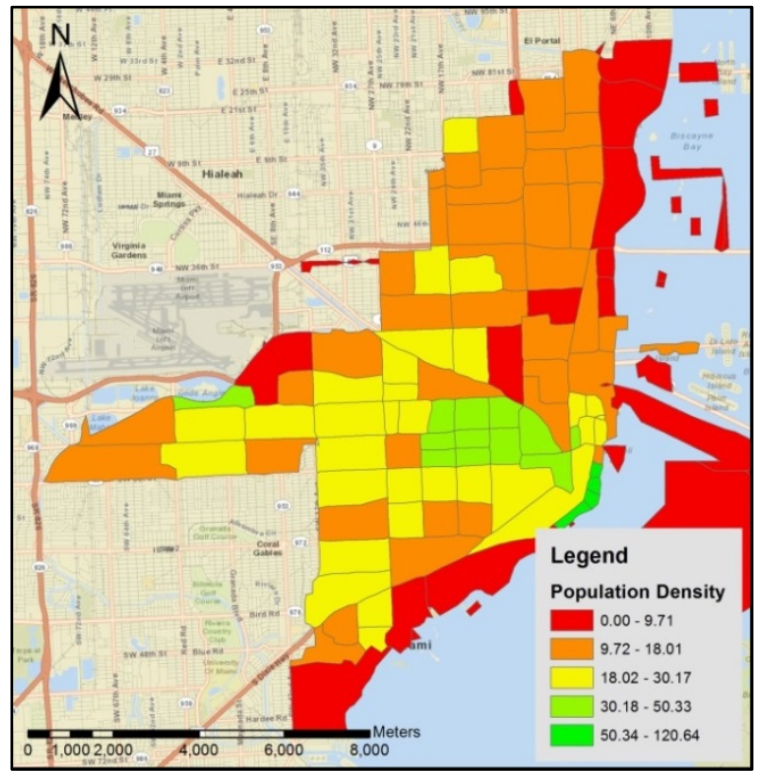

(a) Population density

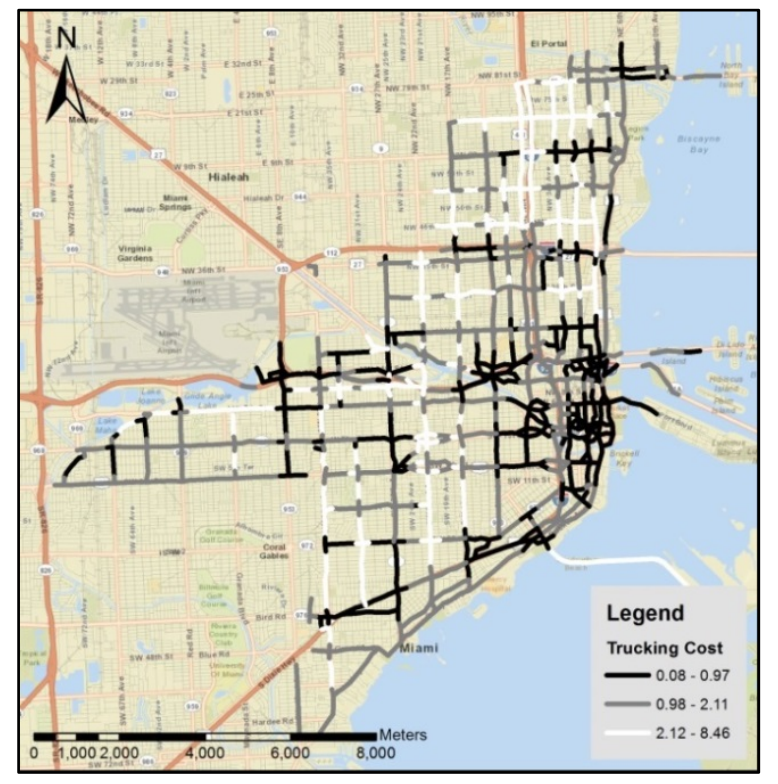

(b) Travel cost

Figure 6.4 Population density and travel costs network. 
Figure 6.4 presents the population density map and the result of travel cost network. After defining the networks using different criteria (exposure risk and trucking cost), the best route for the cargo was identified for each criteria. The best routes for the case study area for each criterion are presented in Figure 6.5. Four different route options were expected based on the exposure risks ( 2 chemicals, day and night transport). However, the health risk for chlorine during day time did not provide a feasible route, while the other three options (i.e., transporting gasoline during the day and night, and chlorine during the night) led to the identification of the best route options. In the figure, route "GasD_Risk” corresponds to the best path based on the risk criterion if the shipment was done during day and the content was gasoline; similarly, “GasN_Risk” shows the best path for shipping gasoline, though during the night. “ChlN_Risk” represents the best route for chlorine shipment, assuming the transport takes place during the night. "TrCost” however, shows the best suggested route based on the trucking cost. "OnD” shows the origin and destination of the cargo, which can be assumed at any locations on the map, defined by the user. As shown in Figure 6.5, finding a route with the lowest trucking cost is directly correlated with the length of the road traveled as show in Figure 6.5. The other routes are based on exposure risks.

One the most referred criterion in transportation of hazardous materials is the travel cost, which is important for evaluating the economic advantages and savings for the shipment. However, the lowest cost route may pass through densely populated areas posing high health risks to people in case of an accidental release. According to Table 6.3, analyses performed for the case study are showed that the differences between the lengths of the route options were not significant. Therefore, the results of this tool can be used to take the less risky paths by a relatively small compromise for the trucking cost. Although, we acknowledge the fact that the aerial distance traveled between the origin and destination of the case study area is relatively small; the argument still can be valid for cases with longer shipment distances. 


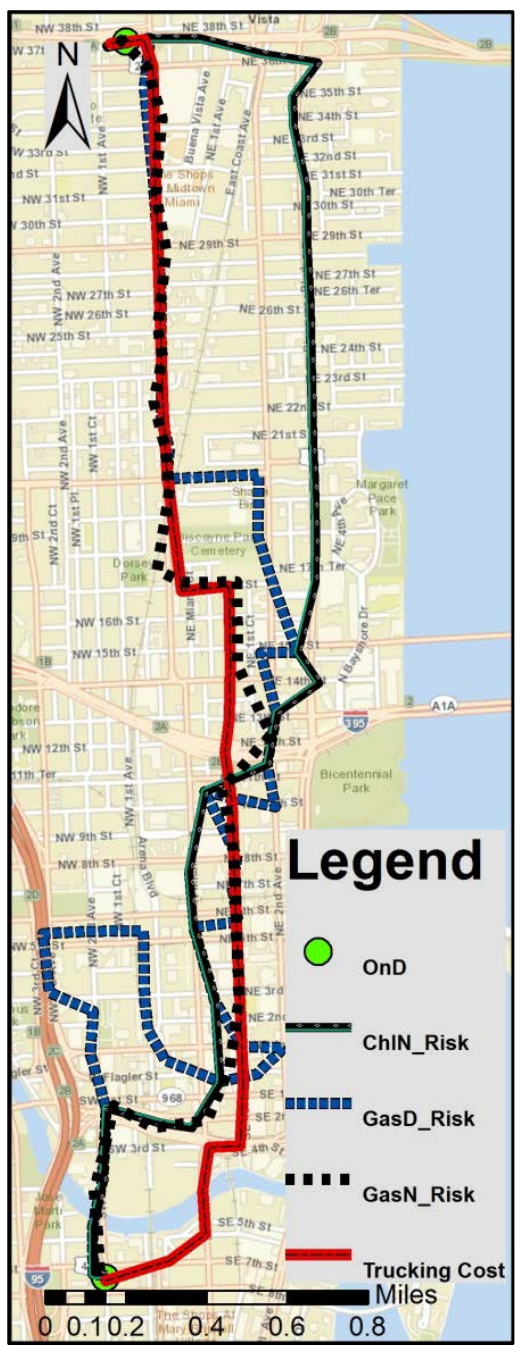

Figure 6.5 Routing options of each criterion.

Table 6.3 Length comparison of route options

\begin{tabular}{lccc}
\hline Best route & $\begin{array}{c}\text { Length } \\
\text { (m) }\end{array}$ & $\begin{array}{c}\text { Increase in } \\
\text { length } \\
\text { (m) }\end{array}$ & $\begin{array}{c}\text { Increase in } \\
\text { length } \\
\text { (\%) }\end{array}$ \\
\hline Chlorine shipment during night (ChlN_Risk) & 6625 & 865 & 15.02 \\
Gasoline shipment during night (GasN_Risk) & 5913 & 153 & 2.66 \\
Gasoline shipment during day (GasD_Risk) & 8598 & 2838 & 49.27 \\
Lowest trucking cost & 5760 & 0 & 0 \\
\hline
\end{tabular}




\subsection{Conclusions}

The objective of this study was to develop a routing tool for identification of the best routes for transporting hazardous cargos by considering different criteria. Trucking costs and exposure risks to accidental releases were the investigation criteria. The tool is capable of finding the best route between an origin and destination within the study area defined by the user. Depending on the evaluation parameters such as the characteristics the material being transported, atmospheric conditions, characteristics of the routes (i.e., population density in neighboring areas, crash data and traffic volume); the best route can change. Also according to the traffic volume or the crash rate of the routes and segments along with the land use and population density of the areas along the routes, the safest route option may be different. The study showed the importance of the time of transport (day or night) on the exposure health risks. The result of the case study showed that the identification of the best route for transporting hazardous chemicals can be challenging due to the conflicting interests of the decision makers. The methodology developed can help to differentiate between the route options, and evaluate the tradeoffs between costs and safety depending of the chemicals being transported.

\section{Acknowledgements}

Partial funding for this research has been provided by Southeastern Transportation Research, Innovation, Development and Education Center (STRIDE), University of Florida as well as the Florida International University Graduate School Dissertation Year Fellowship. 


\section{References}

Alp, E. (1995). Risk-based transportation planning practice: Overall methodology and a case example. Infor, 33(1), 4.

Battelle (2001). Comparative Risks of Hazardous Materials and Non-Hazardous Materials Truck Shipment Accidents/Incidents; Final Report. Prepared for the Federal Motor Carrier Safety Administration.

Branscomb, L., Fagan, M., Auerswald, P. E., Ellis, R. N., Barcham, R. (2010). Rail transportation of toxic inhalation hazards: Policy responses to the safety and security externality. Available at SSRN 2397482.

Craft, R. (2004). Crashes involving trucks carrying hazardous materials. federal motor carrier safety administration. Washington, DC: US Dept.of Transportation.Publication\#: FMCSARI-04-024.

Economic Census (2007).

http://www.rita.dot.gov/bts/sites/rita.dot.gov.bts/files/publications/commodity_flow_survey/2 007/hazardous_materials/pdf/entire.pdf. Accessed June 15, 2015.

EPA (2015), http://www.epa.gov/oppt/aegl/pubs/define.htm. Accessed May 152015.

Fabiano, B., Currò, F., Reverberi, A., Pastorino, R. (2005). Dangerous good transportation by road: From risk analysis to emergency planning. Journal of Loss Prevention in the Process Industries, 18(4), 403-413.

Fender, K. J., Pierce, D. A. (2012). An analysis of the operational costs of trucking: 2011 update. Transportation Research Board 91st Annual Meeting, (12-1090).

Forkenbrock, D. J. (2001). Comparison of external costs of rail and truck freight transportation. Transportation Research Part A: Policy and Practice, 35(4), 321-337.

Griffin, R. D. (2006). Principles of air quality management. CRC Press.

Inanloo, B., Tansel, B. (2015). Explosion impacts during transport of hazardous cargo: GIS-based characterization of overpressure impacts and delineation of flammable zones for ammonia. Journal of environmental management, 156, 1-9.

Inanloo, B., Tansel, B., Jin, X. (2015). A framework for hazardous tanker truck routing: Consideration of health risk, transportation, and congestion costs. Transportation Research Board 94th Annual Meeting, (15-0553)

Inanloo, B., Tansel, B., Jin, X., Bernardo Bricker, A. (2014). Cargo-specific air dispersion and impact zone analysis after accidental release of hazardous materials. Transportation Research Board 93rd Annual Meeting, (14-0519).

Jiang, X., Xu, Z., Deng, Y. (2006). Development in risk study on hazardous chemical materials road transportation. Journal of Catastrophology, 21, 94-98. 
Liu, L., Sun, L., Li, J., Li, C., Hu, X. (2012). An approach to the real-time risk analysis for hazardous material transportation. Intelligent decision technologies (pp. 361-366) Springer.

Ludwig, F., Dabberdt, W. F. (1976). Comparison of two practical atmospheric stability classification schemes in an urban application. Journal of Applied Meteorology, 15(11), 1172-1176.

Manual, H. C. (2000). Highway capacity manual. Washington, DC.

Manual, H. S. (2000). Highway safety manual. Washington, DC.

Margai, F. L. (2001). Health risks and environmental inequity: A geographical analysis of accidental releases of hazardous materials. The Professional Geographer, 53(3), 422-434.

Meeus, J. H. (1991). Astronomical algorithms. Willmann-Bell, Incorporated.

PHMSA, U.S. Department of Transportation, Office of Pipeline Safety (2010). Building Safe Communities: Pipeline Risk and its Application to Local Development Decisions. http:/primis.phmsa.dot.gov/comm/publications/PIPA/PIPA-PipelineRiskReport-Final20101021.pdf. Accessed May15, 2013.

Rakas, J., Teodorović, D., Kim, T. (2004). Multi-objective modeling for determining location of undesirable facilities. Transportation Research Part D: Transport and Environment, 9(2), 125138.

Saccomanno, F. F., Shortreed, J. (1993). Hazmat transport risks: Societal and individual perspectives. Journal of Transportation Engineering, 119(2), 177-188.

Slade, D. H. (1968). Meteorology and atomic energy, 1968.

U.S. Census Bureau (2015). 2012 Commodity Flow Survey. Technical Report. U.S. Department of Transportation and US Department of Commerce. http://www.census.gov/econ/cfs/2012/ec12tcf-us-hm.pdf. Accessed May 25, 2015.

Wu, Z., Duo, Y., Liu, M. (2004). A study on the method of risk assessment of hazardous materials during road transportation. Journal of Basic Science and Engineering, 12, 36-44.

Zhang, J., Hodgson, J., Erkut, E. (2000). Using GIS to assess the risks of hazardous materials transport in networks. European Journal of Operational Research, 121(2), 316-329. 


\section{A Multi-Criteria Routing Tool for Hazardous Material Shipments: Health Risk, Travel Cost, Proximity to Vulnerable Places, and Congestion Costs}

\subsection{Introduction}

Hazardous materials are substances that, if not regulated, can pose threat to the population and the environmental health, safety or property, when transported in commerce (FMCSA, 2006). About 1.5 million tons hazardous material shipments are transported by trucks in the US annually, representing about $59.4 \%$ of the total commodity shipments in 2012, with an increase by 27.3 \% from 2007 to 2012 (U.S. Census Bureau, 2015). The trends in hazardous materials shipments show a steady increase by about $5 \%$ per year. Although the accidents involving hazardous materials are relatively low in terms of number, they are considered as highconsequence incidents, for they can cause injuries, deaths, costly damages and high cleanup efforts (Toumazis and Kwon, 2013).

Substantial research effort has been devoted to routing of hazardous materials (Zografos and Davis, 1989; Lepofsky et al., 1993; Jacobs and Warmerdam, 1994; Giannikos, 1998; Frank et al., 2000; Leonelli et al., 2000; Fabiano et al., 2005; Akgün at al., 2007; Sadjadi, 2007; Bonvicini and Spadoni, 2008; Zografos and Androutsopoulos, 2008). There is considerable amount of research addressing design of road networks for hazardous materials, where evaluation criteria were defined for the assessments (Frank et al., 2000; Zhang et al., 2000; Kara and Verter, 2004; Zografos and Androutsopoulos, 2005; Erkut and Gzara, 2008; Das et al., 2012; Gzara, 2013; Kang et al., 2014). However, most of the studies focus only on travel costs by considering the path length; with studies also taking into account the risk was for network assessment/design. In the field of hazardous materials network design, the term design refers to selection of suitable segments within an existing network of roads, as designing a new transportation network for hazardous goods and freight is not cost effective, therefore, not considered as an option. 
Transport of hazardous materials involves different parties (i.e., shippers, carriers, manufactures, residents, governments and emergency responders) each with different priorities in terms of objectives and criteria for assessing the performance. One the most referred criterion in transportation is the travel cost, which provides a measure for the economic advantages and savings. However, the low cost routes (i.e., shorter) may pass through densely populated areas posing high risks to people, in case of an accident chemical release incident.

A consideration which has not been well studied in the field of hazardous materials transport is the burden that accidents involving hazardous materials pose on transportation networks due to congestions and traffic delays. In the literature, delays that affect the delivery of the hazardous goods have been investigated; however, the traffic delays within the transportation network and the impact on the users of these routes have not been addressed.

This paper proposes a routing methodology capable of evaluation of transportation networks in regards to their suitability for hazardous material shipments. An interactive computer based assessment tool was developed to assess the transportation networks, find the most suitable cargo routes using a multi-criteria-decision-making approach. The suitability of a route is defined depending on the priorities of the person/carrier who is choosing the path. For example, for the shipping carriers, the shortest path may be the best option; on the other hand, for the communities located along the routes, the best route may be the one which avoids areas with high population densities.

\subsection{Methodology}

Road segments were evaluated (quantitatively) and the route options were identified and compared based on the suitability of the road segments within the transportation network. 
The following four criteria were considered in development of the routing tool:

1. Health risks due to exposure after accidental releases,

2. Delay costs,

3. Trucking expenses, and

4. Proximity to vulnerable areas.

The approach used in this study is an interactive and flexible tool; was written in Python programming language; capable of executing the analyses on the transportation network of any given area of interest, provided by users. Evaluations, calculations and analyses of the transportation network are done by one time execution of the program and the outputs are obtained in the form of maps and tables. Using the assessed networks of the evaluation criteria, defining any origin and destination within the assessed network, routing options based on each of the criteria, as well as the best route based on the overall propriety of the route are identified using Network Analysis tool in ArcGIS. Figure 7.1 presents the overall methodology used in developing the route assessment tool. 


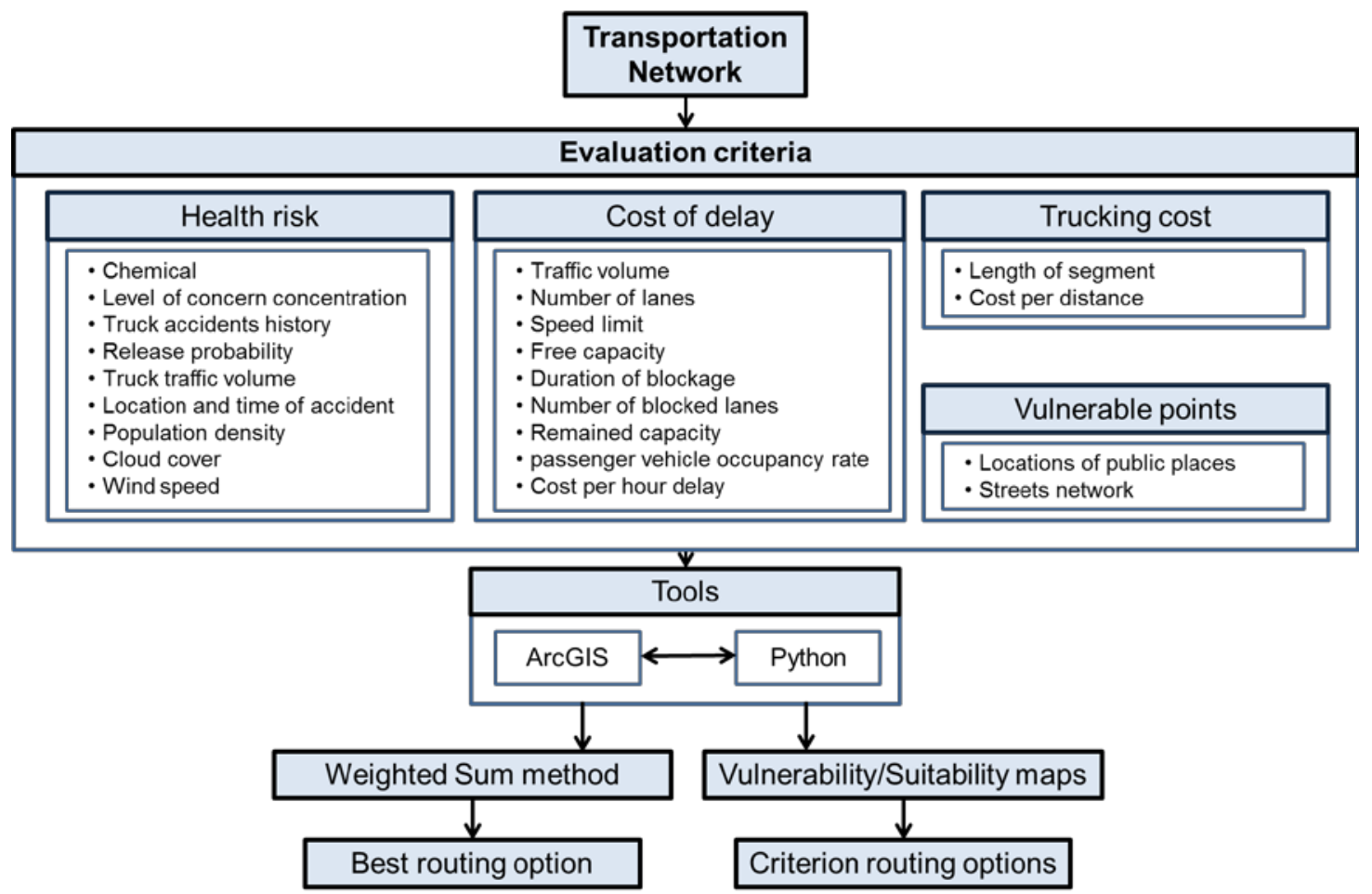

Figure 7.1 Methodology of the hazardous cargo transportation network assessment tool.

\subsubsection{Exposure Health Risk Quantification}

The hazards in risk assessments are usually considered as acute toxicity, flammability, thermal radiation, blast wave, and missile damage (Alp, 1995; and Inanloo and Tansel, 2015). In this paper, risk is defined as a measure of the probability and severity of threat to a receptor due to acute exposure to hazardous material fumes. Acute Exposure Guideline Levels (AEGLs) were developed to the risk to human health caused by exposure to one time, or rare airborne chemicals. To quantify the health risk caused by inhalation of the released chemicals AEGL-3, which represents "the airborne concentration (expressed as ppm or $\mathrm{mg} / \mathrm{m} 3$ ) of a substance above which it is predicted that the general population, including susceptible individuals, could experience lifethreatening health effects or death,” was taken into account as the threshold concentration for health impact radius identifications (EPA, 2015). The impact radius was calculated using 
Gaussian dispersion equation, considering the concentration threshold. The number of exposed people within the threat zone was estimated as a consequence of the accident for each segment of the network. The health risks due to the inhalation of hazardous chemicals after an accidental release was calculated by Equation 1.

Risk $=$ Frequency $\times$ Consequences

Accident frequency can be estimated from the number of similar events occurring per year and the consequences can be expressed from different perspectives (i.e., impacted population, fatalities, size of the impacted area, environmental impacts) (Inanloo et al., 2015). Over the rest of this section the procedure of calculations of the components of risk will be described.

\subsubsection{Accident Frequencies}

In order to calculate the accident frequency, as defined in the Highway Safety Manual (HSM, 2010), the normalized value of the crash frequency with exposure (the degree to which a road user is exposed to traffic risks) was calculated. Exposure in 100 million vehicle miles traveled was calculated by Equation 2. Crash rate was acquired by Equation 3 (HCM, 2000).

$\mathrm{EXPO}=\frac{\text { AADT } \times 365 \times \text { number of years } \times \text { total segment length }}{100,000,000}$

Crash rate $=\frac{\text { Total crash count }}{\text { EXPO }}$ 
where, EXPO is the exposure to accidents and AADT is the Annual Average Daily Traffic. In this study, AADT for trucks was considered to represent the frequency of truck accidents. The total crash count was estimated by identifying accidents involving trucks within a search radius around each segment of the transportation network. The probability of chemical releases in accidents involving trucks was based on the statistics of hazardous material accidents, as the percentage of the accidents which led to chemical releases to the number of total hazardous materials accidents. According to PHMSA, 27.3\% of the hazardous material accidents result in chemical releases (Battelle, 2001).

The crash data was available for the years of 2003-2010. The tool, taking into account the time of evaluations, recognizes whether the transport/accident happens during day or night time, also over the weekdays or weekends; so that the crash rates can be calculated for the corresponding time window based on the historical data.

\subsubsection{Consequence Analysis}

In order to identify and quantify the health impact buffer zones around the road segments, AEGL-3 concentration for one hour exposure of the released chemical was taken into account; through using the Gaussian dispersion formulation to find the farthest distance that the certain concentration would be perceived. The tool is provided with a dictionary of AEGLs for common carried hazardous materials, as the concentration thresholds differ by change in atmospheric conditions and chemicals (Inanloo et al., 2014).

Atmosphere condition corresponds to the ability of the air masses in creating vertical movements. These motions result in dilution of the chemical in the air. The more and faster the movements, the quicker the mixing of the substance in the atmosphere is, and accordingly, lesser would be the expected impacts as the chemical would not stay in the atmosphere long enough to 
cause health impacts. Atmospheric conditions, as defined from unstable to stable; depend on the wind speed, solar radiation, and/or cloud cover.

\subsubsection{Delay Cost}

Accident costs are not limited to property damages, fatalities and injuries; they also include the expenses that occur as an indirect result of the accident, as other users of the transportation system are affected by the incident due to congestions and delays (Inanloo and Tansel, 2015). According to a report in 2007, traffic congestions caused an additional 4.2 billion hours for travel in the US, resulting in consumption of 2.9 billion gallons additional fuel corresponding to a congestion cost of \$78 billion (Schrank and Lomax, 2007).

Delay cost can be estimated by multiplying the delay time caused by an accident with the dollar value of travel time delay. Queuing analysis was used to estimate the incident delays as the major impacts. Based on the queuing theory, total delay time for one incident, TD, can be estimated by the following equation (Hadi et al., 2008):

$\mathrm{TD}=\frac{\mathrm{t}_{\mathrm{R}}^{2}\left(\mu-\mu_{\mathrm{R}}\right) \times\left(\lambda-\mu_{\mathrm{R}}\right)}{2 \times(\mu-\lambda)}$

where, $t_{R}$ is the incident duration, $\lambda$ is the mean arrival rate, $\mu$ is the mean capacity, and, $\mu_{R}$ is the capacity during the incident. The values $\mu$ and, $\mu_{R}$ were acquired from the Highway Capacity Manual (HCM, 2000, and Hadi et al., 2008).

In order to do the calculations of each parameter of Equation 4, other criteria such as number of lanes, speed limits and function class of the road segments (i.e., freeway, expressway, street, etc.) need to be defined (to estimate the capacity of the road, and to further calculate the 
capacity during the incident according to HCM). In this study, only lane blockage was considered, not shoulder disablements.

The delay cost for each route segment was estimated based on the values provided in the 2007 Urban Mobility Report (Schrank and Lomax, 2007). According to the report, the value of travel time delay is $\$ 14.60$ per hour of person travel. Delay costs were estimated by multiplying the value of hourly person travel by the average passenger vehicle occupancy rate which is 1.58 occupants in Florida (FDOT, 2011). In this study the effect of neither ramps nor intersections on the capacity of segments were considered.

\subsubsection{Transportation Costs}

Society and transport companies try to minimize the total cost of conveyance not only to help businesses to remain competitive but also to make sure goods are moved and delivered efficiently (Forkenbrock, 2001). According to a study by the American Transport Research Institute (ATRI) in 2011, the average total carrier cost in 2011 was $\$ 1.706$ per mile. This value was used in this study for trucking cost calculations. Transportation costs were estimated by multiplying the average total carrier cost per unit length by the travel distance for each route link (Fender and Pierce, 2012).

\subsubsection{Vulnerable Points}

In this study, vulnerable places to health problems such as schools, daycares, and hospitals were identified near each road segment in the evaluation of transportation networks for hazardous materials transport. The proposed tool by this study, considers the map of public locations, searches a certain distance around the road segments for any of previously mentioned 
public places and keeps the records of such points, as these public places occupy vulnerable people (e.g., children and patients) who are more vulnerable to exposure risks in case of a chemical release. The search distances were considered to be the same as the buffer zones of risk consequence calculation section.

\subsubsection{Multi-Criteria-Decision-Making Method}

Nearly all the real world problems involve multi objectives and can be modeled using multi-criteria decision making methods (Köksalan, 2011). These techniques help decision makers in ranking the alternatives based on their performances for each criterion, which provides a justification for selection of the best option between alternatives (Carver, 1991). The simplest method which can be utilized in solving multi-criteria problems is to assign weights for each of the criterion in order to combine them into one value, so that a coherent value can be obtained to compare the alternatives (Linkov and Moberg, 2011). The weighted performances of the alternatives can be estimated by the following equation (Equation 5) if the goal is to minimize the impacts (e.g., cost, risk):

Minimum $V(\vec{a})=\sum_{i=1}^{n} w_{i} V_{i}\left(a_{i}\right)$

where, $w_{i}$ is the weight assigned to criterion $i$ and $V_{i}\left(a_{i}\right)$ is the performance of alternative $\vec{a}$ on criterion i. The weight assigned to each criterion plays a significant role in the selection of the best alternative. The weights are identified based on the interests and priorities of decision makers. Therefore, the best alternative may change depending on the weights assigned to the criteria (Read et al., 2014). For example, if the priority is the operation cost over the health risk, delay cost, and proximity to public places; then a higher weight coefficient can be assigned to 
trucking cost which result in selection of a route which leads to lower transportation cost, and probably higher risk and/or cost of delay. In this study weights were assumed to be the same for all the criteria (25\% for each criterion). However, the weight coefficients can be adjusted according to the preferences defined by the user.

\subsubsection{Routing Option Identification}

Having the transportation network evaluated based on the criteria, also equipped with the generated cumulative network as the output of weighted sum method. Employing ArcGIS's Network Analysis tool, assuming any pair of origin and destination within the study area, the best routing option can be identified, whether based on each criterion or the overall function of the route according to all the criteria.

\subsection{Case Study}

Miami Dade and Broward counties in Florida, USA, were selected as the study area of this paper to implicate the tool on a real world problem. The required data for the proposed tool were collected in the formats of maps and tables from different sources of data. However, finding data on truck shipments and their schedules were very challenging, as the data were hard to obtain due to the security purposes, also the lack of records.

The shipment was assumed as a full tanker truck, with the capacity of 9,000 gallons of E10 blend of gasoline, is carrying the cargo from Port Everglades, Hollywood, FL, to a gas station in Downtown, Miami, FL. It was assumed that the entire tanker content is released to the atmosphere, caused by an en-route accident. In reality, spills usually include a part of the cargo and not the entire shipment, however, in order to have taken into consideration the worst case scenario, in this study the whole cargo was presumed to be released by the accident. 
Gasoline consists of several compounds, with different proportions. In this study, Toluene was taken into account for health risk evaluations. The quantity of Toluene was calculated based on its proportion in gasoline. Therefore, in the calculations, the suggested tool uses the predefined level of concern concentration of this substance for the impact radius identifications. Figure 7.2 shows the location of the study area as well as the boundary of the area of interest.

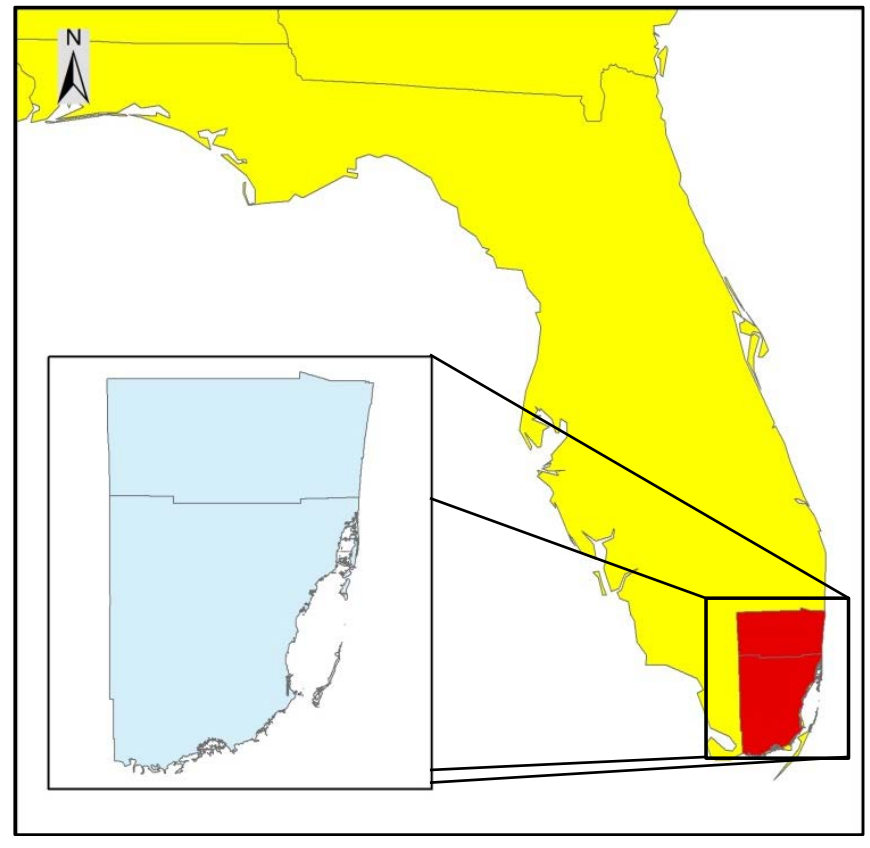

Figure 7.2 Location of the case study area.

\subsection{Results}

The output results include several maps, as well as tables, showing calculated and evaluated properties ready to be interpreted. According to the methodology of this study, equipped with the required data, calculations were executed by Python scripting and were visualized using ArcGIS afterwards. Having identified the stability classes of atmosphere around road segments, the buffer distances for transportation branches were taken into consideration and 
delineated around the links. The buffer distances are different depending on the atmospheric conditions, as they play significant role in the delusion of chemicals in the air, since a chemical which enters the more stable atmospheres tends to stay in the air longer than unstable conditions; the health impact radius is also bigger under stable atmospheres.

The program was run two times; both during day; in a weekday and a weekend day. Therefore, the risk networks were different for the two runs, as the crash rates were different due to the number of crashes during the two time periods. Also, the networks of vulnerable points were different, for the atmospheric conditions varied during the two days, so did the buffer distances. On the other hand, the delay cost and travel cost networks were identical, as the tool did not differentiate between the costs of delay and travel for weekdays and weekends (no related data was available). Traffic volumes also were assumed the same for the two runs. Therefore, there are two sets of result routes for the networks of health risk and vulnerable points, for weekdays and weekends; but, there is just one set of route option for delay cost, also is for travel cost.

Based on the health risk zones around segments, population at risk was calculated using the population density map. In this study, the estimations of population were based on the population density of 2010. Had approximated the population at risk for each segment, also equipped with the 8 year crash history in the area (2003-2010), as well as, truck traffic volume, and crash rates; risks were calculated for road segments as they are shown in Figure 7.3. Figure 7.3 (a and b) show the risk networks during weekdays and weekends, respectively. The risk calculated in this study is the multiplication of number of people to truck involved crash rates (crashes per 100 million vehicles), to the probability of the en-route accident which lead to releases (percentage of total truck crashes). 


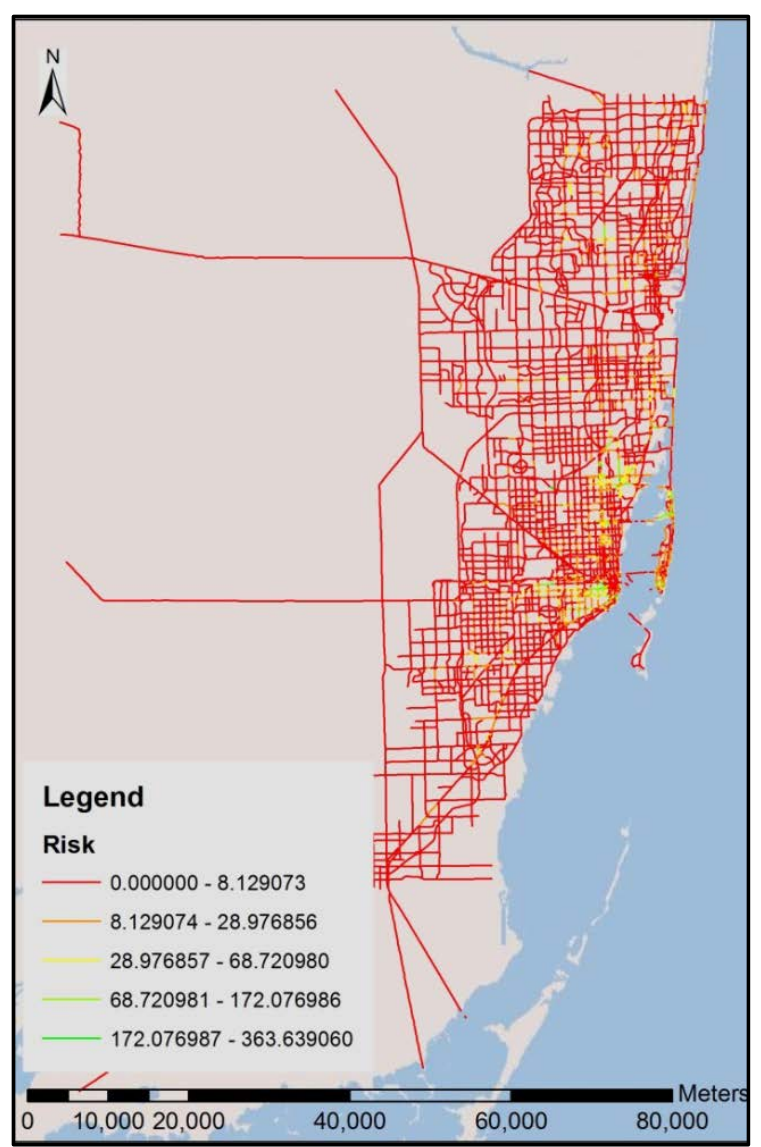

(a) Risk network during weekdays

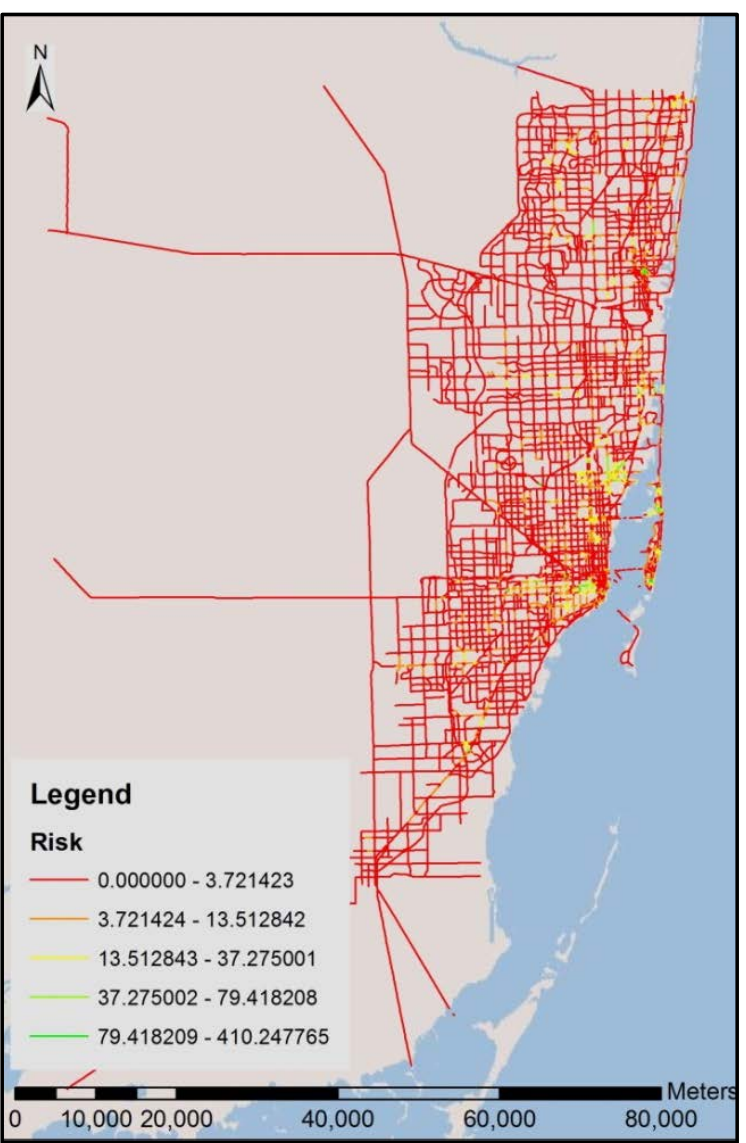

(b) Risk network during weekends

Figure 7.3 Health risk evaluated networks during weekdays and weekends.

In this study, the vulnerable places that were prone to health risk were identified based upon their proximity to the health risk buffer zones, as whether they fell within the risky areas of segments. The number of vulnerable points which located inside the health risk zone of each link was assigned to the segment of the transportation network (Figure 7.4(a and b)).

Figure 7.5 was allocated to the declaration of the calculations and results of delay cost and travel cost networks. Based on the assumptions of this study, closure of three lanes of the segment due to a truck involved accident for one hour was presumed, and calculations were done based on this scenario. Hazardous material accidents are large and serious events, as the accidents which lead to release only, usually cause road closure with the average duration of cleanups of 5 hours (Battelle, 2001). Unlike to the health risk calculations, traffic volume for delay time 
computations were considered as vehicle traffic, while for the crash rate assessment truck traffic volume was considered.

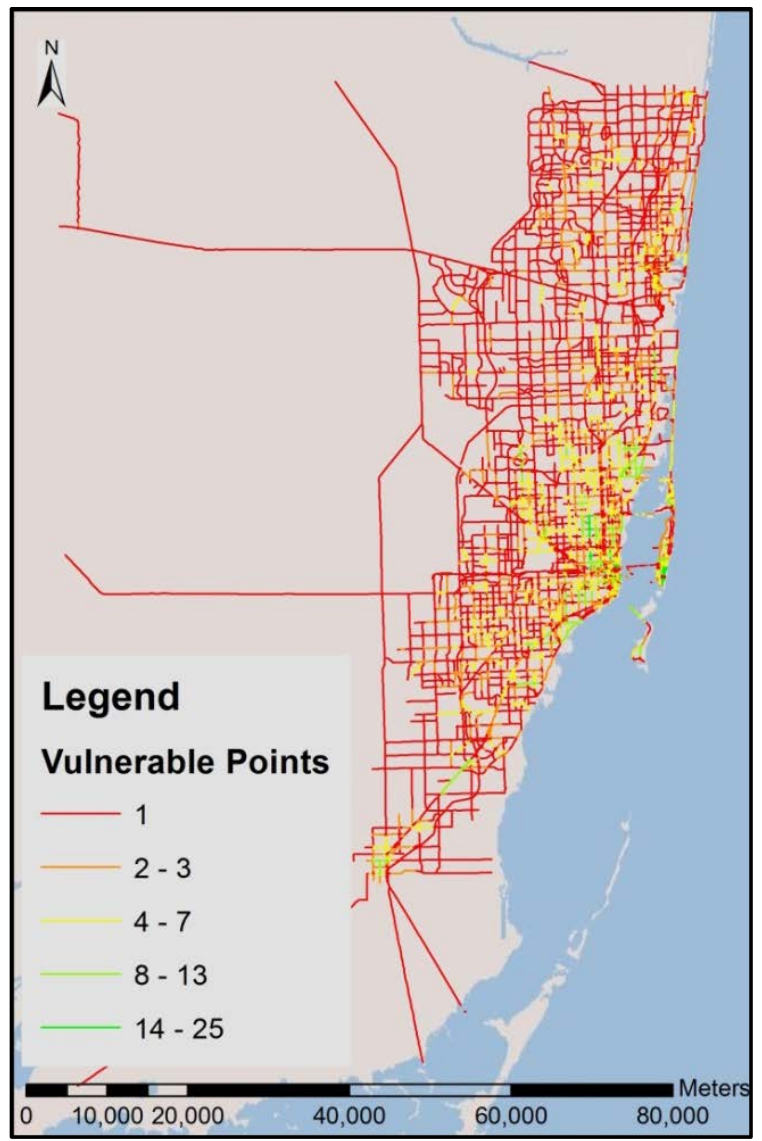

(a) Vulnerbale point during weekdays

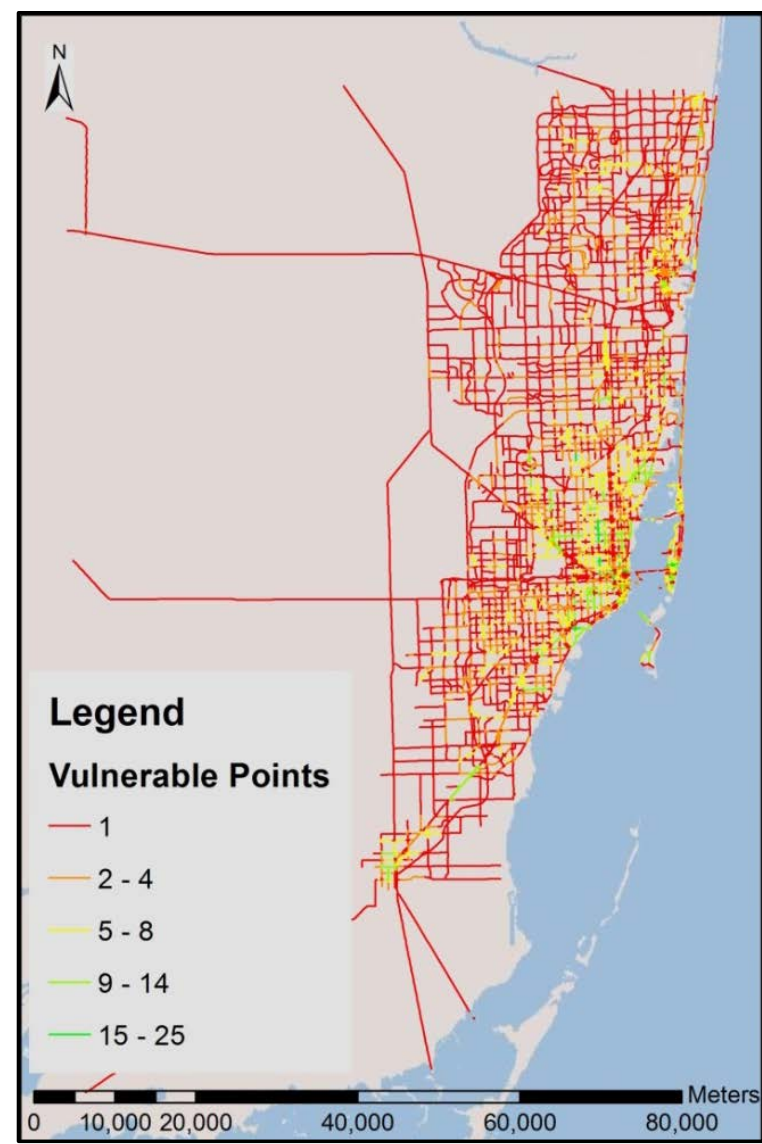

(b) Vulnerbale point during weekends

Figure 7.4 Vulnerable point networks during weekdays and weekends. 


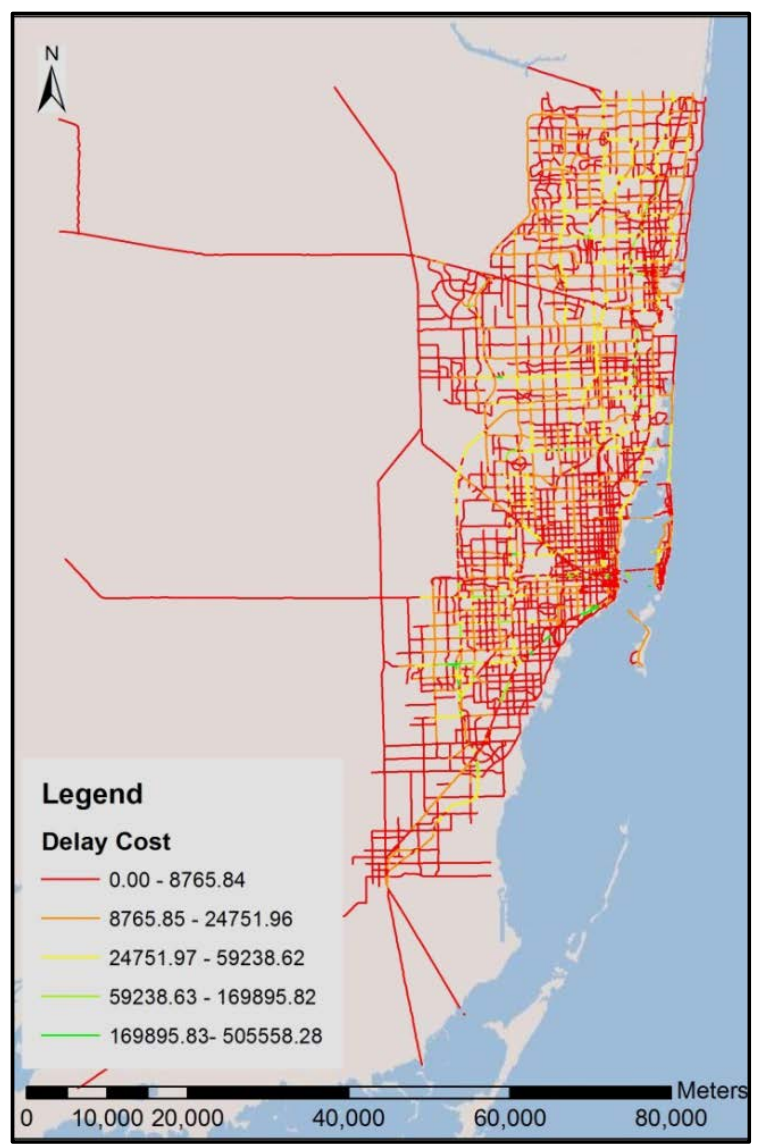

(a) Delay cost

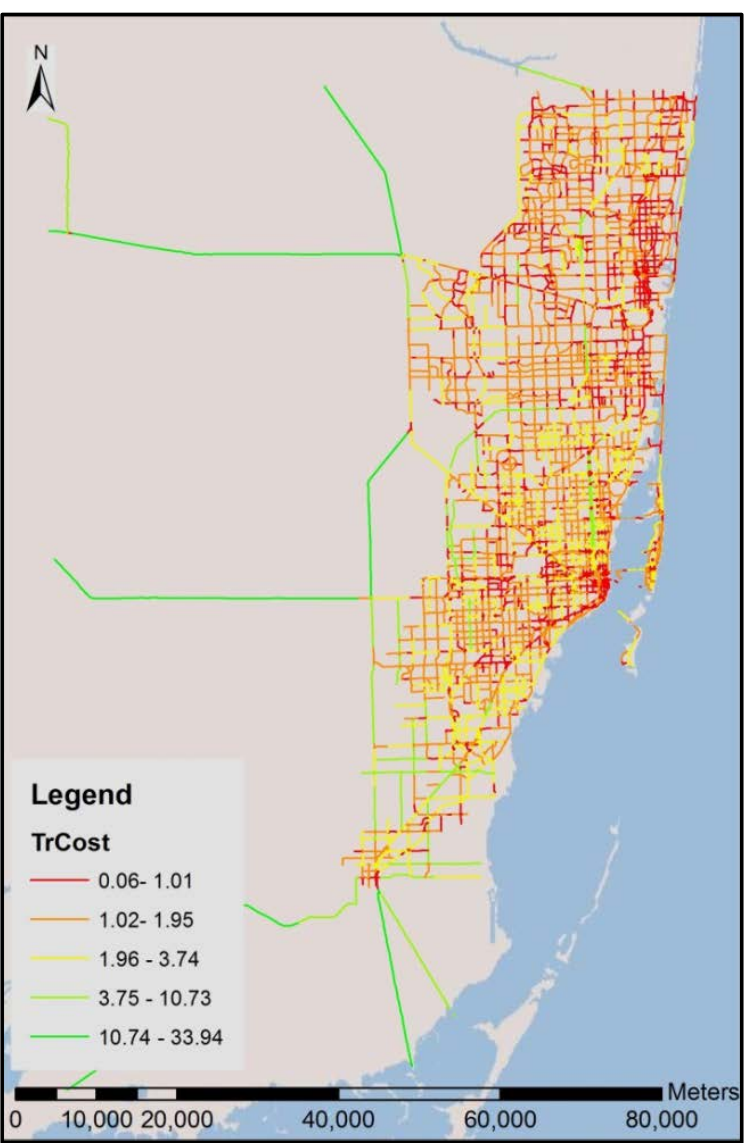

(b) Travel cost

\section{Figure 7.5 Delay and travel costs networks during weekdays and weekends.}

Acquiring the networks of the criteria, the next step was to find the best route for caring the cargo. For the clarification purposes, in this section the best routes based on criteria were shown in Figure 7.6(a). As there were four assessment criteria, there would be the same number of route options, as of each for one criterion, and one best route considering all the criteria overall. However, Figure 7.6(a) shows six different route options, as health risk and vulnerable points have two results for the two runs of the program, as discussed previously. For example, route Risk WDs is the best path based on the risk criterion if the shipment was carried during weekdays; similarly, Vulnerable points WDs is related to the criterion of proximity to public places during weekdays (WnDs and WDs correspond to the routes over the weekends and 
weekdays, respectively). The best routes based on delay cost and travel expense are also shown in the figure.

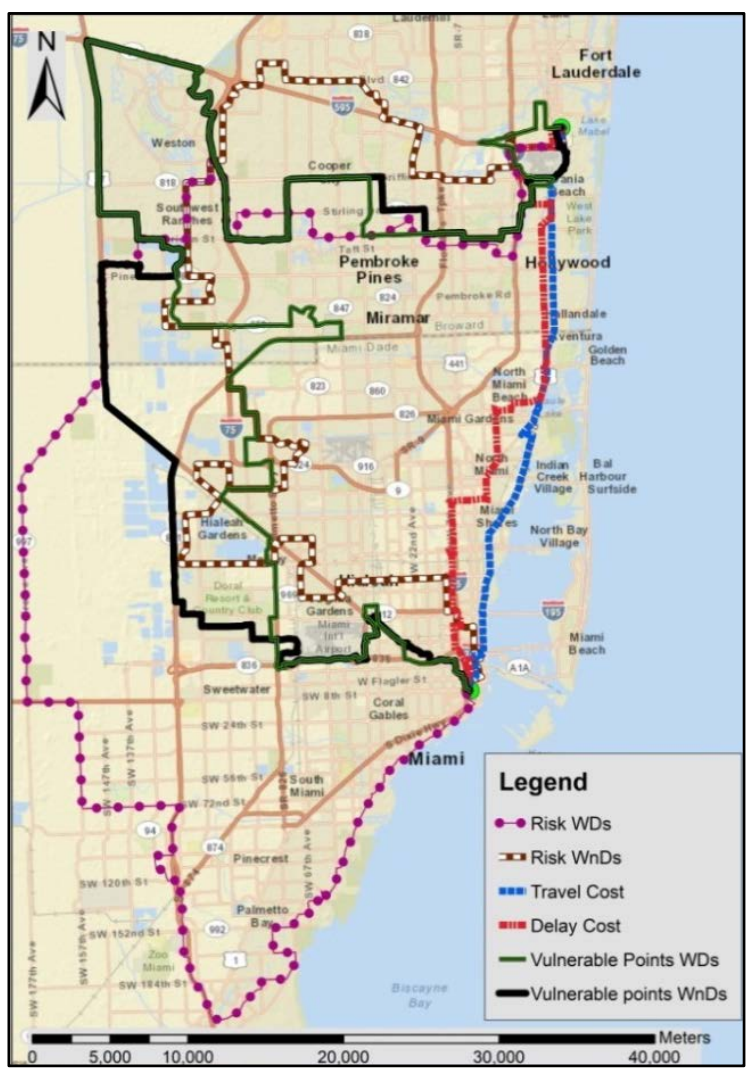

(a) Routing options of each criterion

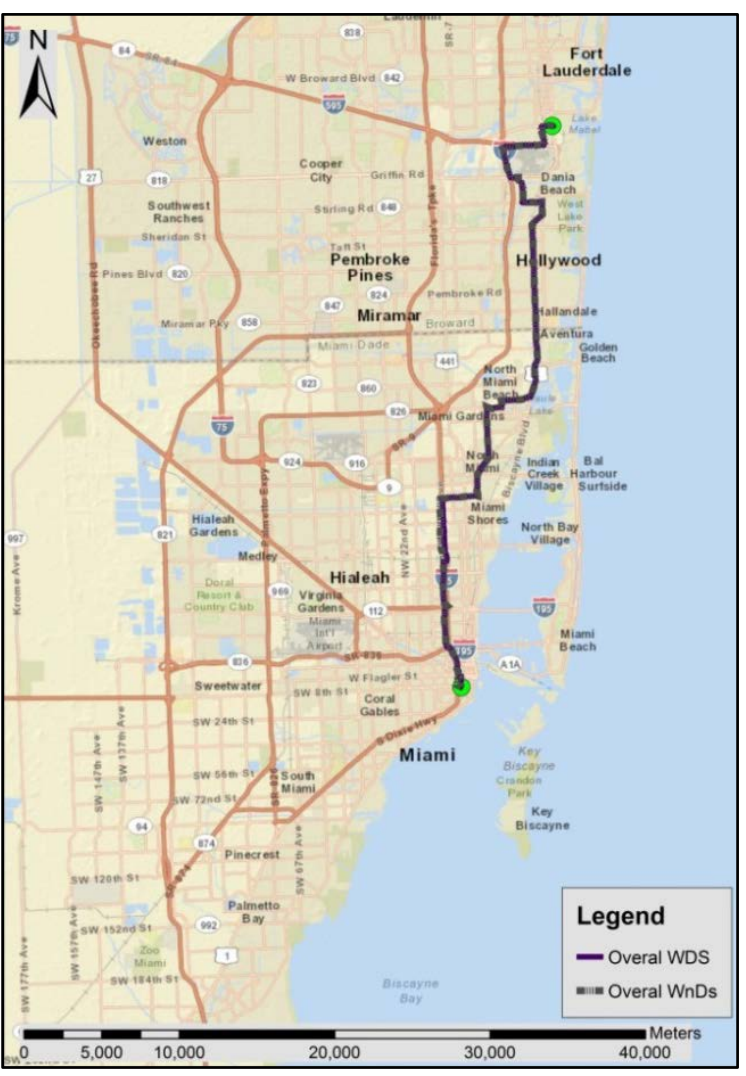

(b) Best routing option based on the criteria

Figure 7.6 Delay and travel costs networks.

The routes offered by health risk and vulnerable points were very long routes to avoid civic areas, while, the routes under considerations of delay cost, and especially trucking cost were shorter (the best trucking cost route was the shortest amongst the generated paths) (Figure 7.6(a)). The health risk route during weekdays was the longest route, as the crash rates were higher during the weekdays and accordingly, the route seeks farther routes from the municipal areas in comparison to those during the weekends. 
As presented in Figure 7.6(b), the suggested overall best routes for the cargo for the shipments during weekdays and weekends are almost the same, although the values of health risk and vulnerable points for the two cases are different. The overall best routes are very similar to the route suggested based on only consideration of the delay costs because the decision making method used by this study (weighted sum) merely sums up the values of each criterion by applying the weight coefficients to produce the output network. The network is evaluated to find the best route with the smallest weighted sum. However, since the order of the numbers under criteria are different (Figure 7.3 to Figure 7.5), assuming the same weight proportions for the criteria, a criterion with a higher order of value has more impact on the selection of the best alternative. Comparing the values of the criteria (Figure 7.3 to Figure 7.5 ), delay cost has the highest order of number, the risk has the second rank, while, vulnerable points and travel cost have the same orders of values. As presented in Figure 7.6(b), the best routing option is almost the same as the best route by delay cost, being affected by the criterion with a large value. The colors scheme used in Figure 7.3 to Figure 7.5 are based on ranges of the value ranges (with equal intervals). The user can chose different thresholds for each criterion for visualization using maps.

\subsection{Conclusions}

The main objective of this study was to develop a routing tool for identification of the best route for transporting hazardous cargos, by considering different criteria individually and collectively. Four criteria used in the analyses were: 1. delay costs, 2. travel costs, 3. exposure health risks, and 4. proximity to vulnerable public places. The result of the case study showed that identification of the best route for transporting hazardous chemicals can be challenging due to the conflicting interests and priorities. The tool is capable of finding the best route between an origin and destination in the area of interest. Depending on the cargo characteristics and atmospheric stability conditions (i.e., quantity and type of the material being transported), as well as the 
characteristics of the routes (i.e., proximate population density, crash data and traffic volume), the overall ratings of the routes can change; so does the best route option. Also depending on the traffic volumes or crash rates of the road segments associated with each path, the best route option may be different.

The decision making method developed in this study uses the weighted sum approach. The quantitative results allow comparison of the routing alternatives in view of the relative importance of different criteria which can be used by the decision makers. The method helps evaluation of the tradeoffs between the options and shows with slightly compromising the trucking costs, high risk routes and long delays can be avoided.

\section{Acknowledgments}

Partial funding for this research has been provided by Southeastern Transportation Research, Innovation, Development and Education Center (STRIDE), University of Florida and the Florida International University Graduate School Dissertation Year Fellowship.

References

FMCSA (Federal Motor Carrier Safety Administration). (2006). Nine Classes of Hazardous Materials.

http://www.fmcsa.dot.gov/facts-research/research-technology/visorcards/yellowcard.pdf

U.S. Census Bureau (2015). 2012 Commodity Flow Survey. Technical Report. U.S. Department of Transportation and US Department of Commerce. http://www.census.gov/econ/cfs/2012/ec12tcf-us-hm.pdf. Accessed May 25, 2015.

Toumazis, I., Kwon, C. (2013). Routing hazardous materials on time-dependent networks using conditional value-at-risk. Transportation Research Part C: Emerging Technologies, 37, 73-92.

Zografos, K. G., Davis, C. F. (1989). Multi-objective programming approach for routing hazardous materials. Journal of Transportation Engineering, 115(6), 661-673. 
Lepofsky, M., Abkowitz, M., Cheng, P. (1993). Transportation hazard analysis in integrated GIS environment. Journal of Transportation Engineering, 119(2), 239-254.

Jacobs, T. L., Warmerdam, J. M. (1994). Simultaneous routing and siting for hazardous-waste operations. Journal of Urban Planning and Development, 120(3), 115-131.

Giannikos, I. (1998). A multiobjective programming model for locating treatment sites and routing hazardous wastes. European Journal of Operational Research, 104(2), 333-342.

Frank, W. C., Thill, J., Batta, R. (2000). Spatial decision support system for hazardous material truck routing. Transportation Research Part C: Emerging Technologies, 8(1), 337-359.

Leonelli, P., Bonvicini, S., Spadoni, G. (2000). Hazardous materials transportation: A riskanalysis-based routing methodology. Journal of hazardous materials, 71(1), 283-300.

Fabiano, B., Currò, F., Reverberi, A., Pastorino, R. (2005). Dangerous good transportation by road: From risk analysis to emergency planning. Journal of Loss Prevention in the Process Industries, 18(4), 403-413.

Akgün, V., Parekh, A., Batta, R., Rump, C. M. (2007). Routing of a hazmat truck in the presence of weather systems. Computers \& Operations Research, 34(5), 1351-1373.

Sadjadi, S. J. (2007). An application of efficient frontier in transportation of hazardous materials. Computers \& Industrial Engineering, 53(2), 357-360.

Bonvicini, S., Spadoni, G. (2008). A hazmat multi-commodity routing model satisfying risk criteria: A case study. Journal of Loss Prevention in the Process Industries, 21(4), 345-358.

Zografos, K. G., Androutsopoulos, K. N. (2008). A decision support system for integrated hazardous materials routing and emergency response decisions. Transportation Research Part C: Emerging Technologies, 16(6), 684-703.

Dadkar, Y., Jones, D., Nozick, L. (2008). Identifying geographically diverse routes for the transportation of hazardous materials. Transportation Research Part E: Logistics and Transportation Review, 44(3), 333-349.

Bianco, L., Caramia, M., Giordani, S. (2009). A bilevel flow model for hazmat transportation network design. Transportation Research Part C: Emerging Technologies, 17(2), 175-196.

Pradhananga, R., Taniguchi, E., Yamada, T. (2010). Ant colony system based routing and scheduling for hazardous material transportation. Procedia-Social and Behavioral Sciences, 2(3), 6097-6108.

Guo, X., Verma, M. (2010). Choosing vehicle capacity to minimize risk for transporting flammable materials. Journal of Loss Prevention in the Process Industries, 23(2), 220-225.

Kara, B. Y., Verter, V. (2004). Designing a road network for hazardous materials transportation. Transportation Science, 38(2), 188-196. 
Erkut, E., Gzara, F. (2008). Solving the hazmat transport network design problem. Computers \& Operations Research, 35(7), 2234-2247.

Zhang, J., Hodgson, J., Erkut, E. (2000). Using GIS to assess the risks of hazardous materials transport in networks. European Journal of Operational Research, 121(2), 316-329.

Zografos, K., Androutsopoulos, K. N. (2005). A decision support system for hazardous materials transportation and emergency response management. 84th Annual Meeting of the Transportation Research Board, Washington, DC.

Gzara, F. (2013). A cutting plane approach for bilevel hazardous material transport network design. Operations Research Letters, 41(1), 40-46.

Das, A., Gupta, A., Mazumder, T. (2012). A comprehensive risk assessment framework for offsite transportation of inflammable hazardous waste. Journal of hazardous materials, 227, 88-96.

Kang, Y., Batta, R., Kwon, C. (2014). Generalized route planning model for hazardous material transportation with var and equity considerations. Computers \& Operations Research, 43, 237-247.

Alp, E. (1995). Risk-based transportation planning practice: Overall methodology and a case example. Infor, 33(1), 4.

Inanloo, B., Tansel, B. (2015). Explosion impacts during transport of hazardous cargo: GIS-based characterization of overpressure impacts and delineation of flammable zones for ammonia. Journal of environmental management, 156, 1-9.

EPA (2015). http://www.epa.gov/oppt/aegl/pubs/define.htm. Accessed May 152015.

Inanloo, B., Tansel, B., Jin, X. (2015). A framework for hazardous tanker truck routing: Consideration of health risk, transportation, and congestion costs. Transportation Research Board 94th Annual Meeting, (15-0553).

Manual, H. C. (2000). Highway capacity manual. Washington, DC.

Manual, H. S. (2000). Highway safety manual. Washington, DC.

Battelle (2001). Comparative Risks of Hazardous Materials and Non-Hazardous Materials Truck Shipment Accidents/Incidents; Final Report. Prepared for the Federal Motor Carrier Safety Administration.

Inanloo, B., Tansel, B., Jin, X., Bernardo Bricker, A. (2014). Cargo-specific air dispersion and impact zone analysis after accidental release of hazardous materials. Transportation Research Board 93rd Annual Meeting, (14-0519).

Schrank, D. L., Lomax, T. J. (2007). The 2007 urban mobility reportTexas Transportation Institute, Texas A \& M University. 
Hadi, M., Shen, L., Zhan, C., Xiao, Y., Corbin, S., Chen, D. (2008). Operation data for evaluating benefits and costs of advanced traffic management components. Transportation Research Record: Journal of the Transportation Research Board, 2086(1), 48-55.

FDOT (Florida Department of Transportation), (2011). http://www.dot.state.fl.us/planning/trends/tc-report/behavior082611.pdf, Accessed May 10, 2015.

Forkenbrock, D. J. (2001). Comparison of external costs of rail and truck freight transportation. Transportation Research Part A: Policy and Practice, 35(4), 321-337.

Fender, K. J., Pierce, D. A. (2012). An analysis of the operational costs of trucking: 2011 update. Transportation Research Board 91st Annual Meeting, (12-1090).

Köksalan, M. M., Wallenius, J., Zionts, S. (2011). Multiple criteria decision making: From early history to the 21st century. World Scientific.

Carver, S. J. (1991). Integrating multi-criteria evaluation with geographical information systems. International Journal of Geographical Information System, 5(3), 321-339.

Linkov, I., Moberg, E. (2011). Multi-criteria decision analysis: Environmental applications and case studies. CRC Press.

Read, L., Madani, K., Inanloo, B. (2014). Optimality versus stability in water resource allocation. Journal of environmental management, 133, 343-354. 


\section{Conclusions}

This dissertation aimed to propose a routing tool suitable for hazardous material cargos in order to prevent possible adverse consequences due to en route accidents and spills. Four criteria were chosen for investigations, specifically: (1) inhalation risk; (2) proximity of the routes to public places (e.g., hospitals, schools, etc.); (3) delay costs due to road closure in case of accidents; and (4) trucking costs, which were the most refereed criterion in selection of the routes by shipping carriers.

As the main study focus of the author of this dissertation was environmental health, great effort was dedicated to bridge the gap between considerations of the environmental (human health) risks, and transportation difficulties of such accidents (due to road closures), as well as to acknowledge the importance of trucking costs that the shipping companies are willing to pay in taking any alternative path for the cargos. In reality, delay costs and health risks are not tangible unless a drastic accident happens, and consequences are forced upon the community and stakeholders; on the other hand, the most palpable parameter to be taken into consideration in routing the cargos is trucking cost. Hence, this dissertation aimed to make the tradeoffs easier by proposing a routing tool which is capable of finding routing alternatives considering overall suitability of the path based on all the aforementioned criteria, as well as each criterion exclusively. This capability helps the shipping companies (as the primary decision makers in the field of hazardous material transports) have a better understanding of the consequences of choosing each routing options, as in some cases by slightly compromising on trucking costs a safer route can be selected. The more insight and information are provided to the carriers, the safer the routes that may be chosen. Thus, the main objective of the dissertation was to suggest cargo paths that are safer while also economically compelling to the shipping companies. 
In order to evaluate transportation networks to find the best route for cargos, it was first necessary to acquire an understanding of the nature of chemical releases and health risks associated with such accidents. Therefore, Chapter 2 and Chapter 3 were dedicated to investigate the possible consequences of hazardous material spills. In Chapter 2, the inhalation impact zones were compared in relation to atmospheric stability and exposure levels for ammonia and hydrogen fluoride. For ammonia, the areas impacted by exposure levels over 1100 ppm (Acute Exposure Guideline Level 3 (AEGL-3)) were limited to less than 0.3 miles downwind from the incident location under unstable atmospheric conditions, which favor high vertical mixing and rapid dilution, and extended further downwind to distances between 0.5 and 0.7 miles under stable atmospheric conditions. For hydrogen fluoride, the AEGL-3 impact zone (exposure levels over $44 \mathrm{ppm}$ ) extended between 0.6 and 0.9 miles directly downwind from the incident location under unstable conditions, and reached approximately 2.0 miles directly downwind from the incident location under stable atmospheric conditions. The results were compared with the Emergency Response Guideline (ERG 2012) and showed agreement with the guideline. In Chapter 3 , the impacted areas and the severity of the probable destructions were evaluated for an explosion by considering the overpressure waves. The expansions of the impact areas under the overpressure value which can lead to property damage for 2 and 20 tons releases of ammonia, under very stable and unstable atmospheric conditions were estimated to be around 1708, 1206, 3742, and 3527 feet, respectively, toward the wind direction. A sensitivity analysis was done to assess the significance of wind speed on the impact zones.

Upon obtaining insights into health consequences of chemical releases in the air, the study continued towards integration of the selected criteria for investigation of pre-identified routing options between a pair of origin and destination points on a case study area as presented in Chapter 4. The results of the case study showed that the identification of the best route for transporting hazardous chemicals can be challenging due to the conflicting interests of the 
decision makers. Depending on the parameters such as the characteristics and the quantity of the materials being transported, atmospheric conditions, and the characteristics of the routes (i.e., proximate population density, crash data and traffic volume), the overall ratings of the routes can change; hence the best route option can be different for each case. Additionally, the safest route option may be different depending on traffic volume or crash rate of the routes and segments, along with the land use and population density of the areas along the routes. While Chapter 4 examined predefined route options, Chapter 5 extended the scope of the study to encompass the entire transportation network considering the evaluation criteria. The networks evaluated by the approach discussed in Chapter 5 were ready to be utilized in the selection of routing options between any origin and destination within the study area, as presented in Chapters 6 and 7 . Chapter 6 focused on health risks and trucking costs. The study showed the importance of the time of transport (day or night) on the exposure health risks. The methodology developed can help to differentiate between the route options, and evaluate the tradeoffs between costs and safety depending of the chemicals being transported. Chapter 7 considered four criteria: (1) delay costs; (2) travel costs; (3) exposure health risks; and (4) proximity to vulnerable public places. The tool was capable of finding the best route between any origins and destinations in the area of interest. Depending on the cargo characteristics (i.e., quantity and type of the material being transported) and atmospheric stability conditions, as well as the characteristics of the routes (i.e., proximate population density, crash data and traffic volume), the overall ratings of the routes can change, which can change the best route option. Also, depending on the traffic volumes or crash rates of the road segments associated with each path, the best route option may be different.

In the field of hazardous materials network design, the term network design refers to selection of suitable segments within an existing network of roads, as designing a new transportation network for hazardous goods and freight transport is not cost effective and therefore generally not considered as an option. The proposed method of this dissertation helps 
the evaluation of the tradeoffs between the options, and shows with slightly compromising the trucking costs, high risk routes and long delays can be avoided.

Future research is necessary to investigate at least all the common carried hazardous chemicals, as this study focused only on a few substances. The method in calculations of delay time and cost used was the Queuing approach; however, other potentially more accurate methods may be utilized in future studies. The air dispersion model used in this study was based on Gaussian equation; more accurate and complicated models could be integrated with the suggested tool. Efforts could also be devoted to the use of real time traffic and atmospheric data, instead of historic data. The lack of information on hazardous chemicals transport was one of the challenging aspects of this study; despite the effort of the author of this dissertation in collecting such data, the information was in many cases not available, which led to making assumptions when necessary; this fact may have led to overestimation of the hazard and impact radii. Given the possible overestimation of the risks due to assumptions (i.e., release of the entire cargo, consideration of the limited historical data on percentage of chemical releases in accidents), the results of this study could be considered as the worst case scenario. However, being equipped with more accurate and comprehensive data in future studies could create results more beneficial to shipping carriers and societies. 
APPENDICES 
Appendix 1- GIS-Based Assessment Tool for Preliminary Delineation of Odor Impact Zones around Landfills: Effect of Atmospheric Conditions on Impact Radius 


\section{Introduction}

Landfill gas is generated by the natural biological process of decomposition of organic material such as paper, animal, food waste, vegetable matter and garden wastes (Allen et al., 1997). The main compounds in landfill gas are methane (45-60 \% v/v) and carbon dioxide (40-60 $\% \mathrm{v} / \mathrm{v}$ ), which both are categorized as greenhouse gases (GHG) (Scheutz et al., 2009). The $\mathrm{CH}_{4}$ component in landfill gas has been reported to have a global warming potential (GWP) index of 25 over a 100-year time horizon. On the other hand, the biogenic $\mathrm{CO}_{2}$ emitted from waste decomposition is considered neutral to climate change (Manfredi et al., 2009; Capaccioni et al., 2011).

Municipal solid waste landfills can be potential sources of air pollution and offensive odors affecting the quality of life and property values of surrounding communities (Sarkar et al., 2003). The character (offensiveness) of an odor is a unique, innate quality that does not vary with intensity. Offensiveness can be distinguished even at very low concentrations. Intensity is the relative measure of the perceived concentration (TCEQ, 2007). How odors are processed, at the behavioral and neural levels, depends on past experiences, current environmental conditions, and psychological and physical state of the individuals (Tansel et al., 2004, 2005, 2006).

Both organic and inorganic sulfur compounds are the primary cause for the odor nature of landfill gas. However, the main responsible compound for the pungent scent originating from landfills is hydrogen sulfide $\left(\mathrm{H}_{2} \mathrm{~S}\right)$ (Pawlowska, 2014). Factors such as size, age, environmental conditions (moisture, temperature, nutrient requirements, $\mathrm{pH}$, and atmospheric conditions) will influence the biodegradation process and odor potential (Speight, 2011; Chemel et al., 2012).

Odors are of the major causes of complains to environmental agencies with an increasing trend in the USA (Mahin, 2003). During waste decomposition, odorous gasses produced even during the initial transition stages as the oxygen gets depleted. Eventually anaerobic 
decomposition begins result in $\mathrm{CH}_{4}$ generation. In general, after 20 years, majority of the organic wastes are decomposed. However, small quantities of gas may continue to be produces in landfills for 50 or more years (Chalvatzaki and Lazaridis, 2010). Human nose can detect and distinguish odors at concentrations even lower than the detectable thresholds by gas chromatography for some odorous compounds (Rappert, 2005).

In recent years, efforts have been directed towards characterizing volatile organic compounds (VOCs) originating from solid waste facilities due to their air quality and health impacts (psychological stress, irritation, toxic reactions) (Atkinson, 2000; Belpomme et al., 2007; Gallego et al., 2008; Hutter et al., 2006; Irigaray et al., 2007; Liang and Liao, 2007; Peng et al., 2006; Wolkoff and Nielsen, 2001). Several methods have been used to assess and quantify odor emissions and odor annoyance levels. For landfills and composting facilities, chemical analyses are used to identify the key compounds during odor release episodes. These key compounds can be used to set up the specifications for a monitoring instrument. Sensory methods, such as dynamic olfactometry or odor panels provide a measure to establish odor annoyance levels.

Some regulatory agencies use general characterization for types/sources of odors (TCEQ, 2007). For waste management facilities, odor levels and odor emission rates cannot be easily determined by a sample collection method. Spot sampling/monitoring over a large area (e.g., landfill, composting) make it questionable for representativeness of the results.

Odor perception depends on physiology, weather conditions, seasonal changes, subjective perception, and interaction of different odors (Firestein, 2001; Noble et al., 2001; Davoli et al., 2003; Zou et al., 2003; Capelli et al., 2008; Gallego et al., 2008). In a recent landfill odor study, among the 68 odorous gases identified (inorganic compounds, halogenated compounds, aromatics, VFAs, aldehydes, ketones, esters, hydrocarbon, and other sulfur and nitrogen compounds); $\mathrm{NH}_{3}$ and $\mathrm{H}_{2} \mathrm{~S}$ accounted for over $90 \%$ and $5 \%$ of the total odorous gas concentrations, respectively (Ying et al., 2012). Transport of odorous compounds and odor 
perception depend on the combined effects of climate conditions (e.g., temperature, humidity, air pressure, and wind direction), facility characteristics (e.g., HDPE membrane cover, landfill gas extraction) and geographical location.

The aim of this study was to delineate the odor impact zones around active and closed landfills and quantify impacted population in relation to atmospheric stability and land use conditions around the landfills. Air dispersion model was coupled with Geographic Information System (GIS) analyses to delineate the impact zone based on land use and estimate the impacted population. The odor levels were estimated based on the total gas production and the percentage of the odorous compounds present in the landfill gas using LANDGem (The Landfill Gas Emissions Model) software. To delineate the odor impact zones, the emission rates of the odorous substances were analyzed with air dispersion model ALOHA (Areal Locations of Hazardous Atmospheres) and mapped using ArcGIS.

\section{Methodology}

To identify the impact odor zones surrounding the landfills, three modeling softwares were used interactively to estimate odor emissions, atmospheric dispersion of odorous compounds in relation to atmospheric stability; and mapping the impact zones to delineate the impacted areas and population which will be within the impact zone. Figure 1 presents the overall framework used for the analyses to delineate the odor impact zones.

The Landfill Gas Emissions Model (LandGEM) is a tool with a Microsoft Excel interface that can be used to estimate emission rates from landfills. It was developed by the Clean Air Technology Center of the US EPA (Environmental Protection Agency) (EPA, 2005). LandGEM is capable of estimation of the landfill gas (as well as methane, carbon dioxide, and other 
compounds) from municipal waste landfills. LandGem estimates the methane generation using the following first order exponential equation:

$$
Q_{C H 4}=\sum_{i=1}^{n} \sum_{j=0.1}^{1} k L_{0}\left(M_{i} / 10\right)\left(e^{-k t_{i j}}\right)
$$

where, $Q_{C H 4}$ is estimated methane generation flow rate (cfm); i and $\mathrm{j}$ are 1-year and 0.1year time increments, respectively; $\mathrm{n}$ is the difference between year of calculation and initial year of waste acceptance; $\mathrm{k}$ is methane generation rate (1/year); and $t_{i j}$ is the age of the $\mathrm{j}^{\text {th }}$ section of waste mass buried in the $\mathrm{i}^{\text {th }}$ year (decimal years); $L_{0}$ is the potential methane generation capacity ( $\left.\mathrm{ft}^{3} / \mathrm{ton}\right), M_{i}$ is the mass of solid waste disposed in the $\mathrm{i}^{\mathrm{th}}$ year (ton). After the methane generation rate is estimated, the rate of total landfill gas is calculated. Based on the total gas generation, and the composition of landfill gas; the rates of generation of other compounds can be estimated in relation to their proportions to the landfill gas. Table 1 presents the typical composition of the landfill gas.

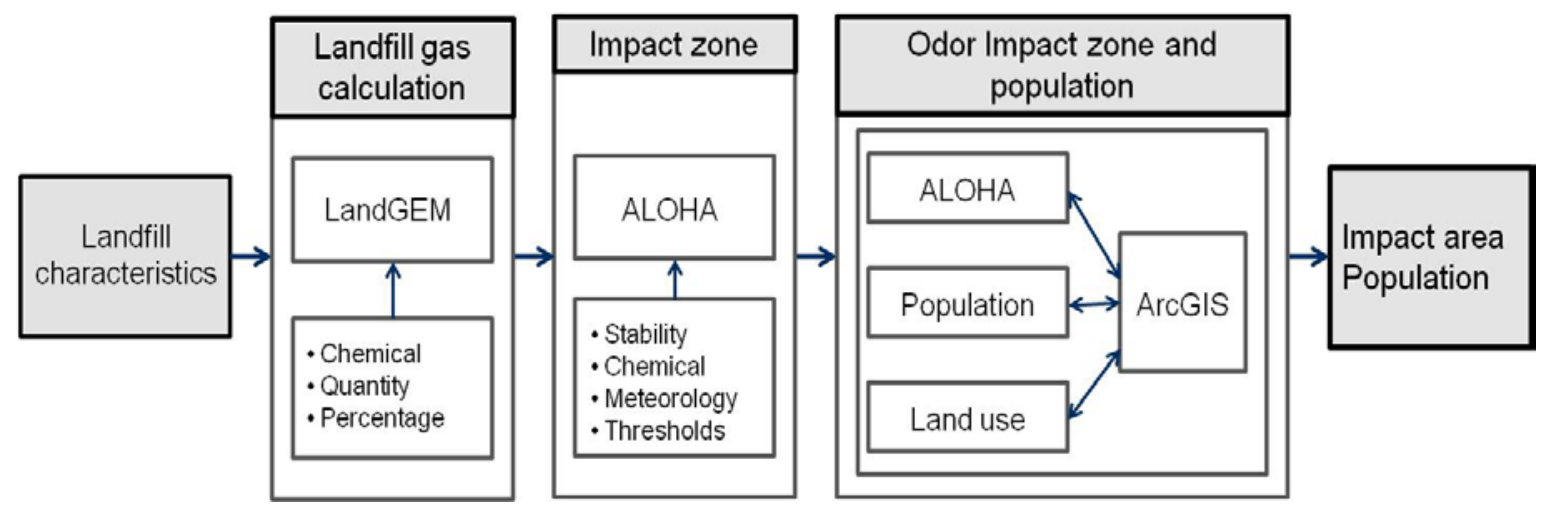

Figure 1. Framework of the odor impact zone analysis.

In this study, hydrogen sulfide was used as the key compound (i.e., main odor source from landfill) for odor emissions. The emission rates were correlated with the generation rates of hydrogen sulfide. Hydrogen sulfide is heavier than air; therefore, it would be transported at the 
lower levels of the atmosphere. Assuming the perception concentration threshold of the chemical by humans, landfill gas emission was modeled as a continuous source for hydrogen sulfide emissions. Table 2 presents the odor threshold levels for the volatile compounds present in landfill gas at municipal solid waste landfills (ATSDR, 2015).

The odor impact zone was estimated conservatively by assuming that the hydrogen sulfide present in the landfill gas will be emitted from the entire landfill and the buffer zones were delineated from the boundary of the landfill site. Since the atmospheric conditions (i.e., temperature, humidity, solar radiation, cloudiness) play an important role in the dispersion of the substance, as the odor is not annoying every day, three different atmospheric stabilities as representatives of various weather conditions were taken into account.

Areal Locations of Hazardous Atmospheres (ALOHA) is an air dispersion model capable of evaluation of release of hazardous chemical vapors, including toxic gas clouds, fires, and explosions (NOAA, 2015). The model uses the release characteristics and generates a threat zone estimate. A threat zone is the region where a hazard (e.g., toxicity) is predicted to exceed a user specified level of concern concentration of the chemical (US DOE, 2004). The air dispersion model ALOHA was utilized visualize the odor impact zones around the landfills based on their size and operational characteristics (e.g., accepted annual waste) as well as atmospheric conditions, since the stability of the atmosphere has a significant effect on the odor dispersion characteristics and human perception (Table 2). The residents who live around landfills do not experience the same level of odor intensity. The odors often reach the human detection threshold during certain time during day/night (e.g., early mornings) or under certain weather conditions (e.g., high humidity and after rain), which is directly influenced by the atmospheric conditions. 
Table 1. Composition of landfill gas (ATSDR, 2015).

\begin{tabular}{lc}
\hline Component & $\begin{array}{c}\text { Composition } \\
(\mathbf{\%} \mathbf{~ v} \mathbf{)}\end{array}$ \\
\hline $\mathrm{CH}_{4}$ & $45-60$ \\
$\mathrm{CO}_{2}$ & $40-60$ \\
$\mathrm{~N}_{2}$ & $2-5$ \\
$\mathrm{O}_{2}$ & $0.1-1$ \\
$\mathrm{NH}_{3}{ }^{c}$ & $0.1-1$ \\
$\mathrm{NMOCs}^{\text {a }}$ & $0.01-0.6$ \\
Sulfides $^{\text {b,c }}$ & $0-1$ \\
Hydrogen & $0-0.2$ \\
$\mathrm{CO}$ & $0-0.2$ \\
\hline
\end{tabular}

${ }^{a}$ Non-methane organic compounds

${ }^{\mathrm{b}}$ Hydrogen sulfide, dimethyl sulfide, mercaptans

${ }^{\mathrm{c}}$ Odorous

Table. 2. Landfill gas components odor thresholds (ATSDR, 2015).

\begin{tabular}{lc}
\hline Component & Odor threshold \\
& $\mathbf{( p p b )}$ \\
\hline Hydrogen sulfide & $0.5-1$ \\
Ammonia & $1,000-5,000$ \\
Benzene & 840 \\
Dichloroethylene & 85 \\
Dichloromethane & $205,000-307,000$ \\
Ethylbenzene & $90-600$ \\
Toluene & $10,000-15,000$ \\
Trichloroethylene & 21,400 \\
Tetrachloroethylene & 50,000 \\
Vinyl chloride & $10,000-20,000$ \\
\hline
\end{tabular}

Air dispersion model (ALOHA) was used the estimate odor annoyance radius. In the analyses, it was assumed that the total produced landfill gas is emitted into the atmosphere and the dispersion calculations were performed using maximum emission rate. The estimated odor 
annoyance distance was delineated as the buffer zone around the landfill using ArcGIS software. In the calculations, wind speed of $5 \mathrm{mph}$ was used for comparing the impact radius around the case study landfills. The wind direction was not taken into account in the analyses. The analyses aimed to identify areas which may be potentially impacted around the landfills (wind blowing from any direction), as the direction changes frequently over day/night. After delineating the odor impact zones on the maps using ArcGIS, and using population density map of the region; the population in the impact zones was estimated.

\section{Case Study Landfills}

Three landfills were compared to demonstrate the methodology. These landfills were Okeechobee Landfill in Florida, South Dade Landfill in Florida, and Fenimore Landfill in New Jersey. Table 3 presents the general characteristics of the case study landfills.

Okeechobee landfill is the largest of the three landfills in terms of both the area and municipal solids waste (MSW) deposited per year. It is located in a rural area in Central Florida with low population density and far from residential areas. On the other hand, Fenimore landfill is the smallest of the three landfills, but closer to the residential areas. This landfill has drawn attention because of the concerns and complaints filed by the neighboring communities since 2012 for the odors emitted.

Okeechobee and South Dade landfills are both operational and active landfills, while Fenimore landfill was closed in 1979. However, in late 2012, the landfill was reopened temporarily. Since then, the numerous complaints have been filed for the odorous emissions. 
Table. 3. Case study landfills.

\begin{tabular}{llcccc}
\hline $\begin{array}{l}\text { Landfill } \\
\text { name }\end{array}$ & Location & $\begin{array}{c}\text { Year of } \\
\text { opening }\end{array}$ & $\begin{array}{c}\text { Year of } \\
\text { closure }\end{array}$ & $\begin{array}{c}\text { Area } \\
\text { (Acres) }\end{array}$ & $\begin{array}{c}\text { MSW } \\
\text { deposited } \\
\text { (Tons/year) }\end{array}$ \\
\hline Okeechobee & Florida, USA & 1992 & 2052 & 833 & $1,600,000$ \\
South Dade & Florida, USA & 1979 & 2029 & 300 & 600,000 \\
Fenimore & New Jersey, USA & 1950 & 1979 & 109 & 400,000 \\
\hline
\end{tabular}

\section{Results and discussion}

Odor impact zones were delineated for each landfill for different atmospheric stability conditions corresponding to unstable, neutral and stable atmospheric conditions; B, C and F respectively, using the Pasquill-Gifford stability categories (Hunter, 2012). Stabilities B, and C refer to daytime hours with unstable conditions. Stability F refers to nighttime, stable conditions and is based on the amount of cloud cover.

Figs. 2-4 compare the impact odor impact zones under different atmospheric conditions at the case study landfills. The odor impact zones showed different impact radius due to differences in landfill characteristics (e.g., size of landfill and amount of solid waste deposited) and land use around the landfills. Under unstable atmospheric conditions (typical for afternoon; conditions B and C), the mixing depth is higher; hence, the odorous releases would be mixed with vertical air movements, keeping the impact radius smaller. However, under stable atmospheric conditions (typical for nighttime, condition F), mixing depth lower; hence, air moves closer to ground; hence, odorous compounds may be carried over larger distances. However, for stability condition F, the odor strength would be less since the air would be diluted over a larger volume. 
Table 3 compares the impact radius of the three case study landfills. The land use around the landfills significantly affects the dispersion characteristics. For example, the presence of large open areas and lack of good tree coverage around the Okeechobee landfill allow air to be dispersed to longer distances. However, the areas around this landfill is sparsely populated, hence, the affected population is relatively small (Table 5). On the other hand, South Dade landfill is closer to the residential areas with good tree coverage. Therefore, the odor impact radius is almost half of that for the Okeechobee landfill; however, the affected population is more than twice that of the Okeechobee landfill (Table 4).

The Fennimore landfill has both residential communities and open areas around the site. Development of the areas around the landfill since its closure in 1979 increased the population density around the landfill. Also, the large open areas around the site serve as corridors for air movement, allowing the odorous compounds to travel longer distances with air currents. Although the Fenimore landfill has the smallest impact area, it has the highest affected population due to the residential land use around the site. This landfill has resulted in numerous complaints oppositions and lawsuit due to the odor annoyance as well as temporary reopening of the site in 2012.

Table 3. Comparison of estimated impacted areas and population by odor emissions around the case study landfills.

\begin{tabular}{lccccccc}
\hline \multirow{2}{*}{ Landfills } & \multicolumn{7}{c}{ Impact radius (miles) Highest strength zone (miles) } \\
\cline { 2 - 5 } \cline { 6 - 8 } & B & C & F & & B & C & F \\
\hline Okeechobee, FL & 0.5 & 0.8 & 2.2 & $0.20-0.30$ & $0.30-0.50$ & $0.90-1.30$ \\
South Dade, FL & 0.1 & 0.4 & 1.2 & $0.04-0.06$ & $0.10-0.30$ & $0.40-0.80$ \\
Fenimore, NJ & 0.08 & 0.2 & 0.8 & 0.03 & -0.05 & $0.08-0.12$ & $0.30-0.50$ \\
\end{tabular}


Table 4. Comparison of estimated impacted areas and population by odor emissions around the case study landfills.

\begin{tabular}{lccccccc}
\hline \multirow{2}{*}{ Landfills } & \multicolumn{3}{c}{ Impact area (Square miles) } & & \multicolumn{4}{c}{ Impacted population } \\
\cline { 2 - 4 } \cline { 6 - 8 } & B & C & F & & B & C & F \\
\hline Okeechobee & 1.97 & 5.80 & 24.85 & & 28 & 84 & 358 \\
South Dade & 0.96 & 2.37 & 7.55 & & 107 & 264 & 841 \\
Fenimore & 0.26 & 0.58 & 2.82 & & 270 & 603 & 2930 \\
\hline
\end{tabular}

\section{Conclusions}

In this study, odor impact zones around three case study landfills were delineated by interactively coupling using LandGEM, ALOHA, and ArcGIS software. Delineation of odor potential annoyance zones can be an effective planning tool for developing appropriate mitigation measures around landfills to minimize odor complaints. The analyses showed that land use characteristics around landfills significantly affect the dispersion characteristics of odorous compounds emitted. This research showed the significance of different atmospheric stability conditions on odor dispersion around landfills. For example, stable atmospheric conditions at nighttime (condition F) would result in larger impact radius; however, odor strength would be less since the air would be diluted over a larger volume.

It should be noted that dispersion model used (ALOHA) has some limitations as it was developed for emergency response to spills. Corrections based on knowledge and experience with regional conditions (i.e., prevalent wind direction) should be considered based on operating conditions at the landfill, emission potential of odorous gases (from working face and/or through cap). In view of the prevalent wind direction (during day and night as well as different seasons) and allocating larger buffer distance in down wind direction should be considered. 
The methodology developed in this study by coupling readily available tools (software) can be used as a planning tool for preliminary delineation of buffer zones around landfills, developing appropriate mitigation measures in view of landfill operating conditions, regional atmospheric characteristics, land use and population density around landfills. Buffer zones may not be enough to avoid annoyance due to odorous compounds released from landfills. Although landfill odor is not classified as a health hazard, the discomfort which it causes can interrupt everyday activities of the residents who live around the landfill sites. 


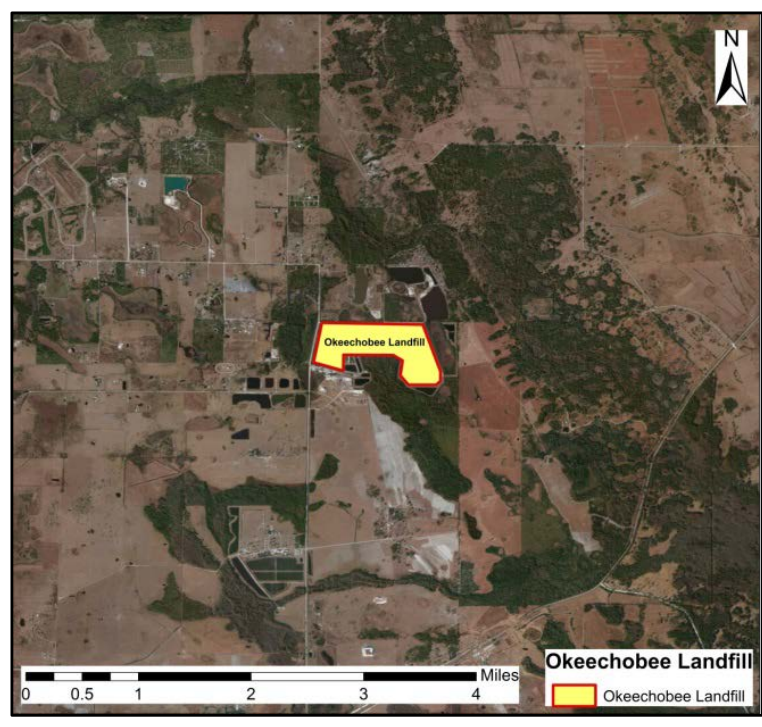

a. Landfill boundary

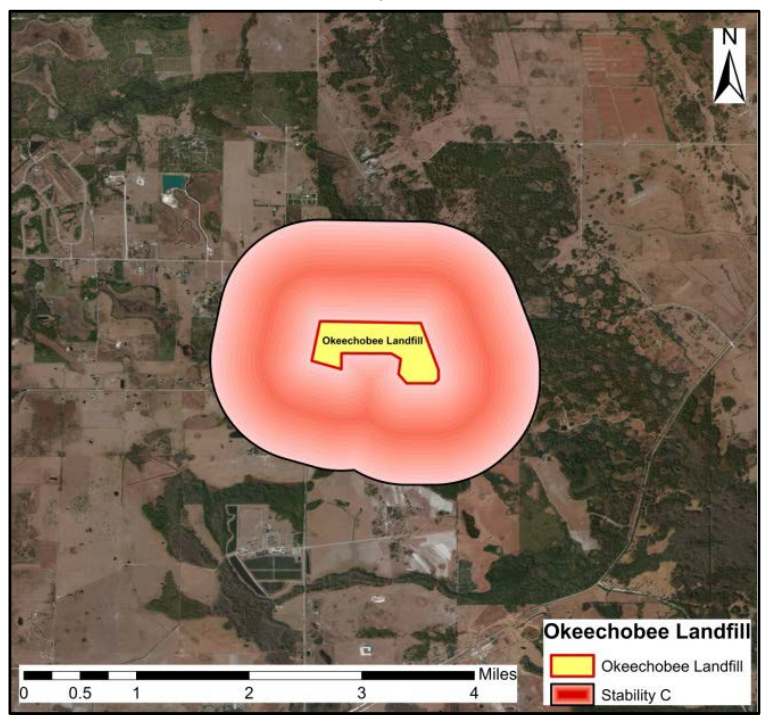

c. Odor impact zone under stability class C

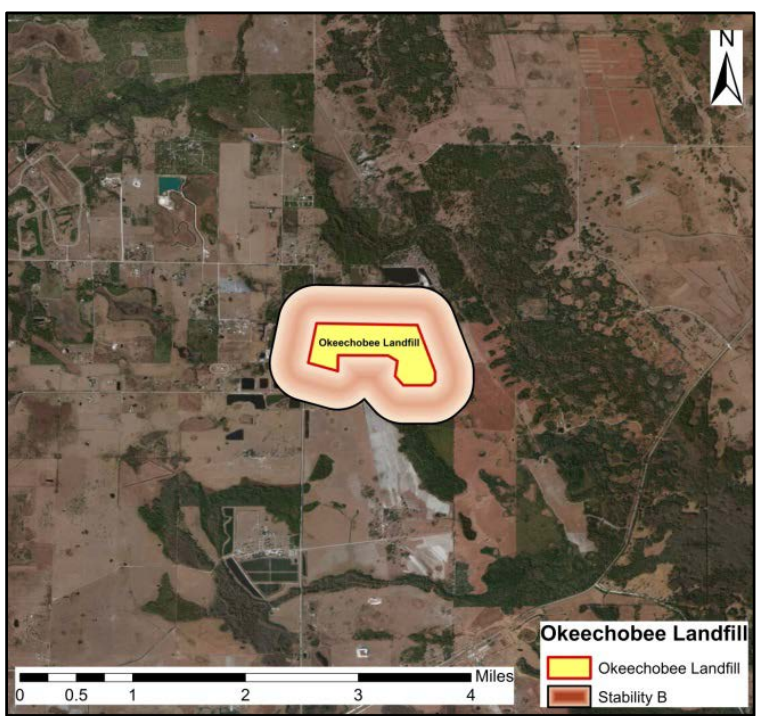

b. Odor impact zone under stability class B

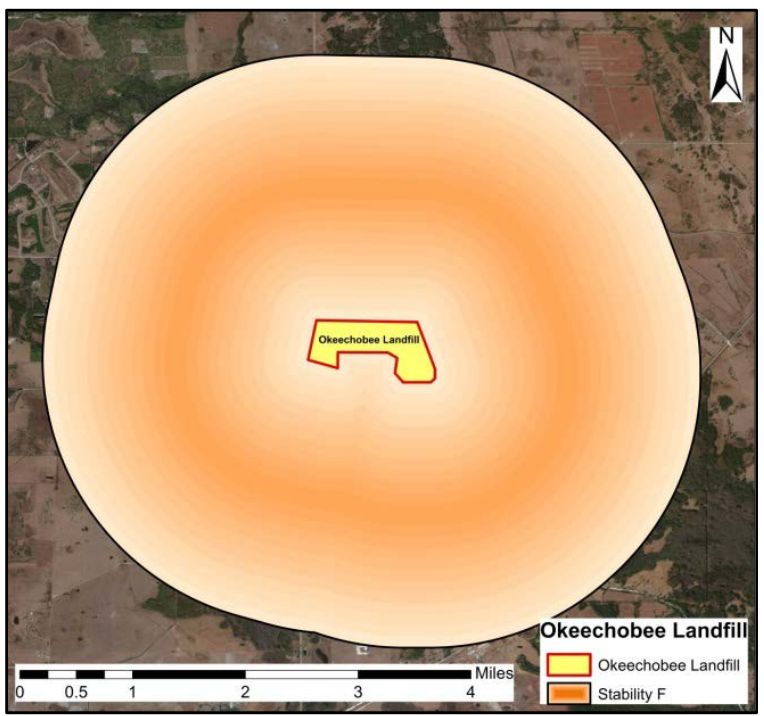

d. Odor impact zone under stability class F Figure 1. Odor impact zones for Okeechobee landfill. 

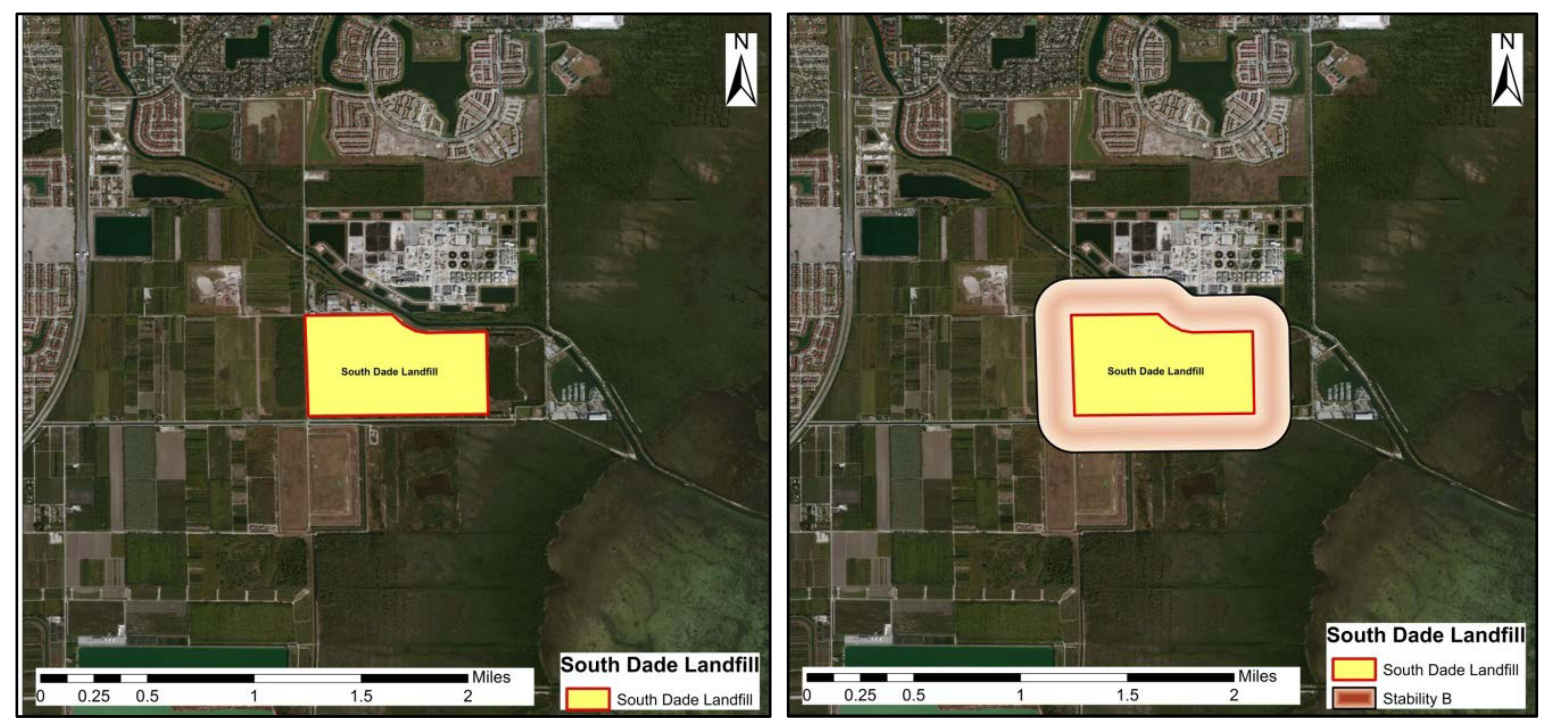

a. Landfill boundary

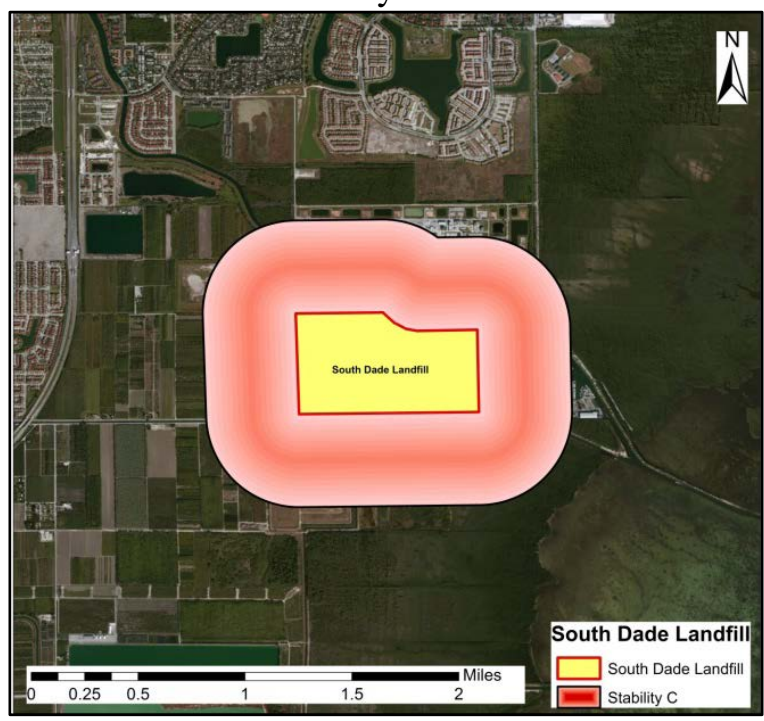

b. Odor impact zone under stability class B

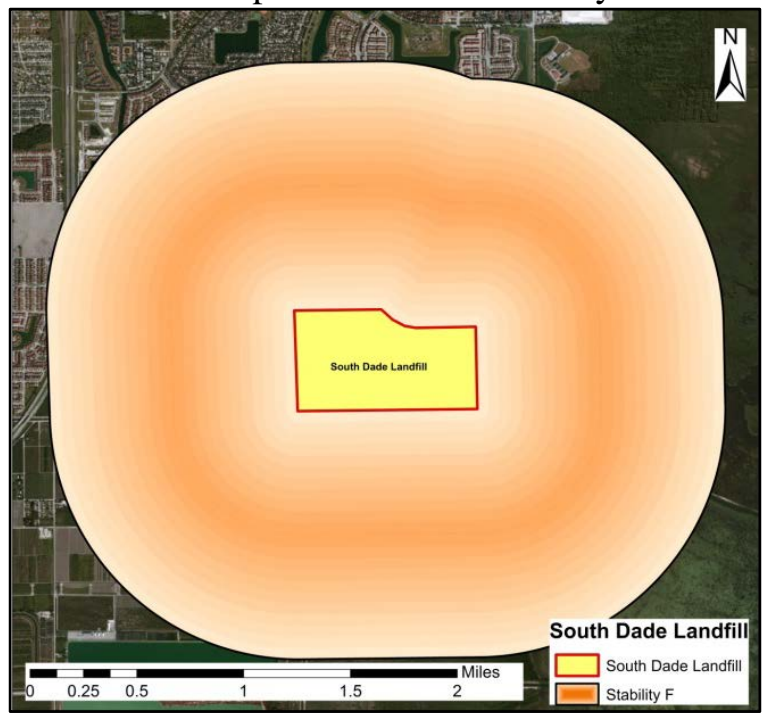

c. Odor impact zone under stability class C

d. Odor impact zone under stability class F Figure 2 Odor impact zones for Sought Dade landfill. 

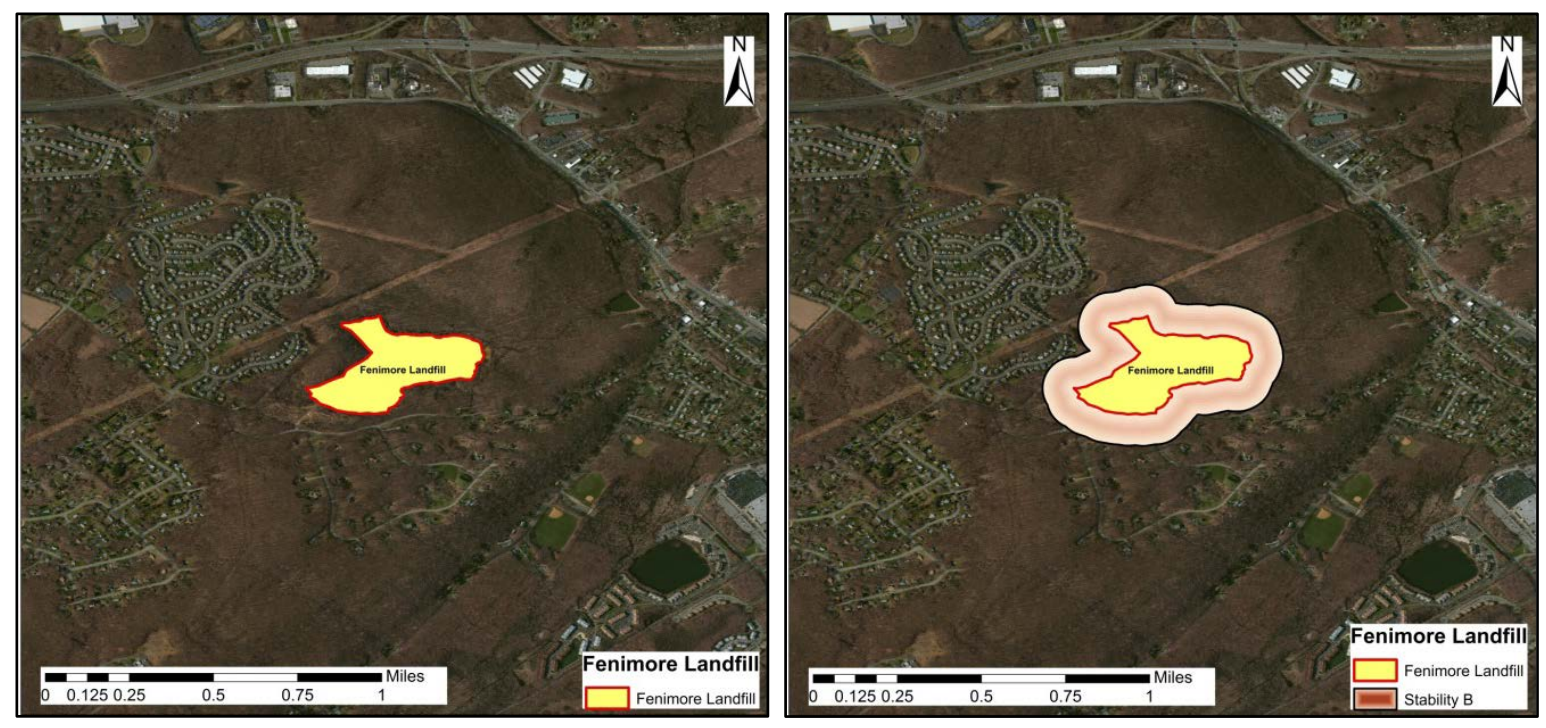

a. Landfill boundary

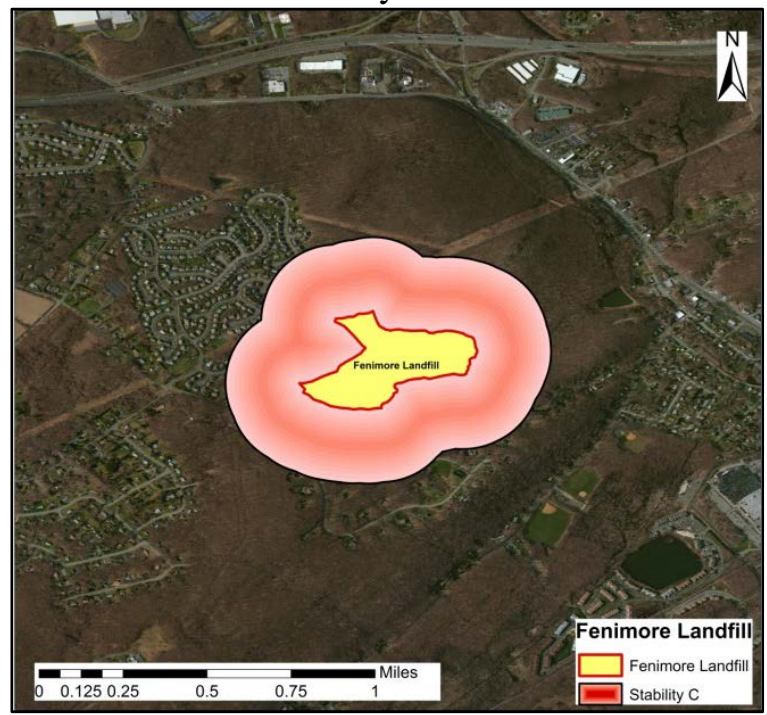

b. Odor impact zone under stability class B

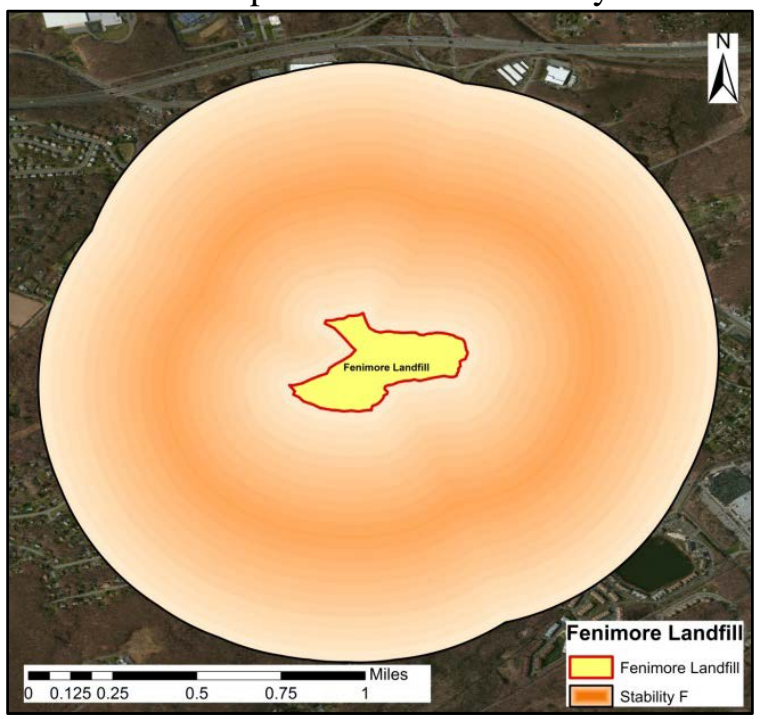

c. Odor impact zone under stability class $\mathrm{C}$

d. Odor impact zone under stability class F Figure 3 Odor impact zones for Fenimore landfill. 


\section{References}

Allen, M. R., Braithwaite, A., Hills, C.C. (1997).Trace organic compounds in landfill gas at seven UK waste disposal sites. Environ. Sci. Technol., 31(4), 1054-1061.

Atkinson, R. (2000). Atmospheric chemistry of VOCs and NOx. Atmos. Environ., 34, 20632101.

Belpomme, D., Irigaray, P., Hardell, L., Clapp, R., Montagnier, L., Epstein, S., Sasco, A.J., 2007. The multitude and diversity of environmental carcinogens. Environ. Res., 105, 414-429.

Capaccioni, B., Caramiello, C., Tatàno, F., Viscione, A. (2011). Effects of a temporary HDPE cover on landfill gas emissions: multiyear evaluation with the static chamber approach at an Italian landfill. Waste Manage., 31, 956-965.

Capelli, L., Sironi, S., Rosso, R.D., Céntola, P., Grande, M.I. (2008). A comparative and critical evaluation of odour assessment methods on a landfill site. Atmos. Environ., 42, 7050-7058.

Chalvatzaki, E., Lazaridis, M., 2010. Assessment of air pollutant emissions from the Akrotiri landfill site (Chania, Greece). Waste Manag. Res., 28(9),778-88.

Chemel, C., Riesenmey, C., Batton-Hubert, M., Vaillant, H. (2012). Odour-impact assessment around a landfill site from weather-type classification, complaint inventory and numerical simulation. J. Environ. Manage., 93(1), 85-94.

Davoli, E., Gangai, M.L., Morselli, L., Tonelli, D., 2003. Characterisation of odorants emissions from landfills by SPME and GC/MS. Chemosphere, 51, 357-368.

EPA (2005). Landfill Gas Emissions Model (LandGEM) Version 3.02 User’s Guide. EPA-600/R05/047.

Firestein, S. (2001). How the olfactory system makes sense of scents. Nature, 413, 211-218.

Gallego, E., Soriano, C., Roca, F.X., Perales, J.F., Alarcon, M., Guardino, X. (2008). Identification of the origin of odour episodes through social participation, chemical control and numerical modelling. Atmos. Environ., 42, 8150-8160.

Hunter, C.H. (2012). A Recommended Pasquill-Gifford Stability Classification Method for Safety Basis Atmospheric Dispersion Modeling at SRS. Savannah River National Laboratory, Aiken, SC, Report No. SRNL-STI-2012-00055

Hutter, H.P., Moshammer, H., Wallner, P., Damberger, B., Tappler, P., Kundi, M. (2006). Health complaints and annoyances after moving into a new office building: a multidisciplinary approach including analysis of questionnaires, air and house dust samples. Int. J. Hyg. Environ. Heal., 209, 65-68.

Irigaray, P., Newby, J.A., Clapp, R., Hardell, L., Howard, V., Montagnier, L., Epstein, S., Belpomme, D. (2007). Lifestyle-related factors and environmental agents causing cancer: An overview. Biomed. Pharmacother., 61, 640-658. 
Liang, H.M., Liao, C.M. (2007). Modeling VOC-odor exposure risk in livestock buildings. Chemosphere, 68, 781-789.

Mahin, T. (2003). Measurement and Regulation of Odors in the USA. Odor measurement review. Ministry of Environment, Japan. http://www.orea.or.jp/en/PDF/Odor_Measurement_Review,.pdf. (online).

Manfredi, S., Tonini, D., Christensen, T.H., Scharff, H. (2009). Landfilling of waste: accounting of greenhouse gases and global warming contributions. Waste Manage. Res., 27, 825-836.

NOAA, 2005. http://response.restoration.noaa.gov/aloha (online).

Noble, R., Hobbs, P.J., Dobrovin-Pennigton, A., Misselbrook, T.H., Mead, A. (2001). Atmospheric pollutants trace gases: olfactory response to mushroom composting emissions as a function of chemical concentration. J. Environ. Qual., 30, 760-767.

Pawlowska, M. (2014). Mitigation of Landfill Gas Emissions. CRC Press, Boca Raton, FL.

Peng,Y.P., Chen, K.S.,Lai, C.H.,Lu, P.J., Kao,J.H.2006.Concentrations of $\mathrm{H}_{2} \mathrm{O}_{2}$ and $\mathrm{HNO}_{3}$ and O3-VOC-NOx sensitivity in ambient air in southern Taiwan. Atmos. Environ., 40, 67416751.

Rappert, S., Müller , R. (2005). Odor compounds in waste gas emissions from agricultural operations and food industries. Waste Manage., 25 (9), 887-907.

Sarkar, U., Hobbs, S.E., Longhurst, P. (2003). Dispersion of odour: a case study with a municipal solid waste landfill site in North London, United Kingdom. J. Environ. Manage., 68(2), 153160.

Scheutz, C., Kjeldsen, P., Bogner, J.E., DeVisscher, A., Hilger, H.A., Huber-Humer, M., Spokas, K. (2009). Microbial methane oxidation processes and technologies for mitigation of landfill gas emissions. Waste Manage. Res., 27(5), 409-455.

Speight, J. G. (2011). The biofuels handbook. No. 5. Royal Society of Chemistry, London, UK.

Tansel, B., Jolis, D., Ho, C.F.H., 2004. Gaseous Emissions from Wastewater Facilities. Water Environ. Res., 76(6), 1343-1374.

Tansel, B., Jolis, D., Ho, C.F.H. (2005). Gaseous Emissions from Wastewater Facilities. Water Environ. Res., 77(6), 1535-1570.

Tansel, B., Jolis, D., Ho, C.F.H. (2006). Gaseous Emissions from Wastewater Facilities. Water Environ. Res., 78(6), 1469-1485.

TCEQ (2007). Texas Comission on Environmental Quality. Odor complaint investigation procedures.

Wolkoff, P., Nielsen, G.D. (2001). Organic compounds in indoor air - their relevance for perceived indoor air quality? Atmos. Environ., 35, 4407-4417. 
U.S. DOE, Office of Environment, Safety and Health (2004). ALOHA computer code application guidance for documented safety analysis; DOE-EH-4.2.1.3-Final ALOHA code guidance, Final report.

Ying, D., Chuanyu, C., Bin, H., Yueen, X., Xuejuan, Z., Yingxu,C., Weixiang, W. (2012). Characterization and control of odorous gases at a landfill site: A case study in Hangzhou, China. Waste Manage., 32( 2), 317-326.

Zou, S.C., Lee, S.C., Chan, C.Y., Ho, K.F., Wang, X.M., Chan, L.Y., Zhang, Z.X. (2003). Characterization of ambient volatile organic compounds at a landfill site in Guangzhou, South China. Chemosphere, 51, 1015-1022. 
Appendix 2- A Multi-Criteria Routing and Scheduling Decision Tool for Transporting Hazardous Cargo: Day Time and Night Time Atmospheric Conditions, Crash Rates, and Delay Times 


\section{Introduction}

According to a study of the accidents involving hazardous materials from late 1970s to early 1980s showed that the incidents of hazardous material accidents which occur on highways are 12 times, 4 times the number of fatalities and 2 times the number of injuries that occurred during rail transport (Blackman, 2001). Hazardous material accidents involving truck shipments in urban areas are more likely to endanger human lives and property. One of the approaches in addressing this challenge is routing and scheduling of shipments to reduce the accidental risks and impacts after accidental releases of hazardous cargo. However, the common attitude in routing hazardous material shipments is to select the shortest path from the origin to the destination. However, in view of the possible impacts after accidental releases of hazardous materials, transport routing and scheduling of hazardous cargos is a more complicated task than simply taking into account only the shortest path. Other consideration such as health risk to society and environment, traffic volumes, risks associated with different routes, weather conditions, and population density play important roles in the selection of the cargo routes. The goal of this study is to develop a multi-criteria decision making tool for routing and scheduling of hazardous material cargos to minimize the health risk, and cost of delays. The effects of atmospheric conditions during the time of day on selection of the cargo routes (scheduling) were considered in evaluating the routing options.

There are a number of studies in the literature which focus on routing and scheduling of hazardous material cargos (Zografos and Davis, 1989; Giannikos, 1998; Coutinho-Rodrigues et al., 1997). The multi-criteria decision making (MCDM) applications are popular in transportation area. For example, MCDM by weighted sum has been used in many studies (Zografos and Androutsopoulos, 2004; Dadkar et al., 2004; Ombuki et al., 2006; Lozanoet al., 2011; Verma, 2009; Iakovou et al., 1999; Verma et al., 2011; Erkut and Alp, 2007). The MCDM by goal programming has also been used in (Zografos and Davis, 1989; Giannikos, 1998; Coutinho- 
Rodrigues et al., 1997). However, MCDM by compromise programming has not been used for hazardous material scheduling and routing.

In this study scheduling and routing were evaluated simultaneously and the desired option (i.e., the route and the period of time during day or night is appropriate for transporting the cargo) was identified by considering the decision criteria. The decision making tool was developed by interfacing with an air dispersion model to account for the health risk associated with the accidental release of hazardous cargo into the air and impacted population. The decision making tool also uses the queuing method to estimate the delay time and the corresponding delay cost for each routing and scheduling option in the case of an accident. Distance between the origin and destination along with the data on the truck operation cost also were employed for the calculation of travel costs. After calculating values of the three criteria, three MCDM methods were employed to analyze the tradeoffs and consequently identify the best routing and scheduling option for transporting the hazardous cargo. MCDM methods which were used in this study are weighted sum, goal programming and compromise programming. The two latter methods are categorized as distance-based decision making methods which try to minimize the distance of the routing/scheduling solution. A case study was used to demonstrate the implementation of the multi-criteria decision tool and compare the results obtained by the three MCDM methods.

\section{Methodology}

Real world decision making problems involve many conflicting criteria and objectives to be taken into consideration in tradeoffs. Therefore, mathematical methods have been developed to aid decision makers to evaluate and compare the alternatives and identify the best alternative among the possible options.

The aim of the multi-criteria decision framework developed by this study is for the selection of routing and scheduling of hazardous cargos. In this study, three criteria used include 
health risk, cost of delay and travel cost for evaluations of the cargo routing and scheduling alternatives. The effect of atmospheric conditions, crash rates and traffic volumes during day and night time were used for evaluation of the alternatives.

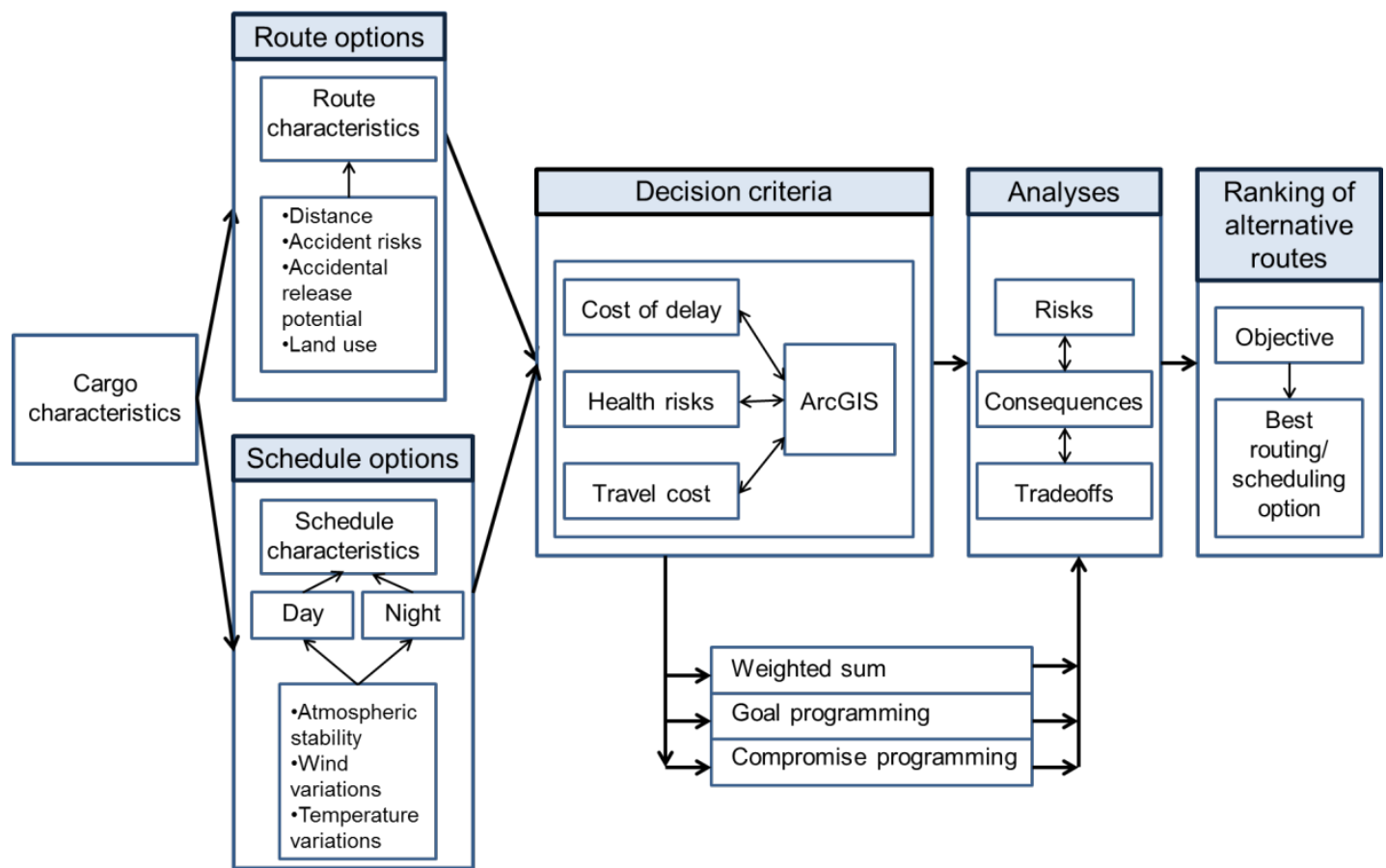

Figure 1 Flow chart for the multi-criteria framework for routing/scheduling options.

As presented in Figure 1, the method used for evaluation of data specific to the routing and scheduling options as well as the cargo characteristics (i.e., crash data, traffic volume, cargo characteristics, accidental releases, health threats causing by hazardous material spills, origin and destination, routing/scheduling options between the origin and the destination). Based on the data available, the routing/scheduling options are evaluated according to the criteria identified. The consequences of accidental releases are evaluated using ArcGIS tools for each alternative. The MCDM methods are used for the comparison of the alternatives and to identify the best routing and scheduling option to transport the hazardous cargo. 


\section{Risk Calculations}

The health risks due to inhalation of hazardous chemicals after an accidental release was calculated by Equation 1:

Risk $=$ Frequency $\times$ Consequences

Accident frequency can be estimated from the number of similar events occurring per year and the consequences can be expressed from different perspectives (i.e., impacted population, fatalities, size of the impacted area, cost of traffic congestion due to delay, environmental impacts) (Pollard, 2008). The air dispersion model Areal Locations Hazardous Atmospheres (ALOHA) was used for estimating the air quality and by incorporating the possible health impacts due to exposure to hazardous materials after released to the atmosphere caused by the accidents (U.S. DOE, 2004).

\section{Accident Frequencies}

The frequency of the accidents involving hazardous material trucks was estimated as defined in the Highway Safety Manual (HSM) from the number of accidents which occurred on the route during a 1-year period (National Research Council, 2010). Crash rate is defined as the normalized value of the crash frequency with exposure (the degree to which a road user is exposed to traffic risks). Exposure in million vehicle miles traveled was calculated by Equation 2. Crash rate was estimated by the Equation 3 (Gan et al., 2012). The crash rates during day and night times were calculated by defining day time from 6:00 to 17:59 and night time from 18:00 to 5:59 and considering crashes and traffic volume during these two periods of time (i.e., day time and night time). 
EXPO $=\frac{\text { AADT } \times 365 \times \text { number of years } \times \text { total segment length }}{1,000,000}$

Crash rate $=\frac{\text { Total crash count }}{\text { EXPO }}$

where, EXPO is exposure and AADT is annual average daily traffic.

\section{Estimation of Consequences}

The air quality dispersion model (ALOHA) was utilized to estimate the air quality impacts in the surrounding areas in terms of hazardous chemical concentrations which can be carried by wind. The health impact zone associated with each route or segment was delineated by overlaying the output impact zones estimated ALOHA along the routes. The impacted zones were mapped using ArcGIS by defining buffer zones based on the impact radius in relation to the levels of concentration (estimated by ALOHA) surrounding each route or segment of the road. The population density map was used to estimate the number of people and the size of the area at risk. In this study, the life-threatening health effects or death hazard zones were identified by ALOHA and were taken into account for calculations of the consequences. Accordingly, based on the size of the impact zones, the risk levels and the consequences were estimated.

Apart from the effect of quantity of the releases chemical on the extent of the threat zones, the size of health impact zones is a function of meteorological characteristics of the atmosphere and accordingly the stability of the atmosphere. Once a chemical is released into the air, it starts mixing with the air's molecules and being diluted, depending on the atmospheric condition the speed of the chemical's dilution varies. Atmospheric stability can be defined as the ability of air's molecules in creating vertical movements which affect the pace of the dilution of the chemical in the atmosphere. Based on the Pasquill atmospheric categories, stabilities can be 
categorized in 6 classes: A to F; the ability of vertical movement of the air particles decreases from an extremely unstable class of A to a very stable class of F. Therefore, the health impact area of the chemical grows by existence of an unstable atmosphere to a stable one. According to the Pasquill table which is shown in Table 1. E and $\mathrm{F}$ are stable atmospheric classes which normally occur during night with a cloudy sky (considering wind speed of 5mph) and unstable class of A, B and C can be observed during day (Inanloo et al., 2014). Although wind plays an important role in dilution of the chemical; atmospheric conditions define the how the chemical will be dispersed under the same wind speed. If the release of the chemical occurs during day time, it is more likely to be diluted faster than that during night.

Table 1 Atmospheric stability categories (Turner, 1994)

\begin{tabular}{|c|c|c|c|c|c|}
\hline \multirow{3}{*}{$\begin{array}{l}\text { Surface wind } \\
\text { speed }^{a}(\text { at } 10 \mathrm{~m}) \\
(\mathrm{m} / \mathrm{s})\end{array}$} & \multirow{2}{*}{\multicolumn{3}{|c|}{$\begin{array}{c}\text { Day }^{b} \\
\text { Incoming solar radiation }\end{array}$}} & \multicolumn{2}{|c|}{ Night } \\
\hline & & & & \multirow{2}{*}{ Cloudy } & \multirow{2}{*}{ Clear } \\
\hline & Strong ${ }^{c}$ & Moderate $^{d}$ & Slight $^{e}$ & & \\
\hline$<5$ & $\mathrm{~A}$ & A-B & B & $E$ & $F$ \\
\hline $5-7$ & A-B & B & $\mathrm{C}$ & E & $\mathrm{F}$ \\
\hline $7-11$ & B & B-C & $\mathrm{C}$ & $\mathrm{D}$ & $\mathrm{E}$ \\
\hline $11-13$ & $\mathrm{C}$ & C-D & $\mathrm{D}$ & $\mathrm{D}$ & D \\
\hline$>13$ & $\mathrm{C}$ & $\mathrm{D}$ & $\mathrm{D}$ & $\mathrm{D}$ & $\mathrm{D}$ \\
\hline
\end{tabular}

${ }^{a}$ Surface wind speed measure at $10 \mathrm{~m}$ above ground.
${ }^{\mathrm{b}}$ A: Very unstable
D: Neutral
B: Moderately unstable
E: Slightly stable
C: Slightly unstable
F: Stable

${ }^{\mathrm{c}}$ Clear summer day with sun higher than $60^{\circ}$ above the horizon.

${ }^{\mathrm{d}}$ Summer day with a few broken clouds, or a clear day with sun $35-60^{\circ}$ above the horizon.

${ }^{\mathrm{e}}$ Fall afternoon, or a cloudy summer day, or clear summer day with sun $15-35^{\circ}$.

\section{Estimation of Delay Cost}

Delay cost was estimated by multiplication of the delay time caused by an accident to the dollar value of travel time delay. Queuing analysis was employed to estimate the accident delays. The total delay time for one incident, TD, was estimated from Equation 4: 
$\mathrm{TD}=\frac{\mathrm{t}_{\mathrm{R}}^{2}\left(\mu-\mu_{\mathrm{R}}\right) \times\left(\lambda-\mu_{\mathrm{R}}\right)}{2 \times(\mu-\lambda)}$

where, $t_{R}$ is the incident duration and $\lambda$ is the mean arrival rate, $\mu$ is the mean capacity, and, $\mu_{R}$ is the capacity during the incident. The values of $\mu$ and $\mu_{R}$ were obtained from the Highway Capacity Manual (2000) (Hadi et al., 2008). According to the 2007 Urban Mobility Report, the value of travel time delay is $\$ 14.60$ per hour of person travel. Hence, delay costs were estimated by multiplying the delay time by the value of hourly person travel and by the average passenger vehicle occupancy rate, which is 1.58 occupants in Florida (FDOT, 2011). Delay costs were calculated for both day and night time according to the arrival rates during the two periods.

\section{Estimation of Trucking Costs}

Operational costs of trucking involve both vehicle-based and driver-based costs. Vehiclebased costs consist of fuel cost, truck lease or purchase payment, maintenance and repair costs, insurance, tires, permits and licenses, and tolls. Driver-based costs include driver wages and benefits. According to the American Transport Research Institute (ATRI), the average total carrier cost in 2011 was $\$ 1.706$ per mile. This value was used in this study. The transportation costs were estimated by multiplying the average total carrier cost with the travel distance for each route (Fender and Pierce, 2012).

\section{Multi-Criteria-Decision-Making Methods}

\section{Weighed Sum}

One of the commonly used methods in solving multi-criteria problems is weighted sum. This method requires assigning weights for each of the criterion and combines the weighted criteria into one value so that a cumulative value can be obtained to compare or rank the 
alternatives. The weighted performances of the alternatives can be estimated by the following equation if the goal is to minimize the impacts (e.g., cost, risk) (Linkov and Moberg, 2011):

$\operatorname{Min}\left\{\sum_{\mathrm{i}=1}^{\mathrm{n}} \mathrm{w}_{\mathrm{i}}\left(\mathrm{C}_{\mathrm{i}, \mathrm{j}}\right)\right\}, \forall \mathrm{j}$

where, $i=\{1,2,3, . ., m\}$ is the set of criteria, $\mathrm{j}=\{1,2,3, . ., \mathrm{n}\}$ is the set of possible routing and scheduling alternatives, $\mathrm{w}_{\mathrm{i}}$ is the weight assigned to the criterion $\mathrm{i}$, and $\mathrm{C}_{\mathrm{i}, \mathrm{j}}$ is the performance of alternative $\mathrm{j}$ on criterion $\mathrm{i}$. The weight assigned to each criterion plays a significant role in the selection of the best alternative. The criteria weights are identified based on the priorities of the decision makers. Therefore, the best alternative by this method may change depending on the weights assigned to the criteria. For example, if the decision maker prioritizes the operation cost over health risk and delay cost, he/she may assign a higher weight to the trucking cost.

\section{Goal Programming}

Goal programming (GP) is a flexible and easy to implement decision making method.

The methodology aims to identify the best alternative with the lowest deviation from the specific goals. There are several goal programming approached available for evaluation of the alternatives. In this study the least squares solution was used to identify the alternative with minimum impacts (for the criteria used).

This goal programming method selects the most preferable routing and scheduling solution as the one which has the minimum total squared distances from the ideal solution and the proposed resource share as described by Equation 6:

$\operatorname{Min}\left\{\sum_{i=1}^{n}\left(w_{i}\left(C_{i}^{*}-C_{i, j}\right)\right)^{2}\right\}, \quad \forall j$ 
where $\mathrm{C}_{\mathrm{i}}^{*}$ is the ideal value of the criterion $\mathrm{i}$.

The least squares solution selects an alternative which minimizes the sum of deviations and does not differentiate between the deviations of the criteria. As a result, it may recommend a solution that favors criteria with high value of goal, which makes this method inappropriate when the goals for each criterion are heterogeneous. An improvement is to consider dissatisfaction as the percent deviation from the ideal solution. In this study, the improved least squares approach was used as provided by Equation 7 (Read et al., 2014):

$\operatorname{Min}\left\{\sum_{i=1}^{n}\left(w_{i} \frac{C_{i}^{*}-C_{i, j}}{C_{i}^{*}}\right)^{2}\right\}, \forall j$

The goal programming method identifies the overall maximum deviations of all criteria from goals and selects a scheme that has the minimum maximum deviation. Thus, the Minimax solution tries to distribute deviations across all criteria homogeneously, which is expected to be more acceptable in practice than an imbalanced distribution of dissatisfaction. Minimax can be formulated as follows:

$\operatorname{Min} \operatorname{Max}\left\{\mathrm{w}_{\mathrm{i}}\left(\mathrm{C}_{\mathrm{i}}^{*}-\mathrm{C}_{\mathrm{i}, \mathrm{j}}\right)\right\}, \forall \mathrm{i}, \forall \mathrm{j}$

Compromise Programming

According to compromise programming (CP), the best solution is the one closest to the ideal point which is defined by a series of distance measures that identify the feasible set. The compromise programming uses the concept of goal programming with normalized values of 
distance deviations to reduce the influences of large values and achieve a realistic comparison between deviations. The method choses the best solution using Equation 9 (Read et al., 2014):

$\operatorname{Min} L_{P}=\left[\sum_{i=1}^{n}\left|w_{i} \frac{C_{i}^{*}-C_{i, j}}{C_{i}^{*}-C_{i}^{-}}\right|^{p}\right]^{1 / p}, \forall i, \forall j$

where $\mathrm{C}_{\mathrm{i}}^{*}$ is the ideal value for of the criteria $\mathrm{i}, \mathrm{C}_{\mathrm{i}}^{-}$is the anti-ideal value and $\mathrm{p}$ is a parameter with values in the range from $[1, \infty]$. Solving the equation for $p=1$ and $p=\infty$ ensures that the solution falls within the compromise set. As the value of p increases, the solution shifts from minimizing the sum of deviations to minimizing the maximum deviations of the criteria (Read et al., 2014).

For $\mathrm{p}=\infty$, the best solution is the one that seeks the lowest level of criterion deviation by minimizing the maximum criterion deviations. In other words, the largest deviation has the greatest influence as identified by the Equation 10 (Romero and Rehman, 2003).

$\operatorname{Min} \operatorname{Max}\left|\frac{C_{i}^{*}-C_{i, j}}{C_{i}^{*}-C_{i}^{-}}\right|, \forall i, \forall j$

\section{Case Study}

In order to show the applicability of the proposed framework on a real world problem, a case study was developed for selection of the best routing/scheduling option for a tanker truck carrying gasoline from a specific origin to a specific destination in Florida, USA. It was assumed that due to an accident the hazardous material cargo (gasoline) was released to air. The accident was assumed to cause the closure of three lanes of the route for one hour. Three different route options were identified based on the location of the origin and destination and the available routes 
(Figure 2 (a)). The health risk and travel and delay costs were calculated for each route to identify the best route.

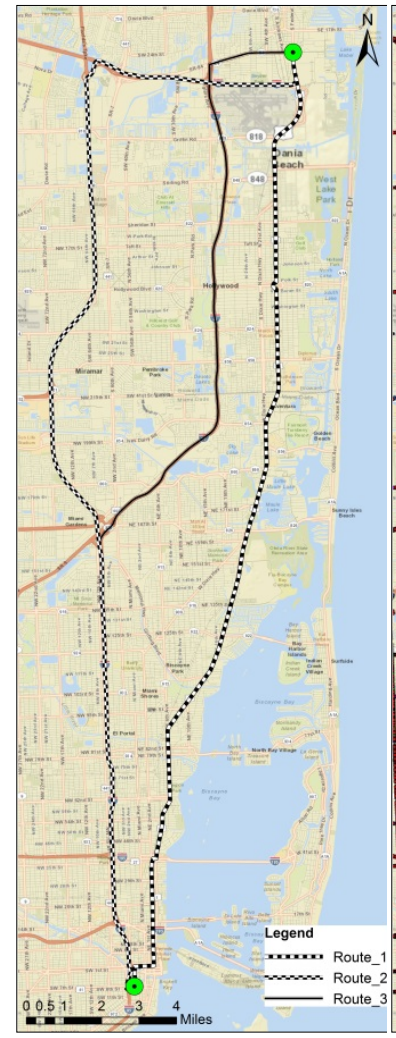

(a) Cargo Routes

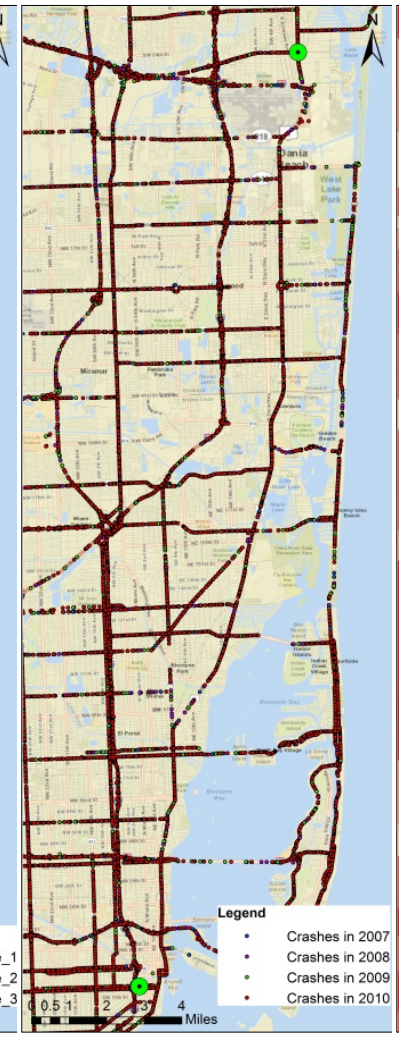

(b) Crashes

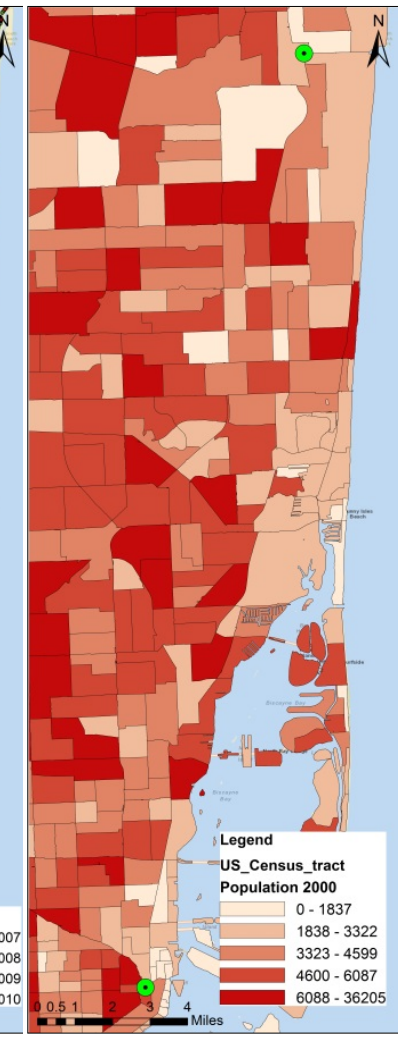

(c) Population density

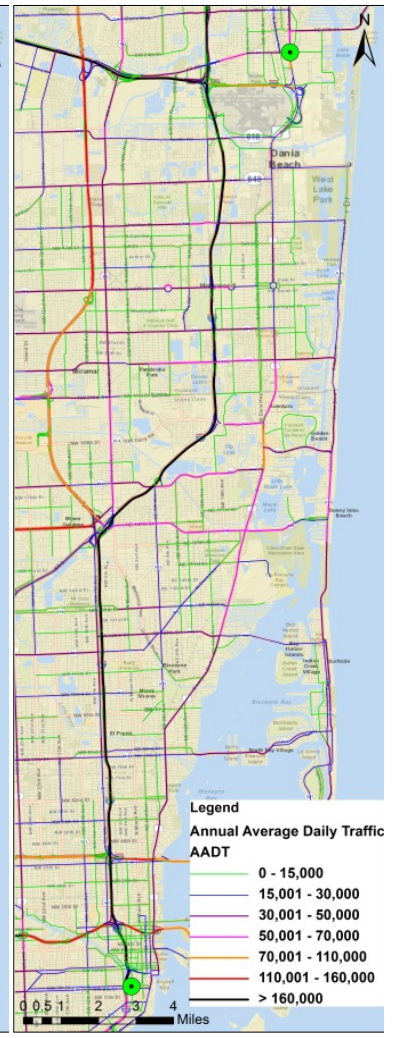

(d) AADT

FIGURE 2 Routing options between origin and destination and data layers.

For the three routing options, two different crash rates during day or night were calculated (Figure 2 (b)). Besides, five possible atmospheric conditions were taken into account which resulted in five different health impact buffer zones. This fact brings the number of routing/scheduling options to 15 alternatives ( 3 routes $\times 5$ health impact radiuses (three during day and two during night). Therefore, 9 out of 15 alternatives were scheduled during the day time and the rest during the night time (Table 2). 
Table 2 Routing/scheduling alternatives characteristics

\begin{tabular}{|c|c|c|c|c|}
\hline \multirow{2}{*}{ Time } & \multirow{2}{*}{ Stability class } & \multicolumn{3}{|c|}{ Route options } \\
\hline & & Route_1 & Route_2 & Route_3 \\
\hline \multirow{3}{*}{$\stackrel{\vec{\Xi}}{\overrightarrow{0}}$} & A & 1 & 2 & 3 \\
\hline & B & 4 & 5 & 6 \\
\hline & $\mathrm{C}$ & 7 & 8 & 9 \\
\hline \multirow{2}{*}{$\begin{array}{l}\vec{z} \\
\frac{0}{20} \\
z\end{array}$} & $\mathrm{E}$ & 10 & 11 & 12 \\
\hline & $\mathrm{F}$ & 13 & 14 & 15 \\
\hline
\end{tabular}

\section{RESULTS}

Two sets of criteria weights were assigned as shown in Table 3 to evaluate the sensitivity of the results. Based on the weight set 1 , the health risk is prioritizes over delay and travel costs. On the other hand, weight set 2 considers the travel cost to be more important. The health risk calculations were performed based on both the area and population at risk. This is due the fact that some parts of the route may pass through unoccupied regions with a small population density and some may pass through highly populated areas. Therefore, for some route options, the area that would be impacted would not be a good representative of the health threat. However, the population at risk (after the release of hazardous material) could be a better representation of the significance of the impacts (i.e., health risks) (Figure 2 (c)).

Table 3 Weight sets characteristics

\begin{tabular}{lcc}
\hline & \multicolumn{2}{c}{ Weight sets } \\
\cline { 2 - 3 } Criteria & $\mathbf{1}$ & $\mathbf{2}$ \\
\hline Health risk (based on area) & 0.5 & 0.2 \\
Health risk (based on population) & 0.5 & 0.2 \\
Delay cost & 0.2 & 0.2 \\
Travel cost & 0.3 & 0.6 \\
\hline
\end{tabular}

Table 4 presents the results of the decision making methods assigning weight sets 1 and 2 for both the area and population at risk perspectives. According to Table 4 (a), based on the 
weighted sum and goal programming methods, alternative 12 was selected as the best routing and scheduling option. This alternative suggests that carrying the cargo through route \#3 and during night (Stability class of E). However, the method selected option 15 which is the route \#3 but under F stability of atmosphere, along with option 12. Compromise programming $(\mathrm{P}=2)$ chose option 10 which corresponds to route \#2 and stability class of E. All the selected options suggest that scheduling the cargo transport during night is better as the atmosphere is more stable in comparison to day time. On the other hand, compromise programming chose route \#1 during the day time (options: 1, 4, 7) and during night under stability of E (alternative 10).

Table 4 (b) presents the ranking of the alternatives by using the weight set 2 and based on the population at risk. As it can be seen, by changing the weight set, the best alternatives are the same as those for weight set 1 , however, there are minor differences in the ranking of some options in relation to each other. Table 4 (c) presents the result of the ranking the alternatives according to weight set 1 by considering the area at risk. Again, the weighted sum and goal programming methods had the same routing and schedule option as the best alternatives in comparison to the result of compromise programming, which is the route \#3 and during the night time under stability of $\mathrm{F}$ (option 15). The two best options are the alternative 12 (route \#3 during night (class E)) and the alternative 15. However, both methods of compromise programming selected alternative 1 (route \#1 and during day time under stability class of A) according to the table.

Based on the results presented in Table 4 (d), the best alternatives are the same as Table 4 (c), with some differences in the result of Compromise Programming (MINMAX) by selecting alternatives 4 and 7 along with alternative 1. Changing the weight set also resulted in some changes in the ranking of other alternatives other than the ranking of the first option. 
Table 4 Ranking of Routing/Scheduling Alternatives

\begin{tabular}{|c|c|c|c|c|c|c|c|c|c|c|c|c|c|c|c|}
\hline \multirow{2}{*}{ Methods } & \multicolumn{4}{|c|}{ (a) } & \multicolumn{11}{|c|}{$\begin{array}{l}\text { Routing/Scheduling Alternatives for weight set \#1 based on population at } \\
\text { risk }\end{array}$} \\
\hline & 1 & 2 & 3 & 4 & 5 & 6 & 7 & 8 & 9 & 10 & 11 & 12 & 13 & 14 & 15 \\
\hline Weighted Sum & 7 & 13 & 10 & 8 & 14 & 11 & 9 & 15 & 12 & 3 & 5 & 1 & 4 & 6 & 2 \\
\hline Least Squares Solution & 7 & 13 & 10 & 7 & 13 & 10 & 7 & 13 & 10 & 3 & 5 & 1 & 4 & 6 & 2 \\
\hline Least Square (Improved) & 7 & 13 & 10 & 8 & 13 & 10 & 9 & 13 & 12 & 3 & 5 & 1 & 4 & 6 & 2 \\
\hline MINIMAX & 7 & 13 & 10 & 7 & 13 & 10 & 7 & 13 & 10 & 3 & 5 & 1 & 3 & 5 & 1 \\
\hline $\begin{array}{l}\text { Compromise Programming } \\
(\mathrm{P}=2)\end{array}$ & 2 & 14 & 9 & 3 & 13 & 10 & 4 & 15 & 11 & 1 & 7 & 5 & 12 & 8 & 6 \\
\hline $\begin{array}{l}\text { Compromise Programming } \\
\text { (MINMAX) }\end{array}$ & 1 & 13 & 9 & 1 & 13 & 9 & 1 & 13 & 9 & 1 & 7 & 5 & 12 & 7 & 6 \\
\hline \multirow[t]{2}{*}{ Methods } & \multicolumn{4}{|c|}{ (b) } & \multicolumn{11}{|c|}{$\begin{array}{c}\text { Routing/Scheduling Alternatives for weight set \#2 based on population at } \\
\text { risk }\end{array}$} \\
\hline & 1 & 2 & 3 & 4 & 5 & 6 & 7 & 8 & 9 & 10 & 11 & 12 & 13 & 14 & 15 \\
\hline Weighted Sum & 7 & 13 & 10 & 8 & 14 & 11 & 9 & 15 & 12 & 3 & 5 & 1 & 4 & 6 & 2 \\
\hline Least Squares Solution & 7 & 13 & 10 & 7 & 13 & 10 & 7 & 13 & 10 & 3 & 5 & 1 & 4 & 6 & 2 \\
\hline Least Square (Improved) & 7 & 13 & 10 & 8 & 13 & 10 & 9 & 13 & 12 & 3 & 5 & 1 & 4 & 6 & 2 \\
\hline MINIMAX & 7 & 13 & 10 & 7 & 13 & 10 & 7 & 13 & 10 & 3 & 5 & 1 & 3 & 5 & 1 \\
\hline $\begin{array}{l}\text { Compromise Programming } \\
(\mathrm{P}=2)\end{array}$ & 2 & 14 & 8 & 3 & 13 & 9 & 4 & 15 & 10 & 1 & 11 & 6 & 5 & 12 & 7 \\
\hline $\begin{array}{l}\text { Compromise Programming } \\
\text { (MINMAX) }\end{array}$ & 1 & 13 & 8 & 1 & 13 & 8 & 1 & 13 & 8 & 1 & 11 & 6 & 5 & 11 & 6 \\
\hline \multirow[t]{2}{*}{ Methods } & \multicolumn{15}{|c|}{ Routing/Scheduling Alternatives for weight set \#1 based on area at risk } \\
\hline & 1 & 2 & 3 & 4 & 5 & 6 & 7 & 8 & 9 & 10 & 11 & 12 & 13 & 14 & 15 \\
\hline Weighted Sum & 7 & 13 & 10 & 8 & 14 & 11 & 9 & 15 & 12 & 3 & 5 & 2 & 4 & 6 & 1 \\
\hline Least Squares Solution & 7 & 13 & 10 & 8 & 13 & 10 & 9 & 13 & 10 & 3 & 5 & 2 & 4 & 6 & 1 \\
\hline Least Square (Improved) & 7 & 13 & 10 & 8 & 13 & 11 & 9 & 13 & 12 & 3 & 5 & 2 & 4 & 6 & 1 \\
\hline MINIMAX & 7 & 13 & 10 & 7 & 13 & 10 & 7 & 13 & 10 & 3 & 5 & 1 & 3 & 5 & 1 \\
\hline $\begin{array}{l}\text { Compromise Programming } \\
(\mathrm{P}=2)\end{array}$ & 1 & 13 & 8 & 2 & 14 & 9 & 3 & 15 & 10 & 11 & 6 & 5 & 12 & 7 & 4 \\
\hline $\begin{array}{l}\text { Compromise Programming } \\
\text { (MINMAX) }\end{array}$ & 1 & 13 & 8 & 2 & 13 & 8 & 3 & 13 & 8 & 11 & 6 & 5 & 12 & 6 & 4 \\
\hline \multirow[t]{2}{*}{ Methods } & \multicolumn{4}{|c|}{ (d) } & \multicolumn{11}{|c|}{ Routing/Scheduling Alternatives for weight set \#2 based on area at risk } \\
\hline & 1 & 2 & 3 & 4 & 5 & 6 & 7 & 8 & 9 & 10 & 11 & 12 & 13 & 14 & 15 \\
\hline Weighted Sum & 7 & 13 & 10 & 8 & 14 & 11 & 9 & 15 & 12 & 3 & 5 & 2 & 4 & 6 & 1 \\
\hline Least Squares Solution & 7 & 13 & 10 & 8 & 13 & 10 & 9 & 13 & 10 & 3 & 5 & 2 & 4 & 6 & 1 \\
\hline Least Square (Improved) & 7 & 13 & 10 & 8 & 13 & 10 & 9 & 13 & 12 & 3 & 5 & 2 & 4 & 6 & 1 \\
\hline MINIMAX & 7 & 13 & 10 & 7 & 13 & 10 & 7 & 13 & 10 & 3 & 5 & 1 & 3 & 5 & 1 \\
\hline $\begin{array}{l}\text { Compromise Programming } \\
(\mathrm{P}=2)\end{array}$ & 1 & 13 & 8 & 2 & 14 & 9 & 3 & 15 & 10 & 4 & 11 & 7 & 5 & 12 & 6 \\
\hline $\begin{array}{l}\text { Compromise Programming } \\
\text { (MINMAX) }\end{array}$ & 1 & 13 & 8 & 1 & 13 & 8 & 1 & 13 & 8 & 4 & 11 & 6 & 5 & 11 & 6 \\
\hline
\end{tabular}


In reality, it is not possible to select the stability conditions of the atmosphere. However, it is a known fact that during the day three atmospheric conditions of A, B and C are more likely to exist and during the night the atmospheric conditions are more likely to be the conditions described by stability classes of $\mathrm{E}$ and $\mathrm{F}$ (under the wind speed selected by this study (5 mph)). However, based on the characteristics of the atmospheric conditions, as the atmosphere becomes unstable, the tendency of air masses in creating vertical movements and mobility of the contaminant increases and air concentration of the contaminant is diluted. On the other hand, when atmosphere is stable, the chemical remains in air for a longer time at high levels which leads to more significant health impacts. During the night and under stability class of F the impact radius is larger in comparison to the other conditions. Therefore, in this study atmospheric stability class of $\mathrm{C}$ and $\mathrm{F}$ were considered as the worst case scenarios for evaluating the day time and night time health impact zones, respectively. The results of the ranking of the alternatives are presented in Table 5.

Table 5 Ranking of Routing/Scheduling Alternatives

\begin{tabular}{|c|c|c|c|c|c|c|}
\hline \multirow{2}{*}{ Methods } & (a) & \multicolumn{5}{|c|}{ Routing/Scheduling Alternatives based on area under risk } \\
\hline & 7 & 8 & 9 & 13 & 14 & 15 \\
\hline \multirow{6}{*}{$\begin{array}{l}\text { Weighted Sum } \\
\text { Least Squares Solution } \\
\text { Least Square (Improved) } \\
\text { MINIMAX } \\
\text { Compromise Programming } \\
(\mathrm{P}=2) \\
\text { Compromise Programming } \\
\text { (MINMAX) }\end{array}$} & 4 & 6 & 5 & 2 & 3 & 1 \\
\hline & 4 & 6 & 5 & 2 & 3 & 1 \\
\hline & 4 & 6 & 5 & 2 & 3 & 1 \\
\hline & 4 & 6 & 5 & 2 & 3 & 1 \\
\hline & 1 & 6 & 4 & 5 & 3 & 2 \\
\hline & 1 & 6 & 4 & 5 & 3 & 2 \\
\hline \multirow[t]{2}{*}{ Methods } & (b) & \multicolumn{5}{|c|}{ Routing/Scheduling Alternatives based on population at risk } \\
\hline & 7 & 8 & 9 & 13 & 14 & 15 \\
\hline Weighted Sum & 4 & 6 & 5 & 2 & 3 & 1 \\
\hline Least Squares Solution & 4 & 6 & 5 & 2 & 3 & 1 \\
\hline Least Square (Improved) & 4 & 6 & 5 & 2 & 3 & 1 \\
\hline MINIMAX & 4 & 6 & 5 & 2 & 3 & 1 \\
\hline $\begin{array}{l}\text { Compromise Programming } \\
(\mathrm{P}=2)\end{array}$ & 1 & 6 & 4 & 2 & 5 & 3 \\
\hline $\begin{array}{l}\text { Compromise Programming } \\
\text { (MINMAX) }\end{array}$ & 1 & 6 & 4 & 2 & 5 & 3 \\
\hline
\end{tabular}


According to Table 5, based on both the area and population at risk, the best alternatives selected by weighted sum and goal programming methods are option 15 (route \#3 during night) and using the compromise programming method option 7 which corresponds to route \#1 and during day time. Therefore, there were not significant differences in the best routing and scheduling options identified by considering either the affected area or the exposed population. The evaluations were performed using the two sets of assigned weights and the results were the same. This may be because the characteristics of the route where weight coefficients did not play an important role in selection of the best alternative.

Based on the results of this study on evaluation of different routing options, in general, during day the health risks are lower; on the other hand, delay cost is higher. The conflicting nature of these two criteria affects the tradeoff between the different routing options.

Two decision making methods of weighted sum and goal programming provided the same results in terms of the best routing and scheduling option and the compromise programming yielded a different routing and scheduling option. The reason for this difference could be the formulation of the methods, the first two methods work with the actual values of the criteria under each alternative, while compromise programming normalizes the values. This procedure decreases the influence of high order values of some criteria and makes the comparison more reasonable. However, compromise programming showed a number of best alternatives in some cases instead of selecting only one option to be implemented for routing and scheduling of the cargo deliveries. For the case study, changing of the weights of the criteria did not have a significant effect on the selection of the best alternative. This might be because of the specific characteristics of the case study used for the evaluations. 


\section{Conclusions}

The main objective of this study was to develop a decision making tool for identification of the best routing and scheduling alternatives for transport of hazardous material cargos. The importance of the atmospheric conditions on the tradeoffs of scheduling options was evaluated. The route options were evaluated in view of atmospheric stability condition during day time and night time along with the corresponding data (i.e., atmospheric condition, traffic volume, possible delays, crashes) to generate scheduling options. The health risks, delay costs and crashes during day and night were considered to identify the best combinations of routing and scheduling options. The analyses showed that during the day time generally the health risks are lower, while, delay costs are higher (travel costs were considered the same at all time). This fact brought a conflicting issue in tradeoffs of routing and scheduling options. According to the decision making methods used (i.e., weighted sum, goal programming and compromise programming) in evaluation of the routing and scheduling options for the case study, the weighted sum and goal programming yielded the same results for the best routing and scheduling option, while compromise programming yielded a different routing and scheduling option. For the case study scenario, changes in weights of the criteria did not have significant influence on the identification of the best alternative.

\section{References}

Blackman Jr, W. C. (2001). Basic hazardous waste management, CRC Press.

Coutinho-Rodrigues, J., Current, J., Climaco, J., Ratick, S. (1997). Interactive spatial decisionsupport system for multiobjective hazardous materials location-routing problems. Transportation Research Record: Journal of the Transportation Research Board, 1602(1), 101-109.

Dadkar, Y., Jones, D., Nozick, L. (2008). Identifying geographically diverse routes for the transportation of hazardous materials. Transportation Research Part E: Logistics and Transportation Review, 44(3), 333-349. 
Erkut, E., Alp, O. (2007). Designing a road network for hazardous materials shipments. Computers \& Operations Research, 34(5), 1389-1405.

Fender, K. J., Pierce, D. A. (2012). An analysis of the operational costs of trucking: 2011 update. Transportation Research Board 91st Annual Meeting, (12-1090)

Florida Department of Transportation (FDOT) (2011). http://www.dot.state.fl.us/planning/trends/tc-report/behavior082611.pdf, Accessed March 10, 2014.

Gan, A., Haleem, K., Alluri, P., Saha, D. (2012). Standardization of Crash Analysis in Florida.

Giannikos, I. (1998). A multiobjective programming model for locating treatment sites and routing hazardous wastes. European Journal of Operational Research, 104(2), 333-342.

Hadi, M., Shen, L., Zhan, C., Xiao, Y., Corbin, S., Chen, D. (2008). Operation data for evaluating benefits and costs of advanced traffic management components. Transportation Research Record: Journal of the Transportation Research Board, 2086(1), 48-55.

Iakovou, E., Douligeris, C., Li, H., Ip, C., Yudhbir, L. (1999). A maritime global route planning model for hazardous materials transportation. Transportation science, 33(1), 34-48.

Inanloo, B., Tansel, B., Jin, X., Bernardo Bricker, A. (2014). Cargo-specific air dispersion and impact zone analysis after accidental release of hazardous materials. Transportation Research Board 93rd Annual Meeting, (14-0519)

Linkov, I., Moberg, E. (2011). Multi-criteria decision analysis: Environmental applications and case studies, CRC Press.

Lozano, A., Muñoz, Á., Macías, L., Antún, J. P. (2011). Hazardous materials transportation in mexico city: Chlorine and gasoline cases. Transportation research part C: emerging technologies, 19(5), 779-789.

Manual, H. C. (2000). Highway capacity manual. Washington, DC.

National Research Council (US) (2010). Transportation Research Board. Task Force on Development of the Highway Safety Manual, and Transportation Officials. Joint Task Force on the Highway Safety Manual. Highway Safety Manual. AASHTO.

Ombuki, B., Ross, B. J., Hanshar, F. (2006). Multi-objective genetic algorithms for vehicle routing problem with time windows. Applied Intelligence, 24(1), 17-30.

Pollard, S. (2008). Risk management for water and wastewater utilitiesIwa publishing.

Read, L., Madani, K., Inanloo, B. (2014). Optimality versus stability in water resource allocation. Journal of environmental management, 133, 343-354.

Romero, C., Rehman, T. (2003). Multiple criteria analysis for agricultural decisions. Elsevier. 
Turner, D. B. (1994). Workbook of atmospheric dispersion estimates: An introduction to dispersion modeling, CRC press.

U.S. DOE, Office of Environment, Safety and Health (2004). ALOHA computer code application guidance for documented safety analysis; DOE-EH-4.2.1.3-final ALOHA code guidance, final report.

Verma, M. (2009). A cost and expected consequence approach to planning and managing railroad transportation of hazardous materials. Transportation research part D: transport and environment, 14(5), 300-308.

Verma, M., Verter, V., Gendreau, M. (2011). A tactical planning model for railroad transportation of dangerous goods. Transportation science, 45(2), 163-174.

Zografos, K. G., Androutsopoulos, K. N. (2004). A heuristic algorithm for solving hazardous materials distribution problems. European Journal of Operational Research, 152(2), 507-519.

Zografos, K. G., Davis, C. F. (1989). Multi-objective programming approach for routing hazardous materials. Journal of Transportation Engineering, 115(6), 661-673. 
VITA

\section{BAHAREH INANLOO}

Born, Tehran, Iran

2002-2007

B.S., Civil \& Environmental Engineering University of Kurdistan

Sanandaj, Iran

2007-2009

Civil Engineer

Tarh and Pajouhesh Consultants

Tehran, Iran

2009-2011

M.S., Civil \& Environmental Engineering

University of Tehran

Tehran, Iran

2012-2015

Graduate Assistant

Florida International University

Miami, Florida

\section{PUBLICATIONS AND PRESENTATIONS}

Inanloo, B., B. Tansel, (January 2016). A multi-crtieria routing tool for hazardous material shipments: health risk, travel cost, proximity to vulnerable places, and congestion costs, Transportation Research Board, annual meeting, Washington D.C.

Inanloo, B. and B. Tansel, (2015). A transportation network assessment tool for hazardous material cargo routing: weighing exposure health risks, proximity to vulnerable areas, delay costs and trucking expenses, Journal of Loss Prevention in the Process Industries, under review.

Inanloo, B. and B. Tansel, (2015). A GIS-based framework for hazardous tanker truck routing: consideration of health risk, transportation and delay costs, Transportation Research Part D, under review.

Inanloo, B. and B. Tansel, (2015). Cargo specific accidental release impact zones for hazardous materials: risk and consequence comparison for ammonia and hydrogen fluoride, Journal of Environment, Systems and Decisions, in press. 
Inanloo, B. and B. Tansel, X. Jin, K. Shams, and A. Gan, (2015). A decision aid gis-based risk assessment and vulnerability analysis approach for transportation and pipeline networks, Journal of Safety Science, Accepted for publication.

Inanloo, B., B. Tansel, (March 2015). Transportation network assessment tool for hazardous material cargo routing: health risk, delay cost and trucking cost, University Transportation Center (UTC) Conference for the Southeastern, Birmingham, USA.

Inanloo, B., B. Tansel and Judicael Guitteny, (May 2015). Hazardous material cargo routing: analysis of health risks, delay costs and trucking costs by segmentation, World Environmental \& Water Resources Congress (EWRI 2015), Austin, Texas.

Tansel, B., B. Inanloo, X. Jin, K. Shams, and A. Gan, (May 2015 ). Interactive vulnerabilities of infrastructure networks: a gis-based integrated asset management planning tool for pipelines and transportation networks”, World Environmental \& Water Resources Congress (EWRI 2015), Austin, Texas.

Inanloo, B., B. Tansel and X. Jin, (January 2015). A framework for hazardous tanker truck routing: consideration of health risk, transportation and congestion costs", Transpiration Research Board, annual meeting, Washington D.C.

Inanloo, B. and B. Tansel, (July 2014). GIS-based analysis and delineation of odor impact zones around landfills: effect of atmospheric stability and meteorological conditions, SWANA Summer conference, Weston, Florida, USA.

Inanloo, B., B. Tansel, X. Jin and A. Bernardo-Bricker, (March 2014). GIS-based routing of hazardous material cargos considering incident costs after accidental release of chemicals” University Transportation Center (UTC) Conference for the Southeastern, Atlanta.

Inanloo, B. and B. Tansel, (2015). Explosion impacts during transport of hazardous cargo: gis-based characterization of overpressure impacts and delineation of flammable zones for ammonia, Journal of Environmental Management, Volume 156, Pages 1-9.

Inanloo, B., B. Tansel, X. Jin and A. Bernardo-Bricker, (June 2014). GIS-based explosion impact intensity analysis of accidental ammonia releases, World Environmental \& Water Resources Congress (EWRI 2014), Portland, Oregon.

Inanloo, B., B. Tansel, X. Jin and A. Bernardo-Bricker, (January 2014). Cargo specific air dispersion and impact zone analysis after accidental releases of hazardous materials, Transportation Research Board, annual meeting, Washington D.C.

Inanloo, B., B. Tansel, X. Jin and A. Bernardo-Bricker, (April 2013). GIS based air dispersion visualization of spill incidents from hazardous cargo, University Transportation Center (UTC) Conference for the Southeastern, Orlando, Florida. 